\title{
Weather Modification by Carbon Dust Absorption of Solar Energy
}

\author{
By \\ W.M. Gray, W.M. Frank, M.L. Corrin and C.A. Stokes
}

Department of Atmospheric Science

Colorado State University

Fort Collins, Colorado

July 1974
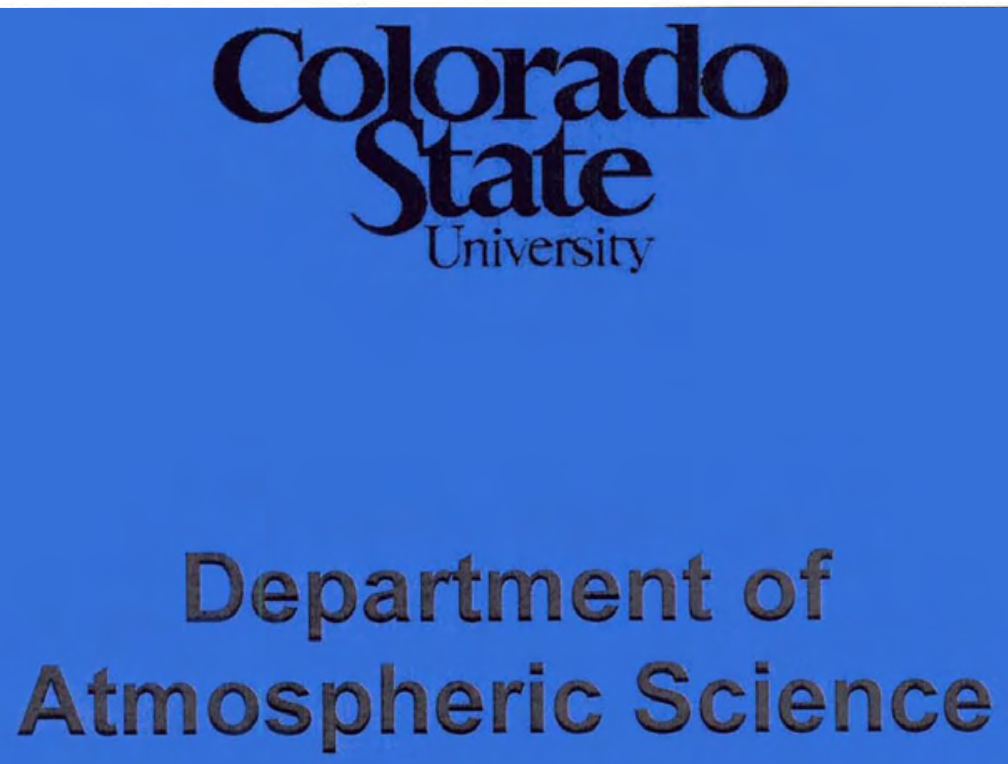

Paper No. 225 
WEATHER MODIFICATION BY CARBON DUST ABSORPTION OF SOLAR ENERGY

by

W. M. Gray, W. M. Frank, M. L. Corrin and C. A. Stokes

Department of Atmospheric Science

Colorado State University

Fort Collins, Colorado

July, 1974

Atmospheric Science Paper No. 225 
The five papers of this report have been written in an attempt to open up a new dialogue among meteorologists and other scientists on the possibility of meso-scale weather modification through carbon dust interception of solar energy. Growing population pressures and predicted future global food shortages dictate that man explore all his possibilities for beneficial weather modification. Nearly all the weather modification efforts over the last quarter century have been aimed at producing changes on the cloud scale through exploitation of the saturated vapor pressure difference between ice and water. This is not to be criticized, but it is time we also consider the feasibility of weather modification on other time-space scales and with other physical hypotheses. The authors wish to share their ideas on this new area of potential. weather modification with other interested individuals and obtain their comments and criticisms. They are hopeful that more exploratory research on this subject can soon be started. 
TABLE OF CONTENTS

Page

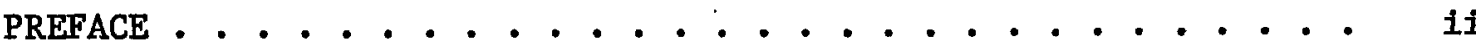

PAPER I: BACKGROUND INFORMATION AND HYPOTHESIS . . . . . . . . 1

I. BACKGROUND DISCUSSION ............ 2

II. CARBON DUST AS AN ARTIFICIAL HEAT SOURCE . . . . 4

III. PHYSICAL HYPOTHESES . . . . . . . . . . 11

IV. DISCUSSION OF SPECIFIC HYPOTHESES . . . . . . . 14

V. COMPARISON OF THIS HYPOTHESIS WITH PREVIOUS RADIATION ALTERATION MODIFICATION PROGRAMS . . . . . . 23

VI. COMPARISON OF CARBON DUST RADIATION ABSORPTION WITH OTHER AEROSOL ABSORPTION . . . . . . . . 28

VII. SYNOPSIS . . . . . . . . . . . 34

PAPER II: RADTATION CHARACTERISTICS . . . . . . . . . 37

I. INTRODUCTION .............. 38

II. RADIATIVE PROPERTIES OF CARBON BLACK IN THE ATMOSPHERE ....................... 39

III. RESULTS ................ 48

IV. CONCLUSIONS ............... 63

PAPER III:GENERATION OF CARBON PARTICLE CLOUDS . . . . . . 66

PAPER IV: ENVIRONMENTAL IMPACT . . . . . . . . . . 76

I. INTRODUCTION .............. 77

II. THE TOXICITY OF CARBON BLACK . . . . . . . . 78

III. HEALTH EFFECTS OF THE BY-PRODUCTS OF CARBON

IV. LONG TERM ATMOSPHERIC EFFECTS . . . . . . . . 87

V. CARBON IN THE OCEANS ............ 93

VI. ESTHETIC EFFECTS ............. 96

VII. SUMMARY ................. 98 
TABLE OF CONTENTS (cont'd)

Page

PAPER V: EVIDENCE FOR HYPOTHESIS AND PROPOSED RESEARCH

PROGRAM . . . . . . . . . . . . 101

I. INTRODUCTION ............... 102

II. OBSERVATIONAL AND THEORETICAL EVIDENCE . . . . . 103

III. NUMERICAL MODELING EVIDENCE . . . . . . . . 128

IV. COST-BENEFIT CONSIDERATIONS . . . . . . . 140

V. SCIENTIFIC UNKNOWNS AND POTENTIAL PROBLEMS . . . . 146

VI. PROPOSED RESEARCH PROGRAM. . . . . . . . . 152

VII. COMPARISON OF CARBON DUST AND SILVER IODIDE MODIFICATION TECHNIQUES . . . . . . . . 160

VIII. RESEARCH JUSTIFICATION . . . . . . . . 162

ABOUT THE AUTHORS . . . . . . . . . . . 168

APPENDIX A . . . . . . . . . . . . 169

APPENDIX B . . . . . . . . . . . . . 172 
Weather Modification by Carbon Dust Absorption of Solar Energy

Paper I: Background Information and Hypothesis

William M. Gray and William M. Frank

\section{ABSTRACT}

Growing global population pressures and predicted future food and energy shortages dictate that man fully explore his potential use of solar energy. The following group of five papers explores the possibility of beneficial weather modification through artificial solar energy absorption. A variety of physical ideas as related to artificial heat sources on different scales of motion are considered. Interest is concentrated on the feasibility of meso-scale ( 100-200 km) weather modification by solar energy absorption by carbon aerosol particles of $\sim 0.1$ micron size or less. Particles of this size maximize solar energy absorption per unit mass.

It is hypothesized that significant beneficial influences can be derived through judicious exploitation of the solar absorption potential of carbon black dust. There is an especially high potential for this over tropical oceans. If dispensed in small enough sizes of one tenth micron or less, solar energy absorption amounts as high as $\sim 2 \times 10^{10} \mathrm{cal} / 1 \mathrm{~b}$ per 10 hours or about $4 \times 10^{11} \mathrm{cal} /$ dollar per 10 hours can be obtained. This is a tremendously powerful heat source, especially if it stimulates an additional oceanic evaporation energy gain. Preliminary observational and modeling information indicates that this artificial heat source can be employed on the meso-scale $(100-200 \mathrm{~km})$ to give significant economic gain regarding precipitation enhancement and tropical storm destruction aleviation. It may also be possible to use carbon dust to enhance precipitation over land areas, alter extra tropical cyclones, and to speed up fog burnoff and snowmelt.

The following five papers discuss this physical hypothesis from the meteorologica1, radiational, engineering, ecological and economic points of view. 


\section{BACKGROUND DISCUSSION}

These papers are written with the purpose of opening up a dialogue on a new area of potential weather modification--namely meso-scale weather modification from solar energy interception by small carbon particles. It would appear that present day weather modification may need a broader scientific outlook. Nearly all the weather modification efforts over the last quarter century have been aimed at producing changes on the cloud scale through exploitation of the saturated vapor pressure difference between ice and water. This is not to be criticized, but it is time we also consider the feasibility of weather modification on other time-space scales and with other physical hypotheses.

\section{a. Need}

Growing global population pressures and predicted food and energy shortages dictate that man fully explore his potential for beneficial weather modification from both an economic and a humanitarian point of view. All physical ideas on all scales of motion should be considered.

\section{b. Physical idea}

Most of the sun's energy penetrates through the earth's atmosphere to the surface. A large direct atmospheric heat source would result if some of this incoming solar energy could, instead, be absorbed directly within the atmosphere. This is especially true over the oceans where most of the incoming solar energy goes into evaporation and where the lower atmosphere does not experience a diurnal temperature variation.

\section{c. General questions}

Can man intercept an appreciable amount of the incoming solar energy in selective areas and convert this energy into significant wind-pressure 
and precipitation changes? Is the tropical and sub-tropical troposphere often in a potentially unstable state such that an addition of artificial energy would trigger beneficial changes? If this is so, what are the Iikely economic effects? The rain which falls over the oceans does not benefit man. Perhaps man in the future will be able to cause a small amount of the rain which would normally fall over the oceans, instead, to occur over land areas in need of precipitation.

d. Technical questions

Can man economically generate carbon dust in sufficiently small sizes ( $<0.1$ micron) such that large area coverages per unit mass of carbon can be obtained? What are the technical and radiational limits to the size of the carbon particles? 


\section{a. Artificial interception of solar radiation}

From 60-80 percent of the incoming solar radiation $\left(I_{0}\right)$ in the cloud free areas reaches the earth's surface. In the tropics this figure is 8085 percent. As pictorially shown on the left portion of Fig. 1, the largest portion of incoming solar energy is absorbed by the oceans. Most of this energy subsequently goes into evaporation. Because this evaporation energy transport from the ocean is not directly dependent on solar radiation, but goes on during both the day and night, the oceanic boundary layer does not experience a large daily heating cycle as is common over land.

If a significant portion of the incoming solar energy over the oceans could be absorbed in the atmospheric boundary layer during the daylight hours, an artificial stimulation of cumulus convection would occur. This might be accomplished by aerosol interception of solar radiation as shown

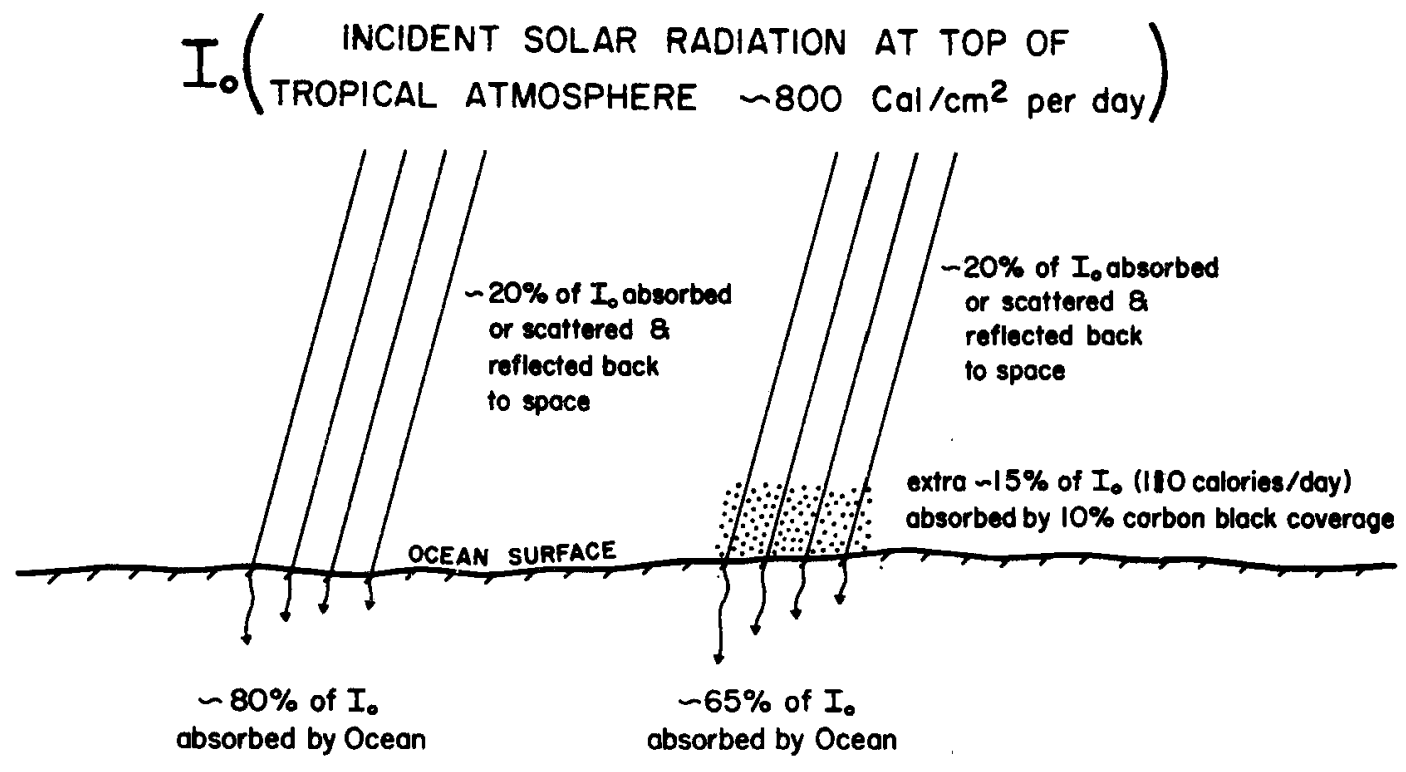

Fig. 1. Contrast of clear air tropical condition with normal solar absorption by atmosphere-ocean (on left) with extra solar absorption with $10 \%$ aerosol coverage in boundary layer (on the right). 
on the right side of Fig. 1. Fig. 2 compares the extra boundary layer short wave heating which is passible in 10 hours due to 15 percent extra absorption of incident solar radiation with the usual 10 hour net long and short wave radiation of the tropical troposphere as determined by Cox and Suomi (1969).

b. Carbon black dust as an artifical atmospheric heat source

The characteristic of carbon dust which makes it so attractive as an atmospheric heat source is the extra-ordinary quantity of solar radiation which can be absorbed by a untt mass of carbon. The following discussion by Frank (Paper II) extensively discusses the characteristics of carbon black dust as an atmospheric absorber of solar radiation from the method

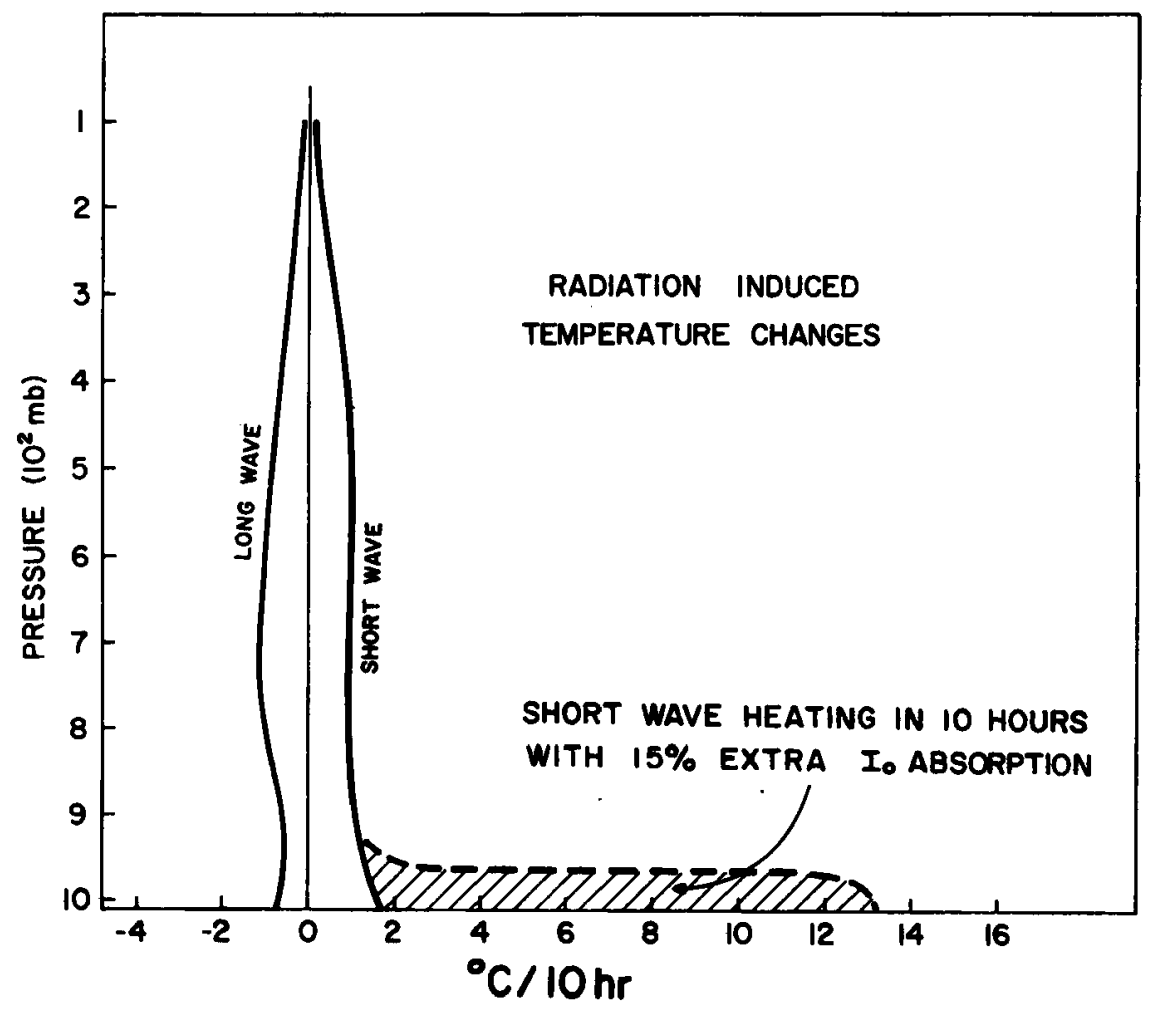

Fig. 2. Comparison of $10 \mathrm{hr}$ heating-cooling rates due to long and short wave radiation in clear regions with the extra boundary layer induced heating (shaded area) which is possible in 10 hours from 15 percent artificial solar absorption. 
of estimating aerosol solar absorption developed by Korb and Möller (1962). The reader ts referred to these papers for a thorough discussion of this subject. For the purpose of discussing the use of carbon black dust as an artificial solar energy source for meso-scale modification, the following information summarizes the pertinent facts on carbon black dust:

1) Carbon black dust consists of fine essentially spherical particles composed of $95-99 \%$ pure carbon, the remainder being made up of volatile materials. It is formed by the controlled incomplete combustion of fossil fuels according to a variety of processes. If put out in sizes less than a few microns, it has negligible fall velocity. Most carbon blacks can be produced in quantity for about $\$ .05$ to $\$ .10$ per $\mathrm{Kg}$.

2) The density of carbon black particles is $2 \mathrm{gm} / \mathrm{cm}^{3}$. The high radiation absorptivity and low heat capacity (about $.125 \mathrm{cal} / \mathrm{g}^{\circ} \mathrm{C}$ ) of carbon dust make it an ideal agent for interception of solar radiation and transfer of this heat to the surrounding air molecules by conduction. Turbulent mixing carries the heat further. Being hydrophobic, carbon dust does not readily absorb water vapor. If put out in small sizes it will not act as a condensation nucleus.

3) Particles of 0.1 micron radius maximize the solar absorption per unit mass but, as discussed by Frank (Paper II), this size is not critical. Solar absorption to weight is not greatly altered by variations in size from $.01 \mu$ to $0.20 \mu$ radius. Individual particles of $0.1 \mu$ radius weigh but $10^{-14} \mathrm{gm}$. It takes $3 \times 10^{13}$ particles or about $0.3 \mathrm{gm}$ of carbon to solidly cover a horizontal cross-section of $1 \mathrm{~m}^{2}$. 
4) Carbon black dust particles heat the surrounding air primarily ( $~ 94 \%$ ) by direct solar energy absorption and rapid molecular conduction of this heat to the surrounding air. About $6 \%$ of the heat transfer from the carbon to the air is accomplished by long-wave radiation.

5) The maximum efficiency of solar radiation to weight and cost requires that the percentage area coverage of carbon black be in the range of $0-30 \%$. Higher carbon area coverage rates cause redundancy in solar absorption and lower energy to weight and cost ratios.

6) Absorption rates for area coverage percentages of $0-20 \%$ are little affected by zenith angle changes up to $65-70^{\circ}$. This allows for 9 to 10 hours of nearly constant absorption rate during daylight hours.

7) One kilogram $(\mathrm{Kg})$ of carbon black dust can absorb more than 40 billion calories of solar radiation in a single 10 hour period. On the other hand, coal, currently the cheapest of conventional combustible fuels, provides on complete combustion about 7 million cal per $\mathrm{Kg}$ or about $1 / 6000$ as much heat per unit mass as the carbon. The relative costs of energy available from carbon black dust and coal are shown in Table 1 . The cost of complete combustion coal heat is about 280 times greater than the cost of carbon heat per $10 \mathrm{hr}$. period. Among energy sources normally used by man only nuclear energy compares with carbon black as a source of accumulation of energy per unit mass, and no known substance compares as a source of heat per unit cost. A 20 Kiloton nuclear explosion produces about the same amount of thermal 
TABLE 1

RELATIVE AMOUNTS AND COSTS OF COAL AND CARBON BLACK DUST ENERGY

Fuel Cost Heat Heat per Unit Cost

(dollar/Kg) (cal/Kg) (cal/dollars)

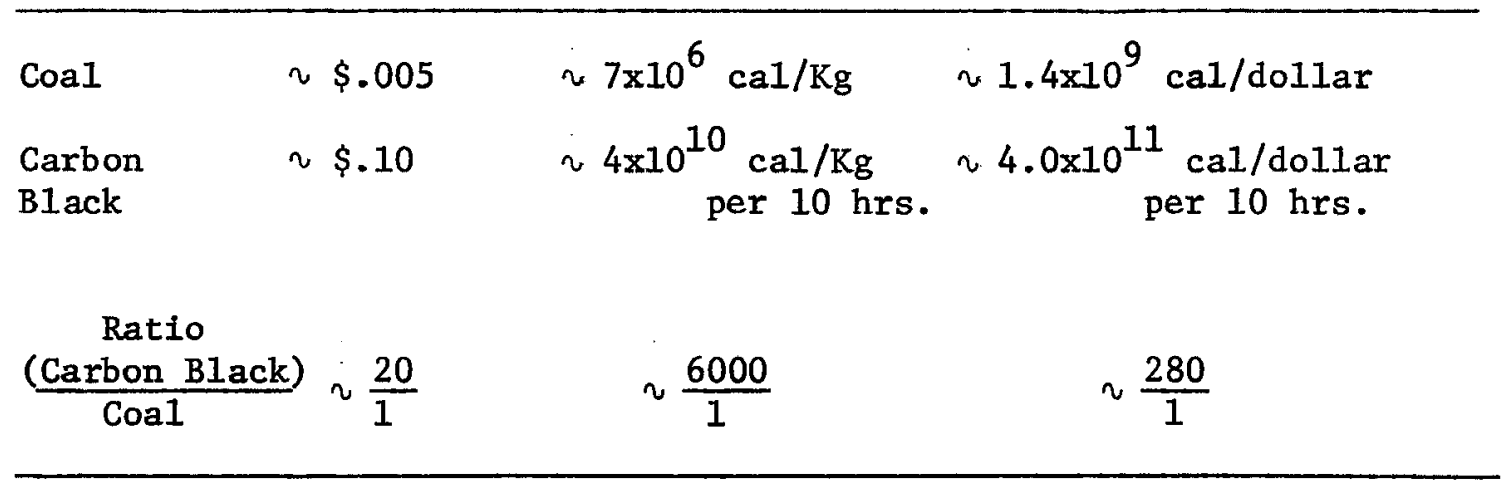

energy as can be obtained from $1,000 \mathrm{Kg}$ of carbon dust in 10 hours of solar heating. In addition, the carbon dust is not necessarily consumed during the heat absorption process and might be used again on following days. Silver iodide seeding in super-cooled clouds can also liberate tremendous amounts of energy per unit mass, but the energy from this source does not locally accumulate unless the cumulus mass compensation for the stimulated convection occurs near and on a time scale of the seeding. This is rare. As the seeded cloud dies out the suspended frozen particles melt and re-evaporate.

8) Table 2 lists the short wave absorption by carbon dust in the tropical boundary layer (surface to $950 \mathrm{mb}$ ) which would result from various carbon dust equivalent area coverages. The concentration of $0.1 \mu$ radius carbon particles per $\mathrm{km}^{2}$ is also shown. For carbon dust area coverages of 10 and 20 percent, only $\sim 25$ and $\sim 50 \mathrm{Kg}$ respectively of carbon dust are needed to cover an 
TABLE 2

TYPICAL TROPICAL BOUNDARY LAYER HEATING RATES FROM 1 MILLION Kg OF CARBON DUST

\begin{tabular}{|c|c|c|c|c|}
\hline Area & $\begin{array}{l}\% \text { Area } \\
\text { Coverage }\end{array}$ & $\begin{array}{c}\text { Carbon Dust Mass } \\
\mathrm{Kg} / \mathrm{km}\end{array}$ & $\begin{array}{l}\text { Net Heat Absorbed } \\
\left(\mathrm{cal} / \mathrm{cm}^{2} 10 \mathrm{hrs}\right)\end{array}$ & $\begin{array}{l}\text { Temperature Change } \\
\left({ }^{\circ} \mathrm{C} / 10 \mathrm{hrs}\right)\end{array}$ \\
\hline $72,000 \mathrm{~km}^{2}$ & $5 \%$ & 11 & 60 & 4 \\
\hline $40,000 \mathrm{~km}^{2}$ & $9 \%$ & 22 & 110 & 8 \\
\hline $20,000 \mathrm{~km}^{2}$ & $18 \%$ & 45 & 200 & 13 \\
\hline $15,000 \mathrm{~km}^{2}$ & $26 \%$ & 65 & 270 & 18 \\
\hline $10,000 \mathrm{~km}^{2}$ & $35 \%$ & 90 & 325 & 22 \\
\hline $6,800 \mathrm{~km}^{2}$ & $53 \%$ & 120 & 410 & 27 \\
\hline $5,100 \mathrm{~km}^{2}$ & $70 \%$ & 180 & 470 & 31 \\
\hline
\end{tabular}

area of one $\mathrm{km}^{2}$. If generation rates are about 10 cents $/ \mathrm{Kg}$, this amounts to but $\$ 2.50$ and $\$ 5$ per one $\mathrm{km}^{2}$ coverage.

Ten percent area coverage of carbon dust provides enough heat to increase the mean temperature of the air within the boundary layer (surface to $950 \mathrm{mb}$ ) at a rate of about $1^{\circ} \mathrm{C} / \mathrm{hr}$ for a 10 hour period. Table 2 also gives the boundary layer heating rates that can be accomplished for various areas and percentage carbon particle coverages with 1 million $\mathrm{Kg}$ of carbon. Fig. 3 portrays comparative areas which can be covered by various amounts of carbon dust at 10 percent area coverage in contrast with the typical size of the large hurricane cloud cluster. This would cause an artificial increase of the mean boundary layer temperature of $1^{\circ} \mathrm{C} / \mathrm{hr}$ for 10 hours over the dotted area shown. These enormous area coverages and heating rates open the possibility of meso-synoptic-scale weather modification. 


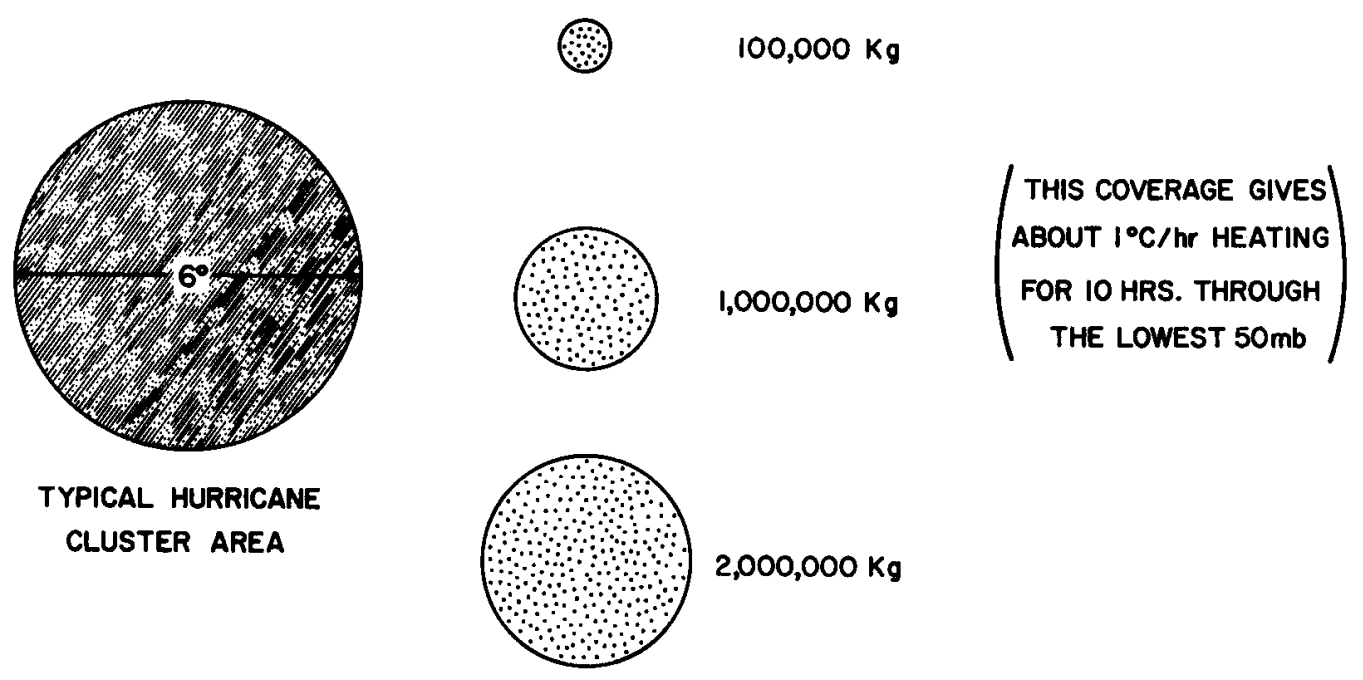

Fig. 3. Comparison of typical hurricane cluster area ( $6^{\circ}$ latitude diameter) with the area (dotted) of 10 percent carbon black coverage which is possible with various amounts of carbon black dust. Estimating the cost of carbon dust to be $\sim \$ 0.10$ per $\mathrm{Kg}$, these three area coverages would require carbon amounts of $\$ 10,000, \$ 100,000$ and $\$ 200,000$. 


\section{PHYSICAL HYPOTHESES}

The energy budget of the globe specifically dictates that the average global precipitation be about a meter per year. The largest portion of this precipitation falls over the oceans and is of no benefit to man. If man could slightly decrease vertical stability conditions over land, a sma11 percentage increase of global land precipitation might result. This could have a sizable beneficial economic impact. This should be man's primary weather modification goal. The proper tapping of solar energy with carbon dust might give man control of an energy source sufficiently large to allow him to objectively contemplate such possibilities.

On a less ambitious scale it is hypothesized that beneficial mesoscale weather modification may be possible in the coming decade or two by solar absorption of carbon dust in the following situations:

a. Rainfall enhancement along tropical and sub-tropical coastlines.

b. Reduction of inner-core hurricane intensity.

c. Cumulonimbus enhancement over selective land regions in need of precipitation.

d. Alteration of extra-tropical cyclones.

e. Fog dissipation.

f. Accelerating snowmelt in agricultural areas.

These are a few of the potential applications to which the interception of solar energy might be put to use by man. There are likely many other atmospheric situations in which man could benefit from application of a meso-scale heat source of the magnitude discussed.

The most likely location for carbon dispersal is over the oceans where the planetary boundary layer does not experience a diurnal temperature cycle and where the stimulation of extra evaporation is possible. 
a. Extra evaporation

The direct heating of air by carbon absorption is but one of two influences which can occur. If accomplished over water bodies, the enhanced solar heating of the air should also stimulate an increase in evaporation. The increased warming of the air will stimulate extra vertical mixing and downward penetration of upper level dryer air to the ocean surface. This dryer air will increase the water vapor pressure difference between the ocean and the air and lead to increased evaporation rates. Evaporation rates may perhaps be increased by double or more their normal values. This evaporation influence can also continue for many hours after the heating has taken place.

It is seen in Fig. 4 that the $\Delta q$ or $q_{s}$ (saturation vapor pressure of the air which is equivalent to the ocean temperature) minus $q$ (vapor content of the air just above the ocean) difference between air at $850 \mathrm{mb}$ and the ocean surface is about three times larger than the difference between surface air and the value representing saturation at the ocean temperature. Any down mixing of upper level air should substantially increase the $q_{s}-q$ of the air just above the ocean. This will substantially increase the evaporation rate. The energy for this increased evaporation, however, will come largely from the ocean and not the air. Thus, it may be possible for the carbon dust solar heating to locally extract energy from the ocean that would not naturally occur. The potential buoyancy of the low levels will later be enhanced by the extra water vapor content. b. Method of dispersion

It appears that it will be possible to manufacture small $\sim 0.1$ micron ( $\mu$ ) size carbon particles directly from liquid petroleum products (i.e. hydrocarbons) on aircraft or from ship or land surface sites. Paper III 


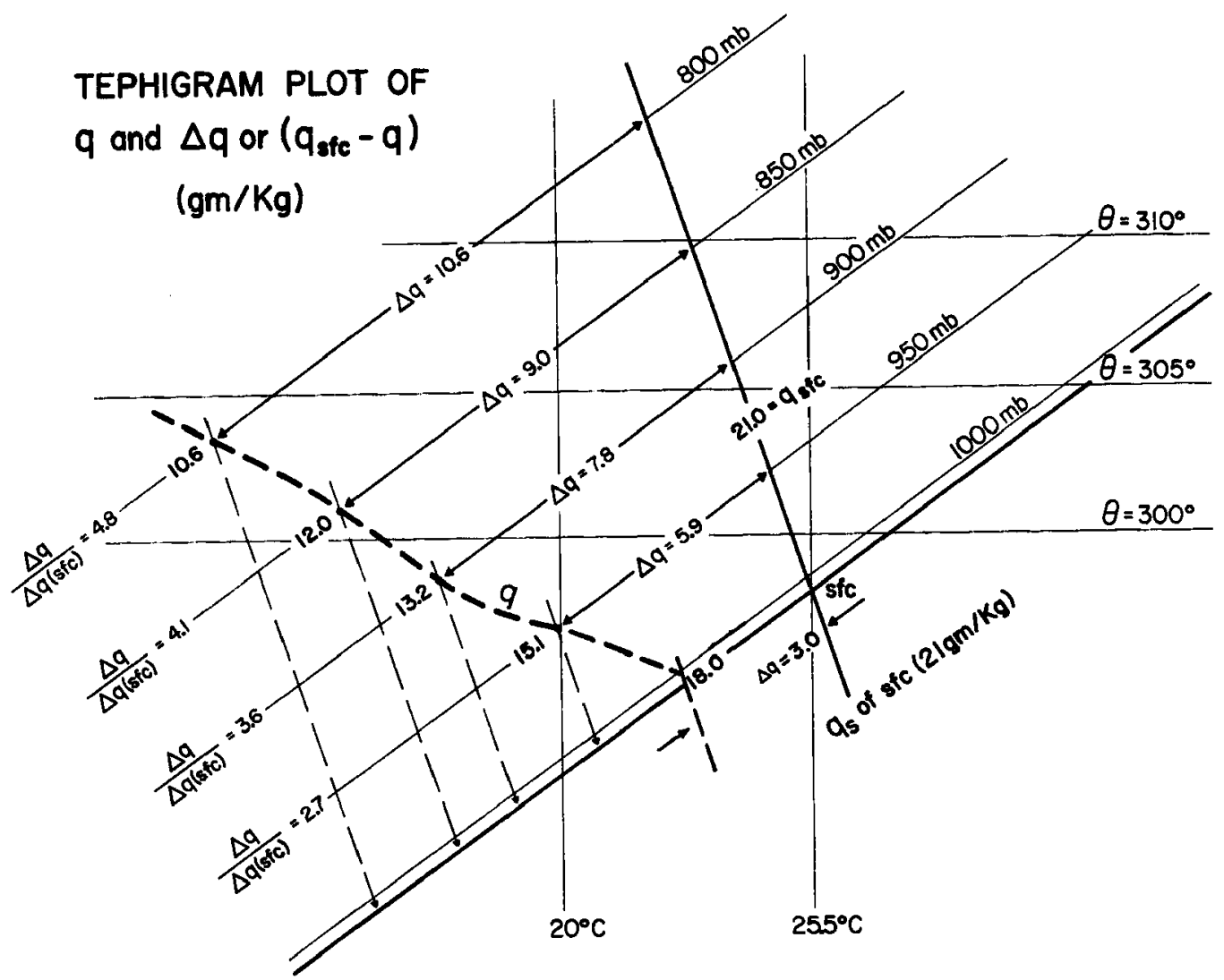

Fig. 4. Portrayal of tropical or sub-tropical specific humidity difference of upper layer air with surface saturated specific humidity of the ocean $\left(q_{s}\right)$ and how extra downward mixing of dryer air would greatly enhance the $q_{s}-q$ values and the oceanic evaporation rates.

by C. A. Stokes shows how it is possible to obtain about $50 \%$ mass yield of carbon or $1 \mathrm{~kg}$ of carbon dust for $2 \mathrm{Kg}$ of liquid hydrocarbons. The carbon particles can thus be generated in the desired size range and dispersed without storing. This prevents handling and clumping problems. Feasibility studies by Stokes are in progress to determine the best methods of manufacture. It is highly desirable that the carbon particles be manufactured at individual dispersion sites. Liquid petroleum can be much more easily handled and dispersed than can solid carbon dust which is purchased at the factory. 
IV. DISCUSSION OF SPECIFIC HYPOTHESES

a. Rainfall enhancement along tropical and sub-tropical coastlines

Precipitation enhancement from weather system genesis or intensification upwind from coastlines with on-shore flow is believed to be a very likely possibility. There are many coastal and adjacent inland regions in the tropics and sub-tropics which need additional precipitation and which have on-shore flow. If tropospheric vertical wind shears are not too large, It is very likely that meso-scale weather system genesis or enhancement is possible.

It is envisaged that an artificial heat source will lend itself to the production of extra cumulus convection and an extra local meso-scale convergence. A sizable amount of extra low level mass and water vapor convergence should occur. A continuing enhancement of cumulus convection should take place. If enough extra convection occurs, then, if tropospheric vertical wind shears are not too large, this extra cumulus heating is likely to feedback to the meso-system and keep it going or intensify it. Maintenance and growth can occur after the original heat has dissipated. Figs. 5 and 6 portray how a weak meso-system might be generated upwind from a tropical coastline.

It must be emphasized that we are discussing a meso-scale heat source and the resulting meso-scale pressure-wind patterns which are induced. We are not discussing the direct stimulation of individual cumulus elements. The individual cumulus elements will result as a consequence of the extra meso-scale low level mass and water vapor convergence. Most previous weather modification schemes have dealt only with the alteration of already existing cumulus. 


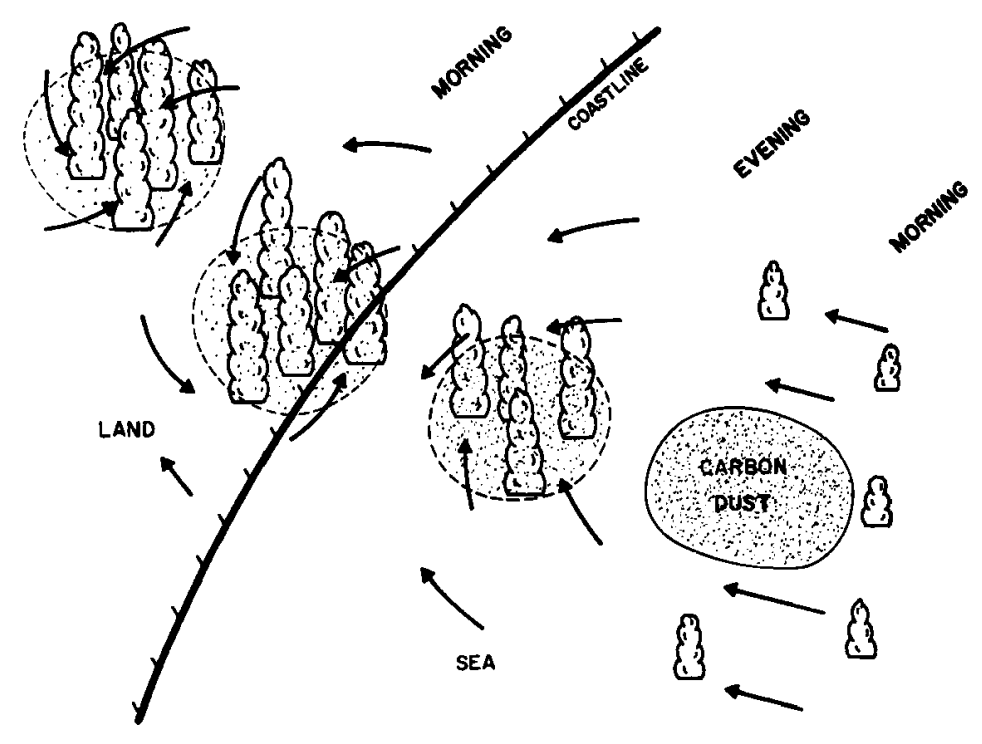

Fig. 5. Plan view portrayal of how carbon dust seeding $1 / 2$ to 2 days upwind from tropical and sub-tropical coastlines might act to generate or enhance a weak meso-scale weather system.

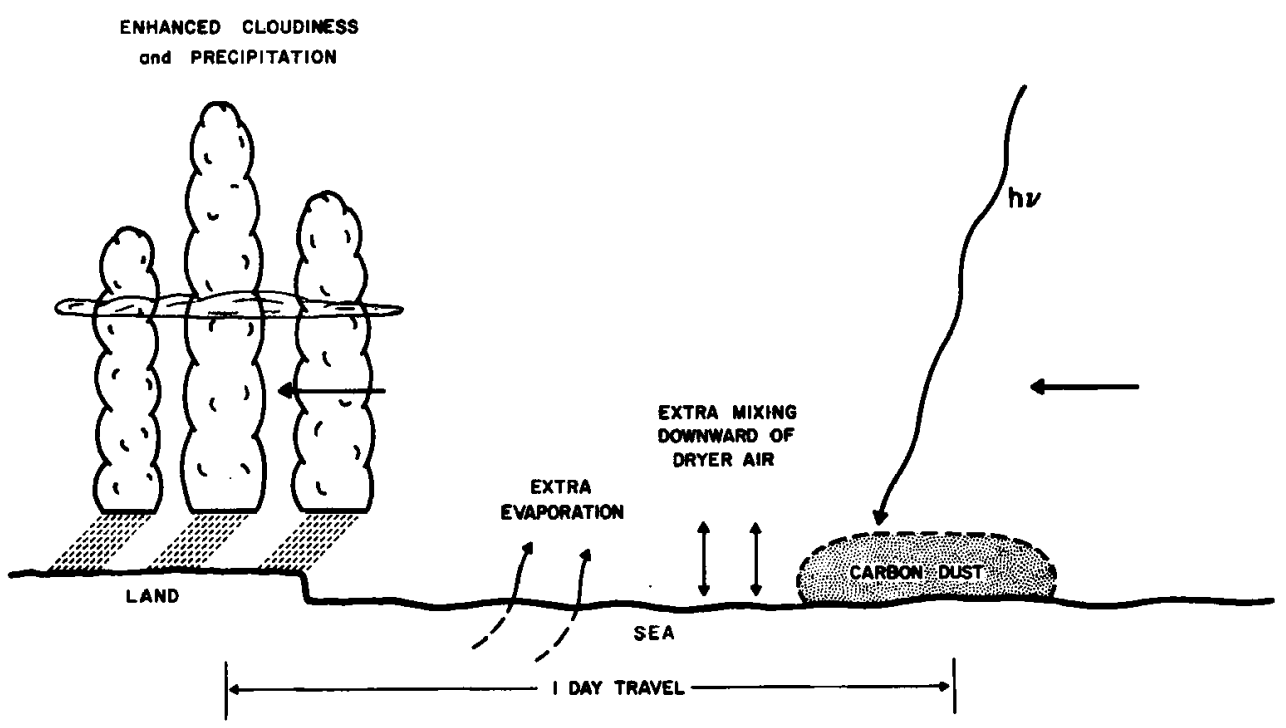

Fig. 6. Cross-section portrayal of carbon dust interception of solar radiation upwind from a coastline with enhanced vertical mixing and evaporation. 


\section{b. Reduction of inner-core hurricane intensity}

The present NOAA stormfury hurricane modification hypothesis [See Project Stormfury Annual Reports of 1971-1972 (available from NOAA NHRL Miami office)] and the one here proposed for carbon dust seeding rests with the physical idea of artifically interupting a portion of the hurricane's low-level inflow which would normally penetrate to the eye wall region and force it to rise, instead, at an outer radius. As extensively discussed by Gray (1973), angular momentum and surface friction considerations dictate that hurricane intensity is crucially dependent on the amount of mass inflow and the radius to which the boundary layer inflow penetrates towards the storm center. Rapid and sizable reductions in the hurricane inner core wind structure would occur if the boundary layer inflow could be artifically reduced by but 5 to 10 percent. If the outer boundary layer surrounding the hurricane shield can be artificially warmed at a rate of about $1 / 2$ to $1 \mathrm{C} / \mathrm{hr}$ for a period of ten hours, a significant stimulation will be given to cumulus convection at radii beyond the eye wall cloud so as to cause a noticeable decrease in the low level inflow to the radius of maximum wind. This should lead to a decrease in the inner core maximum wind velocities. A significant decrease in storm damage should result.

It is hypothesized that if sizable areas surrounding the hurricane cloud cluster can be seeded in the boundary layer with 1-2 million $\mathrm{Kg}$ of carbon black dust, the effect will be to stimulate additional cumulus convection either at the place of the carbon seeding or, if turbulence and large boundary layer mixing occurs, at radif inside the carbon seeding but beyond the radius of maximum winds. The effect of the carbon dust seeding will be to enhance the cumulus buoyancy by increasing the low 
level temperatures and evaporation rates. This will cause more cumulus convection at outer radii and take extra mass out of the boundary layer. The low level inflow into the center should be reduced. This should cause a weakening of the cyclone. More discussion of this physical hypothesis is contained in Paper $\mathrm{V}$.

Fig. 7 is a cross-section view which shows where the proposed carbon black dust would be placed just beyond the edge of the cirrus shield and how this might interrupt part of the low level inflow mass through enhancement of cumulus convection beyond the eye-wall radius. Fig. 8 is a plan view which more explicitly shows the typical regions around the hurricane cirrus shield in the clear moat area where the proposed carbon black seeding would be accomplished. This could likely be accomplished with 10-20 jumbo type cargo aircraft. As the right-front quadrant of the storm usually has the largest inflow, it might be more desirable to concentrate the seeding in the right semi-circle. If not, the seeding can be spread around the entire cluster.

The carbon dust must be placed sufficiently upstream in the moat region such that it does not advect so far underneath the cirrus shield that the solar absorption is lost before its 10 hour heating can be accomplished. In some intense hurricane cases where the moat region is very large it may be desirable to place the carbon dust 36 hours travel away from the cirrus shield and obtain two days of solar heating.

Therefore, the extra solar heating at outer radii is expected to lead to an increase not only of outer radii thermal buoyancy but also of buoyancy due to extra water vapor content from enhanced evaporation. Even though the extra evaporation influences may not be felt at the place of carbon seeding, they are expected to take place in the air before it reaches 


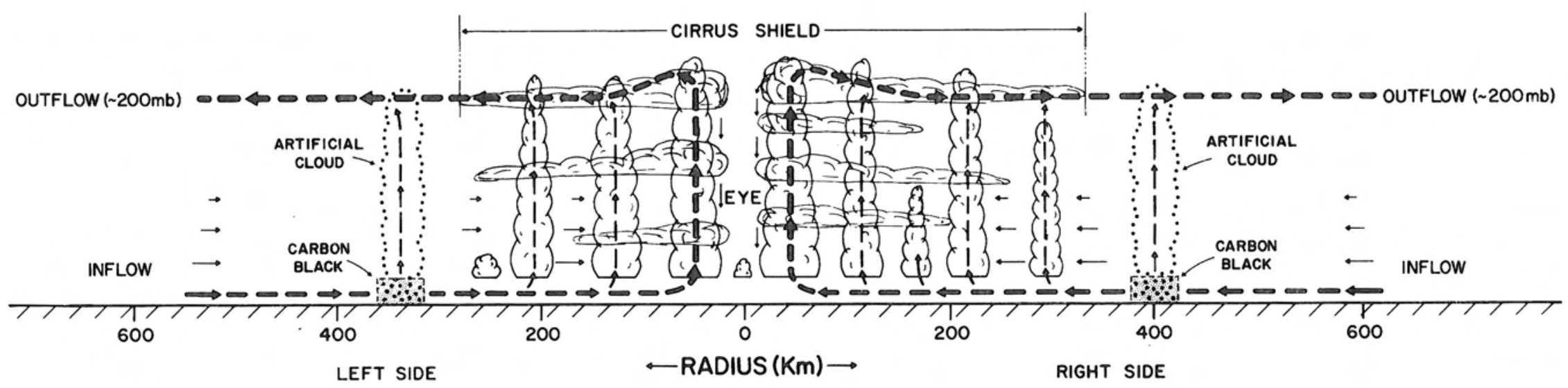

Fig. 7. Idealized portrayal of typical hurricane radial circulation and how carbon black dust seeding of the boundary layer just beyond the cirrus shield might lead to enhanced cumulus convection and reduction of low level inflow which penetrates to the eye-wall cloud. 


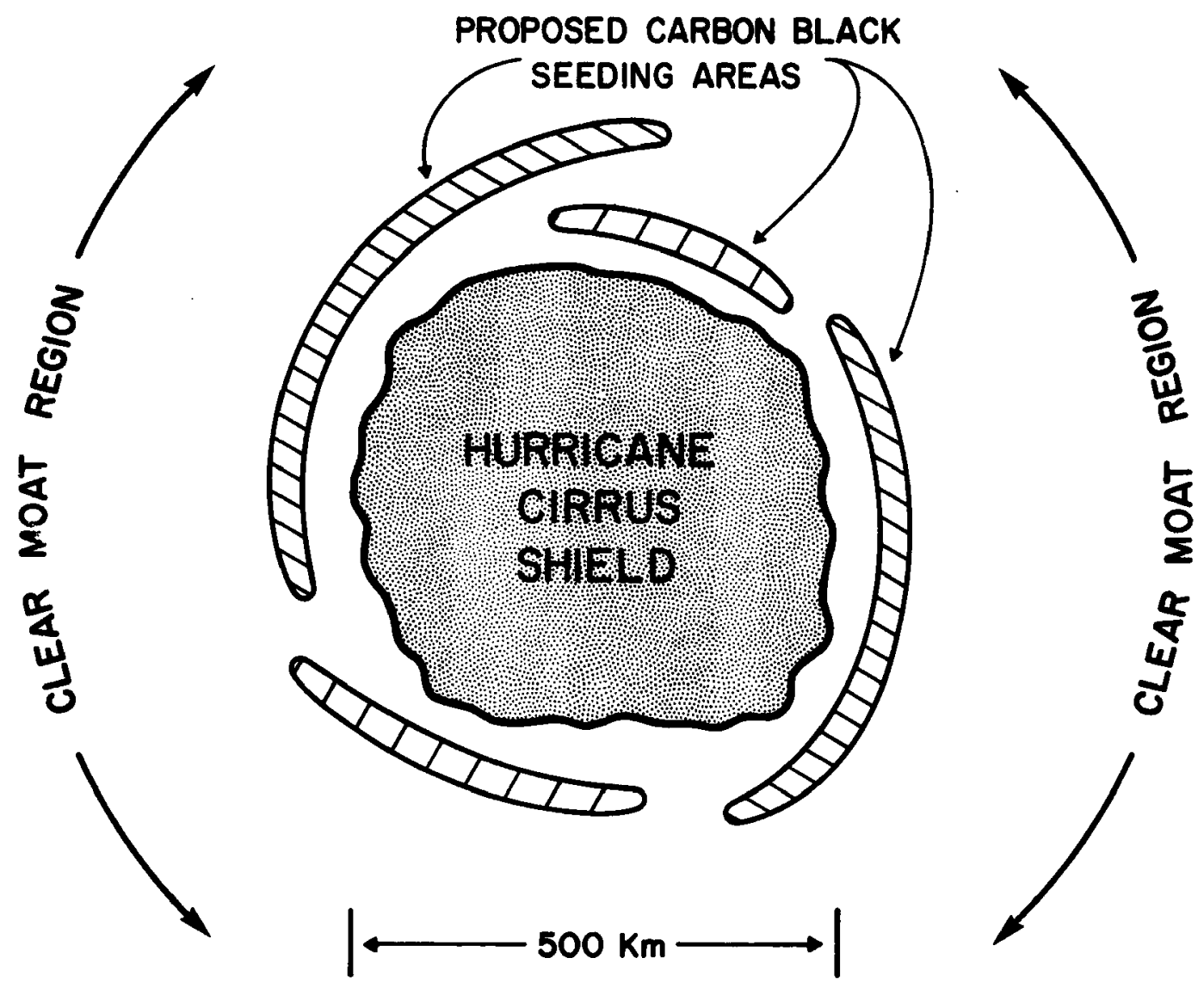

Fig. 8. Long hatched areas show where the hurricane boundary layer seeding of carbon black dust should be accomplished in the clear area moat region 8-10 hours upwind from the hurricane cirrus shield.

the eye-wall radius $18-36$ hours later. Fig. 9 more explicitly shows how enhancement of buoyancy from extra heating and evaporation will lead to more artificially induced cumulus convection at radii beyond the eye-wall cloud and to probable lessening of the inflow to the inner storm region. This should weaken the inner core region of maximum circulation.

\section{c. Cumulonimbus enhancement over selected land regions in need of precipitation}

It is hypothesized that a significant location change and/or enhancement of cumulonimbus convection may be possible over land areas where the potential for cumulus convection is already.high. This is an es- 


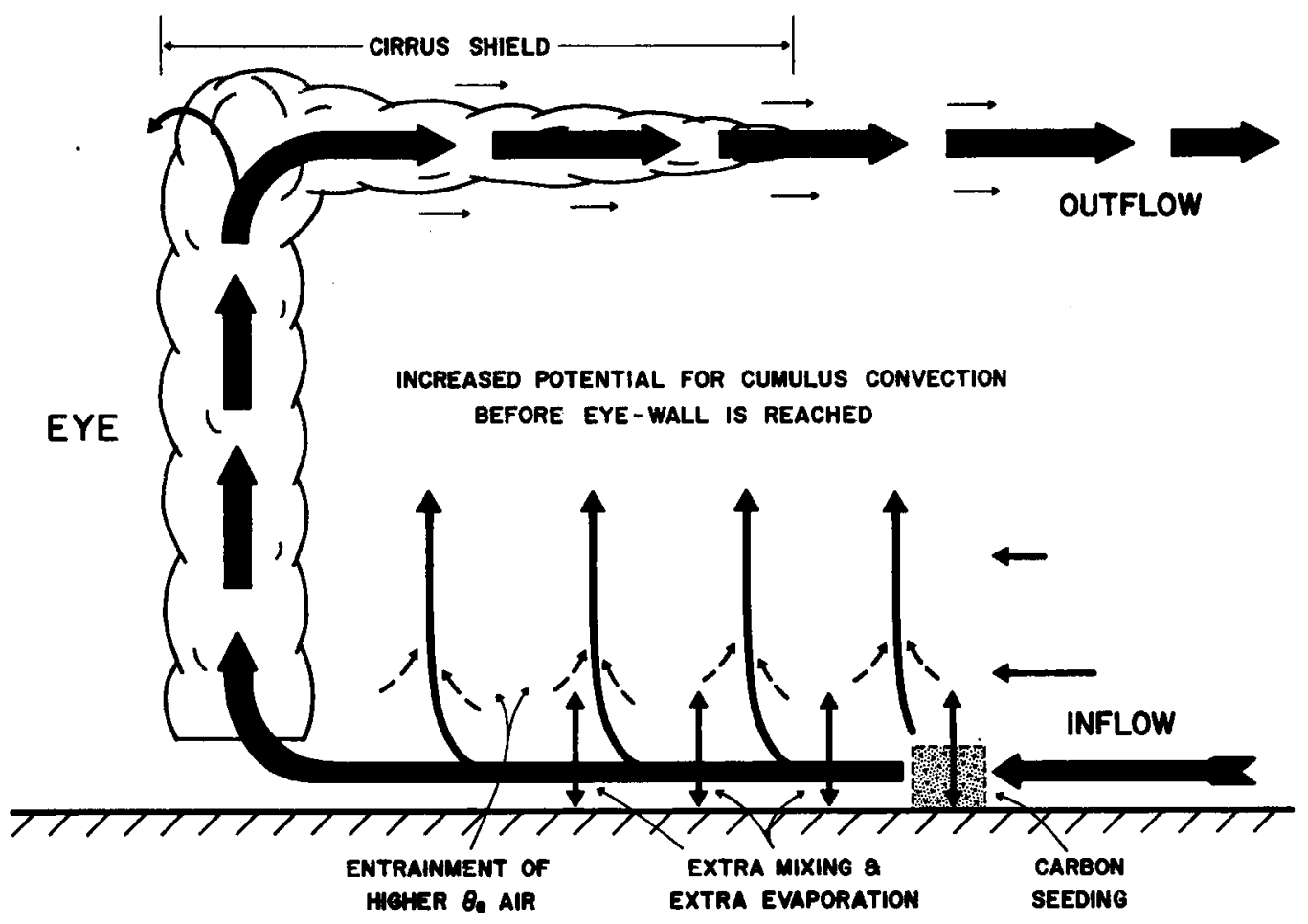

Fig. 9. Idealized view of how an increase of low level temperaturemoisture through carbon dust interception of solar radiation would lead to extra hurricane enhancement of deep cumulus convection at outer radii, and tend to cause less low leve1 mass penetration of the eye-wall cloud region.

pecially likely situation if the land areas have a high amount of evapotranspiration. If the land areas are moist or have dense vegetation, much of the incoming radiation goes to evaporation or storage and the diurnal warming curves are damped. In these situations the carbon dust could be used to more rapidly warm up the boundary layer and to dictate where the initial daytime convection should occur. An area concentration of the morning and early afternoon solar heating would likely produce extra $\mathrm{Cb}$ convection and precipitation if the potential for cumulus convection is already high.

Over land the carbon dust might also be used in selective situations as an elevated heat source (if dispensed from aircraft) and could act as 
a stimulant to earlier and more concentrated cumulus convection. Especially favorable situations would be areas where large-scale low level convergence is present, such as around low pressure systems and along fronts. Here daytime cumulus convection would be expected to break out in the selectively seeded areas where the earliest atmospheric warming occurs.

Carbon dust heating might thus be used to dictate where the earliest thermal destabilization and cumulus convection take place. Early morning stable conditions act to inhibit convection. Any large-scale upward forced circulation would likely relieve itself in the areas which first become thermally unstable.

\section{d. Alteration of extra-tropical cyclones}

A significant economic gain might result if weak extra-tropical storm systems could be intensified in dry regions such as the western U.S. This would likely result in extra precipitation.

When cyclones are intense, move slowly, or are stationary, flooding conditions, heavy snow, and high sea conditions can produce considerable economic loss. This is especially true in the heavily populated areas along the U.S. East Coast and in Western Europe. In this second type of situation economic benefit might result in some cases if the intense cyclones could be artificially weakened. If carbon dust solar heating is employed on a large enough scale,it might be possible for man to produce a modest but significant intensity reduction of extra-tropical cyclones.

Modest cyclone intensification might be accomplished by warming up selective areas at low levels to the east of the extra-tropical cyclone and stimulating extra cumulus convection just east of the storm center. This is likely to produce extra precipitation. If cyclone weakening were desired, then solar energy input to the cold center of the extra-tropical 
cyclone at middle or upper tropospheric levels would likely act to produce a modest but significant vortex weakening.

e. Fog dissipation

Calculations of the radiative absorptivity of carbon and of the amount of solar radiation available inside fog clouds indicate that carbon particles can absorb enough extra radiation to speed-up the dissipation of fog. It is proposed that carbon dust be generated and dispersed directly into the fug from aircraft or ground sources ( $i[$ the fog is not too thick). It is hypothesized that this would significantly accelerate the radiational burn-off of the fog. The logistical and economic requirements of this are not large.

\section{f. Accelerating snowmelt in agricultural regions}

There are several large, relatively flat agricultural areas in the world where a snow cover persisting late into the spring can cause a costly reduction in the length of the growing season. The Great Plains of the U.S. and the Russian wheat belt are good examples. When these areas are snow covered, they typically have surface albedos of from $40 \%-90 \%$ depending upon the age and condition of the snow and have relatively strong inversions just above the boundary layer. Large amounts of carbon dust particles can be dispensed from inexpensive ground generators into the boundary layer. By warming the boundary layer air under proper conditions it should be possible to accelerate the spring melt of the snowpack, thereby increasing the growing season. The high albedo of the snow surface would cause a strong upward diffuse solar radiation flux and thus increase the efficiency of the carbon absorption. Absorption would take place from both the upward and downward fluxes. In addition, the carbon particles should have a relatively long boundary layer residence time due to the strong inversion which should permit multiple day use of the carbon. 


\section{COMPARISON OF THIS HYPOTHESIS WITH PREVIOUS RADIATION ALTERATION MODIFICATION PROGRAMS}

To date, research on the subject of solar weather modification has been centered on fog and natural cloud dissipation and on developing and enhancing individual cumulus. Downie (1960), Fenn and Oser (1962) and Van Straten et al. (1958) have previously discussed the use of carbon dust in this way. The application of these approaches has been limited by the large amounts of heat required to evaporate meaningful amounts of moisture (i.e. $600 \mathrm{cal} / \mathrm{gm}$ ) and by the small amounts of carbon used.

The Naval Research Laboratory seeded 8 cumulus clouds with $1-3 \mathrm{Kg}$ of carbon black in July, 1958 (Van Straten et al. 1958). All of the clouds dissipated to some extent, but observation and instrumentation capabilities were insufficient to establish a definite causal relationship. In addition, clear air at the approximate level of existing cumulus cloud bases was seeded on 5 runs during the same series of tests. Small clouds were observed to form in all cases. Once again it was impossible to establish definite causal relationships. The overall feeling of the test group was that the carbon black did seem to help dissipate existing clouds and form small ones in clear air, but the natural variability of cumulus clouds and the inadequacy of monitoring techniques prohibited any conclusive results.

Laboratory tests by the Naval Research Laboratory in 1958 showed that carbon black did increase dissipation rates of artificially created fogs in cloud chambers which were subjected to heat lamps. However, neither the dissipation mechanism nor the radiative properties of carbon black were quantitatively well established.

The Geophysics Research Directorate made 18 runs seeding small clouds and clear air in October, 1958-April, 1959 (Downie, 1960). Carbon amounts 

from 1-3 Kg per mission were used. Observed results were less successful than those observed earlier by the Naval Research Laboratory. A few clouds dissipated, but others did not. Clear air seeding produced no obvious results although a few small clouds occasionally formed in the test areas. The test personnel concluded that no definite effects of carbon black on clouds could be substantiated through their test results.

In general, these early experiments with carbon black suffered from four major shortcomings:

1) The existing knowledge of the radiative properties of carbon black was entirely inadequate to provide realistic estimates of the energy processes occurring in the atmosphere.

2) The amounts of carbon used were much too small. Small scale diffusion effects could easily dissipate the heat absorbed and overpower the effects of the heat accumulation.

3) Severe logistical and clumping problems associated with the handling and dispersal of the carbon particles were encountered.

4) Adequate observation and instrumentation capabilities to enable conclusive analysis of field test results were not available.

The previous research by C. Downie and B. Silverman* (U.S. Air Force Cambridge Research Lab.), F. Van Straten*, R. Ruskin* (U.S. Navy Research Lab.) and T. Smith* (Private Industry), etc., in general, proved not to be promising. The amounts of carbon used $(5-20 \mathrm{Kg})$ were not consistent with the purposes. Dispersing and clumping problems were encountered. Previous work in the late 1950's and early $1960^{\prime}$ 's was conducted on a scale (generating or intensifying individual cumulus) and with a technology (dispersing already manufactured carbon) which is entirely different than the one proposed in these papers.

\footnotetext{
*Personal communication.
} 
By contrast, this research is concerned with the feasibility of carbon particle modification on the meso-scale ( $\sim 100-200 \mathrm{~km}$ on a side) using amounts of 1-2 million $\mathrm{Kg}$. We are planning to directly manufacture the carbon dust on aircraft or from carbon particle generating sources on ships or at surface sites. By direct manufacture of the carbon black dust from field sources, one avoids the clumping, packing, and logistical problems involved with obtaining the carbon particles from the factory. Previous experimenters did not consider the possibility of manufacturing the carbon dust directly at the experimental location from aircraft or at surface dispersion sites. The carbon particles are thus dispersed directly from the carbon generating burners which convert liquid hydrocarbon fuel to carbon and carbon dioxide. This greatly reduces logistical requirements and assures that the right sized particles will disperse without clumping and other difficulties.

The authors propose to overcome most of the previous experimental shortcomings by expanding the field tests to utilize many thousands of pounds of carbon dust, by manufacturing the carbon particles directly on the delivery vehicle, and by more careful study and monitoring of the heating and meteorological effects.

a. Coating surfaces with black material

The ESSO Oil Company of New Jersey (Black and Tarmy, 1963a, Black, 1963b) has explored the possibility of boundary layer heat augmentation from coating land surfaces with black-top (tar). These results have not been very encouraging. The black-top program has suffered from three basic drawbacks: 
1) The surface air blows over the few miles of black tar field in only a few minutes. Only a relatively small heat input can be made per unit mass of air. The carbon dust scheme, in contrast, has the carbon particles moving with the air mass. The energy input over a number of hours can be very large.

2) The land surface would naturally warm up and heat the air above to an appreciable extent without the black tar. The black top heating is only the difference between its heating and the natural surface land heating which would normally occur. In contrast, when applied over the ocean, nearly all of the solar absorption by the carbon dust is extra energy gain.

3) The envisaged area coverages of the black top of $\sim 100 \mathrm{~km}^{2}$ are too small to have a significant influence. By comparison the authors are proposing the carbon dust heating of area amounts equal to 10,000 to $100,000 \mathrm{~km}^{2}$.

Attempts at melting snow flelds by coating them with carbon dust have, in general, proven unfeasible. Dispensing the carbon dust from aircraft or helicopter requires that the carbon sink to the ground before the winds sweep it away. This requires carbon particles of 100-1000 r radius. These particles are too large to have an economically feasible area to mass ratio except in very highly restricted conditions.

It may thus be concluded that the previous weather modification field programs in radiation alteration were, in general, on much too small a scale and did not have the best physical justification. 
VI. COMPARISON OF CARBON DUST RADIATION ABSORPTION WITH OTHER AEROSOL ABSORPTION

Many researchers have estimated that atmospheric aerosols absorb significant amounts of incoming solar radiation. The question then arises whether analogies exist between the radiative effects of existing atmospheric aerosols, either natural or man made, and the here proposed carbon dust cloud for weather modification.

The two primary radiative differences between the proposed carbon dust cloud and the existing natural and man made atmospheric aerosols are:

1) differences in the absorption and scattering properties of the aerosols and

2) differences in the spacial distribution and amount of the particles. Carbon dust particles of sub-micron size are highly efficient absorbers of solar radiation and exhibit very low levels of backscatter. In contrast, typically $33 \%-100 \%$ of the solar radiation extinction due to most atmospheric aerosol samples is reflected. This normally results in a cooling of the earth/atmosphere system by most atmospheric aerosols as well as an increased atmospheric stability (due to reabsorption of reflected light above the aerosol and lower solar incidence below) above that of a carbon dust cloud in which only $1-10 \%$ of the extinction is due to backscatter. Since the albedo of a carbon dust cloud is only about 1-2\% (Frank and Corrin, Paper IV), the carbon cloud virtually always results in a net warming of the earth/atmosphere system. There is no significant warming above the cloud due to reabsorption of reflected solar radiation, and solar incidence below the cloud is reduced primarily by the amount of absorption in the cloud. It is concluded that a seeded carbon dust cloud is likely to have a significantly smaller radiative effect on the atmo- 
sphere above and below the seeded area than would any naturally occuring atmospheric aerosol. Any stably induced changes of an atmospheric column containing a carbon dust cloud will be predominantly a result of the direct heating of the seeded volume by absorption of solar radiation. The proposed spacial distributions of carbon dust particles are different from those of most normal atmospheric aerosols. A carbon cloud, when inftially dispersed, would be confined to a finite horizontal area with relatively distinct boundaries. This produces strong horizontal gradients of solar absorption between the surrounding air and the carbon cloud, and it is the resulting heating gradients which should result in the anticipated dynamic responses. In addition, most applications prefer a carbon dust cloud dispersed in the planetary boundary layer, perhaps beneath a low level inversion, resulting in a distinct vertical gradient of heating in at least the initial stages. This heating would tend to destabilize the atmospheric column.

Although aerosols in general play a significant role in the global atmospheric radiation budget, situations in which natural or man made aerosols occur in unusually large and localized concentrations are of primary interest here since their occurrences exhibit spacial distribution characteristics similar to the carbon dust cloud. A number of such high aerosol-concentration episodes have been studied with respect to their radiative characteristics and possible influences on the weather. A few of the better known ones are compared with the proposed carbon modification hypothesis below:

1) Desert Dust - Large concentrations of dust frequently occur in the atmosphere downwind of deserts after large windstorms. Perbaps the best known of these are the Sahara Desert dust clouds which 
often move westward over the Atlantic Ocean. The severest of these dust clouds have been estimated to absorb as much as $50-60$ $\mathrm{cal} / \mathrm{cm}^{2}$ per day of solar radiation, (Carlson, Prospero and Hanson, 1973), about $1 / 2$ of the daily absorption of a carbon dust cloud of $10 \%$ horizontal area coverage. However, the great majority of this dust (and hence absorption) is found in the $600 \mathrm{mb}-850 \mathrm{mb}$ layer (Prospero and Carlson, 1972). Therefore, the dust cloud heats the air at elevations significantly above the boundary layer and typically above a strong inversion. This would tend to stabilize the atmosphere and suppress convection. A carbon dust cloud, however, would be dispersed in the boundary layer below the inversion and would tend to destabilize the atmosphere and stimulate convection. In addition, the Sahara dust typically is not strongly concentrated in local areas. Thus, we do not feel that solar absorption by natural atmospheric dust is similar to that of the proposed carbon dust.

2) The modification of weather downwind from large urban areas - Urban weather modification is generally attributed to a combination of the heat plume of the city itself and to changes in condensation and ice nuclei concentrations in the atmosphere (Semonin and Changnon, 1974). However, aerosol absorption of solar radiation in the heavily polluted air downwind from industrial urban areas is also a possible contributing mechanism to the urban induced modification. It is interesting to compare the likely extra urban aerosol solar heating with the proposed solar heating which can be obtained from carbon dust particles. 
Aerosols over the most polluted urban centers are relatively poor absorbers of solar radiation. The atmospheric aerosols with some significant effect upon solar radiation attenuation are in the approximate size range of $.01 \leq x \leq 1 \mu$ and absorb and scatter according to MIE theory. Particles smaller than $r \sim 0.01 \mu$ are generally very poor absorbers of solar radiation while particles much larger than about $r \sim 1.0 \mu$ do not have enough total surface area to absorb much solar radiation due to their low number concentrations.

The imaginary part of the complex index of refraction $\left(\mathrm{n}_{2}\right)$ for natural aerosols which determines their absorptivity has been measured to be about $\mathrm{n}_{2} \simeq 0.01$ although Eiden (1966) has measured tentative values as high as $n_{2}=0.1$ for very heavily polluted urban air. These values are much less than the $.28 \leq n_{2} \leq 2.30$ values exhibited by carbon over the solar spectrum. Although the exact dependence of aerosol absorption upon the imaginary part of the complex index of refraction is very difficult to precisely specify, computations of particle absorptivities by Plass (1965) and others show that carbon particles should absorb from 5 to 100 times more solar radiation per particle than would most atmospheric aerosols in the most effective size range $(.01 \mu \leq x \leq 1.0 \mu)$. The proposed carbon dust configurations exhibit much higher particle concentrations in the highly absorbent $0.01 \mu-1.0 \mu$ size range than do most natural and man produced aerosols. However, during extreme urban air pollution episodes the particulate concentrations in this size range can equal or 
occasionally slightly exceed the proposed carbon dust concentrations (Whitby, Husar, and tiu, 1971).

Because of low particle absorptivity, urban aerosols can be expected to absorb no more than about $5 \%-20 \%$ as much solar radiation as a carbon dust cloud of $10 \%$ area coverage. Such an urban aerosol backscatters a significant amount of solar radiation. This reduces surface heating. In addition, aerosol concentrations of this magnitude usually occur only during meteorological conditions highly unfavorable to developing convection (e.g. subsidence inversion). Finally, the location of the urban aerosol (over land) is less favorable for producing horizontal heating gradients than the oceanic boundary layer site proposed for carbon dust seeding. It may thus be concluded that while an urban aerosol will exhibit some radiative similarities to a carbon dust cloud, the much smaller amounts of solar radiation absorbed and the unfavorable atmospheric and geographic environment in which it typically exists make it highly unlikely that a significant mesoscale atmospheric response will occur. Therefore, the urban aerosol does not provide a very useful analogy to a carbon dust cloud.

3) Rainfall suppression from vegetation fires - From time to time reports have been made of apparent suppression of rainfall downwind from areas where a large amount of agricultural burning occurs. A typical and well documented case is the decrease in precipitation downwind from sugar cane fires which occurs with increasing cane production (Warner, 1968) in Australia. However, this is thought to result from increased concentrations of condensation nuclei from the cane fire smoke rather than from radiative 
effects. This smoke is believed to produce more and smaller cloud drops (Warner and Twomey, 1967). Rainfall requires larger and fewer drops. Precipitation is thus inhibited. The carbon cloud would not act in this manner since the only particles produced in significant quantities during the controlled carbon generation process are the carbon black particles themselves. Carbon black is highly hydrophobic and will not act as an effecive condensation nucleus (Frank and Corrin, Paper IV). Hence, carbon seeding should not have any effect on concentrations of condensation or ice nuclei and should not affect cloud physics processes in this regard.

a. Summary

Although it is tempting to compare localized natural aerosol concentrations to the proposed carbon dust clouds, none of the normally occurring atmospheric aerosols surveyed here have radiative characteristics or spacial distributions similar enough to the carbon dust clouds to allow any meaningful analogies to be drawn. Few normally occurring aerosols exhibit the strong absorptivity of carbon or exist in locally concentrated clouds with relatively sharp boundaries such as a carbon dust cloud. Therefore, it is doubtful that any such aerosols result in an atmospheric response similar to the response which a carbon dust cloud would be expected to produce. 


\section{SYNOPSIS}

Many previously unexplored avenues of beneficial utilization of solar energy may be available to man. It is time for man to explore these areas of potential meso-scale weather modification. The discussions of these papers are very different than most current weather modificatinn schemes which concentrate on alteration of individual cumilus elements.

The following four papers will discuss many of the radiational, technological, ecological and meteorological requirements and problems which are likely to be encountered when man attempts the above types of modification.

Acknowledgements

The authors were much indebted to Professor Myron L. Corrin for many beneficial discussions. 


\section{REFERENCES}

Black, J. F., 1963b: Weather control: Use of asphalt coatings to tap solar energy. Science, 139, 226-227.

Black, J. F. and B. L. Tormy, 1963a: The use of asphalt coatings to increase rainfall. J. Appl. Meteor., 2, 557-564.

Carlson, T. N., J. M. Prospero and K. J. Hanson, 1973: Attenuation of solar radiation by windborne saharan dust off the west coast of Africa. NOAA Technical Memorandum ERL WMPO-7, U.S. Dept. of Commerce, $27 \mathrm{pp}$.

Cox, S. and V. E. Suomi, 1969: Radiation in the free atmosphere. Dept. of Meteor. Univ. of Wisconsin, Final unpublished report to ESSA Research Labs., 68 pp.

Downie, C., 1960: Cloud modification with carbon black. Wentworth H.H. Conference on Cumulus Dynamics, 191-208.

Eiden, R., 1966: The elliptical polarization of light scattered by a volume of atmospheric air. App1. Optics, 5, 569-576.

Fenn, R. W. and H. Oser, 1962: Theoretical considerations on the effectiveness of carbon seeding. U.S. Army Signal Research and Development Lab. Report No. 2258, 25 pp.

Gray, W. M., 1973: Feasibility of beneficial hurricane modification by carbon black seeding. Dept. of Atmos. Sci., Colo. State Univ., Research Report No. 196, 130 pp.

Korb, G. and F.Möller, 1962: Theoretical investigation of energy gain by absorption of solar radiation in clouds. Final Report on U.S. Army Signal Corp. Contract No. DA-91-541-EUC01612, 185 pp. (available from U.S. Army).

Prospero, J. M. and T. N. Carlson, 1972: Vertical and areal distribution of Saharan dust over the western equatorial North Atlantic Ocean. J. Geophysical Res., 5255-5265.

Semonin, R. G. and S. A. Changnon, Jr., 1974: METROMEX: Summary of 19711972 results. Bulletin of the AMS, 55, 95-100.

Van Straten, F. W., R. E. Ruskin, J. E. Dinger and H. J. Mastenbrook, 1958: Preliminary experiments using carbon black for cloud modification and formation. U.S. Naval Res. Lab. Report No. 5235, 17 pp.

Warner, J., 1968: A reduction in rainfall associated with smoke from sugar cane fires - an inadvertent weather modification. J. Atmos. Sci., 247-251. 
REFERENCES (cont'd)

Warner, J. and S. Tuomey, 1967: The production of cloud nuclet in cane fires and the effect on cloud droplet concentration. J. Atmos. Sci., 704-706.

Whitby, K. T., R. B. Husar and B. Y. H. Liu, 1971: The aerosol size distribution of Los Angeles smog. Aerosols and Atmospheric Chemistry, G.M. Hidy ed., Academic Press, New York, 237-264. 
Weather Modification by Carbon Dust Absorption of Solar Energy Paper II: Radiation Characteristics

William M. Frank

ABSTRACT

This paper evaluates the radiational properties of clouds consisting of carbon black particles in aerosol form spread artificially in the atmosphere to absorb solar radiation and hence to create an atmospheric heat source for possible large-scale weather modification. Properties of carbon black are discussed. A method for estimating absorption of solar radiation by clouds developed by Korb and Mö1ler (1962) is applied to study solar absorption and scattering of carbon black dust clouds. The very high energy gain to weight and cost is discussed. 


\section{INTRODUCTION}

This paper is concerned with the potential use of carbon black as a clear air heat source by spreading particles over a large area in order to trigger beneficial mesoscale or synoptic scale flow changes. The radiation properties of carbon clouds of large horizontal extent compared to their vertical depth are studied incorporating the effects of water vapor and planetary surface albedo. Quantitative results are obtained for several cloud models. 
II. RADIATIVE PROPERTIES OF CARBON BLACK DUST IN THE ATMOSPHERE

a. Carbon black

Carbon black dust consists of fine spherical particles composed of 95-99\% pure carbon, the remainder being made up of volatile materials. The density of the carbon particles is about $2.0 \mathrm{~g} / \mathrm{cm}^{3}$. The high radiative absorptivity and low heat capacity (about $.125 \mathrm{cal} / \mathrm{g}^{\circ} \mathrm{C}$ ) of carbon black make it an ideal agent for interception of solar radiation and transfer of this heat to the surroundings by conduction. These properties are discussed in more detail later.

\section{b. Radiation characteristics of carbon black}

The complex index of refraction of carbon particles computed by Krascella (1965) is shown as a function of wavelength in Fig. 1. The absorption $\left(\sigma_{A}\right)$, scattering $\left(\sigma_{S}\right)$ and extinction $\left(\sigma_{E}\right)$ cross sections of spherical carbon particles computed by MIE scattering theory are shown as functions of the size parameter $\alpha=\frac{2 \pi r}{\lambda}$ in Fig. 2. These coefficients are defined as the ratios between the equivalent areas with which particles absorb, scatter, and extinct light and the actual geometric cross section. They are functions of the refractive index of carbon, particle size and the wave length of the affected light. The coefficients are related as shown in equation (1).

$$
\sigma_{E}=\sigma_{A}+\sigma_{S}=\text { extinction cross section }
$$

The values shown in Fig. 2 (Krascella, 1965) are in close agreement with experimental and theoretical estimates of the tinting strength of carbon black particles made by various carbon black companies. Marteney (1965), in a companion study to that of Krascella, obtained 


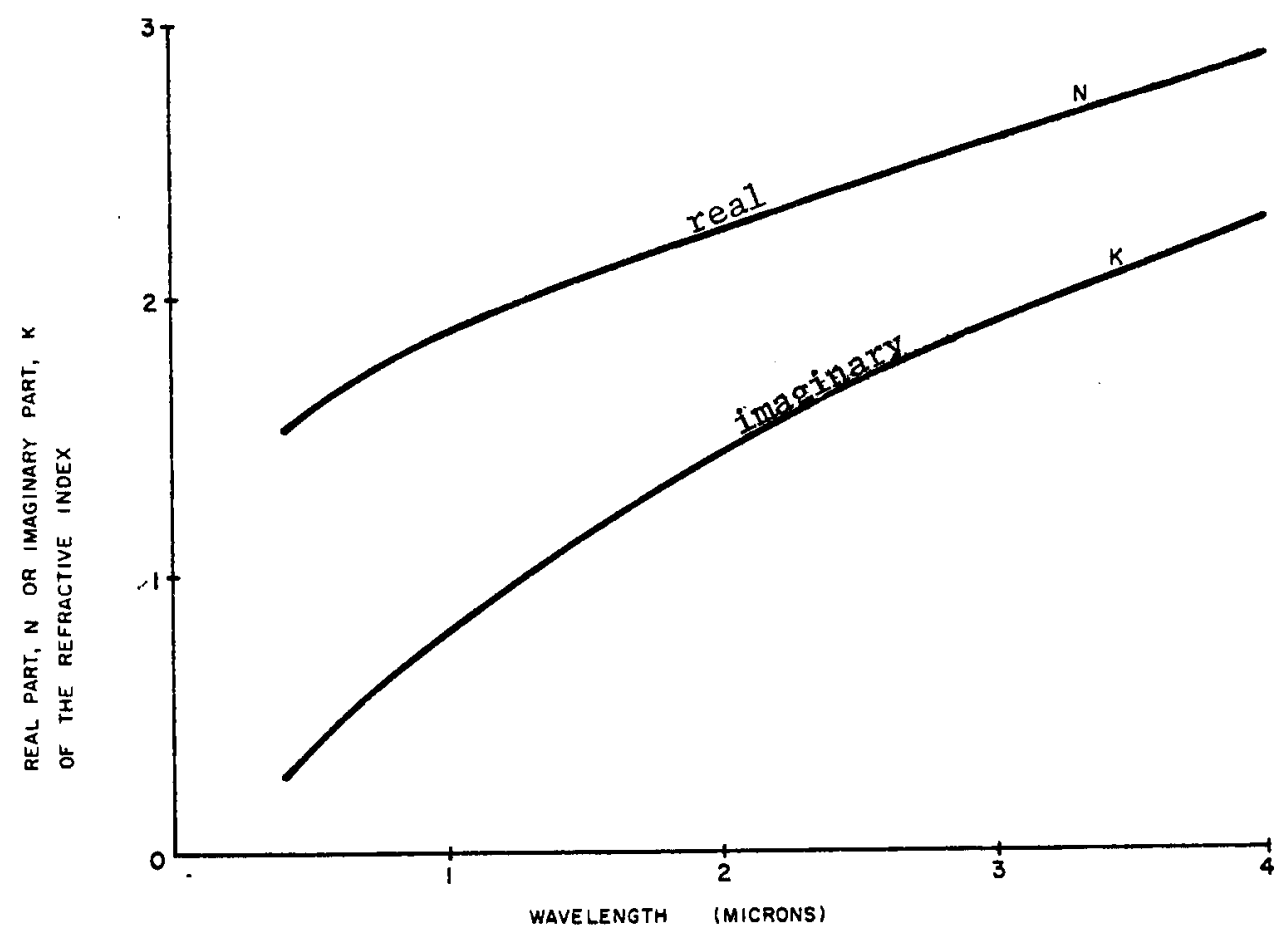

Fig. 1. Variation of the real and imaginary parts of the complex index of refraction of spherical carbon particles with incident wavelength (Krascella, 1965).

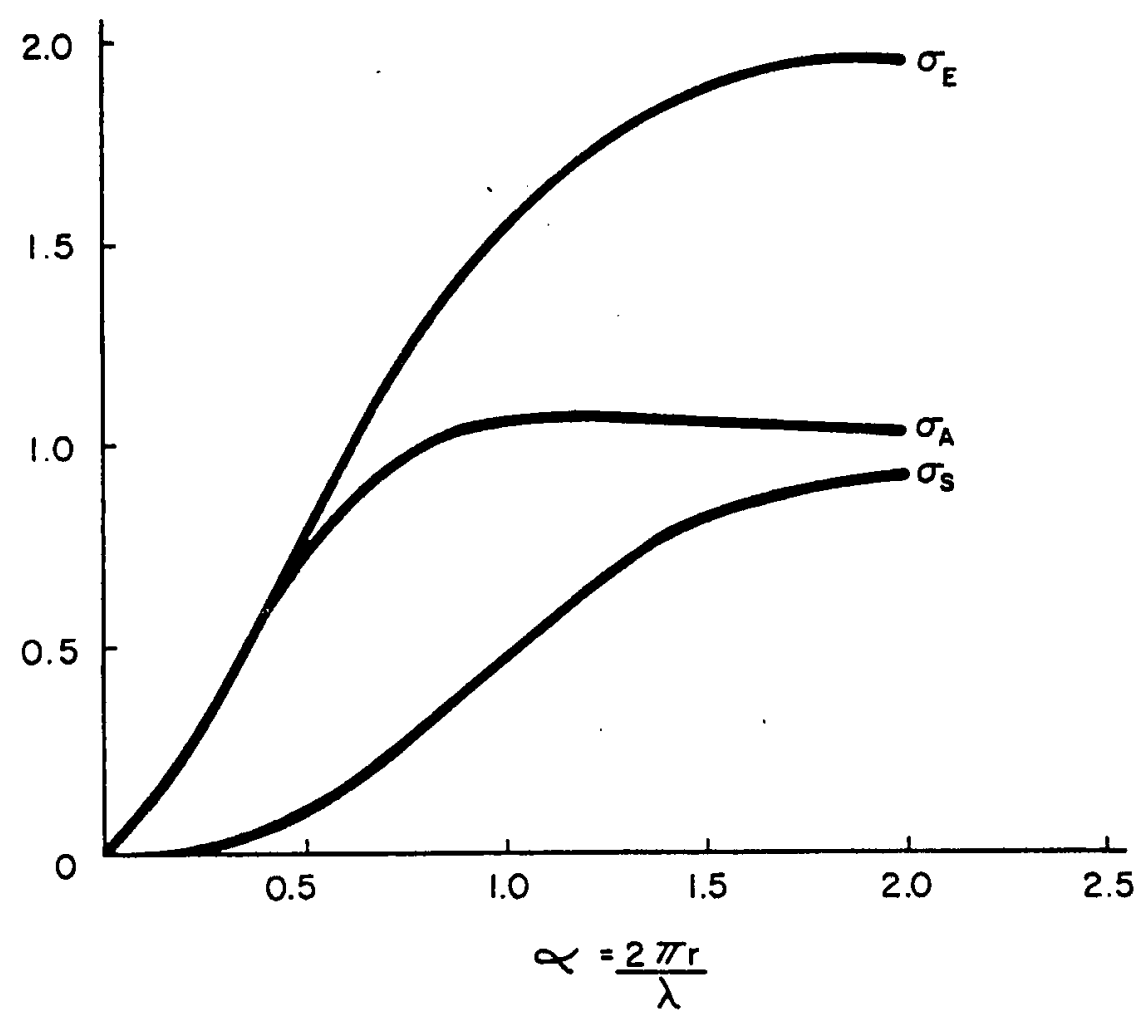

Fig. 2. Extinction $\left(\sigma_{E}\right)$, absorption $\left(\sigma_{A}\right)$ and scattering $\left(\sigma_{S}\right)$ cross sections of spherical carbon particles as functions of size parameter $(\alpha)$. 
experimental absorptivities of carbon particles dispersed in air which are in close agreement with Krascella's theoretical values. Fenn (1962, 1965) estimated somewhat higher values of these parameters. Carbon black particles, when formed, are virtually all spherical and of relatively uniform size and composition. Since the particles will be dispersed into the air immediately after formation, the relevance of the MIE scattering theory to light extinction by carbon particles seems to be reasonable.

\section{c. Characteristics of the carbon cloud}

For this study each carbon dust cloud was assumed to be composed of uniform carbon particles. The clouds are of large horizontal extent compared to their thickness, and each cloud or cloud layer was assumed to be homogeneous. Water vapor contents of the clouds were assigned according to standard atmospheric concentrations depending upon cloud height. All water vapor was assumed to be uncondensed.

The above assumptions were made for convenience of computation. Real situation variations from these assumed values are not felt to be large enough to appreciably alter the results to be shown. Any of the assumptions can be varied to meet individual case refinement as desired.

\section{d. Determination of Optimum Particle Size}

For economic reasons it is desirable to maximize the amount of radiation absorbed by the carbon particles per unit mass. To do this the optimum particle size must be determined. Since the cloud is of relatively large horizontal extent compared to its height, much of the forward scattered incident radiation will be absorbed due to increased optical path length. Hence, we wish to maximize the extinction coefficient of the cloud per unit mass, rather than the absorption coefficient. 
The extinction coefficient of a cloud is given by:

$$
\mathrm{K}_{\mathrm{E}}=\mathrm{N} \cdot \pi \mathrm{r}^{2} \cdot \sigma_{\mathrm{E}}
$$

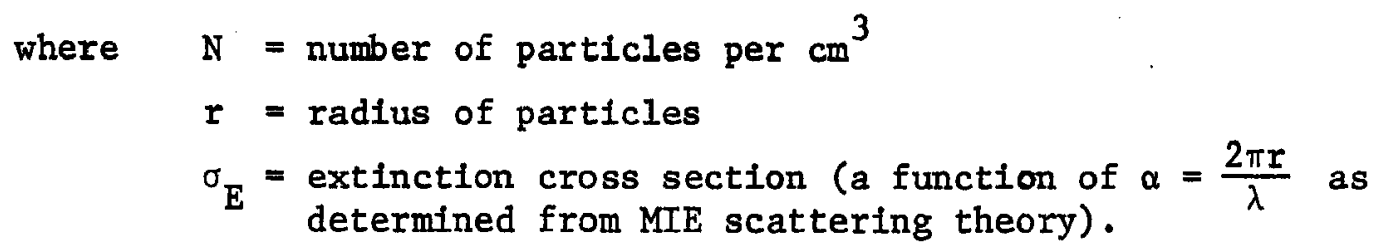

Let the volume of a single carbon particle $=V_{P}=\frac{4}{3} \pi r^{3}$.

Let the total mass of carbon particles $=M_{C}=V_{T} \rho_{C}$

where $\rho_{\mathrm{c}}=$ density of carbon black $\left(\sim 2 \mathrm{gm} / \mathrm{cm}^{3}\right)$

$\mathrm{V}_{\mathrm{T}}=$ total volume of particles

$$
\mathrm{N}=\frac{\mathrm{V}_{\mathrm{T}}}{\mathrm{V}_{\mathrm{P}}}=\frac{\mathrm{M}_{\mathrm{c}}}{\rho_{\mathrm{c}}} \cdot \frac{3}{4 \pi \mathrm{r}^{3}}
$$

Then

$$
\mathrm{K}_{\mathrm{E}}=\frac{3}{4} \quad \frac{\mathrm{M}_{\mathrm{C}}}{\rho_{\mathrm{C}}} \frac{1}{\mathrm{r}} \sigma_{\mathrm{E}}
$$

The size parameter $(\alpha)$ is defined: $\alpha=\frac{2 \pi r}{\lambda} \quad$ where $\lambda$ is the wavelength of radiation. Hence

$$
\begin{gathered}
r=\frac{\alpha \lambda}{2 \pi} \quad \text { and } \\
K_{E}=\frac{3 \pi M_{C}}{2 \rho_{C} \lambda} \quad \frac{\sigma_{E}}{\alpha} .
\end{gathered}
$$




$$
\frac{3 \pi M}{2 \rho_{c} \lambda}=\text { constant }
$$

Hence:

$$
\mathrm{K}_{\mathrm{E}}=\frac{\sigma_{\mathrm{E}}}{\alpha} \cdot \text { (const.) }
$$

$\frac{\sigma_{E}}{\alpha}$ is plotted in Fig. 3. The maximum value of $\frac{\sigma_{E}}{\alpha}$ from this graph will give us the maximum value of $\mathrm{K}_{\mathrm{E}}$ for any given mass per unit volume. Solving graphically $\mathrm{K}_{\mathrm{E}}$ is a maximum at approximately $\alpha=0.7$.

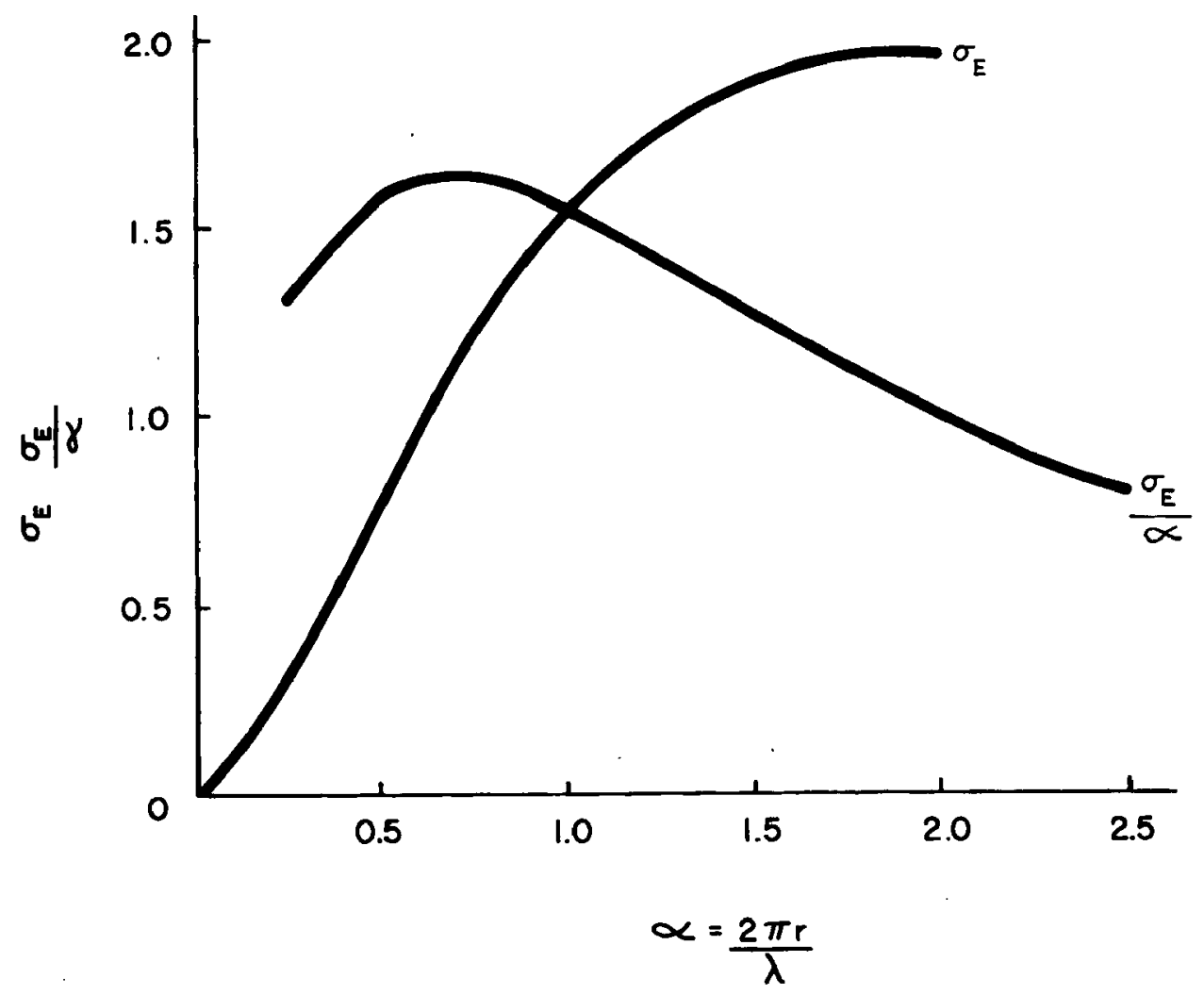

Fig. 3. Extinction cross section $\left(\sigma_{E}\right)$ and $\sigma_{E} / \alpha$ for spherical carbon particles. 
Although sunlight has an intensity peak at $\lambda=.5 \mu$, to maximize the extinction across the entire solar spectrum we shall use the median value of solar wave length which is approximately: $\bar{\lambda} \simeq .72 \mu$. This gives an optimum radius of:

$$
\begin{aligned}
& r=\frac{a \lambda}{2 \pi}=\frac{(0.7)(\lambda)}{2 \pi} \\
& r=.08 \text { micron }(\mu) .
\end{aligned}
$$

For simplicity we shall assume particles of $r=.1 \mu$ for the remainder of this study. Note from the gradual slope of the $\frac{\sigma_{E}}{\alpha}$ curve in Fig. 3 that light extinction per unit mass of carbon is not highly sensitive to particle size changes. Size quality control should not be a crucial problem.

e. Division of the solar spectrum

To average the general transmission function, the solar spectrum must be divided into finite bands, and average values of the extinction coefficient and optical depth must be determined for each band. These parameters vary rather smoothly with changing wave length. However, water vapor absorption is quite irregular with respect to wave length. It is therefore desirable to choose bands such that each of the absorption bands of water vapor will coincide with one of the defined spectral bands. In the spectral bands with no water vapor absorption, water vapor absorption will be zero, and in the bands which coincide with water vapor bands, average values may be determined. (The solar constant value used is $1.95 \mathrm{ly} / \mathrm{min}$.). The spectral divisions used, the water vapor absorption bands, and the solar irradiance (radiant flux incident on a unit area) of each band at the top of the atmosphere are shown in Table 1 . Also shown are the values of the absorption $\left(\sigma_{a}\right)$, scattering $\left(\sigma_{s}\right)$, and extinction $\left(\sigma_{E}\right)$ cross 


\section{TABLE 1}

\section{DIVISION OF SOLAR SPECTRUM}

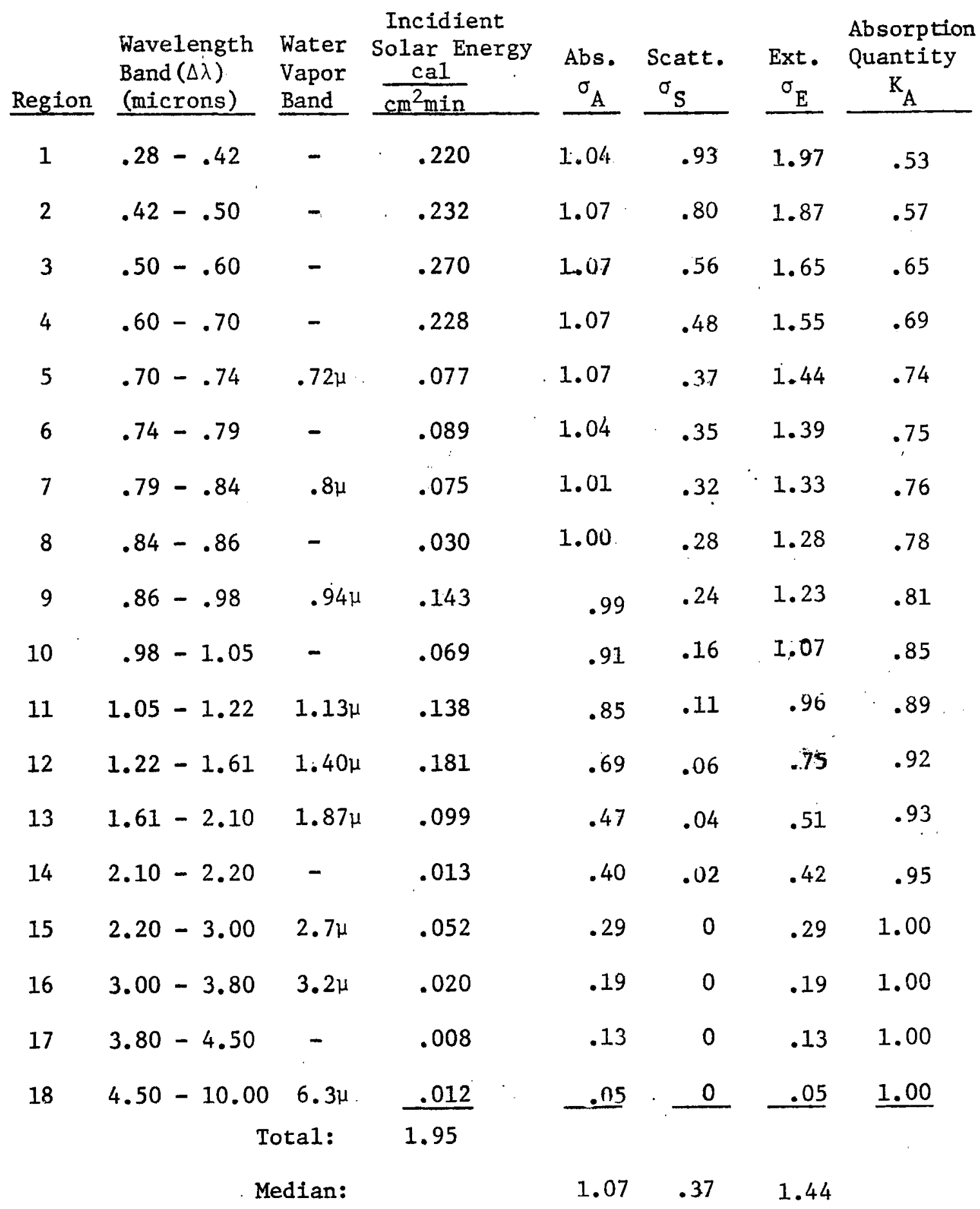


sections and the absorption quantity $\left(\mathrm{K}_{\mathrm{A}}\right)$. Absorption quantity is defined as the ratio of the absorbed light to absorbed plus scattered light as shown in equation (9).

$$
\mathrm{K}_{\mathrm{A}}=\frac{\text { absorption coefficient }+\rho_{W} K_{W}}{\text { extinction coefficient }+\rho_{W} K_{W}}
$$

where

$$
\begin{aligned}
& \rho_{\mathrm{W}}=\text { water vapor density } \\
& \mathrm{K}_{\mathrm{W}}=\text { absorption coefficient of water vapor. }
\end{aligned}
$$

f. Method for solving the equation of radiative transfer through a cloud

A method developed by Korb and Mö1ler (1962) was used to solve the general equation of radiative transfer through a cloud (as developed by Chandrasekhar, 1960). The radiation field was broken up into $2+2 \pi$ fluxes; one directed upward, one downward, and $2 \pi$ fluxes in the horizontal plane. This breaks the general transfer equation down into a series of linear differential equations which give absorption, transmission, and reflection of radiation as percentages of total incident radiation. These equations are shown in appendix I for the cases where surface albedo is zero and where surface albedo is non zero.

The absorption, reflection, and transmission were determined for each given zenith angle and optical depth for a narrow spectral band, and the results were summed for all spectral bands to give total values for given zenith angle and optical depth. Nine zenith angles from $0^{\circ}$ to $80^{\circ}$ at $10^{\circ}$ intervals were chosen. For simplicity, calculations of daily absorption assumed a 12 hour day with the sun directly overhead at noon. The total absorption and transmission per day for each optical depth was obtained by time averaging the values over the 10 hour 40 minute period 
with zenith angles less than $80^{\circ}$ in computation steps of $10^{\circ}$ zenith angle change (40 minutes). Water vapor absorption within the cloud was also included in the computations.

The above radiation model was run assuming no surface reflection and also for various albedos by introducing an upward diffuse radiation field using mean values of the scattering function components. Intensity of the upward scattered field varied with albedo and the amount of light initially transmitted through the cloud.

Solar irradiances at the top of each cloud were reduced using calculations by Dave and Furukawa (1966) to account for ozone $\left(0_{3}\right)$ absorption and molecular scattering above the cloud top. Molecular scattering within the cloud was not considered. Absorption and scattering by molecular oxygen $\left(\mathrm{O}_{2}\right)$ and carbon dioxide $\left(\mathrm{CO}_{2}\right)$ is insignificant for the purposes of these calculations and was not taken into account. Effects of natural tropospheric aerosols were not considered in these calculations.

For each cloud configuration studied, the total absorption of solar radiation by carbon and water vapor was calculated. The absorption of the equivalent volume at the same altitude due to water vapor alone was then calculated. It was assumed that water vapor in the air around the test cloud would absorb radiation at the rate of the carbon-free air. Since the evaluation of carbon black as a heat source was the object of this study, the net effectiveness of the carbon was the difference between the total solar radiation absorbed by the carbon cloud and the radiation that would be absorbed without the carbon cloud. It was expected that the carbon and water vapor cloud would absorb less than the sum of the absorptions of a carbon-only cloud and water-vapor-only cloud due to the redundancy of the absorption characteristics of the two substances at longer wavelengths. This proved to be the case, but the loss in efficiency was very small. 


\section{RESULTS}

a. Absorption in the tropical atmosphere

It is felt that the tropical atmosphere presents the best opportunities for beneficial large scale weather modification. Particular interest is centered on carbon black dust seeding into the tropical boundary layer (1013 mb - $950 \mathrm{mb})$. Absorptions were first computed for clouds containing $4.0 \mathrm{~cm}$ and $5.0 \mathrm{~cm}$ of precipitable water vapor - (ppw) - but no carbon to simulate clear air absorption in the tropical atmosphere. These are the amounts of water vapor found above $950 \mathrm{mb}$ and $1013 \mathrm{mb}$ respectively in a mean tropical cloud cluster. The amounts of solar radiation absorbed per day in clear tropical conditions are shown in Table 2. It is noteworthy that the $5.0 \mathrm{~cm}$ ppw atmosphere absorbs only about $5 \%$ more radiation per day than does the $4.0 \mathrm{~cm}$ ppw atmosphere. This indicates that $95 \%$ of the solar radiation absorbed daily by the $5.0 \mathrm{~cm}$ ppw atmosphere is absorbed by the portion of that atmosphere containing the uppermost $4.0 \mathrm{~cm}$. Since so little solar radiation (about 9 ly/day) is absorbed by the lowest $1 \mathrm{~cm}$ of ppw, no significant redundancy in absorption by water vapor and carbon would occur in a carbon dust cloud dispersed between $1013 \mathrm{mb}$ and $950 \mathrm{mb}$ in the tropics. Therefore, such a carbon dust cloud can be treated as a dry cloud to a reasonably high degree of accuracy.

Calculations of absorption by a dry carbon cloud in the tropical boundary layer (1013-950 mb) were made using reduced values of solar energy incident at the $950 \mathrm{mb}$ level to approximate the effects of water vapor, ozone, and molecular scattering. A surface albedo of $10 \%$ was assumed. Results are shown in Table 3, and net absorption as a function of carbon concentration is shown in Fig. 4. An increasing loss of efficiency of absorption per unit mass occurs at increasing densities as progressively less solar radiation penetrates to the lower levels of carbon, especially at 
high zenith angies. Therefore, from an economic point of view it is desirable to cover large areas with low concentrations if the magnitude of heat gain to carbon dust expended is to be maximized. A carbon particle concentration of 10,000 particles $/ \mathrm{cm}^{3}$ represents $18 \%$ horizontal area coverage for this cloud model. This would require only $45 \mathrm{~kg}$ of carbon black dust per square kilometer of horizontal cloud area.

b. Absorption by carbon dust in the mid-latitude standard atmosphere Computations of daily absorption were made for a cloud extending from sea level to $11 \mathrm{~km}$ containing $2.8 \mathrm{~cm} \mathrm{ppw}$, the approximate mid-1atitude standard atmospheric water vapor content, and carbon particle concentrations from zero to 2000 particles $/ \mathrm{cm}^{3}$. It was assumed that such a

TABLE 2

SHORT WAVE ABSORPTION BY CLEAN AIR TROPICAL ATMOSPHERE

cm precipitable water Absorption:

(1y/day)

$$
4.00
$$

5.03

TABLE 3

SHORT WAVE ABSORPTION BY CARBON DUST CLOUDS OF VARIOUS CONCENTRATIONS IN THE TROPICAL BOUNDARY LAYER (1013-950 mb)

\begin{tabular}{lrrrrrrr}
\hline $\begin{array}{l}\text { Percent Area } \\
\text { Coverage: }\end{array}$ & 0 & $9 \%$ & $18 \%$ & $26 \%$ & $35 \%$ & $53 \%$ & $.70 \%$ \\
$\begin{array}{l}\text { Concentration } \\
(\text { Particles/cm }\end{array}$ & 0 & 5,000 & 10,000 & 15,000 & 20,000 & 30,000 & 40,000 \\
$\begin{array}{l}\text { Net Absorption: } \\
\text { by Carbon (ly/day) }\end{array}$ & 0 & 98 & 177 & 243 & 298 & 384 & 448 \\
\end{tabular}




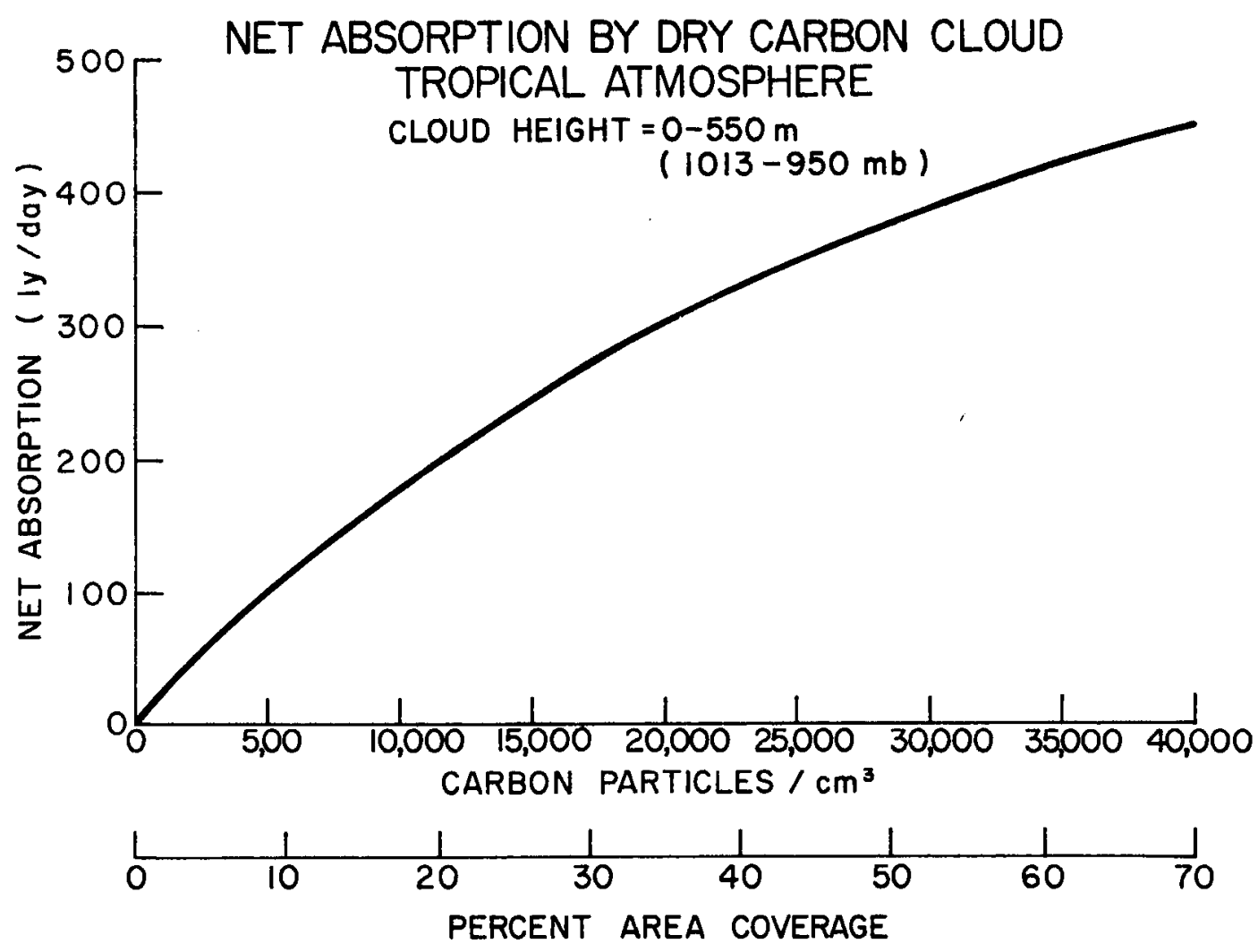

Fig. 4. Net absorption of solar radiation by a dry carbon cloud in the tropical boundary layer.

cloud model might be used to intensify existing broadscale circulations. Total absorptions and net usable absorptions (total absorption minus natural clear air water vapor absorption) per day are shown in Table 4. These absorptions are plotted as functions of cloud density in Fig. 5 . Absorption in langleys per minute rates are plotted as a function of zenith angle for each particle concentration in Fig. 6. This shows the relative effects of decreasing incident solar radiation and increasing optical path length with zenith angle change. It can readily be seen that when dealing with large concentrations of carbon dust, efficiency is considerably lower at zenith angles greater than $60^{\circ}$, which comprises roughly a third of the 12 hour day. Operations requiring large concentrations of carbon black for intense local heating would be most economical during 
TABLE 4

ABSORPTION BY CARBON DUST CLOUD

Cloud Depth 0-11 km

\begin{tabular}{llrlrrrr}
\hline Area Coverage & $0 \%$ & $9 \%$ & $18 \%$ & $26 \%$ & $35 \%$ & $53 \%$ & $70 \%$ \\
Particles $/ \mathrm{cm}^{3}$ & 0 & 250 & 500 & 750 & 1000 & 1500 & 2000 \\
\hline
\end{tabular}

Total

Absorbed $\quad 137$ ly 240 ly 324 ly 394 ly 452 ly 543 1y 610 ly by Cloud

Absorbed by

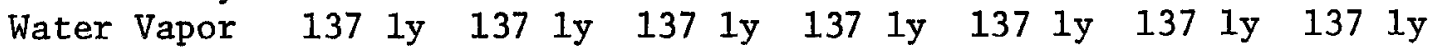

in Clear Air

Net Usable

Absorbed

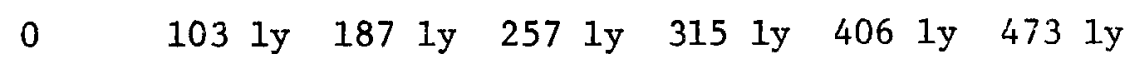

$\mathrm{N}=$ particles $/ \mathrm{cm}^{3}$

$\mathrm{C}=\%$ area coverage of Carbon

ly lost by

competing

with water

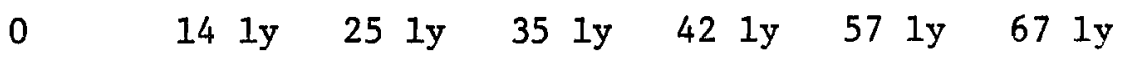

vapor

(absorption by carbon cloud with no water vapor-net usable absorbed) 


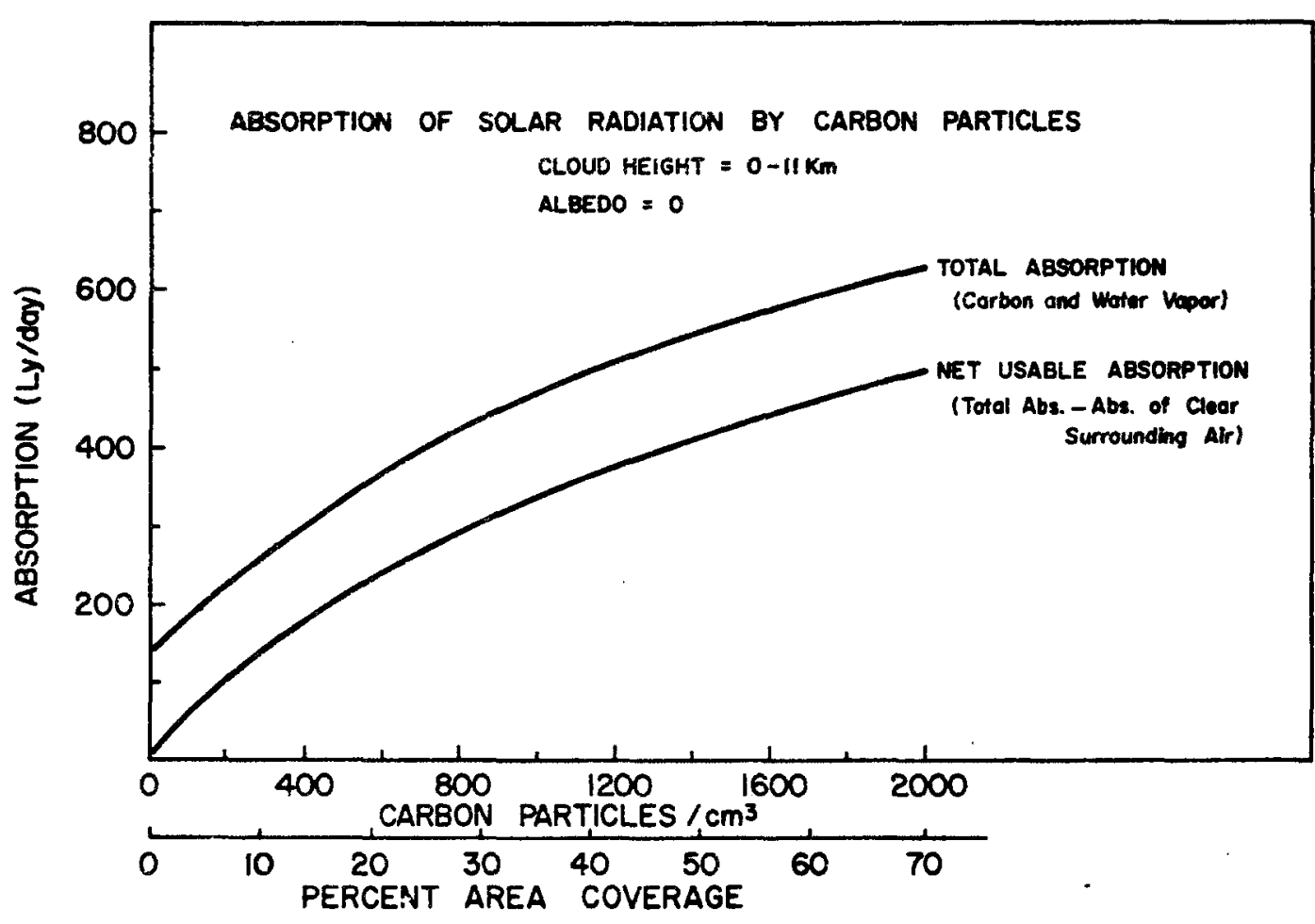

Fig. 5. Total and net usable absorption of solar radiation by carbon particles and water vapor.

the mid-day hours, while those requiring only moderate concentrations $\left(N<500\right.$ particles $\left./ \mathrm{cm}^{3}\right)$ would be efficient throughout the entire solar day.

c. Influence of water vapor absorption

To obtain an estimate of the magnitude of the efficiency loss due to the redundant absorption tendencies of carbon and water vapor at higher wave lengths, absorption values of a 0-11 $\mathrm{km}$ carbon cloud were calculated assuming water vapor content to be zero. The results are plotted in Fig. 7 along with the total and net usable absorption potential for the mid-latitude model. The absorption loss increases with particle concentration, and the ratio of lost absorption to net usable absorption increases slightly. The lost absorption ranges from $0 \%$ to about $14 \%$ of net usable absorption for the densities tested. 


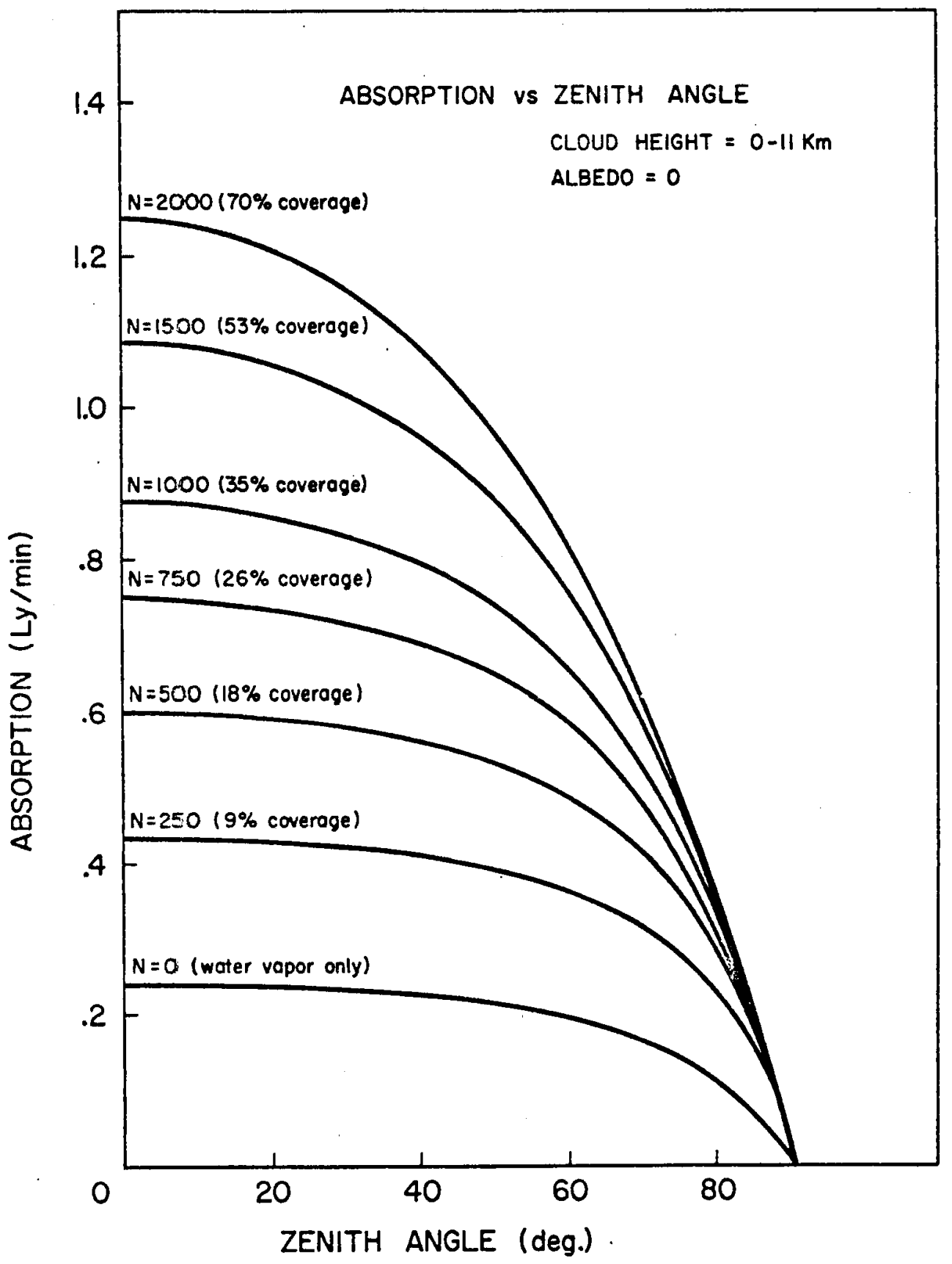

Fig. 6. Variation in absorption of solar radiation with zenith angle. 


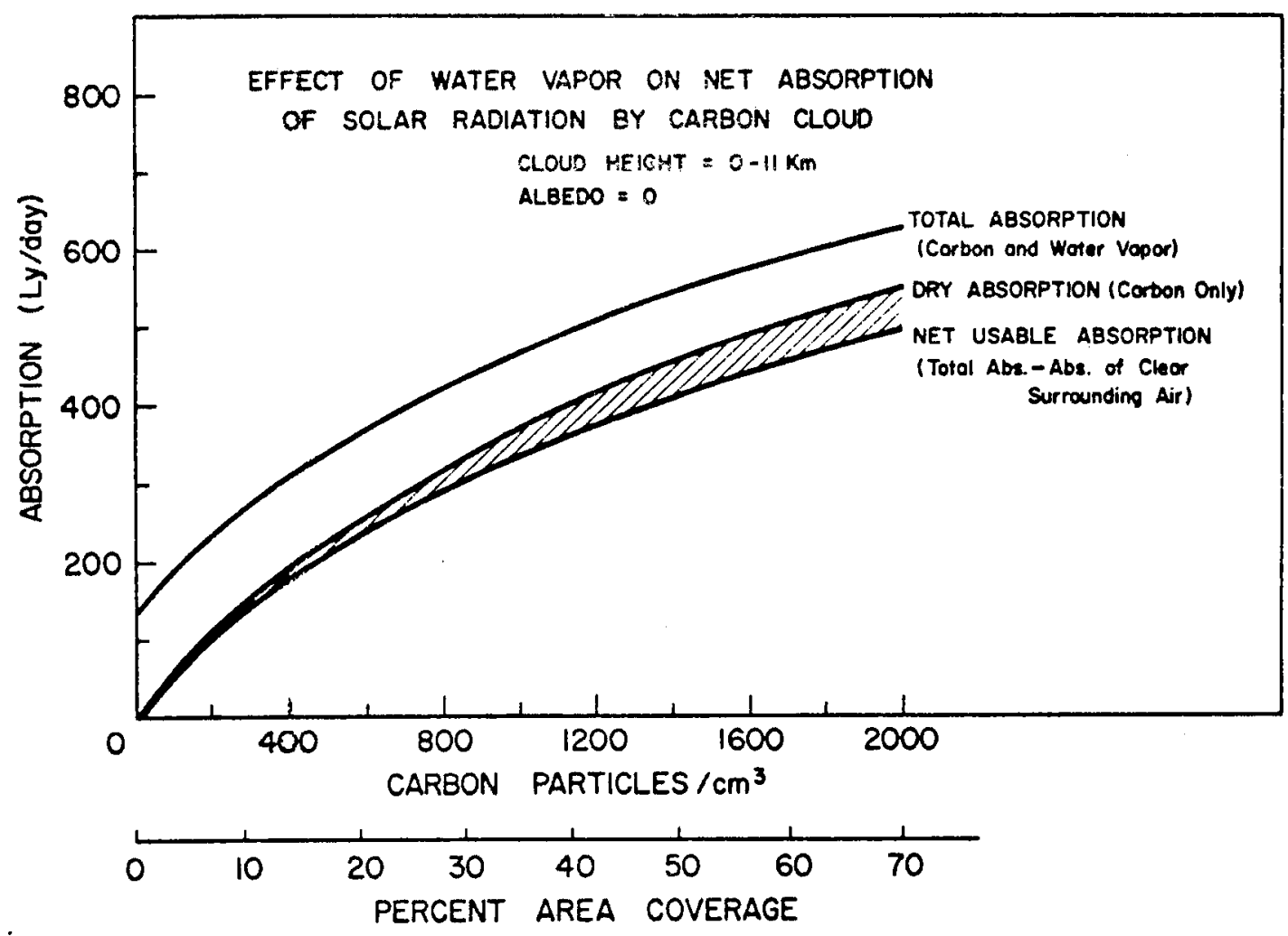

Fig. 7. Loss of efficiency of carbon absorption due to redundant absorption by water vapor.

\section{d. Long wave radiation loss}

To develop a complete heat budget of a carbon black cloud, it is necessary to consider the loss of absorbed radiation due to vertical long wave radiant flux divergence. Korb and Möller (1962) calculated values of long wave flux divergence of various carbon clouds for a 24 hour day. They considered $\mathrm{CO}_{2}$ and water vapor to be selective absorbers and the carbor particles to be gray absorbers. Standard mid-latitude atmospheric values of water vapor concentrations were used. Results are shown in Table 5 . The difference between flux loss from a cloud consisting of carbon, water vapor and $\mathrm{CO}_{2}$ and a similarly dimensional cloud consisting only of water vapor and $\mathrm{CO}_{2}$ represents the loss of effective heating by the carbon black. In the most extreme case, the $1-6 \mathrm{~km}$ cloud with a carbon concentration of 
TABLE 5

LONG WAVE RADITION FLUX DIVERGENCE LOSS BY VARIOUS AEROSOL CLOUD MODELS (Korb and Mö11er, 1962)

\begin{tabular}{|c|c|c|c|c|c|c|c|}
\hline \multicolumn{8}{|c|}{ Long Wave Flux Divergence (1y/24hr) } \\
\hline $\begin{array}{l}\text { Cloud } \\
\text { Height }\end{array}$ & $\begin{array}{l}\text { (1) } \mathrm{H}_{2} \mathrm{O}, \mathrm{CO}_{2} \\
\text { Cloud }\end{array}$ & $\begin{array}{l}\text { (2) } \begin{array}{l}\mathrm{H}_{2} \mathrm{O}, \mathrm{CO}_{2}, \text { Carbon } \\
\left(\mathrm{N}=10^{3} \mathrm{~cm}^{-3}\right) \text { Cloud }\end{array} \\
\end{array}$ & $\begin{array}{l}{[(2)-(1)]} \\
\text { Net Loss by }\end{array}$ & Carbon & $\begin{array}{l}\text { (3) } \begin{array}{l}\mathrm{H}_{2} \mathrm{O}, \mathrm{CO}_{2}, \text { Carbon } \\
\left(\mathrm{N}=104 \mathrm{~cm}^{-3}\right) \mathrm{Cloud}\end{array} \\
\end{array}$ & $\begin{array}{l}{[(3)-(1)]} \\
\text { Net Loss by }\end{array}$ & Carbon \\
\hline $1-2 \mathrm{~km}$ & -33.7 & -34.3 & -0.6 & & -38.6 & -4.9 & \\
\hline $5-6 \mathrm{~km}$ & -23.3 & -23.3 & 0.0 & & -24.9 & -1.6 & \\
\hline $1-6 \mathrm{~km}$ & -126.9 & -128.0 & -1.1 & & -137.2 & -10.3 & \\
\hline $10-11 \mathrm{~km}$ & -14.3 & -14.1 & +.02 & & -11.8 & +2.5 & \\
\hline
\end{tabular}

(Negative values indicate loss) 
$1 \times 10^{4}$ particles per $\mathrm{m}^{3}$, the effective loss is only 10.3 ly which $\mathrm{rep}$ resents only about $2 \%$ of the total solar radiation absorbed in one day by such a cloud. At very high altitudes (the 10-11 $\mathrm{km}$ cloud) there is a slight relative gain of long wave radiation by the cloud. Thus, long wave flux should not have a significant effect on the net radiative energy gain of carbon seeded air. It is assumed, therefore, that virtually all radiation absorbed by the cloud will be directly converted into heat within the absorption layer.

This finding agrees well with the results of a thermodynamic heat transfer analysis of the carbon particles by the author in which it was found that about $95 \%$ of the absorbed solar energy is conducted to the surrounding air while about $5 \%$ is emitted as long wave radiation. Part of the emitted radiation is reabsorbed by carbon particles and water vapor within the carbon cloud resulting in the very low net long wave radiative flux divergences found by Korb and Möller.

\section{e. Influence of surface albedo}

The effects of varying surface albedo upon total daily absorption were taken into account by applying the upward diffuse radiation field described earlier to the mid-latitude cloud model. The effects are the same for the tropical boundary layer cloud. Computations were made for surface albedo values $\left(A_{s}\right)$ of $0 \%, 10 \%, 20 \%, 30 \%$ and $50 \%$. The net absorption values are plotted as functions of particle concentration in Fig. 8. The increase in net absorption due to surface albedo is greatest between concentrations of about 500 and 1500 particles $/ \mathrm{cm}^{3}$ peaking at about 1000 particles $/ \mathrm{cm}^{3}$ (35\% area coverage). It decreases with higher concentrations due to greater initial interception of light and hence lower reflected values. Even with a $50 \%$ surface albedo increase net absorption is changed by only $15 \%$ or 1 ess. 


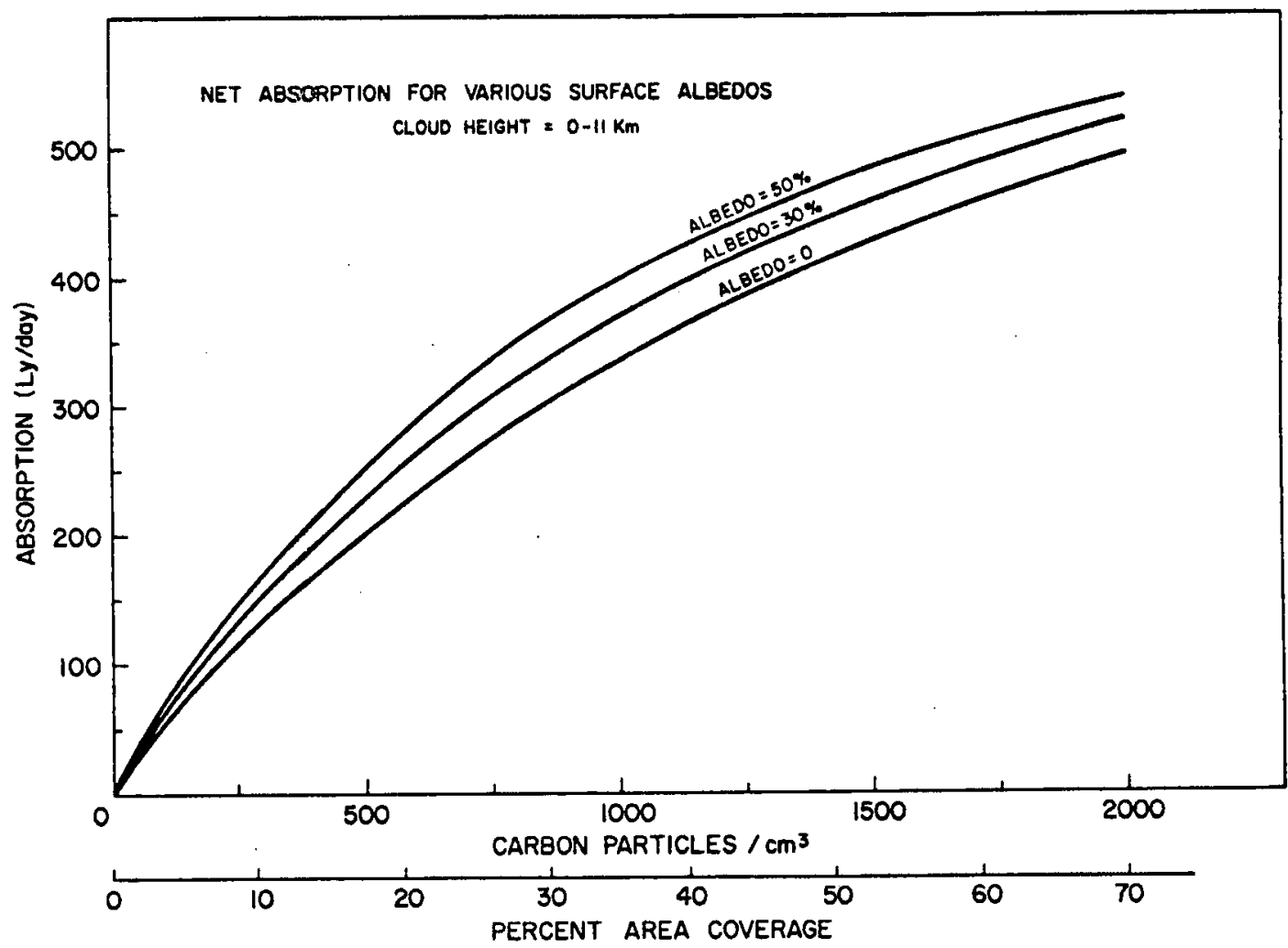

Fig. 8. Absorption of solar radiation by carbon particles dispersed over surfaces with various albedos.

Therefore, although the effects of surface albedo upon absorption are not negligible, they are low enough to be safely neglected in many situations without greatly affecting results.

f. Absorption distribution in the vertical

For application of this study to actual operations, it is necessary to know how the absorbed radiation is distributed vertically through the cloud. To obtain an approximation of this a $4 \mathrm{~km}$ thick cloud was divided into four directly adjacent $1 \mathrm{~km}$ thick layer clouds. For each carbon particle concentration, absorption in each cloud layer was computed, the top layer first, the top plus the second layer next, and so forth. By simple subtraction the amount of solar radiation absorbed in each layer was determined for this homogeneous cloud model. This cloud was located 
between $200 \mathrm{mb}$ and $100 \mathrm{mb}$. For simplicity and with previous demonstration of its small effect, weter vapor absorption was neglected. Surface albedo was also neglected. In this calculation the upward diffuse radiation fieid would have been reduced below values in the previous cloud model due to water vapor absorption of both the downward transmitted and the upward reflected radiation. Amounts absorbed in each layer are shown in Tainle 6. Total absorption is greatest in the upper layer and decreases in each succeeding layer as the amount of light incident at the top of each layer becomes less. As particle concentrations increase, the percentage of absorbed light which is absorbed in the upper layer increases sharply. Therefore, if vertically homogeneous heating is required, the particles must be distributed with lowest concentrations at the top increasing to the heaviest concentrations at the bottom of the cloud.

TABLE 6

ABSORPTION $(1 \mathrm{y} / \mathrm{cm}\}, 10 \mathrm{hr} 40 \mathrm{~min})$ IN EACH CLOUD LAYER

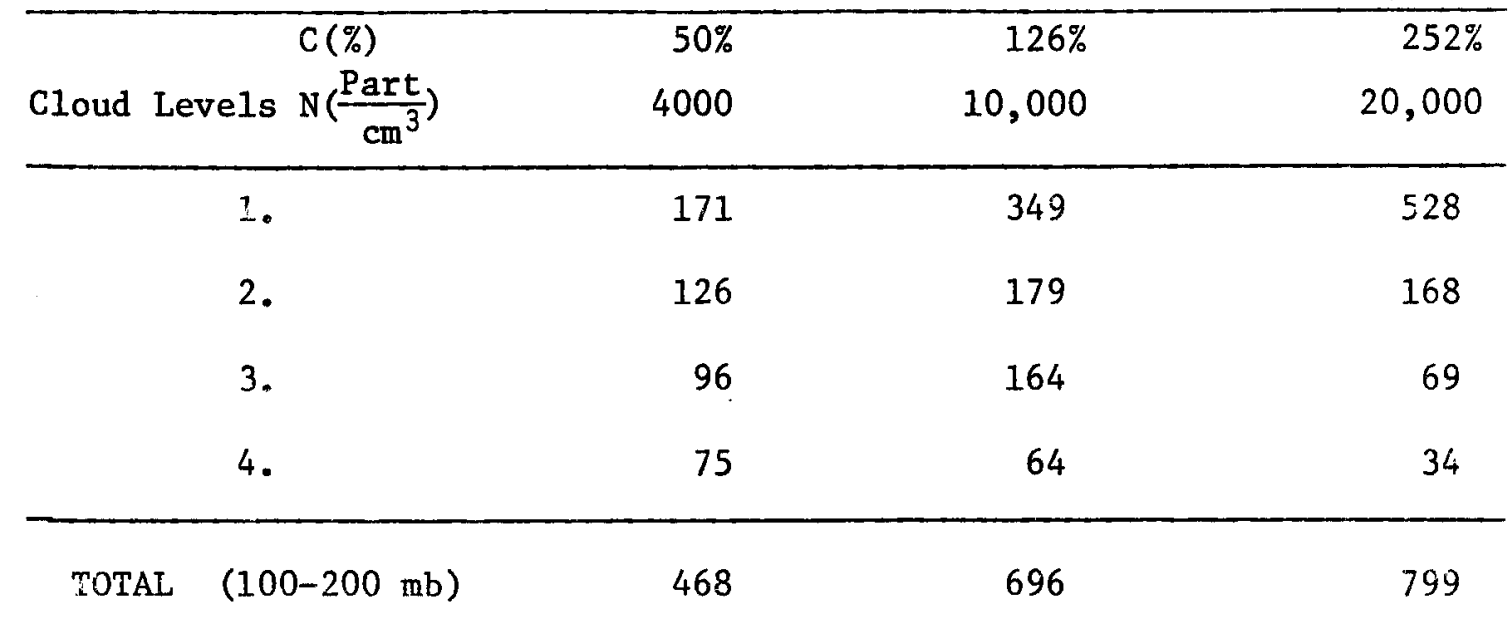




\section{g. Particle size distribution in the vertical}

It was felt that due to relatively high extinction of light in the shorter wavelengths, the light incident upon lower layers of a carbon cloud would exhibit longer median wavelengths than would light incident upon upper layers. A significant increase in median wavelength would indicate that larger particles would be required to maintain optimum absorption per unit mass as determined from Fig. 3. The four layer cloud model from $200 \mathrm{mb}$ to $100 \mathrm{mb}$ was used to evaluate this effect. For each of 3 different carbon particle concentrations, light incident upon the top of each layer was estimated by subtracting previously absorbed light from initial incident light intensities for each spectral region. The median wavelength of light incident upon each layer was calcualted.

Computations were made for carbon particle concentrations of 4,000, 10,000 and 20,000 particles $/ \mathrm{cm}^{3}$. The expected increase in wavelengths of solar light at lower levels did occur. In the most extreme case $(\mathrm{N}=$ 20,000 particles $/ \mathrm{cm}^{3}$ ) the increase in wavelength of incident light from the highest to the lowest of the 4 layers was $76 \%$, but this is a higher concentration of carbon than would probably be used in most types of applications. For the two lower concentrations wavelengths varied only $14 \%(N=4,000$ particles $\left./ \mathrm{cm}^{3}\right)$ and $39 \%\left(\mathrm{~N}=10,000\right.$ particles $\left./ \mathrm{cm}^{3}\right)$. In the lower parts of the troposphere, water vapor absorption in the longer wavelengths would reduce the amounts of the mean wavelength increases. From Fig. 3 it was determined that maximum absorption per unit mass would occur at $\alpha=0.7$ where $\alpha=\frac{2 \pi r}{\lambda}$. A $39 \%$ increase in wavelength would require a $39 \%$ increase in particle radius to maintain optimum absorption efficiency. Since initial optimum particle size was approximated as about $r=.1 \mu$, the optimum particles in the bottom layer of the model cloud would be about 
$r=.13 \mu$ for $N=4,000$ particles $/ \mathrm{cm}^{3}$ and $r=.15 \mu$ for $\mathrm{N}=10,000$ particlẹs $/$

$\mathrm{cm}^{3}$. Particle size variations of these magnitudes do not have a significant effect upon total cloud absorption values.

In addition lower overall light intensities in the lower layers make the importance of having particles of optimum size less in lower layers. than in higher layers. Therefore, for carbon particle concentrations likely to be used in weather modification work, uniform particle sizes can be used without appreciable loss of absorption efficiency per unit mass.

\section{h. Atmospheric residence time}

It is desirable to know approximately how Iong dispersed submicron carbon particles are likely to remain in the atmosphere. The author discusses the probable residence times of carbon particles dispersed in air in paper IV. It was concluded that carbon particles dispersed in the low or middle tropical troposphere would have mean residence times of about 3 to 8 days. This indicates that carbon dispersed in an area with low ventilation (such as a closed circulation) could act as a heat source for more than one day. However, carbon dispersed in the tropical boundary layer would Iikely dissipate much faster due to the high levels of convective activity found there.

i. Major findings

Computations of daily absorption of solar radiation by several configurations of carbon clouds were performed. Carbon black was shown to be a highly efficient absorber of short wave radiation.

The optimum particle size for absorption of solar radiation was determined to be $r=.08 \mu$, but this exact radius is not extremely critical. 
Absorption per unit mass of carbon decreases with increasing carbon concentrations due to the screening out of radiation in the upper layers of the cloud. This effect greatly reduces absorption efficiency at carbon horizontal area coverages greater than about $25 \%$.

Clouds with low concentrations of carbon are relatively efficient absorbers throughout the solar day, while high density clouds are efficient absorbers per unit mass only when the solar zenith angle is sma11.

Redundant absorption tendencies of carbon and water vapor cause some loss of efficiency in carbon cloud absorption compared to absorption of the clear surrounding air. However, this effect is relatively small ( $0-14 \%$ 1oss) in most of the cloud configurations tested. This efficiency loss is negligable for carbon clouds in the tropical boundary layer.

The longwave radiation loss of a carbon cloud is not significantly greater than the longwave radiation loss by an equivalent clear air mass. Therefore, longwave flux divergence should not cause a heat loss by the carbon cloud relative to the surrounding air.

Virtually $100 \%$ of the solar radiation absorbed by the carbon particles is transmitted as heat to the surrounding air.

Increasing surface albedos can increase the absorption of carbon clouds, but the net gain is relatively sma11 ( a cloud over a $50 \%$ albedo surface absorbs only $10-15 \%$ more radiation than a cloud over a $0 \%$ albedo surface).

In a relatively dense vertically homogeneous cloud most of the absorption occurs in the upper layers of the cloud. To obtain uniform vertical absorption the carbon must be distributed with concentrations increasing towards the bottom of the cloud. 
Although the median wavelengths of radiation incident on the lowest layers of the clouds are greater than that of incident solar radiation at the cloud tops, the wavelength shifts are not great enough to require the use of larger carbon particles in the lower cloud layers to maintain maximum absorption efficiency.

Carban particles dispersed in the troposphere should exhibit residence times of approximately 3-8 days. This would indicate that it may be possible to obtain heat for more than one day in cases where the carbon cloud is located in areas of weak ventilation. 


\section{CONCLUSIONS}

\section{a. Carbon black as an atmospheric heat source}

The characteristic of carbon black which makes it attractive as an atmospheric heat source is the extraordinarily large amount of solar radiation per unit mass of carbon which can be absorbed and hence transmitted to the air. One gram of carbon can absorb more than 40 million calories of solar radiation in a single day. On the other hand coal, currently the cheapest of conventional combustible fuels, provides only about 7,000 cal per gram.

It is important to realize the amount of air temperature increase which is possible using carbon black. For example, in the tropical boundary layer $(1013-950 \mathrm{mb}), 1 \times 10^{5} \mathrm{~kg}$ of carbon black could be dispersed into a carbon cloud covering over 4000 square kilometers and extending from sea level to $950 \mathrm{mb}$ with a horizontal area coverage of $9 \%$. This cloud could provide enough heat to increase the temperature of the air within the seeded boundarles by about $8 \mathrm{C}$ per 10 hours. Table 7 shows several cloud configurations and possible cloud heating rates which could be obtained by dispersal of $1 \times 10^{5} \mathrm{~kg}$ of carbon black.

Among energy sources normally used by man only nuclear energy compares with carbon black as a source of energy per unit mass, and no known substance compares as a source of heat per unit cost. A 20 Kiloton nuclear explosion produces about the same amount of thermal energy that $1,000 \mathrm{~kg}$ of carbon black produces in 10 hours. The carbon is not consumed during the heat generation process, and if atmospheric conditions are chosen carefully, residence times of several days are possible with resulting increases in efficiency. The major expense to be expected when attempting to utilize carbon black as an atmospheric heat source is the cost of dispersal. Preliminary cost analysis indicates that 
the cost of air dispersal of large amounts of carbon black from aircraft would be 2-3 times the price of the carbon black itself. Even so, the available heat per unit cost is very large. The amount of solar heating per unit cost which can be realized using a carbon dust cloud seems to be large enough to permit cost effective large scale weather modification.

\section{TABLE 7}

TYPICAL TROPICAL BOUNDARY LAYER CARBON DUST INDUCED HEATING RATES

$$
\begin{aligned}
& \text { Total carbon mass }=1 \times 10^{5} \mathrm{~kg} \\
& \text { Cloud Height }=0.55 \mathrm{~km} \\
& \text { Cloud Configuration: Circular (radius }=\mathrm{r} \text { ) }
\end{aligned}
$$

\begin{tabular}{|c|c|c|c|}
\hline Area & $\begin{array}{c}\% \\
\text { Area } \\
\text { Coverage }\end{array}$ & $\begin{array}{l}\text { Net Heat } \\
\text { Absorbed } \\
\left(\frac{\text { cal }}{\mathrm{cm}^{2} 10 \mathrm{hrs} .}\right)\end{array}$ & $\begin{array}{c}\text { Temperature } \\
\text { Change } \\
\left({ }^{\circ} \mathrm{C} / 10 \mathrm{hrs} .\right)\end{array}$ \\
\hline $7200 \mathrm{~km}^{2}$ & $5 \%$ & 60 & 4 \\
\hline $4000 \mathrm{~km}^{2}$ & $9 \%$ & 110 & 8 \\
\hline $2000 \mathrm{~km}^{2}$ & $18 \%$ & 200 & 13 \\
\hline $1500 \mathrm{~km}^{2}$ & $26 \%$ & 270 & 18 \\
\hline $1000 \mathrm{~km}^{2}$ & $35 \%$ & 325 & 22 \\
\hline $680 \mathrm{~km}^{2}$ & $53 \%$ & 410 & 27 \\
\hline $510 \mathrm{~km}^{2}$ & $70 \%$ & 470 & 31 \\
\hline
\end{tabular}

Acknowledgements

The author wishes to express his gratitude to Prof. Myron Corrin for his aid with the thermodynamic analysis and discussion of the characteristics of carbon black and to Dr. Stephen Cox, Dr. Thomas McKee and Dr. Thomas Vonder Haar for their assistance with radiative theory. Prof. William M. Gray proposed this research topic and acted as the author's overall research advisor. 


\section{REFERENCES}

Chandrasekhar, S., 1960: Radiative transfer. Dover Publications Inc., New York, 393 pp.

Dave, J. V. and P. M. Furukawa, 1966: Scattered radiation in the ozone absorption bands at selected levels of a terrestrial, rayleigh atmosphere. Meteorological Monographs, Vol. 7, No. 29, 270 pp.

Fenn, R. W. and H. Oser, 1962: Theoretical considerations on the effectiveness of carbon seeding. U. S. Army Signal Research and Development Laboratory Report No. 2258, 25 pp.

1965: Scattering properties of concentric soot-water spheres for visible and infrared 1ight. Applied Optics, Vo1. 4, No.11, 1504-1509.

Korb, Gunther and F. Möller, 1962: Theoretical investigation of energy gain by absorption of solar radiation in clouds. Final Report on U.S. Army Signal Corp Contract No. DA-91-541-EUC$1612,185 \mathrm{pp}$.

Krascella, N. L., 1965: Theoretical investigation of the absorption and scattering characteristics of small particles. NASA Report No. CR-210, Office of Technical Services, Dept. of Commerce, Washington, D. C., 57 pp.

Marteney, P. J., 1965: Experimental investigation of the opacity of small particles. NASA Report No. CR-21l, Office of Technical Services, Dept. of Commerce, Washington, 49 pp. 
Weather Modification by Carbon Dust Absorption of Solar Energy

Paper III: Generation of Carbon Particle Clouds

Charles A. Stokes, Sc.D.

157 Hun Road, Princeton, New Jersey 08540

(Consultant to Department of Atmospheric Science, Colorado State University Fort Collins, CO)

\begin{abstract}
This paper discusses the technology required to generate clouds of sub-micron size carbon particles and disperse them directly into the air from airborne, ground, or sea surface sources for use in largescale weather modification experiments. It is determined that it would be feasible to generate such clouds using existing afterburner equipped jet engines with relatively simple modifications.
\end{abstract}


Previous investigators (Downie and Smith, 1958; Fenn and Oser, 1962; Fenn, 1964; Smith et al., 1959; Van Straten et al., 1958; Wexler, 1958) have realized the enormous technical and economic potential for the use of solar intercepting clouds in producing weather modifications. For discussions of certain weather modification applications of a solar energy intercepting cloud of carbon particles and a summary of some of the important previous research in this field, the reader is referred to the companion paper by Gray and Frank (Paper I). To date, however, there has been devised no practical means to create such clouds. The amount of energy that can be absorbed in one day by one pound of carbon particles suitably dispersed in the atmosphere is of the order of $7 \times 10^{7}$ btu $\left(2 \times 10^{10}\right.$ calories) which is to be compared with the heat of combustion of carbon at about 14,500 btu. Except for atomic energy effects there is nothing else known that can produce heat effects of this order with the "consumption" of such a small amount of material. (We place consumption in quotes because the carbon is not actually consumed in the heat absorbing process.)

In this project we were seeking to establish beyond any reasonable doubt the feasibility of ground and airborne generation of clouds of carbon particles in the fraction of a micron size range at a rate of 1050,000 pounds of carbon per hour. Feasibility as used here means that all process steps and types of devices are now in use separately on a large scale so that, given adequate funds and the help of organizations and personnel highly skilled in each of the parts of the process, the basic engineering design of a full scale prototype unit could be started. It should be noted that generation of carbon dust clouds from surface sites (ground or ship based) is quite feasible using approximately the 
same equipment and technology as airborne sources. However, since airborne generation would greatly increase the number of possible applications, it is very important to demonstrate the feasibility of this particular method of generation. It will be assumed that demonstration of the feasibility of airborne generation will be sufficient proof of the feasibility of ground or sea surface (i.e. ship) based generation. The alternatives studied are listed below:

1) Redispersion of carbon made previously. Commercial carbon black has been taken aloft in various aircraft and has been dispersed into the air through venturi devices utilizing air flow to produce the necessary shear of particles for dispersion. This method is judged impractical for the large amount of carbon discharge required by this project. Between 200 and 1000 bags per hour of beaded carbon would have to be handled, opened, finely ground and fed through a disperser. While this might be done in a large afrcraft (e.g. a Boeing 747), the cost of modifying and equipping the aircraft would be very large. A special crew of about 5 to 10 people would be required to handle the carbon in a plane. Degree of dispersion would leave much to be desired, and this alone could make this method impractical.

2) Carry aloft a commercial carbon black furnace.

This alternative is not only more costly but presents weight and power problems. These could be solved in a very large aircraft, but the cost could be enormous.

3) Use of a ram jet engine. This could be done except that such engines are not currently in use. An afterburner is in effect a ram jet added to a turbine jet 
engine. We mention this possibility only to indicate that it has been considered.

4) Use of afterburner type jet engines to generate carbon directly. This alternative was considered by far the cheapest, most effective, most convenient, and safest'alternative. It was therefore chosen for detailed study.

As clearly revealed in published patents, (J. C. Krejci, 1958; Burton F. Latham, Jr. and Robert G. James, 1967; Charles L. De Land, 1967; George F. Friauf and Brian Thorley, 1961a; George F. Friauf and Brian Thorley, 1961b), the carbon generation process essentially consists of burning a primary fuel with about $140 \%$ to $\$ 80 \%$ of theoretical air and then injecting into the hot, turbulent combustion products of the primary fuel a high molecular weight liquid hydrocarbon. A portion of the injected hydrocarbon and part of the hydrogen evolved from the hydrocarbon fuel burn instantly creating a highly luminous flame which is quenched from a theoretical flame temperature of some $3600-3800 \mathrm{~F}$ to an exit temperature of $2700-3000 \mathrm{~F}$ by the endothermic decomposition of that part of the hydrocarbon which is not burned. The decomposition products rapidly condense or polymerize into primary carbon particles which also tend to grow upon each other in chains much like a string of frogs eggs. The entire carbon forming process after injection of the hydrocarbon is complete in a matter of milliseconds. There are patented ways to control the chaining tendency so as to give smaller or larger agglomerates.

It is fairly evident that the afterburner of a jet engine sets up almost ideal conditions for injecting a liquid hydrocarbon fuel into hot primary combustion gases with some residual oxygen content. Missing only are adjustments in air ratios, provisions for injecting the hydro- 
carbon through suitably cooled nozzles, provision of an elongated afterburner shell in order to allow sufficient time for carbon formation and provision for supplemental cooling of the modified afterburner due to the highly luminous radiant flame. There may also be practical problems to be dealt with in protecting the aircraft body from too much heat from the streaming highly luminous flame. The feasibility of adapting an afterburner type jet engine to airborne carbon particle cloud generation is discussed in detail in a feasibility study project by the author (Stokes and Reed, 1973) and in Appendix B of this paper. Such an engine could be mounted easily on a portable test stand on the ground or on a ship for land or sea surface carbon generated.

It is necessary to have a stable, noncorrosive fuel which is liquid and pumpable at a reasonable temperature, preferably not much over 100F. This condition can be met with certain commerical carbon black fuels. Some of the regular aircraft fuel tanks can be used provided precautions are taken against possible damage of any rubber or plastic linings, fittings, seals, etc. by the carbon fuel. The fuel can be kept warm in the tank with electrical immersion heaters powered by the aircraft electrical system. The wattage required is very small.

Having deduced that we could use an afterburner type jet engine to produce the kind and quantity of carbon wanted, we next had to check our findings with engine manufacturers to see if our proposal could be accomplished in a practical fashion. The results were indeed gratifying. The opinion firmly expressed was that existing jet engines could be modifled by lengthening the afterburner and that such an engine could be used in place. As an alternative to using engines that are wing mounted, a "flying test platform" could be used. This is a plane fit- 
ted with a device to lower a jet engine from the fuselage in flight, a commonly used method in engine development work.

An ideal aircraft would be a B-52 with its 8 afterburner engines, 4 of which could be modified. Some re-piping of the fuel tanks would also be required. During take off all engines would be used in the normal manner. In the air 4 engines would be switched to carbon production. The approximate conditions that would apply before and after modification of a typical large afterburner engine are shown in Figs. 1 and 2 .

We have concluded that by slightly modifying readily available jet engines carbon dust particles could be produced and dispersed into the air at a rate of 20-30,000 pounds per hour per engine. Roughly half of the weight of the carbon fuel would appear as carbon particles resulting in a carbon particle production cost of about $4 \zeta-6 \zeta$ per pound. One pound of 0.1 radius carbon particles would contain approximately $4 \times 10^{16}$ particles, and 200 pounds of these particles dispersed in air can absorb over 100 calories of solar radiation per $\mathrm{cm}^{2}$ per day over a one mile square area $\left(4 \times 10^{12} \mathrm{cal} / \mathrm{mile}^{2}\right.$ day $)$ heating the air accordingly. The operation would be safe and in every way feasible from the point of view of fuel combustion, mechanical and aeronautical aspects. Therefore, the carbon dust particles could be generated and dispersed from airborne sources as well as from land or sea surface sites. It is beyond the scope of this paper to go into the engineering details or costs, but these matters are under study. A program for the development and testing of prototype carbon particle generating engines using existing jet aircraft engines and test facilities has been proposed and outlined in a feasibility study report by the author and Reed (1973). 

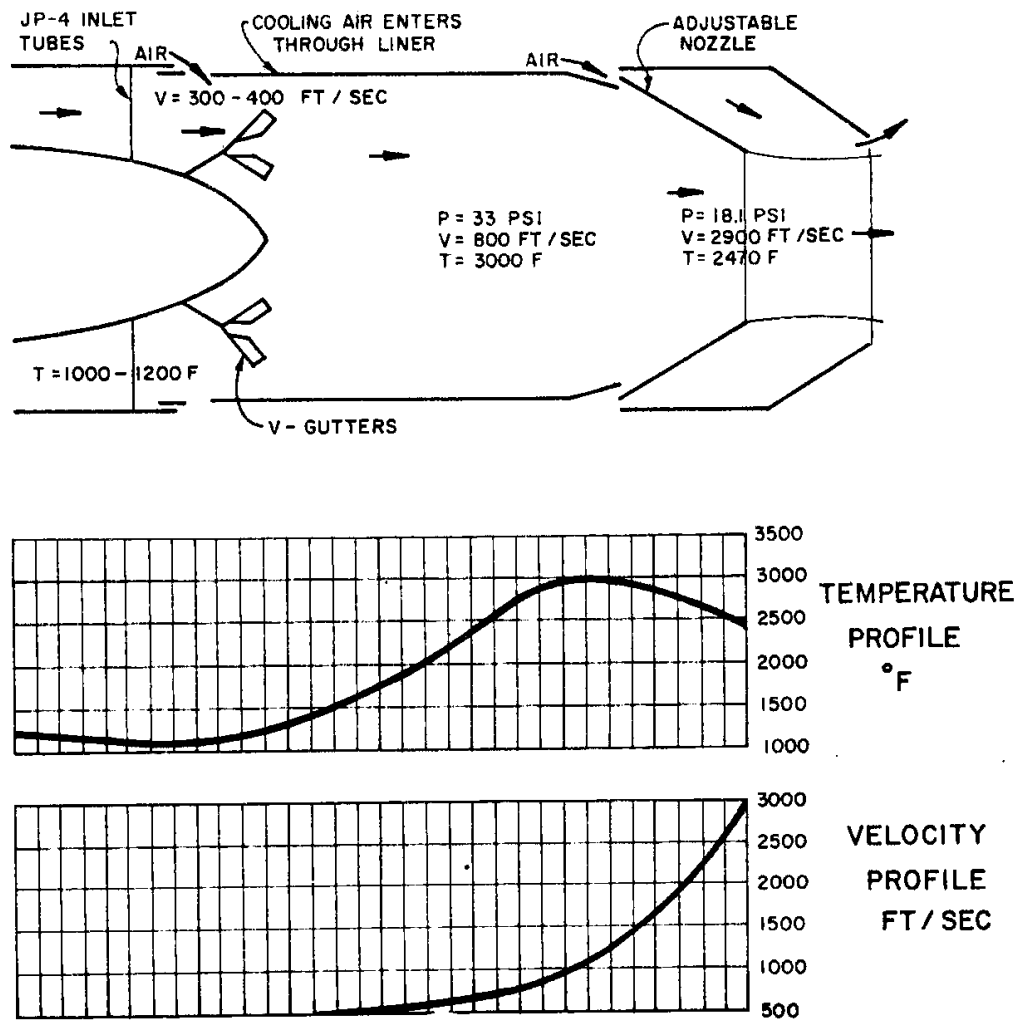

VELOCITY

PROFILE

FT / SEC

Fig. 1. Conditions existing in the afterburner and tailpipe assembly of a typical jet engine during afterburner operation (based on data for the J-57 and J-79 jet engines).
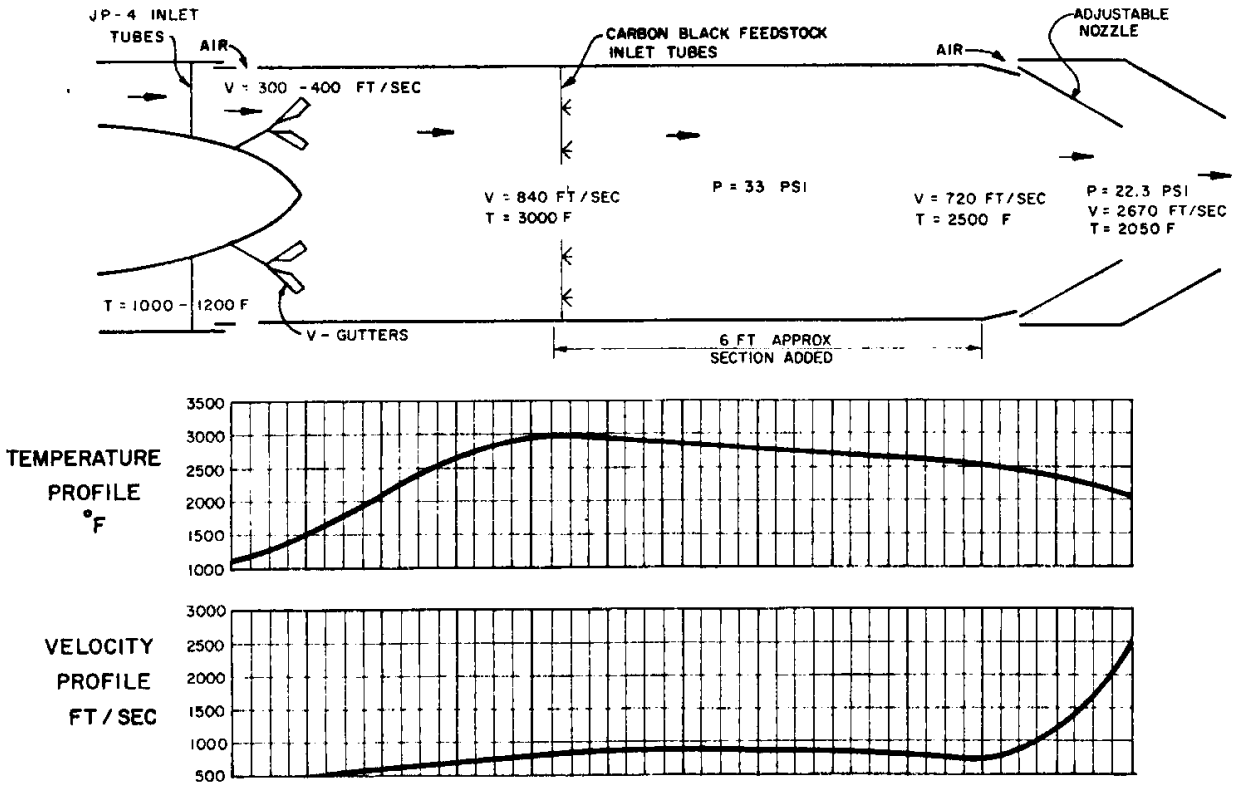

AFTERBURNER AND CARBON GENERATOR OF MODIFIED JET ENGINE

Fig. 2. Approximate conditions existing in the afterburner and tailpipe assembly of a jet engine modified for carbon production (based on estimates for the J-57 and J-79 jet engines). 
Fig. 3 shows how carbon dust would be generated and dispensed from a jet aircraft. Fig. 4 shows a carbon dust smoke plume being generated by an uncontrolled petroleum fire in Wyoming. This is typical of the type of carbon plume which would be used for weather modification. Note the shadow cast by the carbon plume.

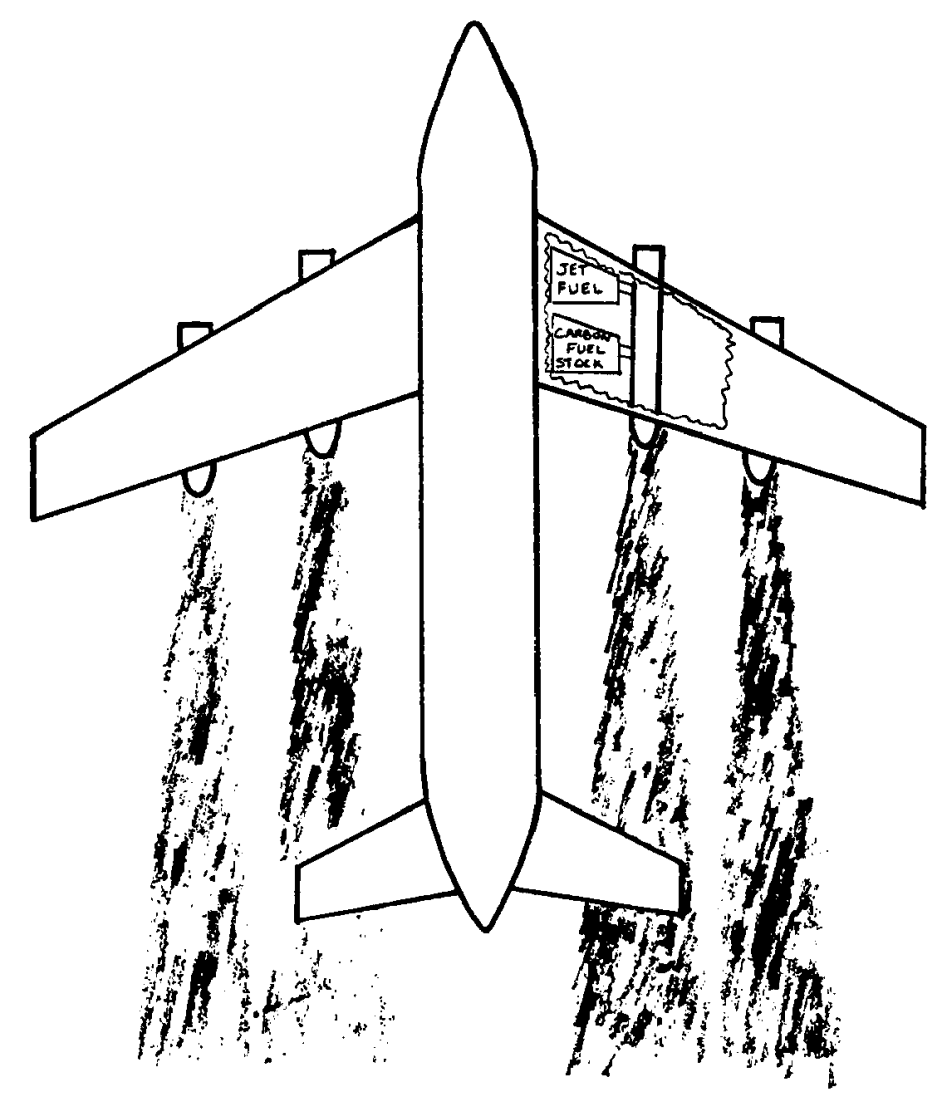

Fig. 3. Illustration of how carbon dust would be generated and dispensed from a jet aircraft. 


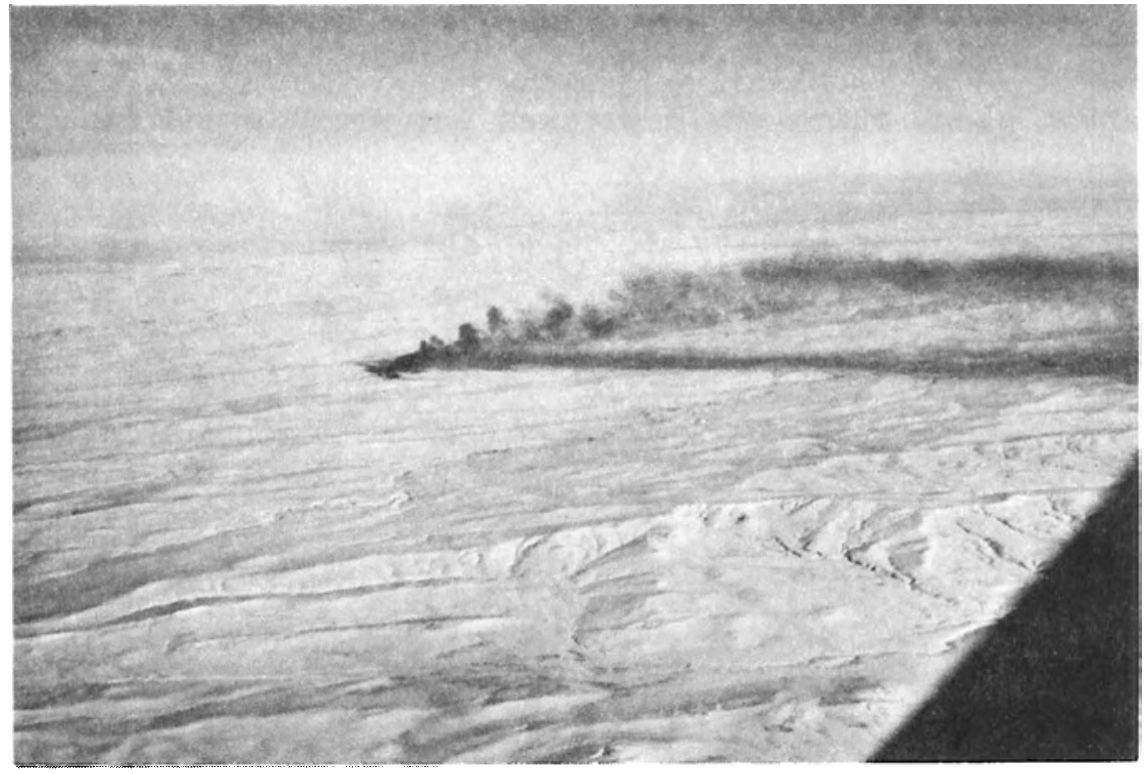

Fig. 4. Carbon dust smoke plume generated from an uncontrolled oil fire in Wyoming. 


\section{REFERENCES}

De Land, Charles L., 1967: U. S. Patent Number 3,301,639.

Downie, Major C. S., and R. B. Smith, 1958: Thermal techniques for dissipating fog from aircraft runways. Air Force Surveys in Geophysics No. 106, Air Force Cambridge Research Center, Bedford, Massachusetts, $38 \mathrm{pp}$.

Fenn, R. W., 1964: Theoretical aspects of carbon seeding. U. S. Army Electronics Research and Development Laboratories Report, 18 pp. , and $\mathrm{H}$. Oser, 1962: Theoretical considerations on the effectiveness of carbon seeding. U. S. Army Signal Research and Development Laboratory Report No. 2258, 25 pp.

Friauf, George F, and Brian Thorley, 1961a: U.S. Patent Number $3,010,794$

$3,010,795$

, 1961b: U.S. Patent Number

Krejci, J. C., 1958: U. S. Patent Number 2,865,717.

Latham, Burton F., Jr., and Robert G. James, 1967: U. S. Patent Number $3,353,915$.

Smith, R. B., R. Wexler, and A. H. Glasser, 1959: Modification of fog and cloud particles in the atmosphere. Allied Research Associates Inc., Final Report on Contract No. AF19 (604)-3492, 47 pp.

Stokes, C. A. and R. S. Reed, 1973: A feasibility study on the adaptation of an afterburner type jet engine to disperse sub-micron carbon particulates in the atmosphere for solar energy interception. A report prepared for Colorado State University, Atmospheric Science Department, $51 \mathrm{pp}$.

Van Straten, F. W., R. E. Ruskin, J. E. Dinger, and H. J. Mastenbrook, 1958: Preliminary experiments using carbon black for cloud modification and formation. U. S. Naval Research Laboratory Report No. $5235,17 \mathrm{pp}$.

Wexler, R., 1958: Seeding with carbon black. Allied Research Associates Inc. Documents No. ARA-553, 7 pp. 
Weather Modification by Carbon Dust Absorption of Solar Energy

Paper IV: Environmental Impact

William M. Frank and Myron L. Corrin

ABSTRACT

Large scale carbon dust weather modification operations will involve the introduction into the atmosphere of substantial quantities of carbon black particles and certain gaseous and particulate by-products of the carbon generation process. The effects of conducting a typical carbon seeding operation upon human health, long term atmospheric conditions, and the ocean and its ecosystem as well as esthetic considerations are discussed.

Carbon black particles are found to be essentially non-toxic to test mammals when ingested, placed in prolonged contact with skin, injected beneath the skin, or inhaled for any length of time and at any concentrations likely to be encountered during any carbon seeding operation. None of the by-products from the carbon generation process would be present in the atmosphere over populated areas at concentrations approaching Environmental Protection Agency (EPA) proposed standards. It was concluded that the generation and dispersal of carbon black particles and their by products into the atmosphere would not have any significant effect upon human health.

Atmospheric effects of carbon dust and its by products generated from carbon seeding operations would be insignificant with regard to alteration of global weather or climate, even if the operations were carried out as frequently as one per day.

Carbon dust which falls to the surface of the oceans would probably sink to the ocean bottom at a rate equal to or exceeding the Stoke's free fall velocity, and therefore, it should not alter the energy balance of the oceans. Being essentially non-toxic and inert, it should not affect the oceanic ecosystem.

Esthetic effects obviously involve highly subjective judgements. However, a typical carbon seeding operation should at most result in a temporary hazy appearance over populated areas which would be much less noticeable than the haziness of the air over most large urban areas. 


\section{INTRODUCTION}

It is probable that the carbon particles used in meso or synoptic scale operations will be manufactured as they are dispersed by the controlled incomplete combustion of some type of petroleum distillate. At this time, the exact nature of the products and the process to be used. are not known but the following estimates will be used:

For each pound of fuel burned, the products will be:

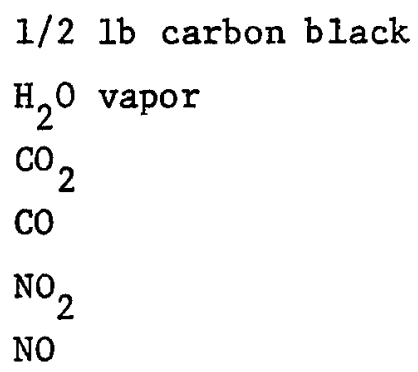

Various hydrocarbons in both gaseous and particulate form

The amounts of the various gases will be estimated later as will the nature of the hydrocarbons. This chapter deals with the physiological effects of the carbon particles and the possible ecological and climatic effects of all of the products. The physiological effects upon humans of $\mathrm{H}_{2} \mathrm{O}$ vapor, $\mathrm{CO}_{2}, \mathrm{NO}_{2}$, NO and $\mathrm{CO}$ are well documented. This section will show that the maximum potential concentrations of these gases will not be detrimental to human health. To evaluate the environmental impact of generating carbon particles and dispersing them into the atmosphere in relatively large amounts (1-2 million pounds per operation) it is convenient to divide the subject into five major areas. These are:

1) toxicity of the carbon black particles,

2) effects of the by-products of the carbon generation process upon human health,

3) long-term effects of carbon black and its by-products upon the atmosphere,

4) impact of the carbon black dust upon the oceanic ecosystem, and

5) temporary esthetic effects of the carbon upon the local area.

Each of these areas will be treated separately below. 


\section{THE TOXICITY OF CARBON BLACK}

It is planned that the carbon particles used in weather modification work will probably be generated as they are dispersed by the incomplete combustion of fossil fuels. Until the actual apparatus has been designed and field tested, it will not be possible to determine the exact chemical composition of the carbon black produced. Therefore, this section is limited to discussion of toxicity studies performed with various existing commercial carbon blacks. The studies mentioned below employed carbon blacks of several different sizes produced by a variety of processes. It is felt that the carbon blacks generated in weather modification work would be essentially similar to some of these commercial varieties tested.

Present carbon weather modification proposals call for dispersal of carbon dust into the atmosphere over the sea about one day upwind of any major land area. Therefore, the initial carbon cloud (concentration of $40 \mu \mathrm{g} / \mathrm{m}^{3}, 1 \mu \mathrm{g} / \mathrm{m}^{3}=10^{-6} \mathrm{~g} / \mathrm{m}^{3}$ ) should diffuse to relatively low concentrations before encountering a populated area.

Carbon black particles are composed primarily of elemental carbon with variable amounts of oxygen, hydrogen, sulfur, and trace amounts of ash components. They are produced by the cambustion of one or more hydrocarbons in an oxygen deficient environment and subsequent condensation of the carbon either in furnaces or in long rows of natural gas burners known as channels. Furnace blacks, which are of the most interest for the purposes of this study, are typically 95-99\% pure carbon. For most purposes, carbon black can be treated as a basically inert substance.

The most complete study of the physiological effects of carbon black was performed by Nau, Neal, and Stembridge (1958, 1958, 1960, 1962) and 
was sponsored by the stace of Texas. They studied the effects of:-
a) ingestion
b) skin contact
c) subcutaneous injection, and
d) inhalation of carbon black by animals.

Fourteen different types of carbon particles ranging from approximately $.005 \mu$ to $.1 \mu$ in diameter were used. These are the size ranges we pro-. pose for modification. Ten of the blacks were produced by variations of the furnace method (the process most likely to be used in weather modification operations), and four were manufactured by channel processes. The results of their tests are summarized below.

\section{a. Ingestion of carbon black}

Carbon black was fed in large doses to a group of mice as part of their regular diet. Different groups were fed:

a) carbon as delivered from the manufacturer

b) carbon which had been extracted by hot benzene to remove certain hydrocarbons which had been absorbed by the carbon

c) a known carcinogen, and

d) carbon which had been allowed to absorb some of the known carcinogen.

Control groups were maintained on their normal diets. It was found that ingestion of large amounts of carbon black, as supplied by the industry or after benzene extraction, produced no changes from normal. Ingestion of the pure carcinogen produced abundant tumors in the mice, but eating carbon black which had absorbed some of the carcinogen caused no effects. Apparent1y, the carcinogen lost most of its toxicity when absorbed by the carbon. Carbon black appears to be harmless when ingested. This result is not surprising since carbon black has been used for years as a certified food coloring in certain foods (jelly beans, licorice, gum drops, etc.) with no reported ill effects. In addition, carbon black is capable of absorbing amounts of at least one carcinogenic hydrocarbon, greatly reducing the toxicity of that substance. 
b. Skin contact

The second phase of the Nau, Neal, and Stembridge (1958) tests dealt with possible effects of various types of carbon black upon prolonged skin contact. The results showed that there were no detectable changes from the normal in hamsters, mice, guinea pigs, rabbits, or monkeys regardless of the amount of carbon contacted by the skin or the exposure time.

\section{c. Subcutaneous injection}

Tests of the effects of carbon black when injected under the skin were performed on mice and rabbits to simulate the possible intrusion of carbon into the body through skin lacerations or abrasions. It was found that injecting carbon black under the skin caused no significant changes from normal. Certain hydrocarbons extracted from the carbon by benzene extraction caused tumors when injected, but these substances are apparently bound so tightly to the carbon that they cause no tumors when unextracted carbon is injected.

In separate lab tests carbon was suspended in solutions of blood plasma and of gastric juice for as long as 7 days. There was no significant elution of hydrocarbons from channel or furnace black suspended in either of these mediums.

d. Inhalation of carbon black

Hamsters, mice, guinea pigs, and monkeys were placed in dust inhalation chambers for 7 hours per day, five days a week. Monkeys were exposed to carbon black for up to 13,000 hours while the mice were exposed for virtually their entire lifetimes. Carbon black concentrations of $2400 \mu \mathrm{g} / \mathrm{m}^{3}$ for furnace blacks and $1600 \mathrm{\mu g} / \mathrm{m}^{3}$ for channel blacks were used. These concentrations are substantially higher than the carbon concentrations 
proposed for use in carbon black weather modification. Initial carbon concentrations during field operations would probably be on the order of $40 \mu \mathrm{g} / \mathrm{m}^{3}$ and would decrease steadily with time. This is $1 / 40$ to $1 / 60$ of the amounts that were used in the inhalation studies.

Results of the inhalation tests showed that there was measurable accumulation of carbon dust in the lungs of test animals only after breathing relatively large concentrations of carbon dust for exposure times greater than about 400 hours. No malignancies or other related disorders were encountered in test animals. These results indicate that inhalation of carbon black has no undesirable effects other than long term particle accumulation in the lungs. This accumulation represents a health hazard only when it occurs in the lower respiratory tract, particularly in the alveoli sacs of the lower lungs where oxygen and carbon dioxide are exchanged between air and the blood. As discussed in the National Air Pollution Control Administration Report No. AP-49 (1969) this intake and deposition of particles upon the alveoli is strongly size dependent. Fig. I from this report shows

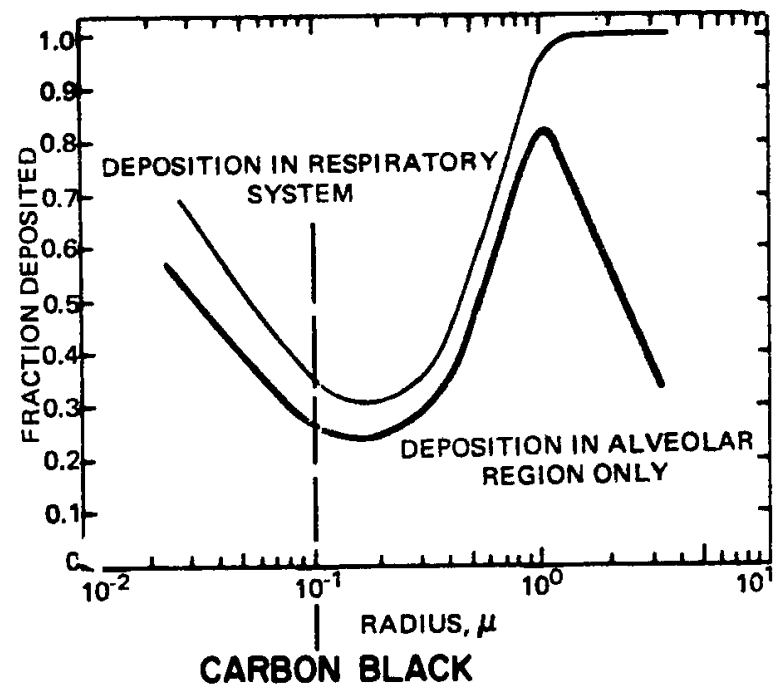

Fig. 1. Calculated fraction of particles deposited in the respiratory tract as a function of particle radius. (This figure represents the calculated efficiencies of deposition of particles of various sizes in the tracheobronchial and alveolar regions of the respiratory system, and shows the size for minimum efficiency.) (From NAPA Report AP-49, 1969). The broken line shows the $0.1 \mu$ carbon particles to be used. 
that there is a minimum efficiency in particle deposition within the alveoli for particles on the order of $r=.1 \mu$. These are the size carbon particles to be manufactured for weather modification operations. Therefore, the carbon particles used in this study are less likely to be retained in the alveoli than most natural or other man-made aerosols.

The Environmental Protection Agency (EPA) in the Federal Register of December 23, 1971, has set contaminants standards by mean geometric average of weight of particles per cubic meter. The minimum level representing the onset of undesirable particulate levels has been established as $70 \mu \mathrm{g} / \mathrm{m}^{3}$. By way of comparison, the particulate loadings of the proposed carbon experiment would initially be only about $40-50 \mu \mathrm{g} / \mathrm{m}^{3}$ (representing $10 \%$ equivalent horizontal area coverage by the carbon) and should decrease considerably due to diffusion and rainout before the carbon cloud would be advected inland over a populated area.

\section{TABLE 1}

Summary of NASN Suspended Particulate Samples for

Urban Stations by Population Class, 1957-1963

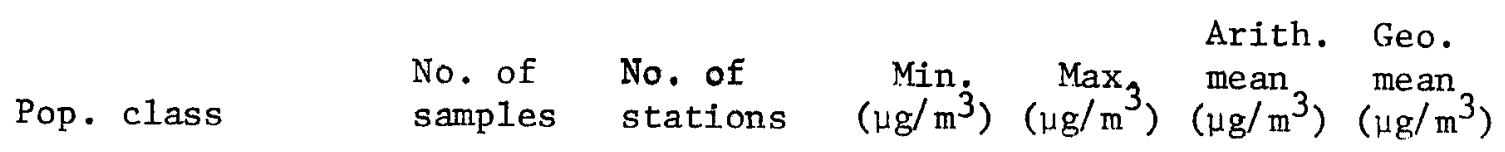

1. 3 million and over

$\begin{array}{rrrrrr}316 & 2 & 57 & 714 & 182 & 167 \\ 519 & 3 & 34 & 594 & 161 & 146 \\ 1191 & 7 & 14 & 658 & 129 & 113 \\ 3053 & 19 & 18 & 977 & 128 & 112 \\ 9531 & 92 & 10 & 1706 & 113 & 100 \\ 5806 & 81 & 6 & 982 & 111 & 93 \\ 1606 & 23 & 5 & 679 & 85 & 71 \\ 484 & 6 & 11 & 539 & 80 & 63 \\ 150 & 5 & 22 & 396 & 100 & 84\end{array}$

Table from Stern, 1968, $\mu \mathrm{g} / \mathrm{m}^{3}$ means micrograms per cubic meter $\left(10^{-6} \mathrm{~g} / \mathrm{m}^{3}\right)$. 
Table 1 shows typical particulate loadings over different sizes of United States cities. It is clear that the carbon cloud, even at its initial concentration (10\% area coverage), represents a much smaller aerosol loading than would be found over any of these cities on an average day. This factor together with the low retention efficiency in the alveoli of $0.1 \mu$ size particles, the relatively short exposure time to be expected from advection of a carbon cloud over a populated area, and the nontoxicity of the carbon particles point to the conclusion that inhalation of carbon particles dispersed auring the proposed operation will not constitute a hazard to human health. 


\section{HEALTH EFFECTS OF THE BY-PRODUCTS OF CARBON GENERATION}

The by-products of carbon black generation are water vapor $\left(\mathrm{H}_{2} \mathrm{O}\right)$, carbon dioxide $\left(\mathrm{CO}_{2}\right)$, carbon monoxide $(\mathrm{CO})$, nitric oxide (NO), nitrogen dioxide $\left(\mathrm{NO}_{2}\right)$, and small amounts of various gaseous and particulate hydrocarbons. Since the exact fuel and generator design are not yet known, it is not possible to state exactly what proportions and amounts of each of these substances will be present. However, it is fairly well established that there will be at least $0.5 \mathrm{lb}$ of carbon produced from each pound of fuel consumed. Two of the gases, $\mathrm{CO}_{2}$ and $\mathrm{H}_{2} \mathrm{O}$, are not considered pollutants. Another, NO, is essentially non-toxic but is of interest because of its rapid conversion to $\mathrm{NO}_{2}$ in the atmosphere and because of its role in the formation of photochemical smog. For the purpose of estimating maximum effects, it will be assumed that $\mathrm{CO}$ will be produced in a quantity equal to $25 \%$ of the initial fuel weight and that the combined nitrogen oxides (NO and $\mathrm{NO}_{2}$ ) and the gaseous hydrocarbons will be produced equal to $10 \%$ of fuel weight. This should provide very generous overestimates of their concentrations. The resulting concentrations of these gases in the initially dispersed carbon cloud will be compared to the health standards proposed by the environmental protection agency. However, it should be noted that since the proposed weather modification operations would be carried out over the oceans at least one day upwind from coasts, the concentrations of the gases when they reach populated areas should be much lower, probably an order of magnitude more dilute. It is assumed that a large scale weather modification operation might utilize as much as 2 million lbs of carbon black requiring the consumption of about 4 million Ibs of fuel. Using the above criteria, amounts of 1 million 1 bs 
of CO and 400,000 lbs of nitrogen oxides and hydrocarbons will be assumed. A carbon cloud of this magnitude will cover approximately $40,000 \mathrm{~km}^{2}$ at $10 \%$ horizontal area coverage. The proposed cloud would extend from the surface to about $0.5 \mathrm{~km}$ when initially dispersed. The volume of the model cloud is approximately $2 \times 10^{13} \mathrm{~m}^{3}$. The concentrations of the by-product gases as initially dispersed together with proposed EPA standards are shown in Table 2. Particulate hydrocarbons are not differentiated

\section{TABLE 2}

Concentrations of Carbon By-Product Gases and Proposed EPA Standards

\begin{tabular}{|c|c|c|}
\hline Gas & $\begin{array}{l}\text { Maximum Initial Dispersed } \\
\text { Concentration } \\
\end{array}$ & $\begin{array}{c}\text { Proposed EPA } \\
\text { Standards } \\
\end{array}$ \\
\hline $\mathrm{CO}$ & $0.018 \mathrm{ppm}$ & $\begin{array}{l}9 \mathrm{ppm} \text { (max } 8 \text { hour con- } \\
\text { centration, not to be } \\
\text { exceeded more than } \\
\text { once per year). }\end{array}$ \\
\hline $\mathrm{NO}, \mathrm{NO}_{2}$ & $9 \mu \mathrm{g} / \mathrm{m}^{3}$ & $\begin{array}{l}100 \mathrm{\mu g} / \mathrm{m}^{3} \text { (annual } \\
\text { arithmetic mean) }\end{array}$ \\
\hline Gaseous Hydrocarbons & $9 \mu \mathrm{g} / \mathrm{m}^{3}$ & $\begin{array}{l}125 \mathrm{\mu g} / \mathrm{m}^{3} \text { (max } 3 \text { hour } \\
\text { concentration, not to } \\
\text { be exceeded more than } \\
\text { once per year). }\end{array}$ \\
\hline
\end{tabular}

from other particulates in EPA standards. Their effect on the total particulate loading of the atmosphere is insignificant compared to the effects of the carbon particles themselves on that loading, and the particulate hydrocarbons will not be considered separately here. The effects of the carbon dust particles on atmospheric pollution levels are discussed elsewhere in this paper.

It is obvious that the carbon monoxide ( $\mathrm{CO}$ ) produced will be insignificant compared to proposed pollution standards. The concentration of CO produced would be far too small to have any physiological effect 
upon humans. It may be concluded safely that there will be no hazard resulting from co during carbon manufacture. Nitrogen oxides and hydrocarbons would also be produced at levels significantly lower than proposed EPA standards. It should be noted that the estimate of $10 \%$ yield by mass of either of these two substances during the carbon manufacture process constitutes a very large overestimate of their likely concentrations. The above figures were chosen to demonstrate that even with a large margin of error local concentrations should not create a health hazard. Since the concentrations of all of the gases in Table 2 should be reduced by an order of magnitude before the carbon cloud is advected over land, it seems safe to say that the by-products of the carbon generation process should not create any important pollution problems. 


\section{LONG TERM ATMOSPHERIC EFFECTS}

To evaluate the long term atmospheric effects of performing one or more carbon weather modification operations, it is necessary to establish the approximate residence time of the carbon particles in the atmosphere as well as the physical effects of the carbon upon the earth atmosphere. system. The principal mechanisms for removal of aerosols from the atmosphere are rainout (particles becoming attached to raindrops during the condensation process) and washout (particles being captured by falling raindrops during precipitation). Particles on the order of $r=.1 \mu$ will not fall out of the atmosphere from gravitational forces in any reasonable amount of time. Washout is an effective removal mechanism only for relatively large particles (larger than a few microns). Adam and Semonin (1970) have shown that for particles in the $1 \mu$ size range, a $0.5 \mathrm{~cm} / \mathrm{hr}$ rain will remove less than $1 \%$ of the particles per hour via washout. Kerker, et al. (1970) found that collection efficiencies (ratio of mass of particles swept out by falling droplet to total mass of particles in volume swept out by droplet) of $0.3 \mu$ particles by raindrops is only on the order of $.01 \%$. These results indicate that washout is a very inefficient removal mechanism for sub micron sized particles. Rainout appears to be the principal removal mechanism for sub micron aerosol particles. Peterson and Crawford (1970), using a large cloud diffusion code model with a precipitation scavenging option, found that rainout is a more important removal mechanism than washout for sub micron particles, but it is difficult to obtain accurate estimates of rainout efficiencies for specific particle sizes.

Martel (1970) estimated that natural atmospheric particles in middle latitudes have residence times of about 6 days in the lower to middle troposphere. Studies of sediment patterns of eolian dust (land derived dust 
carried by the air) from the floor of the Atlantic Ocean off of West Africa by Chester (1972) indicate that the entire troposphere there is cleansed of the eolian dust in less than 10 days. More than $70 \%$ of the eolian dust particles measured are smaller than $4 \mu$ in diameter and were assumed to have been removed by precipitation scavenging, probably rainout. Figure 2 shows that natural aerosol particles range from about $.01 \mu$ to $100 \mu$ in size with the greatest number of particles being concentrated in the size range from .01 $\mu$ to .1 $\mu$ (Quanze1, 1970; Junge, 1955; Ikebe and Kawano, 1970; Junge and Jaenicke, 1971). Carbon particles of .14 radius should not differ greatly from mean atmospheric particles with respect to size. Although carbon particles differ in composition from most natural atmospheric aerosols, they should have aerodynamic properties similar to those of other basically inert particles. Therefore, an assumption that carbon particles dispersed in the lower troposphere $(1000 \mathrm{mb}-700 \mathrm{mb})$ would have mean residence times of but 3 to 8 days seems reasonable. Carbon particles dispersed in the oceanic tropical boundary layer would likely dissipate more quickly than average due to the high levels of convective activity found there.

Carbon particles dispersed in the atmosphere may affect the global scale climate in two ways. They may slightly decrease the earth-atmosphere system albedo, and they could redistribute solar energy in the vertical if some of the carbon was to reach the upper atmosphere. Being basically inert and highly hydrophobic, the carbon should not cause any changes in condensation nuclei or ice nuclei concentrations. The albedo increase is due to the low backscatter of clouds of carbon particles (less than $2 \%$ for even a relatively dense carbon cloud) and their high absorptivity (Frank, 1973). A carbon cloud will absorb an appreciable amount of both incoming 


\title{
Weather Modification by Carbon Dust Absorption of Solar Energy
}

\author{
By \\ W.M. Gray, W.M. Frank, M.L. Corrin and C.A. Stokes
}

Department of Atmospheric Science

Colorado State University

Fort Collins, Colorado

July 1974

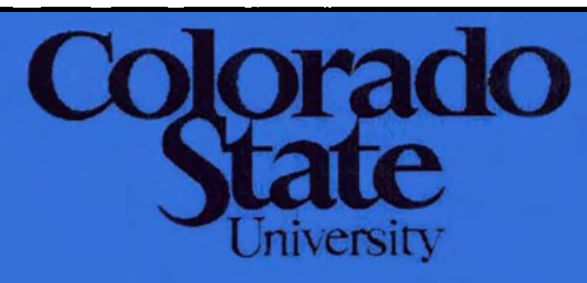

Department of
Atmospheric Science

Paper No. 225 
WEATHER MODIFICATION BY CARBON DUST ABSORPTION OF SOLAR ENERGY

by

W. M. Gray, W. M. Frank, M. L. Corrin and C. A. Stokes

\author{
Department of Atmospheric Science \\ Colorado State University \\ Fort Collins, Colorado
}

July, 1974

Atmospheric Science Paper No. 225 
The five papers of this report have been written in an attempt to open up a new dialogue among meteorologists and other scientists on the possibility of meso-scale weather modification through carbon dust interception of solar energy. Growing population pressures and predicted future global food shortages dictate that man explore all his possibilities for beneficial weather modification. Nearly all the weather modification efforts over the last quarter century have been aimed at producing changes on the cloud scale through exploitation of the saturated vapor pressure difference between ice and water. This is not to be criticized, but it is time we also consider the feasibility of weather modification on other time-space scales and with other physical hypotheses. The authors wish to share their ideas on this new area of potential. weather modification with other interested individuals and obtain their comments and criticisms. They are hopeful that more exploratory research on this subject can soon be started. 
TABLE OF CONTENTS

Page

PREFACE ............................ 1 ... 1

PAPER I: BACKGROUND INFORMATION AND HYPOTHESIS . . . . . . . . 1

I. BACKGROUND DISCUSSION ............ 2

II. CARBON DUST AS AN ARTIFICIAL HEAT SOURCE . . . . 4

III. PHYSICAL HYPOTHESES . . . . . . . . . . . 11

IV. DISCUSSION OF SPECIFIC HYPOTHESES . . . . . . . 14

V. COMPARISON OF THIS HYPOTHESIS WITH PREVIOUS RADIATION ALTERATION MODIFICATION PROGRAMS . . . . . 23

VI. COMPARISON OF CARBON DUST RADIATION ABSORPTION WITH OTHER AEROSOL ABSORPTION .......... 28

VII. SYNOPSIS ............... 34

PAPER II: RADIATION CHARACTERISTICS . . . . . . . . 37

I. INTRODUCTION ............... 38

II. RADIATIVE PROPERTIES OF CARBON BLACK IN THE ATMOSPHERE ................ . . 39

III. RESULTS ................. 48

IV. CONCLUSTONS ............... 63

PAPER III:GENERATION OF CARBON PARTICLE CLOUDS . . . . . . . 66

PAPER IV: ENVIRONMENTAL IMPACT . . . . . . . . . . . 76

I. INTRODUCTION ............... . 77

II. THE TOXICITY OF CARBON BLACK . . . . . . . 78

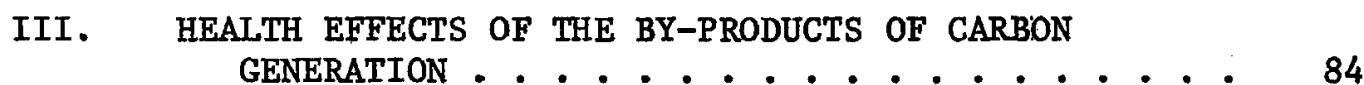

IV. LONG TERM ATMOSPHERIC EFFECTS . . . . . . . . 87

V. CARBON IN THE OCEANS .............. 93

VI. ESTHETIC EFFECTS . . . . . . . . . . 96

VII. SUMMARY . . . . . . . . . . . . 98 
TABLE OF CONTENTS (cont'd)

Page

PAPER V: EVIDENCE FOR HYPOTHESIS AND PROPOSED RESEARCH

PROGRAM . . . . . . . . . . . . . 101

I. INTRODUCTION ................ 102

II. OBSERVATIONAL AND THEORETICAL EVIDENCE . . . . . 103

III. NUMERICAL MODELING EVIDENCE . . . . . . . . 128

IV. COST-BENEFIT CONSIDERATIONS ......... 140

v. SCIENTIFIC UNKNOWNS AND POTENTIAL PROBLEMS . . . 146

VI. PROPOSED RESEARCH PRQGRAM. .......... 152

VII. COMPARISON OF CARBON DUST AND SILVER IODIDE MODIFICATION TECHNIQUES .......... 160

VIII. RESEARCH JUSTIFICATION . . . . . . . . 162

ABOUT THE AUTHORS . . . . . . . . . . . . . . . . 168

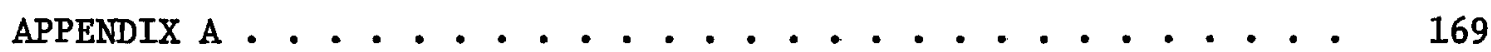

APPENDIX B .............................. 172 
Weather Modification by Carbon Dust Absorption of Solar Energy Paper I: Background Information and Hypothesis

William M. Gray and WiIliam M. Frank

ABSTRACT

Growing global population pressures and predicted future food and energy shortages dictate that man fully explore his potential use of solar energy. The following group of five papers explores the possibility of beneficial weather modification through artificlal solar energy absorption. A varlety of physical ideas as related to artificial heat sources on different scales of motion are considered. Interest is concentrated on the feasibility of meso-scale ( 100-200 km) weather modification by solar energy absorption by carbon aerosol particles of $\sim 0.1$ micron size or less. Particles of this size maximize solar energy absorption per unit mass.

It is hypothesized that significant beneficial influences can be derived through judicious exploitation of the solar absorption potential of carbon black dust. There is an especially high potential for this over tropical oceans. If dispensed in small enough sizes of one tenth micron or less, solar energy absorption amounts as high as $\sim 2 \times 10^{10}$ cal/1b per 10 hours or about $4 \times 10^{11} \mathrm{cal} /$ dollar per 10 hours can be obtained. This is a tremendously powerful heat source, especially if it stimulates an additional oceanic evaporation energy gain. Preliminary observational and modeling information indicates that this artificial heat source can be employed on the meso-scale $(100-200 \mathrm{~km})$ to give significant economic gain regarding precipitation enhancement and tropical storm destruction aleviation. It may also be possible to use carbon dust to enhance precipitation over land areas, alter extra tropical cyclones, and to speed up fog burnoff and snowmelt.

The following five papers discuss this physical hypothesis from the meteorological, radiational, engineering, ecological and economic points of view. 


\section{BACKGROUND DISCUSSION}

These papers are written with the purpose of opening up a dialogue on a new area of potential weather modification--namely meso-scale weather modification from solar energy interception by small carbon particles. It would appear that present day weather modification may need a broader scientific outlook. Nearly all the weather modification efforts over the last quarter century have been aimed at producing changes on the cloud scale through exploitation of the saturated vapor pressure difference between ice and water. This is not to be criticized, but it is time we also consider the feasibility of weather modification on other time-space scales and with other physical hypotheses.

a. Need

Growing global population pressures and predicted food and energy shortages dictate that man fully explore his potential for beneficial weather modification from both an economic and a humanitarian point of view. All physical ideas on all scales of motion should be considered.

b. Physical idea

Most of the sun's energy penetrates through the earth's atmosphere to the surface. A large direct atmospheric heat source would result if some of this incoming solar energy could, instead, be absorbed directly within the atmosphere. This is especially true over the oceans where most of the incoming solar energy goes into evaporation and where the lower atmosphere does not experience a diumal temperature variation.

\section{c. General questions}

Can man intercept an appreciable amount of the incoming solar energy in selective areas and convert this energy into significant wind-pressure 
and precipitation changes? Is the tropical and sub-tropical troposphere often in a potentially unstable state such that an addition of artificial energy would trigger beneficial changes? If this is so, what are the 1ikely economic effects? The rain which falls over the oceans does not benefit man. Perhaps man in the future will be able to cause a small amount of the rain which would normally fall over the oceans, instead, to occur over land areas in need of precipitation.

\section{d. Technical questions}

Can man economically generate carbon dust in sufficiently small sizes (< 0.1 micron) such that large area coverages per unit mass of carbon can be obtained? What are the technical and radiational limits to the size of the carbon particles? 


\section{a. Artificial interception of solar radiation}

From 60-80 percent of the incoming solar radiation $\left(I_{0}\right)$ in the cloud free areas reaches the earth's surface. In the tropics this figure is 8085 percent. As pictorially shown on the left portion of Fig. 1, the largest portion of incoming solar energy is absorbed by the oceans. Most of this energy subsequently goes into evaporation. Because this evaporation energy transport from the ocean is not directly dependent on solar radiation, but goes on during both the day and night, the oceanic boundary layer does not experience a large daily heating cycle as is common over land.

If a significant portion of the incoming solar energy over the oceans could be absorbed in the atmospheric boundary layer during the daylight hours, an artificial stimulation of cumulus convection would occur. This might be accomplished by aerosol interception of solar radiation as shown

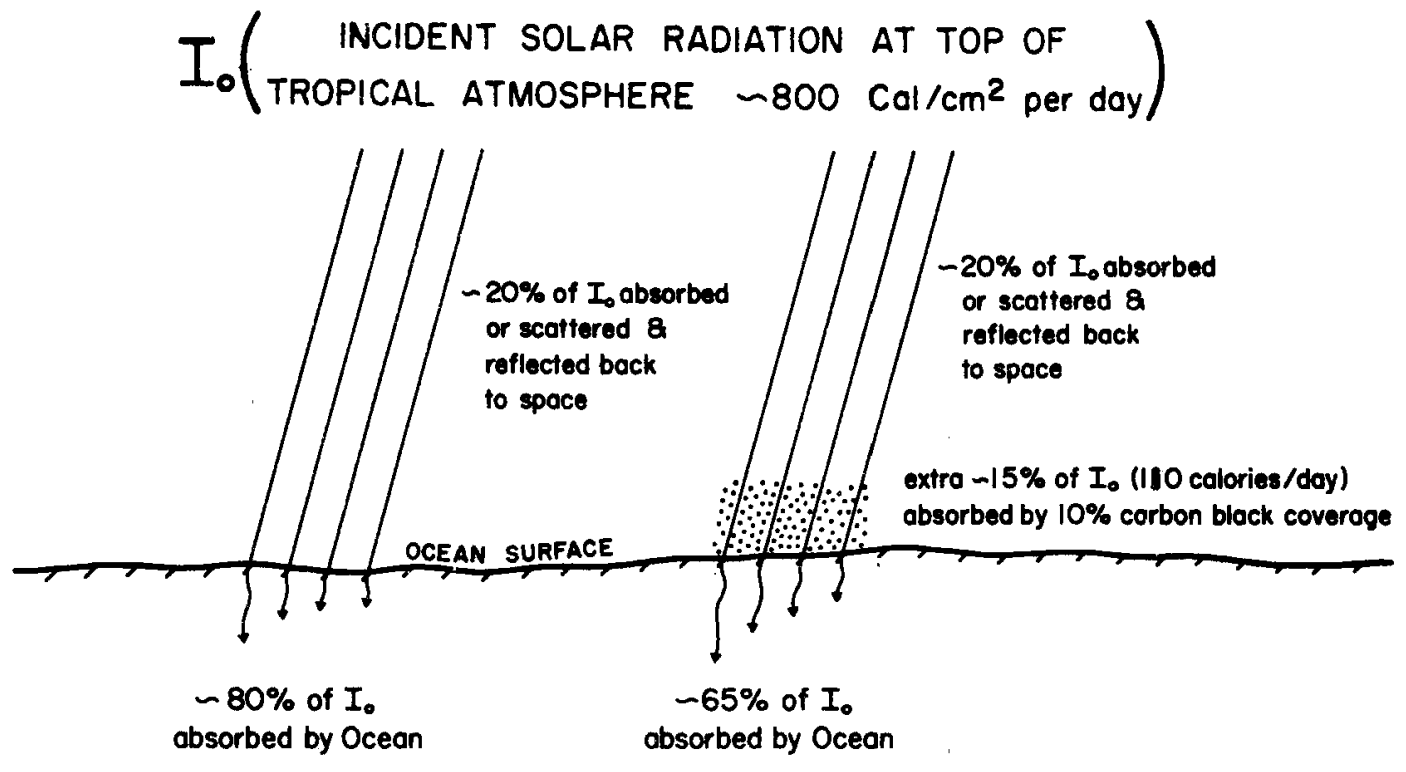

Fig. 1. Contrast of clear air tropical condition with normal solar absorption by atmosphere-ocean (on left) with extra solar absorption with $10 \%$ aerosol coverage in boundary layer (on the right). 
on the right side of Fig. 1. Fig. 2 compares the extra boundary layer short wave heating which is possible in 10 hours due to 15 percent extra absorption of incident solar radiation with the usual 10 hour net long and short wave radiation of the tropical troposphere as determined by Cox and Suomi (1969).

b. Carbon black dust as an artifical atmospheric heat source

The characteristic of carbon dust which makes it so attractive as an atmospheric heat source is the extra-ordinary quantity of solar radiation which can be absorbed by a untt mass of carbon. The following discussion by Frank (Paper II) extensively discusses the characteristics of carbon black dust as an atmospheric absorber of solar radiation from the method

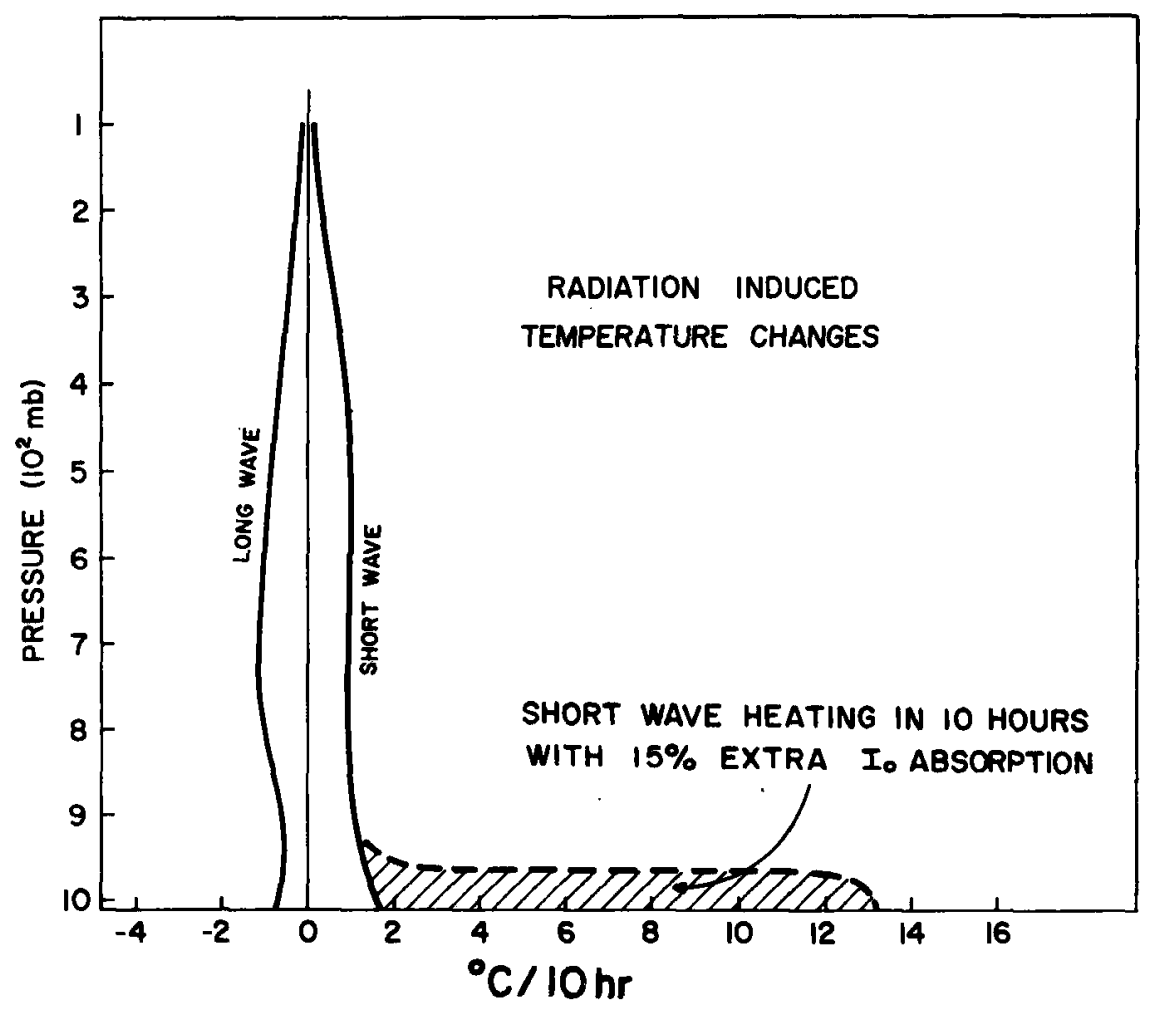

Fig. 2. Comparison of $10 \mathrm{hr}$ heating-cooling rates due to long and short wave radiation in clear regions with the extra boundary layer induced heating (shaded area) which is possible in 10 hours from 15 percent artificial solar absorption. 
of estimating aerosol solar absorption developed by Korb and Möller (1962). The reader is referred to these papers for a thorough discussion of this subject. For the purpose of discussing the use of carbon black dust as an artificial solar energy source for meso-scale modification, the following information summarizes the pertinent facts on carbon black dust:

1) Carbon black dust consists of fine essentially spherical particles composed of $95-99 \%$ pure carbon, the remainder being made up of volatile materials. It is formed by the controlled incomplete combustion of fossil fuels according to a variety of processes. If put out in sizes less than a few microns, it has negligible fall velocity. Most carbon blacks can be produced in quantity for about $\$ .05$ to $\$ .10$ per $\mathrm{Kg}$.

2) The density of carbon black particles is $2 \mathrm{gm} / \mathrm{cm}^{3}$. The high radiation absorptivity and low heat capacity (about $.125 \mathrm{cal} / \mathrm{g}^{\circ} \mathrm{C}$ ) of carbon dust make it an ideal agent for interception of solar radiation and transfer of this heat to the surrounding air molecules by conduction. Turbulent mixing carries the heat further. Being hydrophobic, carbon dust does not readily absorb water vapor. If put out in small sizes it will not act as a condensation nucleus.

3) Particles of 0.1 micron radius maximize the solar absorption per unit mass but, as discussed by Frank (Paper II), this size is not critical. Solar absorption to weight is not greatly altered by variations in size from $.01 \mu$ to $0.20 \mu$ radius. Individual particles of $0.1 \mu$ radius weigh but $10^{-14} \mathrm{gm}$. It takes $3 \times 10^{13}$ particles or about $0.3 \mathrm{gm}$ of carbon to solidly cover a horizontal cross-section of $1 \mathrm{~m}^{2}$. 
4) Carbon black dust particles heat the surrounding air primarily ( $\sim 94 \%$ ) by direct solar energy absorption and rapid molecular conduction of this heat to the surrounding air. About $6 \%$ of the heat transfer from the carbon to the air is accomplished by long-wave radiation.

5) The maximum efficiency of solar radiation to weight and cost requires that the percentage area coverage of carbon black be in the range of $0-30 \%$. Higher carbon area coverage rates cause redundancy in solar absorption and lower energy to weight and cost ratios.

6) Absorption rates for area coverage percentages of $0-20 \%$ are little affected by zenith angle changes up to $65-70^{\circ}$. This allows for 9 to 10 hours of nearly constant absorption rate during daylight hours.

7) One kilogram $(\mathrm{Kg})$ of carbon black dust can absorb more than 40 billion calories of solar radiation in a single 10 hour period. On the other hand, coal, currently the cheapest of conventional combustible fuels, provides on complete combustion about 7 million cal per $\mathrm{Kg}$ or about $1 / 6000$ as much heat per unit mass as the carbon. The relative costs of energy available from carbon black dust and coal are shown in Table 1 . The cost of complete combustion coal heat is about 280 times greater than the cost of carbon heat per $10 \mathrm{hr}$. period. Among energy sources normally used by man only nuclear energy compares with carbon black as a source of accumulation of energy per unit mass, and no known substance compares as a source of heat per unit cost. A 20 Kiloton nuclear explosion produces about the same amount of thermal 
TABIE 1

RELATIVE AMOUNTS AND COSTS OF COAL AND CARBON BLACK DUST ENERGY

\begin{tabular}{|c|c|c|c|}
\hline Fue1 & $\begin{array}{c}\text { Cost } \\
\text { do11ar } / \mathrm{Kg})\end{array}$ & $\begin{array}{c}\text { Heat } \\
(\mathrm{cal} / \mathrm{Kg})\end{array}$ & $\begin{array}{c}\text { Heat per Unit Cost } \\
\text { (cal/dollars) }\end{array}$ \\
\hline Coa1 & $\sim \$ .005$ & $\sim 7 \times 10^{6} \mathrm{cal} / \mathrm{Kg}$ & $\sim 1.4 \times 10^{9} \mathrm{cal} / \mathrm{dollar}$ \\
\hline $\begin{array}{l}\text { Carbon } \\
\text { Black }\end{array}$ & $\sim \$ .10$ & $\begin{array}{l}\approx 4 \times 10^{10} \mathrm{cal} / \mathrm{Kg} \\
\operatorname{per} 10 \mathrm{hrs} .\end{array}$ & $\begin{array}{c}\sim 4.0 \times 10^{11} \mathrm{cal} / \mathrm{dollar} \\
\text { per } 10 \mathrm{hrs} .\end{array}$ \\
\hline $\begin{array}{l}\text { Ratio } \\
\frac{\text { (Carbon Black) }}{\text { Coal }}\end{array}$ & k) $\sim \frac{20}{1}$ & $\sim \frac{6000}{1}$ & $\sim \frac{280}{1}$ \\
\hline
\end{tabular}

energy as can be obtained from $1,000 \mathrm{Kg}$ of carbon dust in 10 hours of solar heating. In addition, the carbon dust is not necessarily consumed during the heat absorption process and might be used again on following days. Silver iodide seeding in super-cooled clouds can also liberate tremendous amounts of energy per unit mass, but the energy from this source does not locally accumulate unless the cumulus mass compensation for the stimulated convection accurs near and on a time scale of the seeding. This is rare. As the seeded cloud dies out the suspended frozen particles melt and re-evaporate.

8) Table 2 lists the short wave absorption by carbon dust in the tropical boundary layer (surface to $950 \mathrm{mb}$ ) which would result from various carbon dust equivalent area coverages. The concentration of $0.1 \mu$ radius carbon particles per $\mathrm{km}^{2}$ is also shown. For carbon dust area coverages of 10 and 20 percent, only $\sim 25$ and $\sim 50 \mathrm{Kg}$ respectively of carbon dust are needed to cover an 
TABLE 2

TYPICAL TROPICAL BOUNDARY LAYER HEATING RATES FROM I MILLION Kg OF CARBON DUST

\begin{tabular}{|c|c|c|c|c|}
\hline Area & $\begin{array}{l}\% \text { Area } \\
\text { Coverage }\end{array}$ & $\begin{array}{c}\text { Carbon Dust Mass } \\
\qquad \mathrm{Kg} / \mathrm{km}^{2}\end{array}$ & $\begin{array}{l}\text { Net Heat Absorbed } \\
\left(\mathrm{cal} / \mathrm{cm}^{2} 10 \mathrm{hrs}\right)\end{array}$ & $\begin{array}{l}\text { Temperature Change } \\
\left({ }^{\circ} \mathrm{C} / 10 \mathrm{hrs}\right)\end{array}$ \\
\hline $72,000 \mathrm{~km}^{2}$ & $5 \%$ & 11 & 60 & 4 \\
\hline $40,000 \mathrm{~km}^{2}$ & $9 \%$ & 22 & 110 & 8 \\
\hline $20,000 \mathrm{~km}^{2}$ & $18 \%$ & 45 & 200 & 13 \\
\hline $15,000 \mathrm{~km}^{2}$ & $26 \%$ & 65 & 270 & 18 \\
\hline $10,000 \mathrm{~km}^{2}$ & $35 \%$ & 90 & 325 & 22 \\
\hline $6,800 \mathrm{~km}^{2}$ & $53 \%$ & 120 & 410 & 27 \\
\hline $5,100 \mathrm{~km}^{2}$ & $70 \%$ & 180 & 470 & 31 \\
\hline
\end{tabular}

area of one $\mathrm{km}^{2}$. If generation rates are about 10 cents $/ \mathrm{Kg}$, this amounts to but $\$ 2.50$ and $\$ 5$ per one $\mathrm{km}^{2}$ coverage.

Ten percent area coverage of carbon dust provides enough heat to increase the mean temperature of the air within the boundary layer (surface to $950 \mathrm{mb}$ ) at a rate of about $1^{\circ} \mathrm{C} / \mathrm{hr}$ for a 10 hour period. Table 2 also gives the boundary layer heating rates that can be accomplished for various areas and percentage carbon particle coverages with 1 million $\mathrm{Kg}$ of carbon. Fig. 3 portrays comparative areas which can be covered by various amounts of carbon dust at 10 percent area coverage in contrast with the typical size of the large hurricane cloud cluster. This would cause an artificial increase of the mean boundary layer temperature of $1^{\circ} \mathrm{C} / \mathrm{hr}$ for 10 hours over the dotted area shown. These enormous area coverages and heating rates open the possibility of meso-synoptic-scale weather modification. 


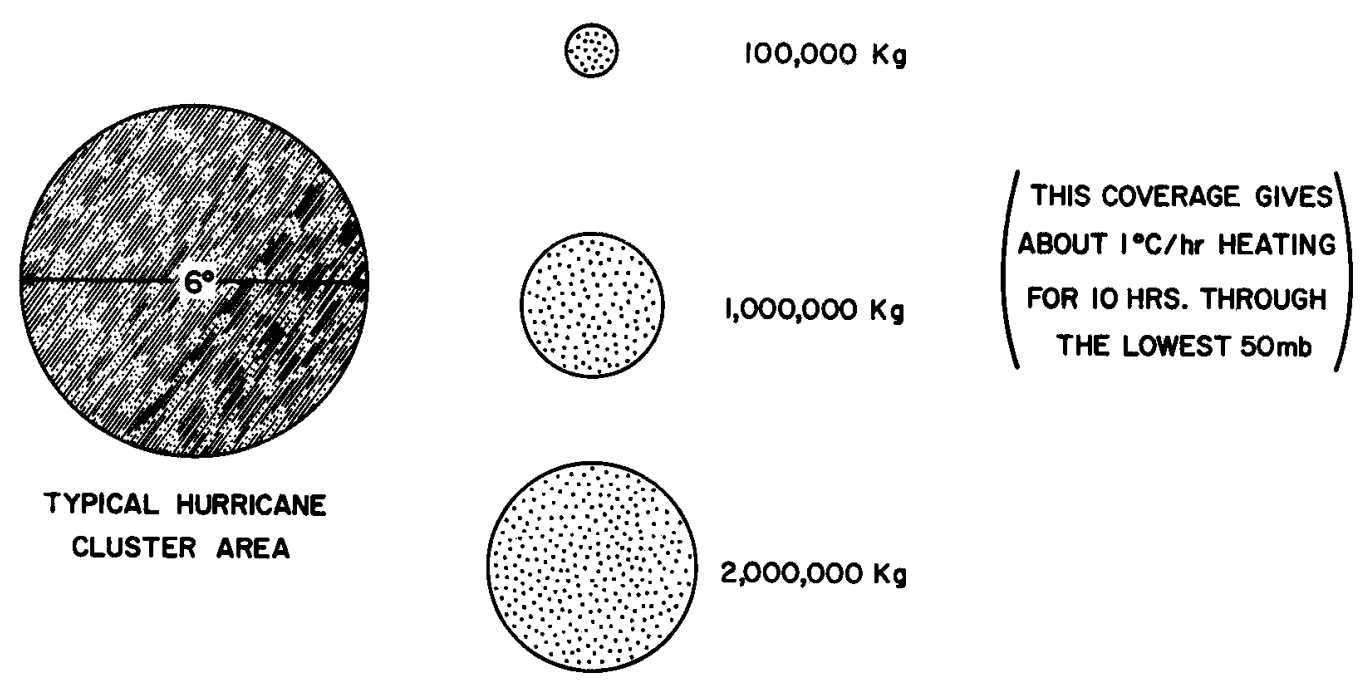

Fig. 3. Comparison of typical hurricane cluster area ( $6^{\circ}$ latitude diameter) with the area (dotted) of 10 percent carbon black coverage which is possible with various amounts of carbon black dust. Estimating the cost of carbon dust to be $\sim \$ 0.10$ per $\mathrm{Kg}$, these three area coverages would require carbon amounts of $\$ 10,000, \$ 100,000$ and $\$ 200,000$. 


\section{PHYSICAL HYPOTHESES}

The energy budget of the globe specifically dictates that the average global precipitation be about a meter per year. The largest portion of this precipitation falls over the oceans and is of no benefit to man. If man could slightly decrease vertical stability conditions over land, a small percentage increase of global land precipitation might result. This could have a sizable beneficial economic impact. This should be man's primary weather modification goal. The proper tapping of solar energy with carbon dust might give man control of an energy source sufficiently large to allow him to objectively contemplate such possibilities.

On a less ambitious scale it is hypothesized that beneficial mesoscale weather modification may be possible in the coming decade or two by solar absorption of carbon dust in the following situations:

a. Rainfall enhancement along tropical and sub-tropical coastlines.

b. Reduction of inner-core hurricane intensity.

c. Cumulonimbus enhancement over selective land regions in need of precipitation.

d. Alteration of extra-tropical cyclones.

e. Fog dissipation.

f. Accelerating snowmelt in agricultural areas.

These are a few of the potential applications to which the interception of solar energy might be put to use by man. There are likely many other atmospheric situations in which man could benefit from application of a meso-scale heat source of the magnitude discussed.

The most likely location for carbon dispersal is over the oceans where the planetary boundary layer does not experience a diurnal temperature cycle and where the stimulation of extra evaporation is possible. 
a. Extra evaporation

The direct heating of air by carbon absorption is but one of two influences which can occur. If accomplished over water bodies, the enhanced solar heating of the air should also stimulate an increase in evaporation. The increased warming of the air will stimulate extra vertical mixing and downward penetration of upper level dryer air to the ocean surface. This dryer air will increase the water vapor pressure difference between the ocean and the air and lead to increased evaporation rates. Evaporation rates may perhaps be increased by double or more their normal values. This evaporation influence can also continue for many hours after the heating has taken place.

It is seen in Fig. 4 that the $\Delta q$ or $q_{s}$ (saturation vapor pressure of the air which is equivalent to the ocean temperature) minus $q$ (vapor content of the air just above the ocean) difference between air at $850 \mathrm{mb}$ and the ocean surface is about three times larger than the difference between surface air and the value representing saturation at the ocean temperature. Any down mixing of upper level air should substantially increase the $q_{s}-q$ of the air just above the ocean. This will substantially increase the evaporation rate. The energy for this increased evaporation, however, will come largely from the ocean and not the air. Thus, it may be possible for the carbon dust solar heating to locally extract energy from the ocean that would not naturally occur. The potential buoyancy of the low levels will later be enhanced by the extra water vapor content. b. Method of dispersion

It appears that it will be possible to manufacture small $\sim 0.1$ micron (u) size carbon particles directly from liquid petroleum products (i.e. hydrocarbons) on aircraft or from ship or land surface sites. Paper III 


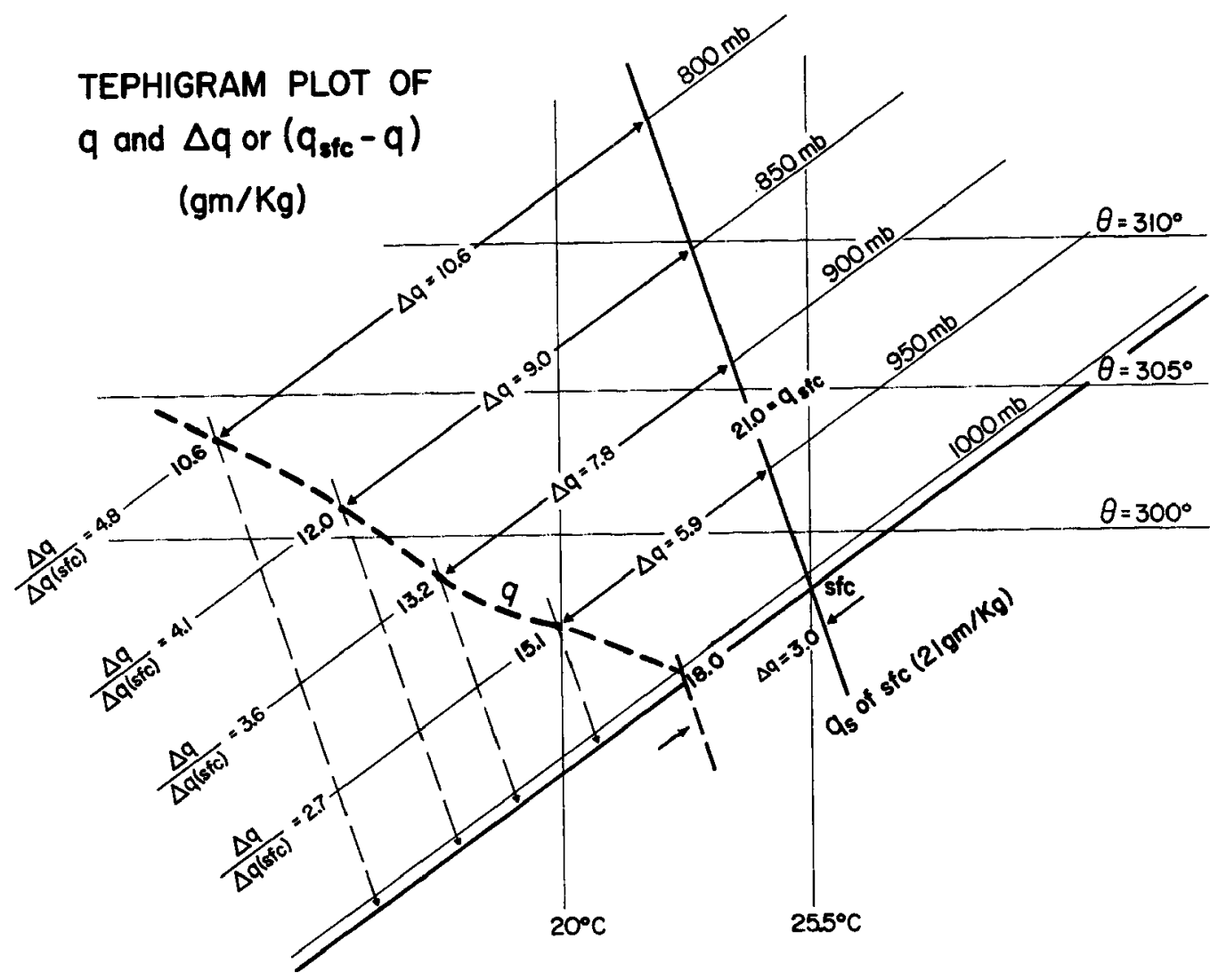

Fig. 4. Portrayal of tropical or sub-tropical specific humidity difference of upper layer air with surface saturated specific humidity of the ocean $\left(q_{s}\right)$ and how extra downward mixing of dryer air would greatly enhance the $q_{s}-q$ values and the oceanic evaporation rates.

by C. A. Stokes shows how it is possible to obtain about $50 \%$ mass yield of carbon or $1 \mathrm{Kg}$ of carbon dust for $2 \mathrm{Kg}$ of liquid hydrocarbons. The carbon particles can thus be generated in the desired size range and dispersed without storing. This prevents handling and clumping problems. Feasibility studies by Stokes are in progress to determine the best methods of manufacture. It is highly desirable that the carbon particles be manufactured at individual dispersion sites. Liquid petroleum can be much more easily handled and dispersed than can solid carbon dust which is purchased at the factory. 
a. Rainfall enhancement along tropical and sub-tropical coastlines

Precipitation enhancement from weather system genesis or intensification upwind from coastlines with an-shore flow is believed to be a very likely possibility. There are many coastal and adjacent inland regions in the tropics and sub-tropics which need additional precipitation and which have on-shore flow. If tropospheric vertical wind shears are not too large, it is very likely that meso-scale weather system genesis or enhancement is possible.

It is envisaged that an artificial heat source will lend itself to the production of extra cumulus convection and an extra local meso-scale convergence. A sizable amount of extra low level mass and water vapor convergence should occur. A continuing enhancement of cumulus convection should take place. If enough extra convection occurs, then, if tropospheric vertical wind shears are not too large, this extra cumulus heating is likely to feedback to the meso-system and keep it going or intensify it. Maintenance and growth can occur after the original heat has dissipated. Figs. 5 and 6 portray how a weak meso-system might be generated upwind from a tropical coastline.

It must be emphasized that we are discussing a meso-scale heat source and the resulting meso-scale pressure-wind patterns which are induced. We are not discussing the direct stimulation of individual cumulus elements. The individual cumulus elements will result as a consequence of the extra meso-scale low level mass and water vapor convergence. Most previous weather modification schemes have dealt only with the alteration of already existing cumulus. 


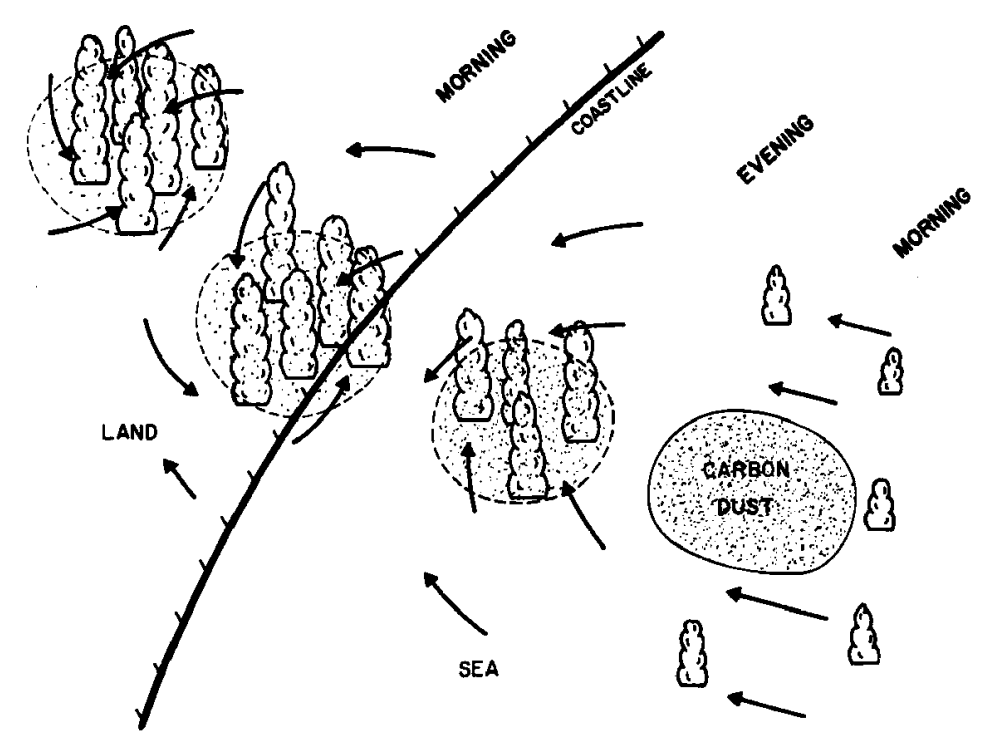

Fig. 5. Plan view portrayal of how carbon dust seeding $1 / 2$ to 2 days upwind from tropical and sub-tropical coastlines might act to generate or enhance a weak meso-scale weather system.

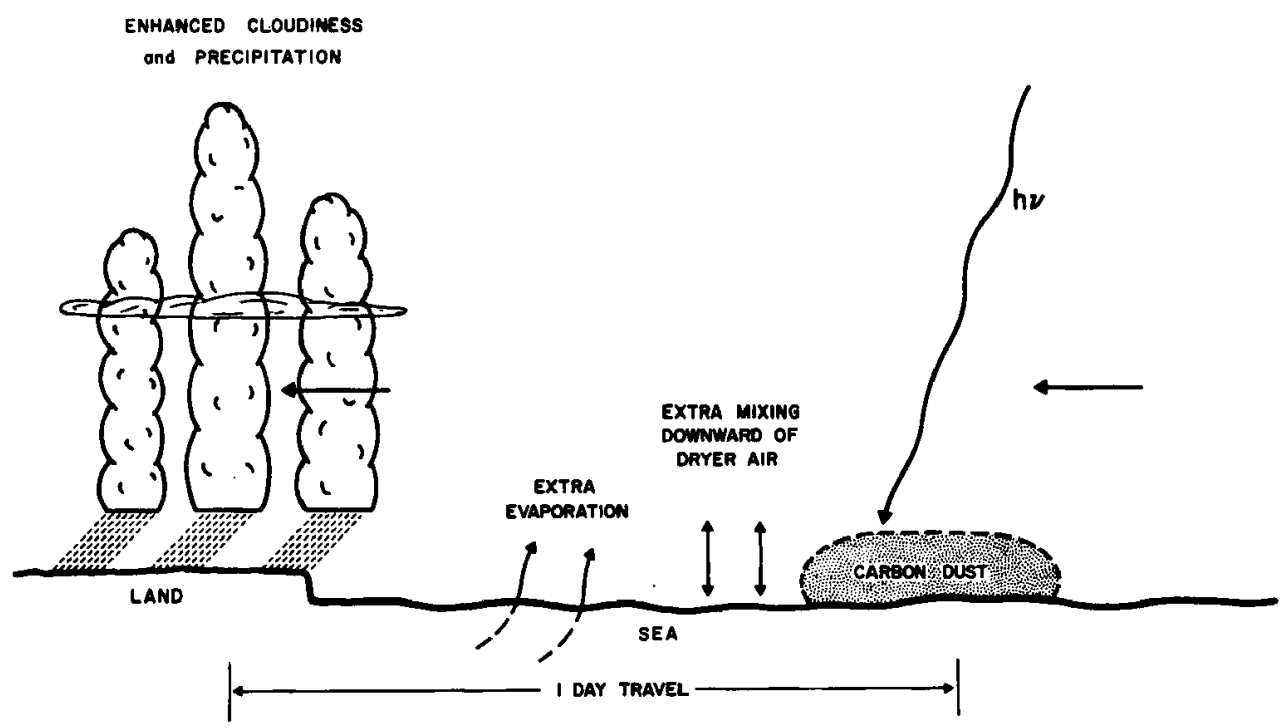

Fig. 6. Cross-section portrayal of carbon dust interception of solar radiation upwind from a coastline with enhanced vertical mixing and evaporation. 
b. Reduction of inner-core hurricane intensity

The present NOAA stormfury hurricane modification hypothesis [See Project Stormfury Annual Reports of 1971-1972 (available from NOAA NHRL Miami office)] and the one here proposed for carbon dust seeding rests with the physical idea of artifically interupting a portion of the hurricane's low-1evel inflow which would normally penetrate to the eye wall region and force it to rise, instead, at an outer radius. As extensively discussed by Gray (1973), angular momentum and surface friction considerations dictate that hurricane intensity is crucially dependent on the amount of mass inflow and the radius to which the boundary layer inflow penetrates towards the storm center. Rapid and sizable reductions in the hurricane inner core wind structure would occur if the boundary layer inflow could be artifically reduced by but 5 to 10 percent. If the outer boundary layer surrounding the hurricane shield can be artificially warmed at a rate of about $1 / 2$ to $1 \mathrm{C} / \mathrm{hr}$ for a period of ten hours, a significant stimulation will be given to cumulus convection at radii beyond the eye wall cloud so as to cause a noticeable decrease in the low level inflow to the radius of maximum wind. This should lead to a decrease in the inner core maximum wind velocities. A significant decrease in storm damage should result.

It is hypothesized that if sizable areas surrounding the hurricane cloud cluster can be seeded in the boundary layer with 1-2 million $\mathrm{Kg}$ of carbon black dust, the effect will be to stimulate additional cumulus convection either at the place of the carbon seeding or, if turbulence and large boundary layer mixing occurs, at radif inside the carbon seeding but beyond the radius of maximum winds. The effect of the carbon dust seeding will be to enhance the cumulus buoyancy by increasing the low 
level temperatures and evaporation rates. This will cause more cumulus convection at outer radii and take extra mass out of the boundary layer. The low level inflow into the center should be reduced. This should cause a weakening of the cyclone. More discussion of this physical hypothesis is contained in Paper V.

Fig. 7 is a cross-section view which shows where the proposed carbon black dust would be placed just beyond the edge of the cirrus shield and how this might interrupt part of the low level inflow mass through enhancement of cumulus convection beyond the eye-wall radius. Fig. 8 is a plan view which more explicitly shows the typical regions around the hurricane cirrus shield in the clear moat area where the proposed carbon black seeding would be accomplished. This could likely be accomplished with 10-20 jumbo type cargo aircraft. As the right-front quadrant of the storm usually has the largest inflow, it might be more desirable to concentrate the seeding in the right semi-circle. If not, the seeding can be spread around the entire cluster.

The carbon dust must be placed sufficiently upstream in the moat region such that it does not advect so far underneath the cirrus shield that the solar absorption is lost before its 10 hour heating can be accomplished. In some intense hurricane cases where the moat region is very large it may be desirable to place the carbon dust 36 hours travel away from the cirrus shield and obtain two days of solar heating.

Therefore, the extra solar heating at outer radii is expected to lead to an increase not only of outer radii thermal buoyancy but also of buoyancy due to extra water vapor content from enhanced evaporation. Even though the extra evaporation influences may not be felt at the place of carbon seeding, they are expected to take place in the air before it reaches 


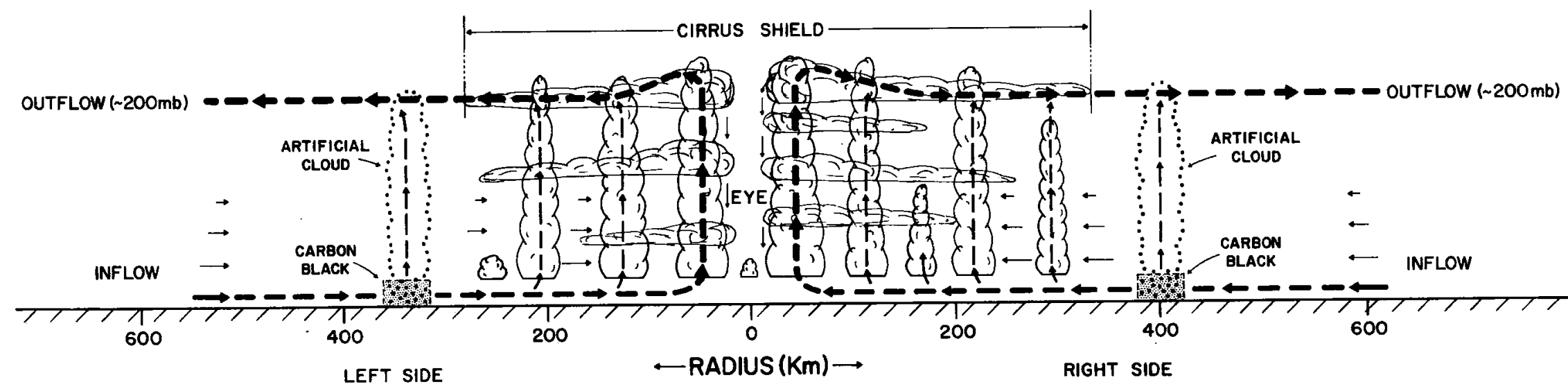

Fig. 7. Idealized portrayal of typical hurricane radial circulation and how carbon black dust seeding of the boundary layer just beyond the cirrus shield might lead to enhanced cumulus convection and reduction of low level inflow which penetrates to the eye-wall cloud. 


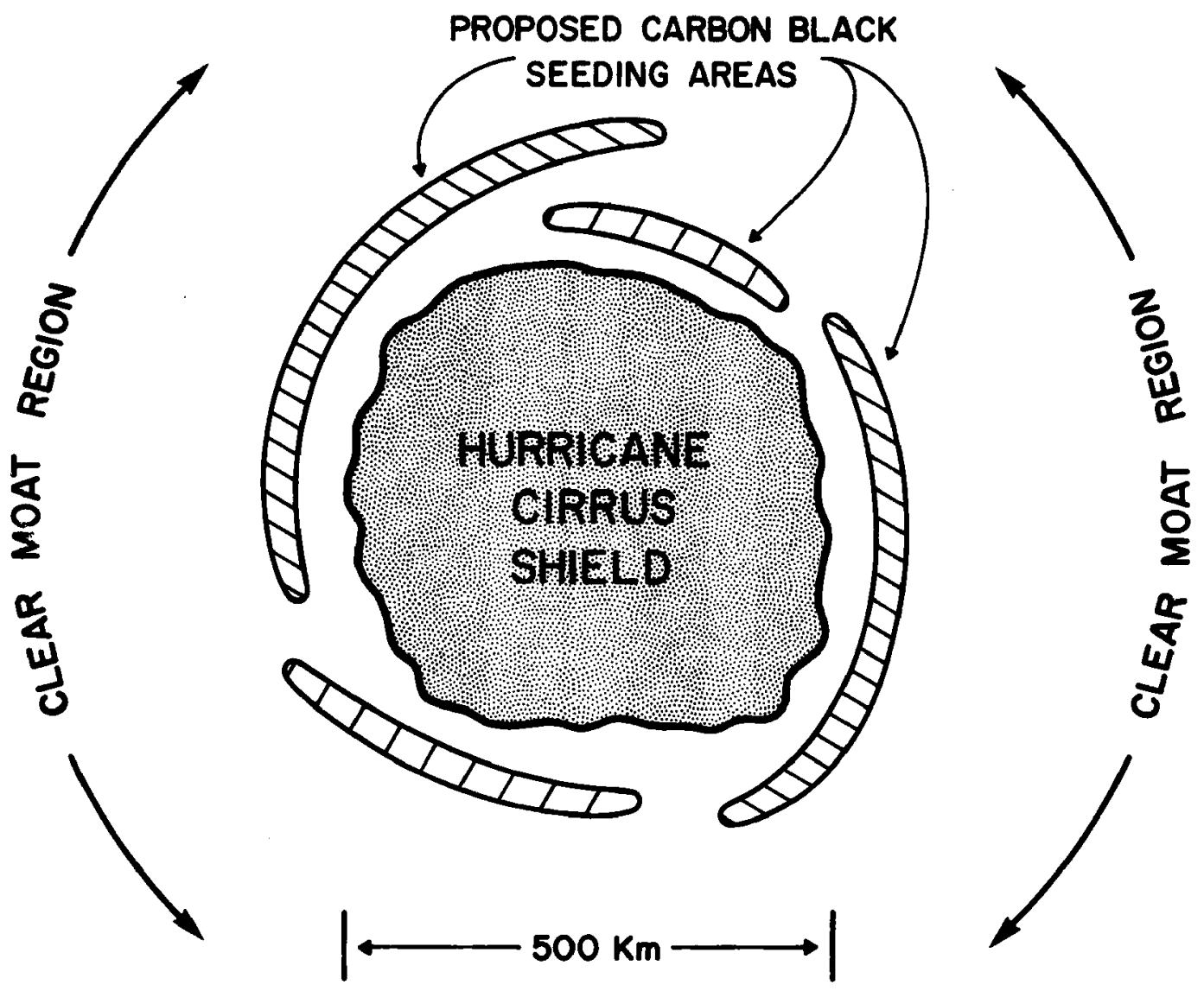

Fig. 8. Long hatched areas show where the hurricane boundary layer seeding of carbon black dust should be accomplished in the clear area moat region 8-10 hours upwind from the hurricane cirrus shield.

the eye-wall radius 18-36 hours later. Fig. 9 more explicitly shows how enhancement of buoyancy from extra heating and evaporation will lead to more artificially induced cumulus convection at radil beyond the eye-wall cloud and to probable lessening of the inflow to the inner storm region. This should weaken the inner core region of maximm circulation.

\section{c. Cumulonimbus enhancement over selected land regions in need of precipitation}

It is hypothesized that a significant location change and/or enhancement of cumulonimbus convection may be possible over land areas where the potential for cumulus convection is already.high. This is an es- 


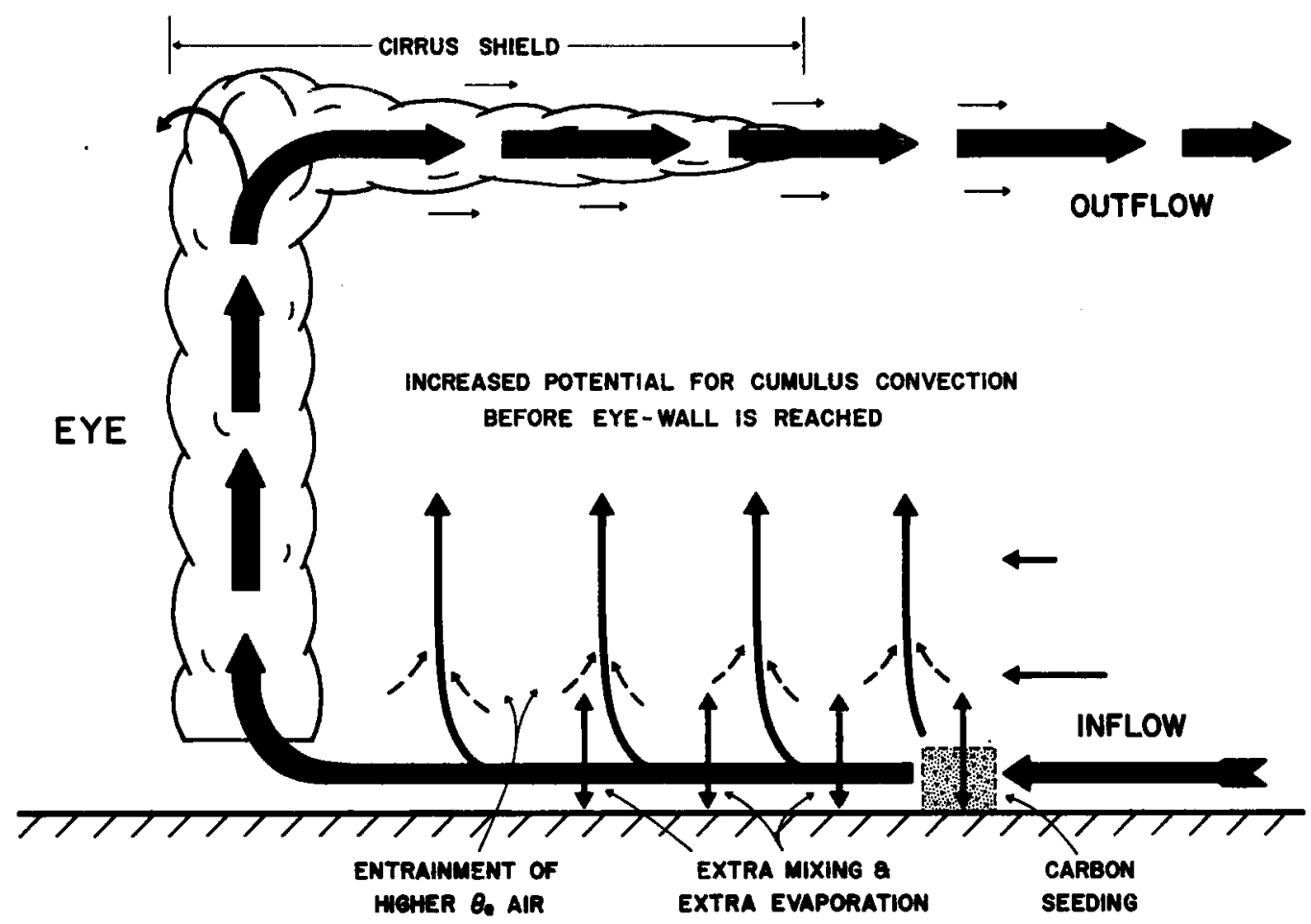

Fig. 9. Idealized view of how an increase of low level temperaturemoisture through carbon dust interception of solar radiation would lead to extra hurricane enhancement of deep cumulus convection at outer radii, and tend to cause less low level mass penetration of the eye-wall cloud region.

pecially likely situation if the land areas have a high amount of evapotranspiration. If the land areas are moist or have dense vegetation, much of the incoming radiation goes to evaporation or storage and the diurnal warming curves are damped. In these situations the carbon dust could be used to more rapidly warm up the boundary layer and to dictate where the initial daytime convection should occur. An area concentration of the morning and early afternoon solar heating would likely produce extra $\mathrm{Cb}$ convection and precipitation if the potential for cumulus convection is already high.

Over land the carbon dust might also be used in selective situations as an elevated heat source (if dispensed from aircraft) and could act as 
a stimulant to earlier and more concentrated cumulus convection. Especially favorable situations would be areas where large-scale low level convergence is present, such as around low pressure systems and along fronts. Here daytime cumulus convection would be expected to break out in the selectively seeded areas where the earliest atmospheric warming occurs.

Carbon dust heating might thus be used to dictate where the earliest thermal destabilization and cumulus convection take place. Early morning stable conditions act to inhibit convection. Any large-scale upward forced circulation would likely relieve itself in the areas which first become thermally unstable.

\section{d. Alteration of extra-tropical cyclones}

A significant economic gain might result if weak extra-tropical storm systems could be intensified in dry regions such as the western U.S. This would likely result in extra precipitation.

When cyclones are intense, move slowly, or are stationary, flooding conditions, heavy snow, and high sea conditions can produce considerable economic loss. This is especially true in the heavily populated areas along the U.S. East Coast and in Western Europe. In this second type of situation economic benefit might result in some cases if the intense cyclones could be artificlally weakened. If carbon dust solar heating is employed on a large enough scale, it might be possible for man to produce a modest but significant intensity reduction of extra-tropical cyclones.

Modest cyclone intensification might be accomplished by warming up selective areas at low levels to the east of the extra-tropical cyclone and stimulating extra cumulus convection just east of the storm center. This is likely to produce extra precipitation. If cyclone weakening were desired, then solar energy input to the cold center of the extra-tropical 
cyclone at middle or upper tropospheric levels would likely act to produce a modest but significant vortex weakening.

e. Fog dissipation

Calculations of the radiative absorptivity of carbon and of the amount of solar radiation available inside fog clouds indicate that carbon particles can absorb enough extra radiation to speed-up the dissipation of fog.

It is proposed that carbon dust be generated and dispersed directly into tine fug from aircraft or ground sources (ii the fog is not too thick). It is hypothesized that this would significantly accelerate the radiational burn-off of the fog. The logistical and economic requirements of this are not large.

f. Accelerating snowmelt in agricultural regions

There are several large, relatively flat agricultural areas in the world where a snow cover persisting late into the spring can cause a costly reduction in the length of the growing season. The Great Plains of the U.S. and the Russian wheat belt are good examples. When these areas are snow covered, they typically have surface albedos of from $40 \%-90 \%$ depending upon the age and condition of the snow and have relatively strong inversions just above the boundary layer. Large amounts of carbon dust particles can be dispensed from inexpensive ground generators into the boundary layer. By warming the boundary layer air under proper conditions it should be possible to accelerate the spring melt of the snowpack, thereby increasing the growing season. The high albedo of the snow surface would cause a strong upward diffuse solar radiation flux and thus increase the efficiency of the carbon absorption. Absorption would take place from both the upward and downward fluxes. In addition, the carbon particles should have a relatively long boundary layer residence time due to the strong inversion which should permit multiple day use of the carbon. 


\section{COMPARISON OF THIS HYPOTHESIS WITH PREVIOUS RADIATION ALTERATION MODIFICATION PROGRAMS}

To date, research on the subject of solar weather modification has been centered on fog and natural cloud dissipation and on developing and enhancing individual cumulus. Downie (1960), Fenn and Oser (1962) and Van Straten et al. (1958) have previously discussed the use of carbon dust in this way. The application of these approaches has been limited by the large amounts of heat required to evaporate meaningful amounts of moisture (i.e. $600 \mathrm{cal} / \mathrm{gm}$ ) and by the small amounts of carbon used. The Naval Research Laboratory seeded 8 cumulus clouds with $1-3 \mathrm{Kg}$ of carbon black in July, 1958 (Van Straten et al. 1958). All of the clouds dissipated to some extent, but observation and instrumentation capabilities were insufficient to establish a definite causal relationship. In addition, clear air at the approximate level of existing cumulus cloud bases was seeded on 5 runs during the same series of tests. Small clouds were observed to form in all cases. Once again it was impossible to establish definite causal relationships. The overall feeling of the test group was that the carbon black did seem to help dissipate existing clouds and form small ones in clear air, but the natural variability of cumulus clouds and the inadequacy of monitoring techniques prohibited any conclusive results.

Laboratory tests by the Naval Research Laboratory in 1958 showed that carbon black did increase dissipation rates of artificially created fogs in cloud chambers which were subjected to heat lamps. However, neither the dissipation mechanism nor the radiative properties of carbon black were quantitatively well established.

The Geophysics Research Directorate made 18 runs seeding small clouds and clear air in October, 1958-April, 1959 (Downie, 1960). Carbon amounts 

from 1-3 Kg per mission were used. Observed results were less successful than those observed earlier by the Naval Research Laboratory. A few clouds dissipated, but others did not. Clear air seeding produced no obvious results although a few small clouds occasionally formed in the test areas. The test personnel concluded that no definite effects of carbon black on clouds could be substantiated through their test results.

In general, these early experiments with carbon black suffered from four major shortcomings:

1) The existing knowledge of the radiative properties of carbon black was entirely inadequate to provide realistic estimates of the energy processes occurring in the atmosphere.

2) The amounts of carbon used were much too small. Small scale diffusion effects could easily dissipate the heat absorbed and overpower the effects of the heat accumulation.

3) Severe logistical and clumping problems associated with the handling and dispersal of the carbon particles were encountered.

4) Adequate observation and instrumentation capabilities to enable conclusive analysis of field test results were not available.

The previous research by C. Downie and B. Silverman * (U.S. Air Force Cambridge Research Lab.), F. Van Straten*, R. Ruskin* (U.S. Navy Research Lab.) and T. Smith (Private Industry), etc., in general, proved not to be promising. The amounts of carbon used $(5-20 \mathrm{Kg})$ were not consistent with the purposes. Dispersing and clumping problems were encountered. Previous work in the late 1950's and early 1960's was conducted on a scale (generating or intensifying individual cumulus) and with a technology (dispersing already manufactured carbon) which is entirely different than the one proposed in these papers.

\footnotetext{
${ }^{\star}$ Personal communication.
} 
By contrast, this research is concerned with the feasibility of carbon particle modification on the meso-scale ( $\sim 100-200 \mathrm{~km}$ on a side) using amounts of 1-2 million $\mathrm{Kg}$. We are planning to directly manufacture the carbon dust on aircraft or from carbon particle generating sources on ships or at surface sites. By direct manufacture of the carbon black dust from field sources, one avoids the clumping, packing, and logistical problems involved with obtaining the carbon particles from the factory. Previous experimenters did not consider the possibility of manufacturing the carbon dust directly at the experimental location from aircraft or at surface dispersion sites. The carbon particles are thus dispersed directly from the carbon generating burners which convert liquid hydrocarbon fuel to carbon and carbon dioxide. This greatly reduces logistical requirements and assures that the right sized particles will disperse without clumping and other difficulties.

The authors propose to overcome most of the previous experimental shortcomings by expanding the field tests to utilize many thousands of pounds of carbon dust, by manufacturing the carbon particles directly on the delivery vehicle, and by more careful study and monitoring of the heating and meteorological effects.

a. Coating surfaces with black material

The ESSO Oil Company of New Jersey (Black and Tarmy, 1963a, Black, 1963b) has explored the possibility of boundary layer heat augmentation from coating land surfaces with black-top (tar). These results have not been very encouraging. The black-top program has suffered from three basic drawbacks: 
1) The surface air blows over the few miles of black tar field in only a few minutes. Only a relatively small heat input can be made per unit mass of air. The carbon dust scheme, in contrast, has the carbon particles moving with the air mass. The energy input over a number of hours can be very large.

2) The land surface would naturally warm up and heat the air above to an appreciable extent without the black tar. The black top heating is only the difference between its heating and the natural surface land heating which would normally occur. In contrast, when applied over the ocean, nearly all of the solar absorption by the carbon dust is extra energy gain.

3) The envisaged area coverages of the black top of $\sim 100 \mathrm{~km}^{2}$ are too small to have a significant influence. By comparison the authors are proposing the carbon dust heating of area amounts equal to 10,000 to $100,000 \mathrm{~km}^{2}$.

Attempts at melting snow fields by coating them with carbon dust have, In general, proven unfeasible. Dispensing the carbon dust from aircraft or helicopter requires that the carbon sink to the ground before the winds sweep it away. This requires carbon particles of $100-1000 \mu$ radius. These particles are too large to have an economically feasible area to mass ratio except in very highly restricted conditions.

It may thus be concluded that the previous weather modification field programs in radiation alteration were, in general, on much too small a scale and did not have the best physical justification. 


\section{COMPARISON OF CARBON DUST RADIATION ABSORPTION WITH OTHER AEROSOL ABSORPTION}

Many researchers have estimated that atmospheric aerosols absorb significant amounts of incoming solar radiation. The question then arises whether analogies exist between the radiative effects of existing atmospheric aerosols, either natural or man made, and the here proposed carbon dust cloud for weather modification.

The two primary radiative differences between the proposed carbon dust cloud and the existing natural and man made atmospheric aerosols are:

1) differences in the absorption and scattering properties of the aerosols and

2) differences in the spacial distribution and amount of the particles. Carbon dust particles of sub-micron size are highly efficient absorbers of solar radiation and exhibit very low levels of backscatter. In contrast, typically $33 \%-100 \%$ of the solar radiation extinction due to most atmospheric aerosol samples is reflected. This normally results in a cooling of the earth/atmosphere system by most atmospheric aerosols as well as an increased atmospheric stability (due to reabsorption of reflected light above the aerosol and lower solar incidence below) above that of a carbon dust cloud in which only $1-10 \%$ of the extinction is due to backscatter. Since the albedo of a carbon dust cloud is only about 1-2\% (Frank and Corrin, Paper IV), the carbon cloud virtually always results in a net warming of the earth/atmosphere system. There is no significant warming above the cloud due to reabsorption of reflected solar radiation, and solar incidence below the cloud is reduced primarily by the amount of absorption in the cloud. It is concluded that a seeded carbon dust cloud is likely to have a significantly smaller radiative effect on the atmo- 
sphere above and below the seeded area than would any naturally occuring atmospheric aeroso1. Any stably induced changes of an atmospheric column containing a carbon dust cloud will be predominantly a result of the direct heating of the seeded volume by absorption of solar radiation. The proposed spacial distributions of carbon dust particles are different from those of most normal atmospheric aerosols. A carbon cloud, when initially dispersed, would be confined to a finite horizontal area with relatively distinct boundaries. This produces strong horizontal gradients of solar absorption between the surrounding air and the carbon cloud, and it is the resulting heating gradients which should result in the anticipated dynamic responses. In addition, most applications prefer a carbon dust cloud dispersed in the planetary boundary layer, perhaps beneath a low level inversion, resulting in a distinct vertical gradient of heating in at least the initial stages. This heating would tend to destabilize the atmospheric calumn.

Although aerosols in general play a significant role in the global atmospheric radiation budget, situations in which natural or man made aerosols occur in unusually large and localized concentrations are of primary interest here since their occurrences exhibit spacial distribution characteristics similar to the carbon dust cloud. A number of such high aerosol-concentration episodes have been studied with respect to their radiative characteristics and possible influences on the weather. A few of the better known ones are compared with the proposed carbon modification hypothesis below:

1) Desert Dust - Large concentrations of dust frequently occur in the atmosphere downwind of deserts after large windstorms. Perhaps the best known of these are the Sahara Desert dust clouds which 
often move westward over the Atlantic Ocean. The severest of these dust clouds have been estimated to absorb as much as 50-60 $\mathrm{cal} / \mathrm{cm}^{2}$ per day of solar radiation, (Carlson, Prospero and Hanson, 1973), about $1 / 2$ of the daily absorption of a carbon dust cloud of $10 \%$ horizontal area coverage. However, the great majority of this dust (and hence absorption) is found in the $600 \mathrm{mb}-850 \mathrm{mb}$ layer (Prospero and Carlson, 1972). Therefore, the dust cloud heats the air at elevations significantly above the boundary layer and typically above a strong inversion. This would tend to stabilize the atmosphere and suppress convection. A carbon dust cloud, however, would be dispersed in the boundary layer below the inversion and would tend to destabilize the atmosphere and stimulate convection. In addition, the Sahara dust typically is not strongly concentrated in local areas. Thus, we do not feel that solar absorption by natural atmospheric dust is similar to that of the proposed carbon dust.

2) The modification of weather downwind from large urban areas - Urban weather modification is generally attributed to a combination of the heat plume of the city itself and to changes in condensation and ice nuclei concentrations in the atmosphere (Semonin and Changnon, 1974). However, aerosol absorption of solar radiation in the heavily polluted air downwind from industrial urban areas is also a possible contributing mechanism to the urban induced modification. It is interesting to compare the likely extra urban aerosol solar heating with the proposed solar heating which can be obtained from carbon dust particles. 
Aerosols over the most polluted urban centers are relatively poor absorbers of solar radiation. The atmospheric aerosols with some significant effect upon solar radiation attenuation are in the approximate size range of $.01 \leq r \leq 1 \mu$ and absorb and scatter according to MIE theory. Particles smaller than $r \sim 0.01 \mu$ are generally very poor absorbers of solar radiation while particles much larger than about $r \sim 1.0 \mu$ do not have enough total surface area to absorb much solar radiation due to their low number concentrations.

The imaginary part of the complex index of refraction $\left(\mathrm{n}_{2}\right)$ for natural aerosols which determines their absorptivity has been measured to be about $n_{2} \simeq 0.01$ although Eiden (1966) has measured tentative values as high as $\mathrm{n}_{2}=0.1$ for very heavily polluted urban air. These values are much less than the $.28 \leq \mathrm{n}_{2} \leq 2.30$ values exhibited by carbon over the solar spectrum. Although the exact dependence of aerosol absorption upon the imaginary part of the complex index of refraction is very difficult to precisely specify, computations of particle absorptivities by Plass (1965) and others show that carbon particles should absorb from 5 to 100 times more solar radiation per particle than would most atmospheric aerosols in the most effective size range $(.01 \mu \leq r \leq 1.0 \mu)$. The proposed carbon dust configurations exhibit much higher particle concentrations in the highly absorbent $0.01 \mu-1.0 \mu$ size range than do most natural and man produced aerosols. However, during extreme urban air pollution episodes the particulate concentrations in this size range can equal or 
occasionally slightly exceed the proposed carbon dust concentrations (Whitby, Husar, and Liu, 1971).

Because of low particle absorptivity, urban aerosols can be expected to absorb no more than about $5 \%-20 \%$ as much solar radiation as a carbon dust cloud of $10 \%$ area coverage. Such an urban aerosol backscatters a significant amount of solar radiation. This reduces surface heating. In addition, aerosol concentrations of this magnitude usually occur only during meteorological conditions highly unfavorable to developing convection (e.g. subsidence inversion). Finally, the location of the urban aerosol (over land) is less favorable for producing horizontal heating gradients than the oceanic boundary layer site proposed for carbon dust seeding. It may thus be concluded that while an urban aerosol will exhibit some radiative similarities to a carbon dust cloud, the much smaller amounts of solar radiation absorbed and the unfavorable atmospheric and geographic environment in which it typically exists make it highly unlikely that a significant mesoscale atmospheric response will occur. Therefore, the urban aerosol does not provide a very useful analogy to a carbon dust cloud. 3) Rainfall suppression from vegetation fires - From time to time reports have been made of apparent suppression of rainfall downwind from areas where a large amount of agricultural burning occurs. A typical and well documented case is the decrease in precipitation downwind from sugar cane fires which occurs with increasing cane production (Warner, 1968) in Australia. However, this is thought to result from increased concentrations of condensation nuclei from the cane fire smoke rather than from radiative 
effects. This smoke is believed to produce more and smaller cloud drops (Warner and Twomey, 1967). Rainfall requires larger and fewer drops. Precipitation is thus inhibited. The carbon cloud would not act in this manner since the only particles produced in significant quantities during the controlled carbon generation process are the carbon black particles themselves. Carbon black is highly hydrophobic and will not act as an effecive condensation nucleus (Frank and Corrin, Paper IV). Hence, carbon seeding should not have any effect on concentrations of condensation or ice nuclel and should not affect cloud physics processes in this regard.

\section{a. Summary}

Although it is tempting to compare localized natural aerosol concentrations to the proposed carbon dust clouds, none of the normally occurring atmospheric aerosols surveyed here have radiative characteristics or spacial distributions similar enough to the carbon dust clouds to allow any meaningful analogies to be drawn. Few normally occurring aerosols exhibit the strong absorptivity of carbon or exist in locally concentrated clouds with relatively sharp boundaries such as a carbon dust cloud. Therefore, it is doubtful that any such aerosols result in an atmospheric response similar to the response which a carbon dust cloud would be expected to produce. 


\section{SYNOPSIS}

Many previously unexplored avenues of beneficial utilization of solar energy may be available to man. It is time for man to explore these areas of potential meso-scale weather modification. The discussions of these papers are very different than most current weather modificatinn schemes which concentrate on alteration of individual cumulus elements.

The following four papers will discuss many of the radiational, technological, ecological and meteorological requirements and problems which are likely to be encountered when man attempts the above types of modification.

Acknowledgements

The authors were much indebted to Professor Myron L. Corrin for many beneficial discussions. 


\section{REFERENCES}

Black, J. F., 1963b: Weather control: Use of asphalt coatings to tap solar energy. Science, 139, 226-227.

Black, J. F. and B. L. Tormy, 1963a: The use of asphalt coatings to increase rainfall. J. Appl. Meteor., 2, 557-564.

Carlson, T. N., J. M. Prospero and K. J. Hanson, 1973: Attenuation of solar radiation by windborne saharan dust off the west coast of Africa. NOAA Technical Memorandum ERL WMPO-7, U.S. Dept. of Commerce, $27 \mathrm{pp}$.

Cox, S. and V. E. Suomi, 1969: Radiation in the free atmosphere. Dept. of Meteor. Univ. of Wisconsin, Final unpublished report to ESSA Research Labs., 68 pp.

Downie, C., 1960: Cloud modification with carbon black. Wentworth H.H. Conference on Cumulus Dynamics, 191-208.

Eiden, R., 1966: The elliptical polarization of light scattered by a volume of atmospheric air. App1. Optics, 5, 569-576.

Fenn, R. W. and H. Oser, 1962: Theoretical considerations on the effectiveness of carbon seeding. U.S. Army Signal Research and Development Lab. Report No. 2258, 25 pp.

Gray, W. M., 1973: Feasibility of beneficial hurricane modification by carbon black seeding. Dept. of Atmos. Sci., Colo. State Univ., Research Report No. 196, 130 pp.

Korb, G. and F. Mö1ler, 1962: Theoretical investigation of energy gain by absorption of solar radiation in clouds. Final Report on U.S. Army Signal Corp. Contract No. DA-91-541-EUC01612, 185 pp. (available from U.S. Army).

Prospero, J. M. and T. N. Carlson, 1972: Vertical and areal distribution of Saharan dust over the western equatorial North Atlantic Ocean. J. Geophysical Res., 5255-5265.

Semonin, R. G. and S. A. Changnon, Jr., 1974: METROMEX: Summary of 19711972 results. Bulletin of the AMS, 55, 95-100.

Van Straten, F. W., R. E. Ruskin, J. E. Dinger and H. J. Mastenbrook, 1958: Preliminary experiments using carbon black for cloud modification and formation. U.S. Naval Res. Lab. Report No. 5235, 17 pp.

Warner, J., 1968: A reduction in rainfall associated with smoke from sugar cane fires - an inadvertent weather modification. J. Atmos. Sci., 247-251. 


\section{REFERENCES (cont'd)}

Warner, J. and S. Tuomey, 1967: The production of cloud nuclei in cane fires and the effect on cloud droplet concentration. J. Atmos. Sci., 704-706.

Whitby, K. T., R. B. Husar and B. Y. H. Liu, 1971: The aerosol size distribution of Los Angeles smog. Aerosols and Atmospheric Chemistry,

G.M. Hidy ed., Academic Press, New York, 237-264. 
Weather Modification by Carbon Dust Absorption of Solar Energy

Paper II: Radiation Characteristics

William M. Frank

ABSTRACT

This paper evaluates the radiational properties of clouds consisting of carbon black particles in aerosol form spread artificially in the atmosphere to absorb solar radiation and hence to create an atmospheric heat source for possible large-scale weather modification. Properties of carbon black are discussed. A method for estimating absorption of solar radiation by clouds developed by Korb and Möller (1962) is applied to study solar absorption and scattering of carbon black dust clouds. The very high energy gain to weight and cost is discussed. 


\section{INTRODUCTION}

This paper is concerned with the potential use of carbon black as a clear air heat source by spreading particles over a large area in order to trigger beneficial mesoscale or synoptic scale flow changes. The radiation properties of carbon clouds of large horizontal extent compared to their vertical depth are studied incorporating the effects of water vapor and planetary surface albedo. Quantitative results are obtained for several cloud models. 
II. RADIATIVE PROPERTIES OF CARBON BLACK DUST IN THE ATMOSPHERE

\section{a. Carbon black}

Carbon black dust consists of fine spherical particles composed of 95-99\% pure carbon, the remainder being made up of volatile materials. The density of the carbon particles is about $2.0 \mathrm{~g} / \mathrm{cm}^{3}$. The high radiative absorptivity and low heat capacity (about $.125 \mathrm{cal} / \mathrm{g}^{\circ} \mathrm{C}$ ) of carbon black make it an ideal agent for interception of solar radiation and transfer of this heat to the surroundings by conduction. These properties are discussed in more detail later.

\section{b. Radiation characteristics of carbon black}

The complex index of refraction of carbon particles computed by Krascella (1965) is shown as a function of wavelength in Fig. 1. The absorption $\left(\sigma_{A}\right)$, scattering $\left(\sigma_{S}\right)$ and extinction $\left(\sigma_{E}\right)$ cross sections of spherical carbon particles computed by MIE scattering theory are shown as functions of the size parameter $\alpha=\frac{2 \pi r}{\lambda}$ in Fig. 2. These coefficients are defined as the ratios between the equivalent areas with which particles absorb, scatter, and extinct light and the actual geometric cross section. They are functions of the refractive index of carbon, particle size and the wave length of the affected light. The coefficients are related as shown in equation (1).

$$
\sigma_{E}=\sigma_{A}+\sigma_{S}=\text { extinction cross section }
$$

The values shown in Fig. 2(Krascella, 1965) are in close agreement with experimental and theoretical estimates of the tinting strength of carbon black particles made by various carbon black companies. Marteney (1965), in a companion study to that of Krascella, obtained 


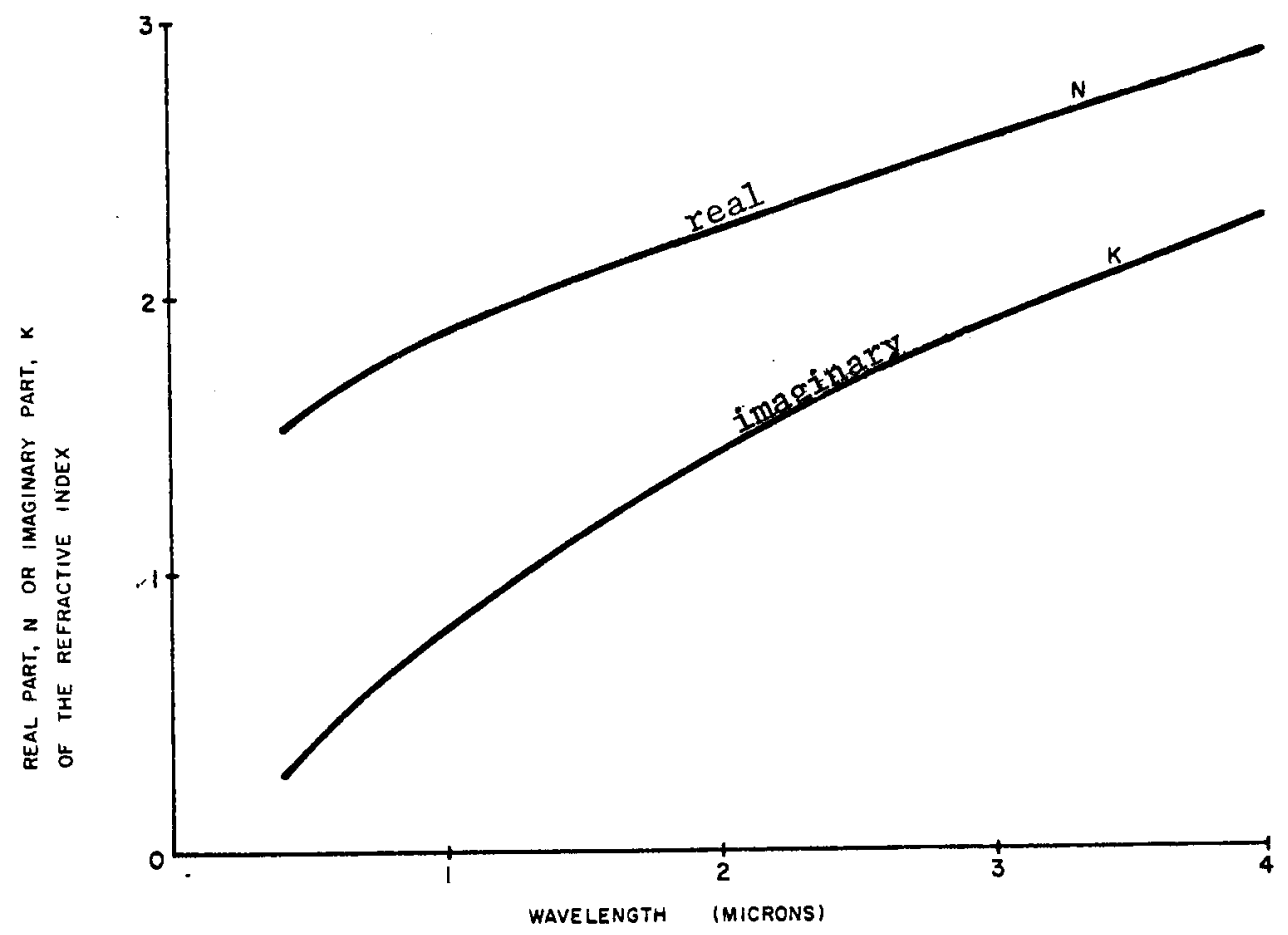

Fig. 1. Variation of the real and imaginary parts of the complex index of refraction of spherical carbon particles with incident wavelength (Krascella, 1965).

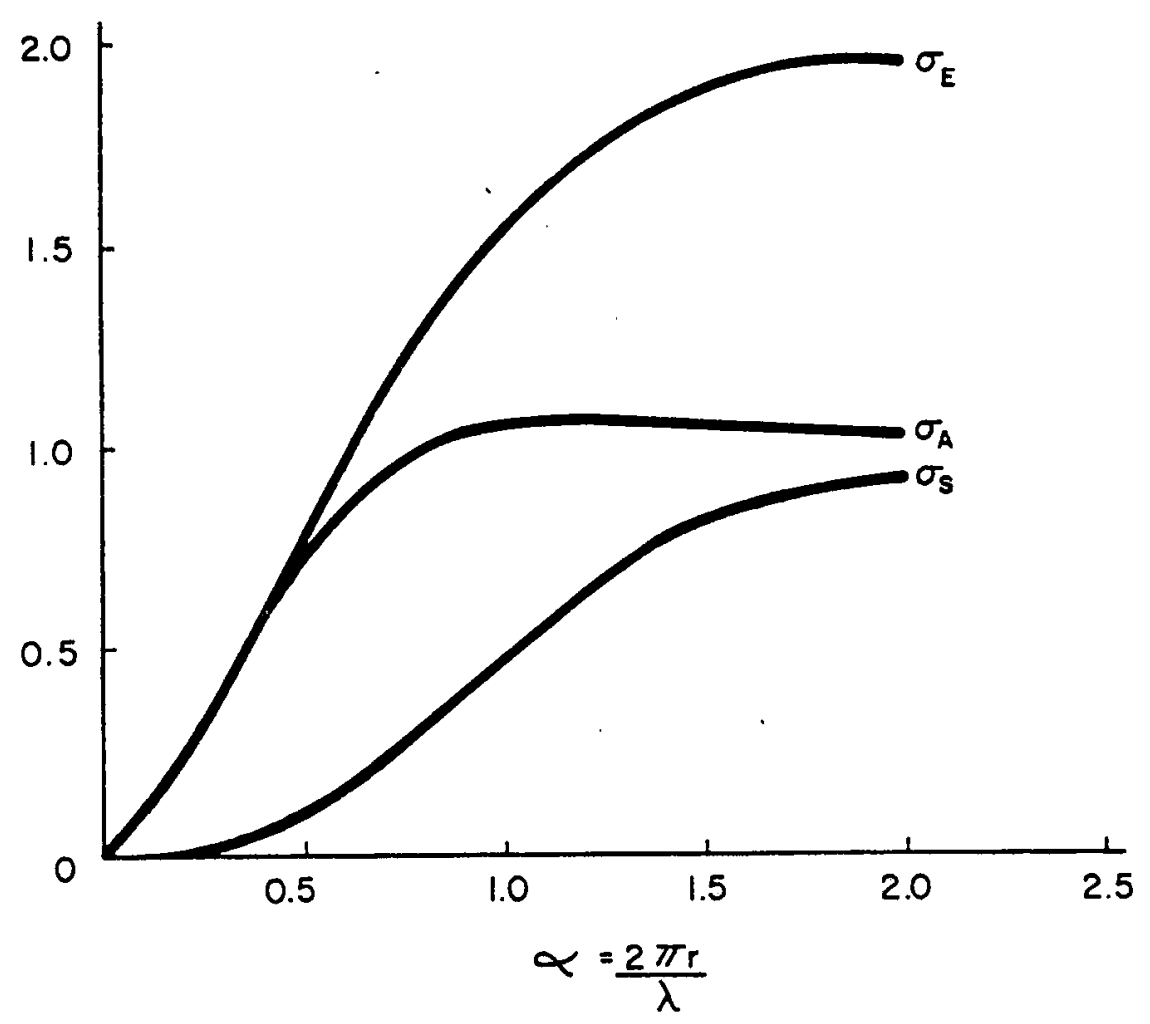

Fig. 2. Extinction $\left(\sigma_{E}\right)$, absorption $\left(\sigma_{A}\right)$ and scattering $\left(\sigma_{S}\right)$ cross sections of spherical carbon particles as functions of size parameter $(\alpha)$. 
experimental absorptivities of carbon particles dispersed in air which are in close agreement with Krascella's theoretical values. Fenn (1962, 1965) estimated somewhat higher values of these parameters. Carbon black particles, when formed, are virtually all spherical and of relatively uniform size and composition. Since the particles will be dispersed into the air immediately after formation, the relevance of the MIE scattering theory to light extinction by carbon particles seems to be reasonable.

\section{c. Characteristics of the carbon cloud}

For this study each carbon dust cloud was assumed to be composed of uniform carbon particles. The clouds are of large horizontal extent compared to their thickness, and each cloud or cloud layer was assumed to be homogeneous. Water vapor contents of the clouds were assigned according to standard atmospheric concentrations depending upon cloud height. All water vapor was assumed to be uncondensed.

The above assumptions were made for convenience of computation. Real situation variations from these assumed values are not felt to be large enough to appreciably alter the results to be shown. Any of the assumptions can be varied to meet individual case refinement as desired.

\section{d. Determination of Optimum Particle Size}

For economic reasons it is desirable to maximize the amount of radiation absorbed by the carbon particles per unit mass. To do this the optimum particle size must be determined. Since the cloud is of relatively large horizontal extent compared to its height, much of the forward scattered incident radiation will be absorbed due to increased optical path length. Hence, we wish to maximize the extinction coefficient of the cloud per unit mass, rather than the absorption coefficient. 
The extinction coefficient of a cloud is given by:

$$
\mathrm{K}_{E}=\mathrm{N} \cdot \pi \mathrm{r}^{2} \cdot \sigma_{E}
$$

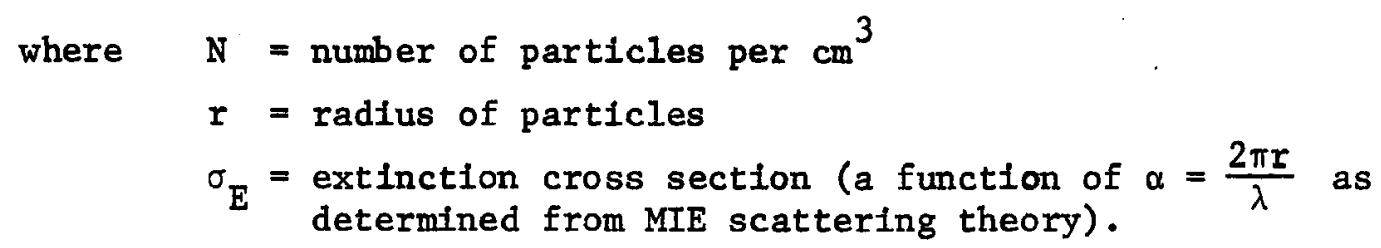

Let the volume of a single carbon particle $=V_{P}=\frac{4}{3} \pi r^{3}$.

Let the total mass of carbon particles $=\mathrm{M}_{\mathrm{C}}=\mathrm{V}_{\mathrm{T}} \rho_{\mathrm{C}}$

where $\rho_{c}=$ density of carbon black $\left(\sim 2 \mathrm{gm} / \mathrm{cm}^{3}\right)$

$\mathrm{V}_{\mathrm{T}}=$ total volume of particles

$$
\mathrm{N}=\frac{\mathrm{V}_{\mathrm{T}}}{\mathrm{V}_{\mathrm{P}}}=\frac{\mathrm{M}_{\mathrm{c}}}{\rho_{\mathrm{c}}} \cdot \frac{3}{4 \pi \mathrm{r}} 3 .
$$

Then

$$
\mathrm{K}_{\mathrm{E}}=\frac{3}{4} \frac{\mathrm{M}_{\mathrm{C}}}{\rho_{\mathrm{C}}} \frac{1}{\mathrm{r}} \sigma_{\mathrm{E}}
$$

The size parameter $(\alpha)$ is defined: $\alpha=\frac{2 \pi r}{\lambda} \quad$ where $\lambda$ is the wavelength of radiation. Hence

$$
\begin{gathered}
r=\frac{\alpha \lambda}{2 \pi} \quad \text { and } \\
\mathrm{K}_{\mathrm{E}}=\frac{3 \pi \mathrm{M}_{\mathrm{C}}}{2 \rho_{\mathrm{C}} \lambda} \quad \frac{\sigma_{\mathrm{E}}}{\alpha} .
\end{gathered}
$$




$$
\frac{3 \pi M_{c}}{2 p c^{\lambda}}=\text { constant }
$$

Hence:

$$
\mathrm{K}_{\mathrm{E}}=\frac{\sigma_{\mathrm{E}}}{\alpha} \cdot \text { (const.), }
$$

$\frac{\sigma_{E}}{\alpha}$ is plotted in Fig. 3. The maximum value of $\frac{\sigma_{E}}{\alpha}$ from this graph will give us the maximum value of $\mathrm{K}_{\mathrm{E}}$ for any given mass per unit volume. Solving graphically $\mathrm{K}_{E}$ is a maximum at approximately $\alpha=0.7$.

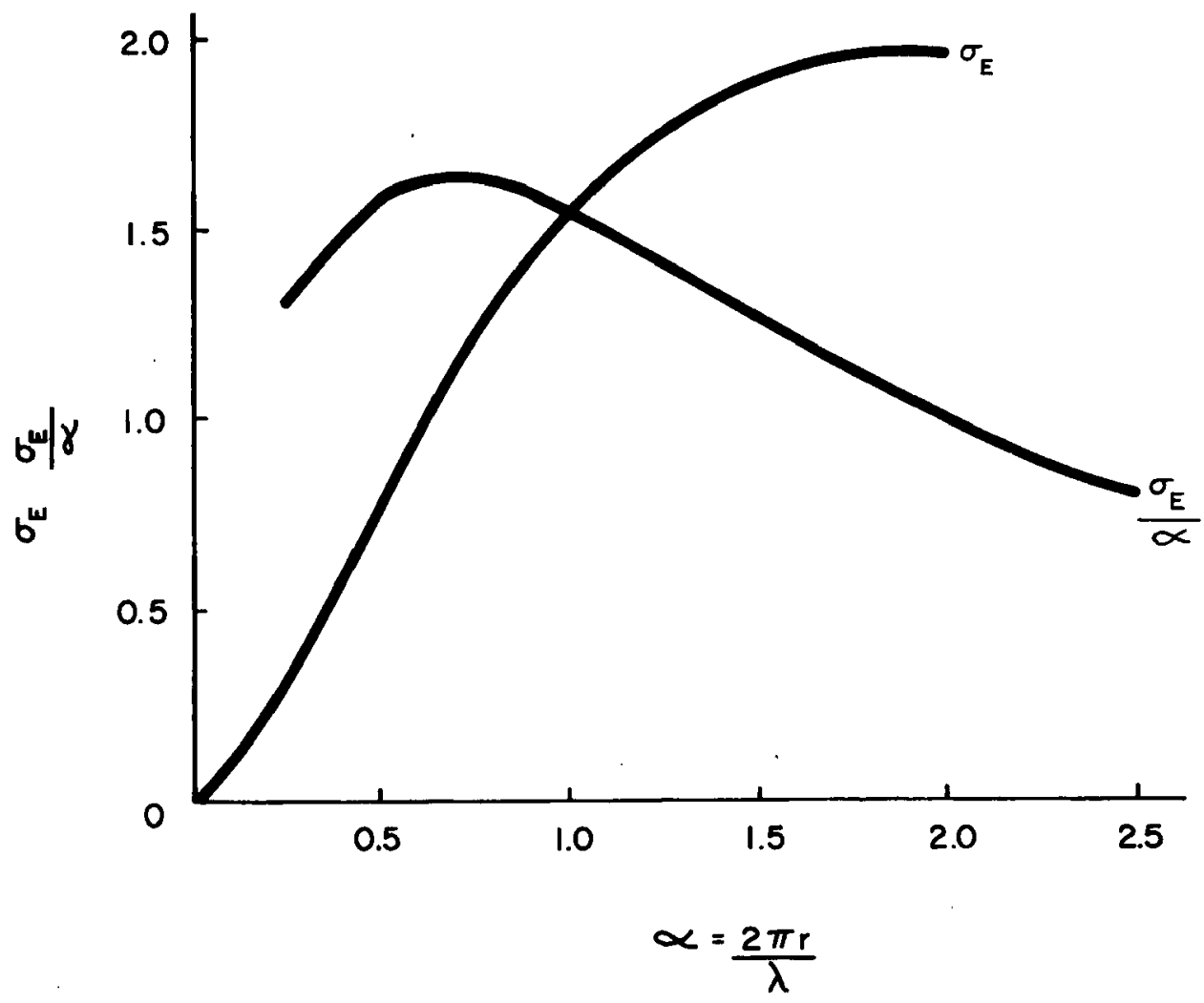

Fig. 3. Extinction cross section $\left(\sigma_{E}\right)$ and $\sigma_{E} / \alpha$ for spherical carbon particles. 
Although sunlight has an intensity peak at $\lambda=.5 \mu$, to maximize the extinction across the entire solar spectrum we shall use the median value of solar wave length which is approximately: $\bar{\lambda} \simeq .72 \mu$. This gives an optimum radius of:

$$
\begin{aligned}
& r=\frac{a \lambda}{2 \pi}=\frac{(0.7)(\lambda)}{2 \pi} \\
& r=.08 \text { micron }(\mu) .
\end{aligned}
$$

For simplicity we shall assume particles of $\mathrm{r}=.1 \mu$ for the remainder of this study. Note from the gradual slope of the $\frac{\sigma_{E}}{\alpha}$ curve in Fig. 3 that light extinction per unit mass of carbon is not highly sensitive to particle size changes. Size quality control should not be a crucial problem.

\section{e. Division of the solar spectrum}

To average the general transmission functinn, the solar spectrum must be divided into finite bands, and average values of the extinction coefficient and optical depth must be determined for each band. These parameters vary rather smoothly with changing wave length. However, water vapor absorption is quite irregular with respect to wave length. It is therefore desirable to choose bands such that each of the absorption bands of water vapor will coincide with one of the defined spectral bands. In the spectral bands with no water vapor absorption, water vapor absorption will be zero, and in the bands which coincide with water vapor bands, average values may be determined. (The solar constant value used is $1.951 \mathrm{y} / \mathrm{min.}$ ). The spectral divisions used, the water vapor absorption bands, and the solar irradiance (radiant flux incident on a unit area) of each band at the top of the atmosphere are shown in Table 1. Also shown are the values of the absorption $\left(\sigma_{a}\right)$, scattering $\left(\sigma_{s}\right)$, and extinction $\left(\sigma_{E}\right)$ cross 
TABLE 1

DIVISION OF SOLAR SPECTRUM

\begin{tabular}{|c|c|c|c|c|c|c|c|}
\hline Region & $\begin{array}{l}\text { Wave length } \\
\text { Band }(\Delta \dot{\lambda}) \\
\text { (microns) } \\
\end{array}$ & $\begin{array}{l}\text { Water } \\
\text { Vapor } \\
\text { Band } \\
\end{array}$ & $\begin{array}{l}\text { Incidient } \\
\text { Solar Energy } \\
\frac{\mathrm{cal}}{\mathrm{cm}^{2} \mathrm{~min}}\end{array}$ & $\begin{array}{c}\mathrm{Abs} . \\
\sigma_{\mathrm{A}} \\
\end{array}$ & $\begin{array}{l}\text { Scatt. } \\
\sigma_{S} \\
\end{array}$ & $\begin{array}{c}\text { Ext. } \\
\sigma_{E} \\
\end{array}$ & $\begin{array}{c}\text { Absorption } \\
\text { Quantity } \\
\mathrm{K}_{\mathrm{A}} \\
\end{array}$ \\
\hline 1 & $.28-.42$ & - & .220 & 1.04 & .93 & 1.97 & .53 \\
\hline 2 & $.42-.50$ & - & . .232 & 1.07 & .80 & 1.87 & .57 \\
\hline 3 & $.50-.60$ & - & .270 & 1.07 & .56 & 1.65 & .65 \\
\hline 4 & $.60-.70$ & - & .228 & 1.07 & .48 & 1.55 & .69 \\
\hline 5 & $.70-.74$ & $.72 \mu$ & .077 & 1.07 & .37 & 1.44 & .74 \\
\hline 6 & $.74-.79$ & - & .089 & 1.04 & .35 & 1.39 & .75 \\
\hline 7 & $.79-.84$ & $.8 \mu$ & .075 & 1.01 & .32 & 1.33 & .76 \\
\hline 8 & $.84-.86$ & - & .030 & 1.00 & .28 & 1.28 & .78 \\
\hline 9 & $.86-.98$ & $.94 \mu$ & .143 & .99 & .24 & 1.23 & .81 \\
\hline 10 & $.98-1.05$ & - & .069 & .91 & .16 & 1.07 & .85 \\
\hline 11 & $1.05-1.22$ & $1.13 \mu$ & .138 & .85 & .11 & .96 & .89 \\
\hline 12 & $1.22-1.61$ & $1.40 \mu$ & .181 & .69 & .06 & .75 & .92 \\
\hline 13 & $1.61-2.10$ & $1.87 \mu$ & .099 & .47 & .04 & .51 & .93 \\
\hline 14 & $2.10-2.20$ & - & .013 & .40 & .02 & .42 & .95 \\
\hline 15 & $2.20-3.00$ & $2.7 \mu$ & .052 & .29 & 0 & .29 & 1.00 \\
\hline 16 & $3.00-3.80$ & $3.2 \mu$ & .020 & .19 & 0 & .19 & 1.00 \\
\hline 17 & $3.80-4.50$ & - & .008 & .13 & 0 & .13 & 1.00 \\
\hline 18 & $4.50-10.00$ & $6.3 \mu$ & .012 &. .05 & 0 & .05 & 1.00 \\
\hline \multicolumn{8}{|c|}{ Total: } \\
\hline & & edian: & & 1.07 & .37 & 1.44 & \\
\hline
\end{tabular}


sections and the absorption quantity $\left(\mathrm{K}_{\mathrm{A}}\right)$. Absorption quantity is defined as the ratio of the absorbed light to absorbed plus scattered light as shown in equation (9).

$$
\mathrm{K}_{\mathrm{A}}=\frac{\text { absorption coefficient }+\rho_{W} K_{W}}{\text { extinction coefficient }+\rho_{W} K_{W}}
$$

where

$$
\begin{aligned}
& \rho_{\mathrm{W}}=\text { water vapor density } \\
& \mathrm{K}_{\mathrm{W}}=\text { absorption coefficient of water vapor. }
\end{aligned}
$$

f. Method for solving the equation of radiative transfer through a cloud

A method developed by Korb and Möller (1962) was used to solve the general equation of radiative transfer through a cloud (as developed by Chandrasekhar, 1960). The radiation field was broken up into $2+2 \pi$ fluxes; one directed upward, one downward, and $2 \pi$ fluxes in the horizontal plane. This breaks the general transfer equation down into a series of linear differential equations which give absorption, transmission, and reflection of radiation as percentages of total incident radiation. These equations are shown in appendix I for the cases where surface albedo is zero and where surface albedo is non zero.

The absorption, reflection, and transmission were determined for each given zenith angle and optical depth for a narrow spectral band, and the results were summed for all spectral bands to give total values for given zenith angle and optical depth. Nine zenith angles from $0^{\circ}$ to $80^{\circ}$ at $10^{\circ}$ intervals were chosen. For simplicity, calculations of daily absorption assumed a 12 hour day with the sun directly overhead at noon. The total absorption and transmission per day for each optical depth was obtained by time averaging the values over the 10 hour 40 minute period 
with zenith angles less than $80^{\circ}$ in computation steps of $10^{\circ}$ zenith angle change (40 minutes). Water vapor absorption within the cloud was also included in the computations.

The above radiation model was run assuming no surface reflection and also for various albedos by introducing an upward diffuse radiation field using mean values of the scattering function components. Intensity of the upward scattered field varied with albedo and the amount of light initially transmitted through the cloud.

Solar irradiances at the top of each cloud were reduced using calculations by Dave and Furukawa (1966) to account for ozone $\left(\mathrm{O}_{3}\right)$ absorption and molecular scattering above the cloud top. Molecular scattering within the cloud was not considered. Absorption and scattering by molecular oxygen $\left(\mathrm{O}_{2}\right)$ and carbon dioxide $\left(\mathrm{CO}_{2}\right)$ is insignificant for the purposes of these calculations and was not taken into account. Effects of natural tropospheric aerosols were not considered in these calculations.

For each cloud configuration studied, the total absorption of solar radiation by carbon and water vapor was calculated. The absorption of the equivalent volume at the same altitude due to water vapor alone was then calculated. It was assumed that water vapor in the air around the test cloud would absorb radiation at the rate of the carbon-free air. Since the evaluation of carbon black as a heat source was the object of this study, the net effectiveness of the carbon was the difference between the total solar radiation absorbed by the carbon cloud and the radiation that would be absorbed without the carbon cloud. It was expected that the carbon and water vapor cloud would absorb less than the sum of the absorptions of a carbon-only cloud and water-vapor-only cloud due to the redundancy of the absorption characteristics of the two substances at longer wavelengths. This proved to be the case, but the loss in efficiency was very small. 


\section{RESULTS}

\section{a. Absorption in the tropical atmosphere}

It is felt that the tropical atmosphere presents the best opportunities for beneficial large scale weather modification. Particular interest is centered on carbon black dust seeding into the tropical boundary layer (1013 mb - $950 \mathrm{mb})$. Absorptions were first computed for clouds containing $4.0 \mathrm{~cm}$ and $5.0 \mathrm{~cm}$ of precipitable water vapor - (ppw) - but no carbon to simulate clear air absorption in the tropical atmosphere. These are the amounts of water vapor found above $950 \mathrm{mb}$ and $1013 \mathrm{mb}$ respectively in a mean tropical cloud cluster. The amounts of solar radiation absorbed per day in clear tropical conditions are shown in Table 2 . It is noteworthy that the $5.0 \mathrm{~cm}$ ppw atmosphere absorbs only about $5 \%$ more radiation per day than does the $4.0 \mathrm{~cm}$ ppw atmosphere. This indicates that $95 \%$ of the solar radiation absorbed daily by the $5.0 \mathrm{~cm}$ ppw atmosphere is absorbed by the portion of that atmosphere containing the uppermost $4.0 \mathrm{~cm}$. Since so little solar radiation (about $9 \mathrm{ly} /$ day) is absorbed by the lowest $1 \mathrm{~cm}$ of ppw, no significant redundancy in absorption by water vapor and carbon would occur in a carbon dust cloud dispersed between $1013 \mathrm{mb}$ and $950 \mathrm{mb}$ in the tropics. Therefore, such a carbon dust cloud can be treated as a dry cloud to a reasonably high degree of accuracy.

Calculations of absorption by a dry carbon cloud in the tropical boundary layer (1013-950 mb) were made using reduced values of solar energy incident at the $950 \mathrm{mb}$ level to approximate the effects of water vapor, ozone, and molecular scattering. A surface albedo of $10 \%$ was assumed. Results are shown in Table 3, and net absorption as a function of carbon concentration is shown in Fig. 4. An increasing loss of efficiency of absorption per unit mass occurs at increasing densities as progressively less solar radiation penetrates to the lower levels of carbon, especially at 
high zenith angles. Therefore, from an economic point of view it is desirable to cover large areas with low concentrations if the magnitude of heat gain to carbon dust expended is to be maximized. A carbon particle concentration of 10,000 particles $/ \mathrm{cm}^{3}$ represents $18 \%$ horizontal area coverage for this cloud model. This would require only $45 \mathrm{~kg}$ of carbon black dust per square kilometer of horizontal cloud area.

b. Absorption by carbon dust in the mid-latitude standard atmosphere Computations of daily absorption were made for a cloud extending from sea level to $11 \mathrm{~km}$ containing $2.8 \mathrm{~cm} \mathrm{ppw,} \mathrm{the} \mathrm{approximate} \mathrm{mid-latitude}$ standard atmospheric water vapor content, and carbon particle concentrations from zero to 2000 particles $/ \mathrm{cm}^{3}$. It was assumed that such a

TABLE 2

SHORT WAVE ABSORPTION BY CLEAN AIR TROPICAL ATMOSPHERE

SHORT WAVE ABSORPTION BY CARBON DUST CLOUDS OF VARIOUS CONCENTRATIONS IN THE TROPICAL BOUNDARY LAYER (1013-950 mb)

\begin{tabular}{lccccccc}
\hline $\begin{array}{l}\text { Percent Area } \\
\text { Coverage: }\end{array}$ & 0 & $9 \%$ & $18 \%$ & $26 \%$ & $35 \%$ & $53 \%$ & $70 \%$ \\
$\begin{array}{l}\text { Concentration } \\
(\text { Particles/cm }\end{array}$ & 0 & 5,000 & 10,000 & 15,000 & 20,000 & 30,000 & 40,000 \\
$\begin{array}{l}\text { Net Absorption: } \\
\text { by Carbon (ly/day) }\end{array}$ & 0 & 98 & 177 & 243 & 298 & 384 & 448 \\
\end{tabular}




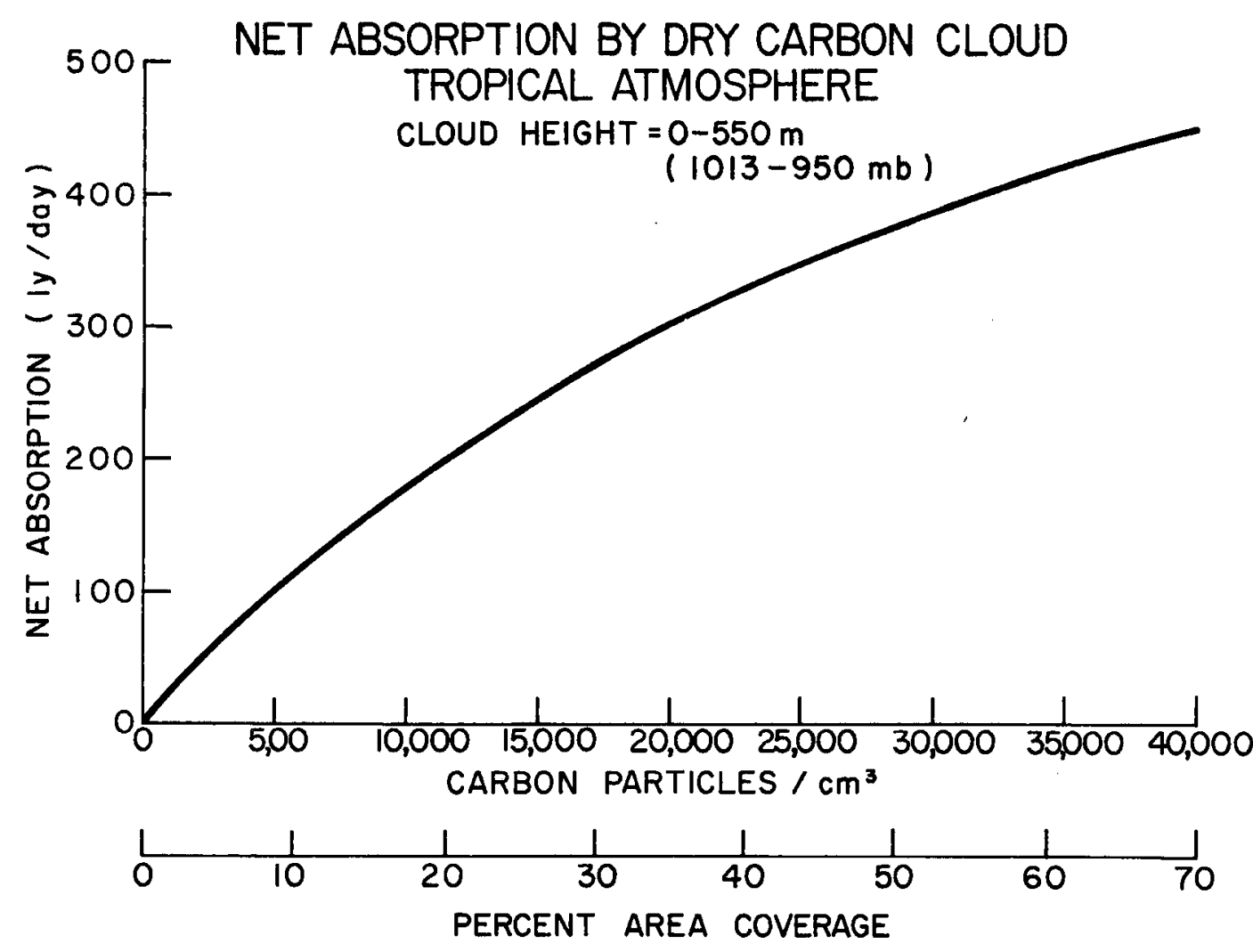

Fig. 4. Net absorption of solar radiation by a dry carbon cloud in the tropical boundary layer.

cloud model might be used to intensify existing broadscale circulations. Total absorptions and net usable absorptions (total absorption minus natural clear air water vapor absorption) per day are shown in Table 4 . These absorptions are plotted as functions of cloud density in Fig. 5 . Absorption in langleys per minute rates are plotted as a function of zenith angle for each particle concentration in Fig. 6. This shows the relative effects of decreasing incident solar radiation and increasing optical path length with zenith angle change. It can readily be seen that when dealing with large concentrations of carbon dust, efficiency is considerably lower at zenith angles greater than $60^{\circ}$, which comprises roughly a third of the 12 hour day. Operations requiring large concentrations of carbon black for intense local heating would be most economical during 
TABLE 4

ABSORPTION BY CARBON DUST CLOUD

Cloud Depth 0-11 km

\begin{tabular}{llrlrrrr}
\hline Area Coverage & $0 \%$ & $9 \%$ & $18 \%$ & $26 \%$ & $35 \%$ & $53 \%$ & $70 \%$ \\
Particles $/ \mathrm{cm}^{3}$ & 0 & 250 & 500 & 750 & 1000 & 1500 & 2000 \\
\hline
\end{tabular}

Total

Absorbed $\quad 137$ ly 240 ly 324 ly 394 ly 452 ly 543 ly 610 ly

by Cloud

Absorbed by

$\begin{array}{lllllllllllllll}\text { Water Vapor } & 137 & 1 y & 137 & 1 y & 137 & 1 y & 137 & 1 y & 137 & 1 y & 137 & 1 y & 137 & 1 y\end{array}$

in Clear Air

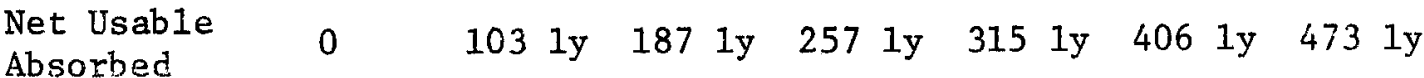

$\mathrm{N}=$ particles $/ \mathrm{cm}^{3}$

$\mathrm{C}=\%$ area coverage of Carbon

ly lost by competing with water

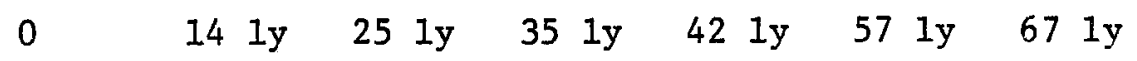
vapor

(absorption by carbon cloud with no water vapor-net usable absorbed) 


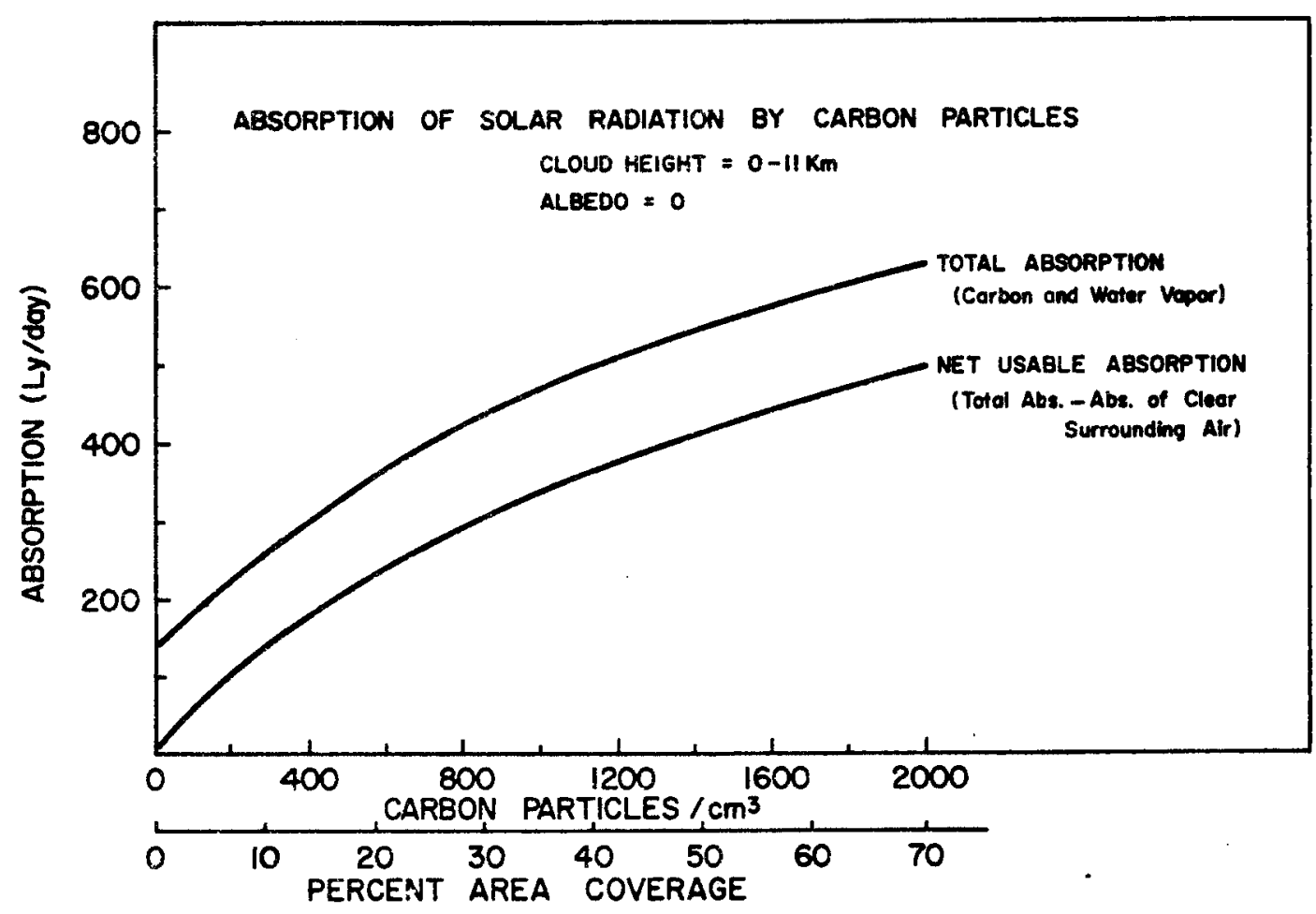

Fig. 5. Total and net usable absorption of solar radiation by carbon particles and water vapor.

the mid-day hours, while those requiring only moderate concentrations $\left(\mathrm{N}<500\right.$ particles $\left./ \mathrm{cm}^{3}\right)$ would be efficient throughout the entire solar day.

c. Influence of water vapor absorption

To obtain an estimate of the magnitude of the efficiency loss due to the redundant absorption tendencies of carbon and water vapor at higher wave lengths, absorption values of a 0-11 $\mathrm{km}$ carbon cloud were calculated assuming water vapor content to be zero. The results are plotted in Fig. 7 along with the total and net usable absorption potential for the mid-latitude model. The absorption loss increases with particle concentration, and the ratio of lost absorption to net usable absorption increases slightly. The lost absorption ranges from $0 \%$ to about $14 \%$ of net usable absorption for the densities tested. 


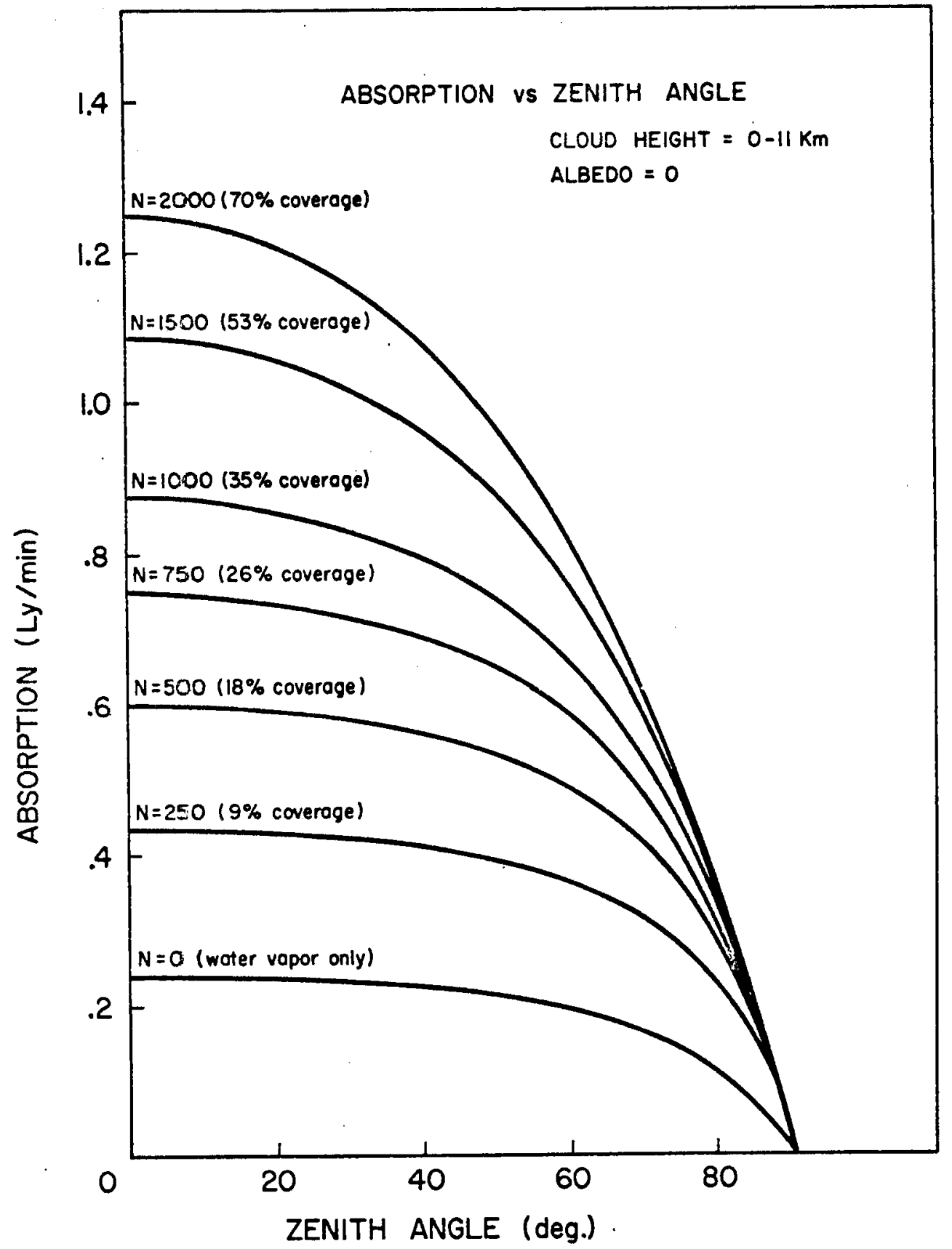

Fig. 6. Variation in absorption of solar radiation with zenith angle. 


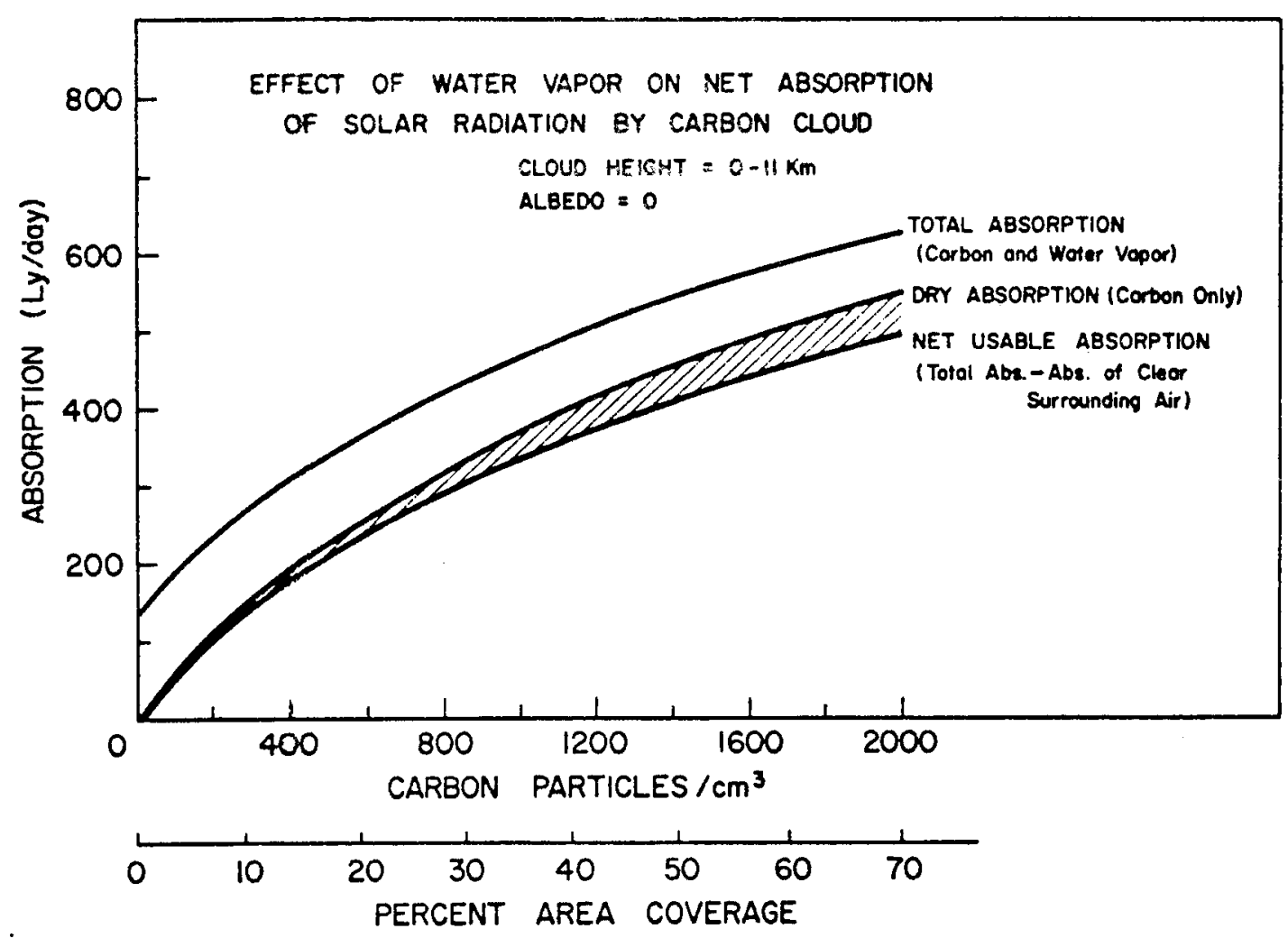

Fig. 7. Loss of efficiency of carbon absorption due to redundant absorption by water vapor.

\section{d. Long wave radiation loss}

To develop a complete heat budget of a carbon black cloud, it is necessary to consider the loss of absorbed radiation due to vertical long wave radiant flux divergence. Korb and Moller (1962) calculated values of long wave flux divergence of various carbon clouds for a 24 hour day. They considered $\mathrm{CO}_{2}$ and water vapor to be selective absorbers and the carbor particles to be gray absorbers. Standard mid-latitude atmospheric values of water vapor concentrations were used. Results are shown in Table 5. The difference between flux loss from a cloud consisting of carbon, water vapor and $\mathrm{CO}_{2}$ and a similarly dimensional cloud consisting only of water vapor and $\mathrm{CO}_{2}$ represents the loss of effective heating by the carbon black. In the most extreme case, the 1-6 km cloud with a carbon concentration of 
TABLE 5

LONG WAVE RADITION FLUX DIVERGENCE LOSS BY VARIOUS AEROSOL CLOUD MODELS (Korb and Mö11er, 1962)

\begin{tabular}{|c|c|c|c|c|c|c|c|}
\hline \multicolumn{8}{|c|}{ Long Wave Flux Divergence (1y/24hr) } \\
\hline $5-6 \mathrm{~km}$ & -23.3 & -23.3 & 0.0 & & -24.9 & -1.6 & \\
\hline $1-6 \mathrm{~km}$ & -126.9 & -128.0 & -1.1 & & -137.2 & -10.3 & \\
\hline
\end{tabular}

(Negative values indicate loss) 
$1 \times 10^{4}$ particles per em ${ }^{3}$, the effective loss is only $10.31 \mathrm{y}$ which $\mathrm{r} e \mathrm{p}^{\cdots}$ resents only about $2 \%$ of the total solar radiation absorbed in one day by such a cloud. At very high altitudes (the $10-11 \mathrm{~km}$ cloud) there is a slight relative gain of long wave radiation by the cloud. Thus, long wave flux should not have a significant effect on the net radiative energy gain of carbon seeded air. It is assumed, therefore, that virtually all radiation absorbed by the cloud will be directly converted into heat within the absorption 1ayer.

This finding agrees well with the results of a thermodynamic heat transfer analysis of the carbon particles by the author in which it was found that about $95 \%$ of the absorbed solar energy is conducted to the surrounding air while about $5 \%$ is emitted as long wave radiation. Part of the emitted radiation is reabsorbed by carbon particles and water vapor within the carbon cloud resulting in the very low net long wave radiative flux divergences found by Korb and Möller.

\section{e. Influence of surface albedo}

The effects of varying surface albedo upon total daily absorption were taken into account by applying the upward diffuse radiation field described earlier to the mid-latitude cloud model. The effects are the same for the tropical boundary layer cloud. Computations were made for surface albedo values $\left(A_{s}\right)$ of $0 \%, 10 \%, 20 \%, 30 \%$ and $50 \%$. The net absorption values are plotted as functions of particle concentration in Fig. 8. The increase in net absorption due to surface albedo is greatest between concentrations of about 500 and 1500 particles $/ \mathrm{cm}^{3}$ peaking at about 1000 particles $/ \mathrm{cm}^{3}(35 \%$ area coverage). It decreases with higher concentrations due to greater initial interception of light and hence lower reflected values. Even with a $50 \%$ surface albedo increase net absorption is changed by on $1 y 15 \%$ or 1 ess, 


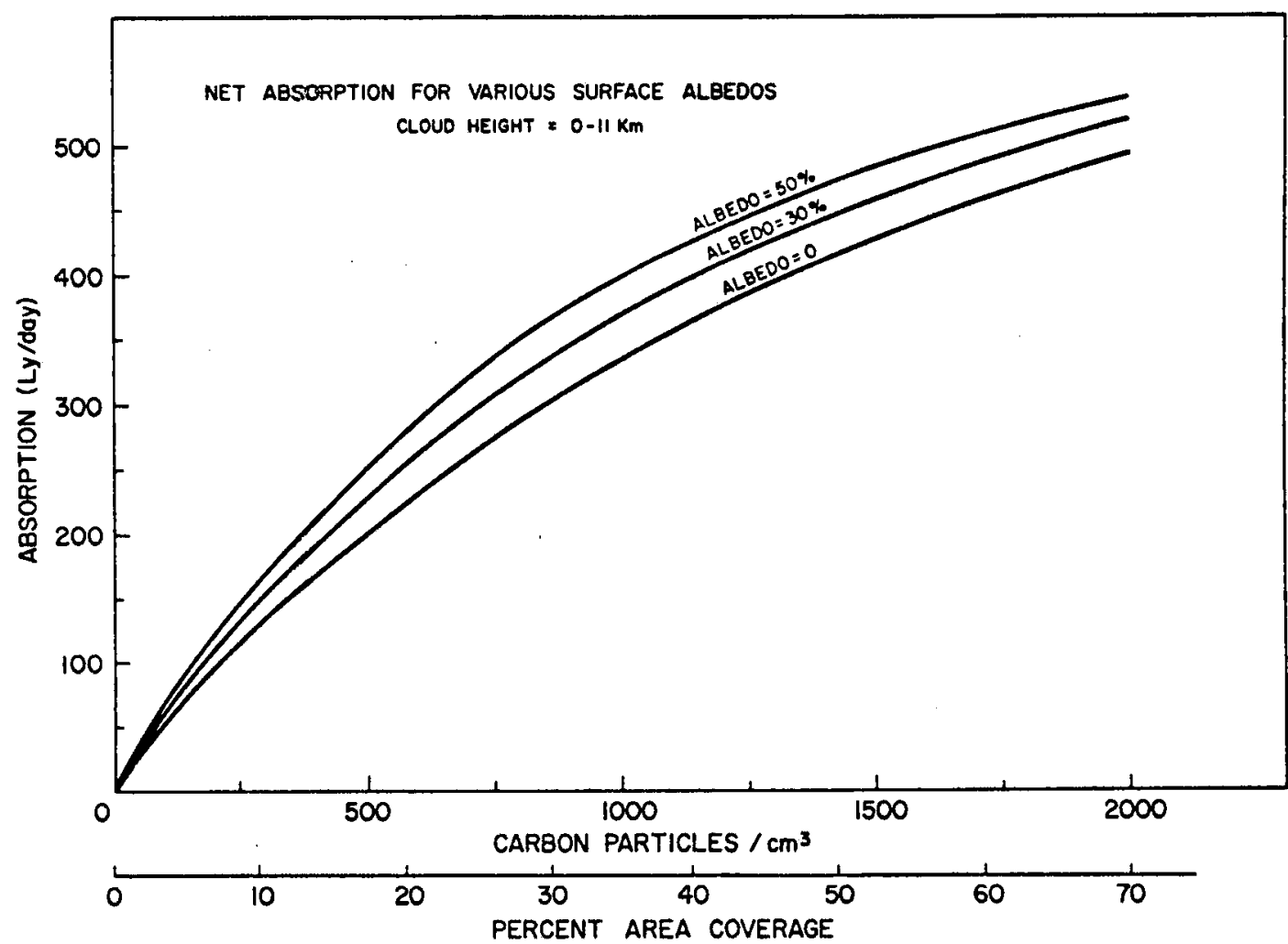

Fig. 8. Absorption of solar radiation by carbon particles dispersed over surfaces with various albedos.

Therefore, although the effects of surface albedo upon absorption are not negligible, they are low enough to be safely neglected in many situations without greatly affecting results.

f. Absorption distribution in the vertical

For application of this study to actual operations, it is necessary to know how the absorbed radiation is distributed vertically through the cloud. To obtain an approximation of this a $4 \mathrm{~km}$ thick cloud was divided into four directly adjacent $1 \mathrm{~km}$ thick layer clouds. For each carbon particle concentration, absorption in each cloud layer was computed, the top layer first, the top plus the second layer next, and so forth. By simple subtraction the amount of solar radiation absorbed in each layer was determined for this homogeneous cloud model. This cloud was located 
between $200 \mathrm{mb}$ and $100 \mathrm{mb}$. For simplicity and with previous demonstration of its small effect, water vapor absorption was neglected. Surface aibedo was also neglected. In this calculation the upward diffuse radiation field would have been reduced below values in the previous cloud model due to water vapor absorption of both the downward transmitted and the upward reflected radiation. Amounts absorbed in each layer are shown in Tanle 6. Total absorption is greatest in the upper layer and decreases in each succeeding layer as the amount of light incident at the top of each layer becomes less. As particle concentrations increase, the percentage of absorbed light which is absorbed in the upper layer increases sharply. Therefore, if vertically homogeneous heating is required, the particles must be distributed with lowest concentrations at the top increasing to the heaviest concentrations at the bottom of the cloud.

TABLE 6

ABSORPTION $(1 \mathrm{y} / \mathrm{cm}\}, 10 \mathrm{hr} 40 \mathrm{~min})$ IN EACH CLOUD LAYER

\begin{tabular}{|c|c|c|c|c|}
\hline \multirow{2}{*}{\multicolumn{2}{|c|}{$\begin{array}{c}C(\%) \\
\text { Cloud Levels } N\left(\frac{\text { Part }}{\mathrm{cm}^{3}}\right)\end{array}$}} & $50 \%$ & $126 \%$ & $252 \%$ \\
\hline & & 4000 & 10,000 & 20,000 \\
\hline \multicolumn{2}{|r|}{1.} & 171 & 349 & 528 \\
\hline \multicolumn{2}{|r|}{2.} & 126 & 179 & 168 \\
\hline \multicolumn{2}{|r|}{3.} & 96 & 164 & 69 \\
\hline \multicolumn{2}{|r|}{4.} & 75 & 64 & 34 \\
\hline mOT & $\mathrm{AL} \quad(100-200 \mathrm{mb})$ & 468 & 696 & 799 \\
\hline
\end{tabular}




\section{g. Particle size distribution in the vertical}

It was felt that due to relatively high extinction of light in the shorter wavelengths, the light incident upon lower layers of a carbon cloud would exhibit longer median wavelengths than would light incident upon upper layers. A significant increase in median wavelength would indicate that larger particles would be required to maintain optimum absorption per unit mass as determined from Fig. 3. The four layer cloud model from $200 \mathrm{mb}$ to $100 \mathrm{mb}$ was used to evaluate this effect. For each of 3 different carbon particle concentrations, light incident upon the top of each layer was estimated by subtracting previously absorbed light from initial incident light intensities for each spectral region. The median wavelength of light incident upon each layer was calcualted.

Computations were made for carbon particle concentrations of 4,000 , 10,000 and 20,000 particles $/ \mathrm{cm}^{3}$. The expected increase in wavelengths of solar light at lower levels did accur. In the most extreme case $(\mathrm{N}=$ 20,000 particles $/ \mathrm{cm}^{3}$ ) the increase in wavelength of incident light from the highest to the lowest of the 4 layers was $76 \%$, but this is a higher concentration of carbon than would probably be used in most types of applications. For the two lower concentrations wavelengths varied only $14 \%(\mathrm{~N}=4,000$ particles $\left./ \mathrm{cm}^{3}\right)$ and $39 \%\left(N=10,000\right.$ particles $\left./ \mathrm{cm}^{3}\right)$. In the lower parts of the troposphere, water vapor absorption in the longer wavelengths would reduce the amounts of the mean wavelength increases. From Fig. 3 it was determined that maximum absorption per unit mass would occur at $\alpha=0.7$ where $\alpha=\frac{2 \pi r}{\lambda}$. A $39 \%$ increase in wavelength would require a $39 \%$ increase in particle radius to maintain optimum absorption efficiency. Since initial optimum particle size was approximated as about $r=.1 \mu$, the optimum particles in the bottom layer of the model cloud would be about 
$r=.13 \mu$ for $N=4,000$ particles $/ \mathrm{cm}^{3}$ and $\mathrm{r}=.15 \mu$ for $\mathrm{N}=10,000$ particlẹs $/$

$\mathrm{cm}^{3}$. Particle size variations of these magnitudes do not have a significant effect upon total cloud absorption values.

In addition lower overall light intensities in the lower layers make the importance of having particles of optimum size less in lower layers. than in higher layers. Therefore, for carbon particle concentrations likely to be used in weather modification work, uniform particle sizes can be used without appreciable loss of absorption efficiency per unit mass.

\section{h. Atmospheric residence time}

It is desirable to know approximately how Iong dispersed submicron carbon particles are likely to remain in the atmosphere. The author discusses the probable residence times of carbon particles dispersed in air in paper IV. It was concluded that carbon particles dispersed in the low or middle tropical troposphere would have mean residence times of about 3 to 8 days. This indicates that carbon dispersed in an area with low ventilation (such as a closed circulation) could act as a heat source for more than one day. However, carbon dispersed in the tropical boundary layer would likely dissipate much faster due to the high levels of convective activity found there.

i. Major findings

Computations of daily absorption of solar radiation by several configurations of carbon clouds were performed. Carbon black was shown to be a highly efficient absorber of short wave radiation.

The optimum particle size for absorption of solar radiation was determined to be $r=.08 \mu$, but this exact radius is not extremely critical. 
Absorption per unit mass of carbon decreases with increasing carbon concentrations due to the screening out of radiation in the upper layers of the cloud. This effect greatly reduces absorption efficiency at carbon horizontal area coverages greater than about $25 \%$.

Clouds with low concentrations of carbon are relatively efficient absorbers throughout the solar day, while high density clouds are efficient absorbers per unit mass only when the solar zenith angle is small.

Redundant absorption tendencies of carbon and water vapor cause some loss of efficiency in carbon cloud absorption compared to absorption of the clear surrounding air. However, this effect is relatively small ( $0-14 \%$ 1oss) in most of the cloud configurations tested. This efficiency loss is negligable for carbon clouds in the tropical boundary layer.

The longwave radiation loss of a carbon cloud is not significantly greater than the longwave radiation loss by an equivalent clear air mass. Therefore, longwave flux divergence should not cause a heat loss by the carbon cloud relative to the surrounding air.

Virtually $100 \%$ of the solar radiation absorbed by the carbon particles is transmitted as heat to the surrounding air.

Increasing surface albedos can increase the absorption of carbon clouds, but the net gain is relatively small ( a cloud over a $50 \%$ albedo surface absorbs only $10-15 \%$ more radiation than a cloud over a $0 \%$ albedo surface).

In a relatively dense vertically homogeneous cloud most of the absorption occurs in the upper layers of the cloud. To obtain uniform vertical absorption the carbon must be distributed with concentrations increasing towards the bottom of the cloud. 
Although the median wavelengths of radiation incident on the lowest layers of the clouds are greater than that of incident solar radiation at the cloud tops, the wavelength shifts are not great enough to require the use of larger carbon particles in the lower cloud layers to maintain maximum absorption efficiency.

Carban particles dispersed in the troposphere should exhibit residence times of approximately 3-8 days. This would indicate that it may be possible to obtain heat for more than one day in cases where the carbon cloud is located in areas of weak ventilation. 


\section{CONCLUSIONS}

\section{a. Carbon black as an atmospheric hieat source}

The characteristic of carbon black which makes it attractive as an atmospheric heat source is the extraordinarily large amount of solar radiation per unit mass of carbon which can be absorbed and hence transmitted to the air. One gram of carbon can absorb more than 40 million calories of solar radiation in a single day. On the other hand coal, currently the cheapest of conventional combustible fuels, provides only about 7,000 cal per gram.

It is important to realize the amount of air temperature increase which is possible using carbon black. For example, in the tropical boundary layer $(1013-950 \mathrm{mb}), 1 \times 10^{5} \mathrm{~kg}$ of carbon black could be dispersed into a carbon cloud covering over 4000 square kilometers and extending from sea level to $950 \mathrm{mb}$ with a horizontal area coverage of $9 \%$. This cloud could provide enough heat to increase the temperature of the air within the seeded boundaries by about $8 \mathrm{C}$ per 10 hours. Table 7 shows several cloud configurations and possible cloud heating rates which could be obtained by dispersal of $1 \times 10^{5} \mathrm{~kg}$ of carbon black.

Among energy sources normally used by man only nuclear energy compares with carbon black as a source of energy per unit mass, and no known substance compares as a source of heat per unit cost. A 20 Kiloton nuclear explosion produces about the same amount of thermal energy that $1,000 \mathrm{~kg}$ of carbon black produces in 10 hours. The carbon is not consumed during the heat generation process, and if atmospheric conditions are chosen carefully, residence times of several days are possible with resulting increases in efficiency. The major expense to be expected when attempting to utilize carbon black as an atmospheric heat source is the cost of dispersal. Preliminary cost analysis indicates that 
the cost of air dispersal of large amounts of carbon black from aircraft would be 2-3 times the price of the carbon black itself. Even so, the available heat per unit cost is very large. The amount of solar heating per unit cost which can be realized using a carbon dust cloud seems to be large enough to permit cost effective large scale weather modification.

\section{TABLE 7}

TYPICAL TROPICAL BOUNDARY LAYER CARBON DUST INDUCED HEATING RATES

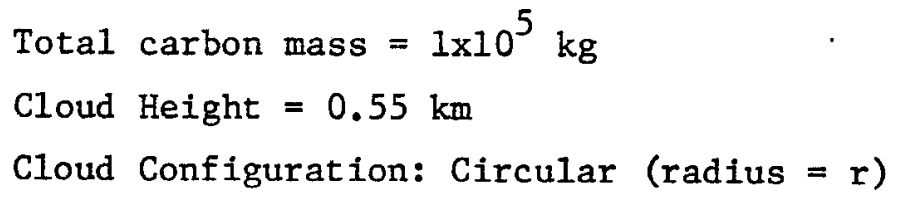

\begin{tabular}{|c|c|c|c|}
\hline Area & $\begin{array}{c}\% \\
\text { Area } \\
\text { Coverage }\end{array}$ & $\begin{array}{l}\text { Net Heat } \\
\text { Absorbed } \\
\left(\frac{\text { cal }}{\mathrm{cm}^{2} 10 \mathrm{hrs} .}\right)\end{array}$ & $\begin{array}{c}\text { Temperature } \\
\text { Change } \\
\left({ }^{\circ} \mathrm{C} / \text { lohrs. }\right)\end{array}$ \\
\hline $7200 \mathrm{~km}^{2}$ & $5 \%$ & 60 & 4 \\
\hline $4000 \mathrm{~km}^{2}$ & $9 \%$ & 110 & 8 \\
\hline $2000 \mathrm{~km}^{2}$ & $18 \%$ & 200 & 13 \\
\hline $1500 \mathrm{~km}^{2}$ & $26 \%$ & 270 & 18 \\
\hline $1000 \mathrm{~km}^{2}$ & $35 \%$ & 325 & 22 \\
\hline $680 \mathrm{~km}^{2}$ & $53 \%$ & 410 & 27 \\
\hline $510 \mathrm{~km}^{2}$ & $70 \%$ & 470 & 31 \\
\hline
\end{tabular}

Acknowledgements

The author wishes to express his gratitude to Prof. Myron Corrin for his aid with the thermodynamic analysis and discussion of the characteristics of carbon black and to Dr. Stephen Cox, Dr. Thomas McKee and $\mathrm{Dr}$. Thomas Vonder Haar for their assistance with radiative theory. Prof. William M. Gray proposed this research topic and acted as the author's overall research advisor. 


\section{REFERENCES}

Chandrasekhar, S., 1960: Radiative transfer. Dover Publications Inc., New York, 393 pp.

Dave, J. V. and P. M. Furukawa, 1966: Scattered radiation in the ozone absorption bands at selected levels of a terrestrial, rayleigh atmosphere. Meteorological Monographs, Vol. 7, No. 29, 270 pp.

Fenn, R. W. and H. Oser, 1962: Theoretical considerations on the effectiveness of carbon seeding. U. S. Army Signal Research and Development Laboratory Report No. 2258, 25 pp.

, 1965: Scattering properties of concentric soot-water spheres for visible and infrared light. Applied Optics, Vo1. 4, No.11, 1504-1509.

Korb, Gunther and F. Möller, 1962: Theoretical investigation of energy gain by absorption of solar radiation in clouds. Final Report on U.S. Army Signal Corp Contract No. DA-91-541-EUC$1612,185 \mathrm{pp}$.

Krascella, N. L., 1965: Theoretical investigation of the absorption and scattering characteristics of small particles. NASA Report No. CR-210, Office of Technical Services, Dept. of Commerce, Washington, D. C., 57 pp.

Marteney, P. J., 1965: Experimental investigation of the opacity of small particles. NASA Report No. CR-211, Office of Technical Services, Dept. of Commerce, Washington, 49 pp. 
Weather Modification by Carbon Dust Absorption of Solar Energy

Paper III: Generation of Carbon Particle Clouds

Charles A. Stokes, Sc.D.

157 Hun Road, Princeton, New Jersey 08540

(Consultant to Department of Atmospheric Science, Colorado State University Fort Collins, CO)

\begin{abstract}
This paper discusses the technology required to generate clouds of sub-micron size carbon particles and disperse them directly into the air from airborne, ground, or sea surface sources for use in largescale weather modification experiments. It is determined that it would be feasible to generate such clouds using existing afterburner equipped jet engines with relatively simple modifications.
\end{abstract}


Previous investigators (Downie and Smith, 1958; Fenn and Oser, 1962; Fenn, 1964; Smith et al., 1959; Van Straten et al., 1958; Wexler, 1958) have realized the enormous technical and economic potential for the use of solar intercepting clouds in producing weather modifications. For discussions of certain weather modification applications of a solar energy intercepting cloud of carbon particles and a sumary of some of the important previous research in this field, the reader is referred to the companion paper by Gray and Frank (Paper I). To date, however, there has been devised no practical means to create such clouds. The amount of energy that can be absorbed in one day by one pound of carbon particles suitably dispersed in the atmosphere is of the order of $7 \times 10^{7}$ btu ( $2 \times 10^{10}$ calories $)$ which is to be compared with the heat of combustion of carbon at about 14,500 btu. Except for atomic energy effects there is nothing else known that can produce heat effects of this order with the "consumption" of such a small amount of material. (We place consumption in quotes because the carbon is not actually consumed in the heat absorbing process.)

In this project we were seeking to establish beyond any reasonable doubt the feasibility of ground and airborne generation of clouds of carbon particles in the fraction of a micron size range at a rate of 1050,000 pounds of carbon per hour. Feasibility as used here means that al1 process steps and types of devices are now in use separately on a large scale so that, given adequate funds and the help of organizations and personnel highly skilled in each of the parts of the process, the basic engineering design of a full scale prototype unit could be started. It should be noted that generation of carbon dust clouds from surface sites (ground or ship based) is quite feasible using approximately the 
same equipment and technology as airborne sources. However, since airborne generation would greatly increase the number of possible applications, it is very important to demonstrate the feasibility of this particular method of generation. It will be assumed that demonstration of the feasibility of airborne generation will be sufficient proof of the feasibility of ground or sea surface (i.e. ship) based generation. The alternatives studied are listed below:

1) Redispersion of carbon made previously. Commercial carbon black has been taken aloft in various aircraft and has been dispersed into the air through venturi devices utilizing air flow to produce the necessary shear of particles for dispersion. This method is judged impractical for the large amount of carbon discharge required by this project. Between 200 and 1000 bags per hour of beaded carbon would have to be handled, opened, finely ground and fed through a disperser. While this might be done in a large aircraft (e.g. a Boeing 747), the cost of modifying and equipping the aircraft would be very large. A special crew of about 5 to 10 people would be required to handle the carbon in a plane. Degree of dispersion would leave much to be desired, and this alone could make this method impractical.

2) Carry aloft a commercial carbon black furnace. This alternative is not only more costly but presents weight and power problems. These could be solved in a very large aircraft, but the cost could be enormous.

3) Use of a ram jet engine. This could be done except that such engines are not currently in use. An afterburner is in effect a ram jet added to a turbine jet 
engine. We mention this possibility only to indicate that it has been considered.

4) Use of afterbumer type jet engines to generate carbon directly. This alternative was considered by far the cheapest, most effective, most convenient, and safest'alternative. It was therefore chosen for detailed study.

As clearly revealed in published patents, (J. C. Krejci, 1958; Burton F. Latham, Jr. and Robert G. James, 1967; Charles L. De Land, 1967; George F. Friauf and Brian Thorley, 1961a; George F. Friauf and Brian Thorley, 1961b), the carbon generation process essentially consists of burning a primary fuel with about $140 \%$ to $380 \%$ of theoretical air and then injecting into the hot, turbulent combustion products of the primary fuel a high molecular weight liquid hydrocarbon. A portion of the injected hydrocarbon and part of the hydrogen evolved from the hydrocarbon fuel burn instantly creating a highly luminous flame which is quenched from a theoretical flame temperature of some $3600-3800 \mathrm{~F}$ to an exit temperature of $2700-3000 F$ by the endothermic decomposition of that part of the hydrocarbon which is not burned. The decomposition products rapidly condense or polymerize into primary carbon particles which also tend to grow upon each other in chains much like a string of frogs eggs. The entire carbon forming process after injection of the hydrocarbon is complete in a matter of milliseconds. There are patented ways to control the chaining tendency so as to give smaller or larger agglomerates.

It is fairly evident that the afterburner of a jet engine sets up almost ideal conditions for injecting a liquid hydrocarbon fuel into hot primary combustion gases with some residual oxygen content. Missing only are adjustments in air ratios, provisions for injecting the hydro- 
carbon through suitably cooled nozzles, provision of an elongated afterburner shell in order to allow sufficient time for carbon formation and provision for supplemental cooling of the modified afterburner due to the highly luminous radiant flame. There may also be practical problems to be dealt with in protecting the aircraft body from too much heat from the streaming highly luminous flame. The feasibility of adapting an afterburner type jet engine to airborne carbon particle cloud generation is discussed in detail in a feasibiliț study project by the author (Stokes and Reed, 1973) and in Appendix B of this paper. Such an engine could be mounted easily on a portable test stand on the ground or on a ship for land or sea surface carbon generated.

It is necessary to have a stable, noncorrosive fuel which is 1iquid and pumpable at a reasonable temperature, preferably not much over 100F. This condition can be met with certain commerical carbon black fuels. Some of the regular aircraft fuel tanks can be used provided precautions are taken against possible damage of any rubber or plastic linings, fittings, seals, etc. by the carbon fuel. The fuel can be kept warm in the tank with electrical immersion heaters powered by the aircraft electrical system. The wattage required is very small.

Having deduced that we could use an afterburner type jet engine to produce the kind and quantity of carbon wanted, we next had to check our findings with engine manufacturers to see if our proposal could be accomplished in a practical fashion. The results were indeed gratifying. The opinion firmly expressed was that existing jet engines could be modified by lengthening the afterburner and that such an engine could be used in place. As an alternative to using engines that are wing mounted, a "flying test platform" could be used. This is a plane fit- 
ted with a device to lower a jet engine from the fuselage in flight, a commonly used method in engine development work.

An ideal aircraft would be a B-52 with its 8 afterburner engines, 4 of which could be modified. Some re-piping of the fuel tanks would also be required. During take off all engines would be used in the normal manner. In the air 4 engines would be switched to carbon production. The approximate conditions that would apply before and after modification of a typical large afterburner engine are shown in Figs. 1 and 2 .

We have concluded that by slightly modifying readily available jet engines carbon dust particles could be produced and dispersed into the air at a rate of $20-30,000$ pounds per hour per engine. Roughly half of the weight of the carbon fuel would appear as carbon particles resulting in a carbon particle production cost of about $4 c-6 c$ per pound. One pound of 0.1 radius carbon particles would contain approximately $4 \times 10^{16}$ particles, and 200 pounds of these particles dispersed in air can absorb over 100 calories of solar radiation per $\mathrm{cm}^{2}$ per day over a one mile square area $\left(4 \times 10^{12} \mathrm{cal} / \mathrm{mile}^{2}\right.$ day) heating the air accordingly. The operation would be safe and in every way feasible from the point of view of fuel combustion, mechanical and aeronautical aspects. Therefore, the carbon dust particles could be generated and dispersed from airborne sources as well as from land or sea surface sites. It is beyond the scope of this paper to go into the engineering details or costs, but these matters are under study. A program for the development and testing of prototype carbon particle generating engines using existing jet aircraft engines and test facilities has been proposed and outlined in a feasibility study report by the author and Reed (1973). 

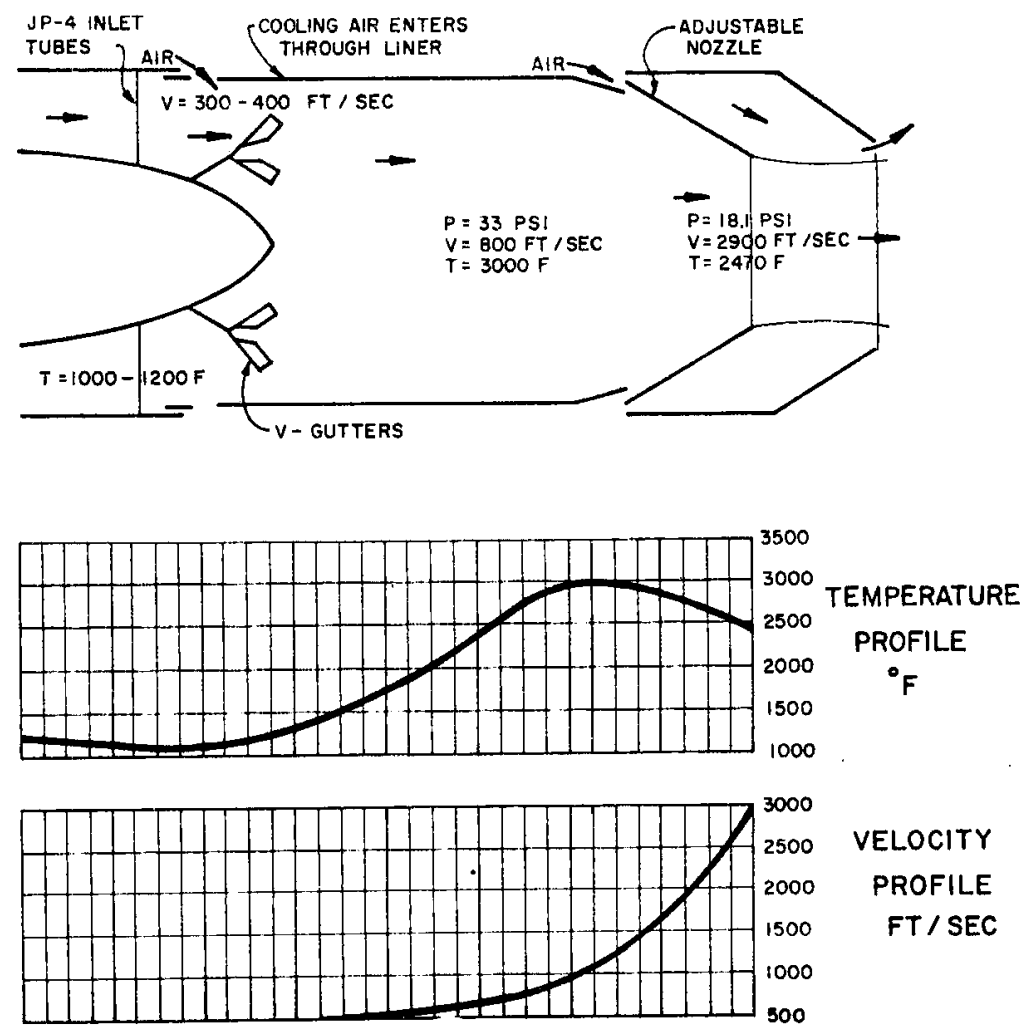

VELOCITY

PROFILE

FT / SEC

Fig. 1. Conditions existing in the afterburner and tailpipe assembly of a typical jet engine during afterburner operation (based on data for the J-57 and J-79 jet engines).
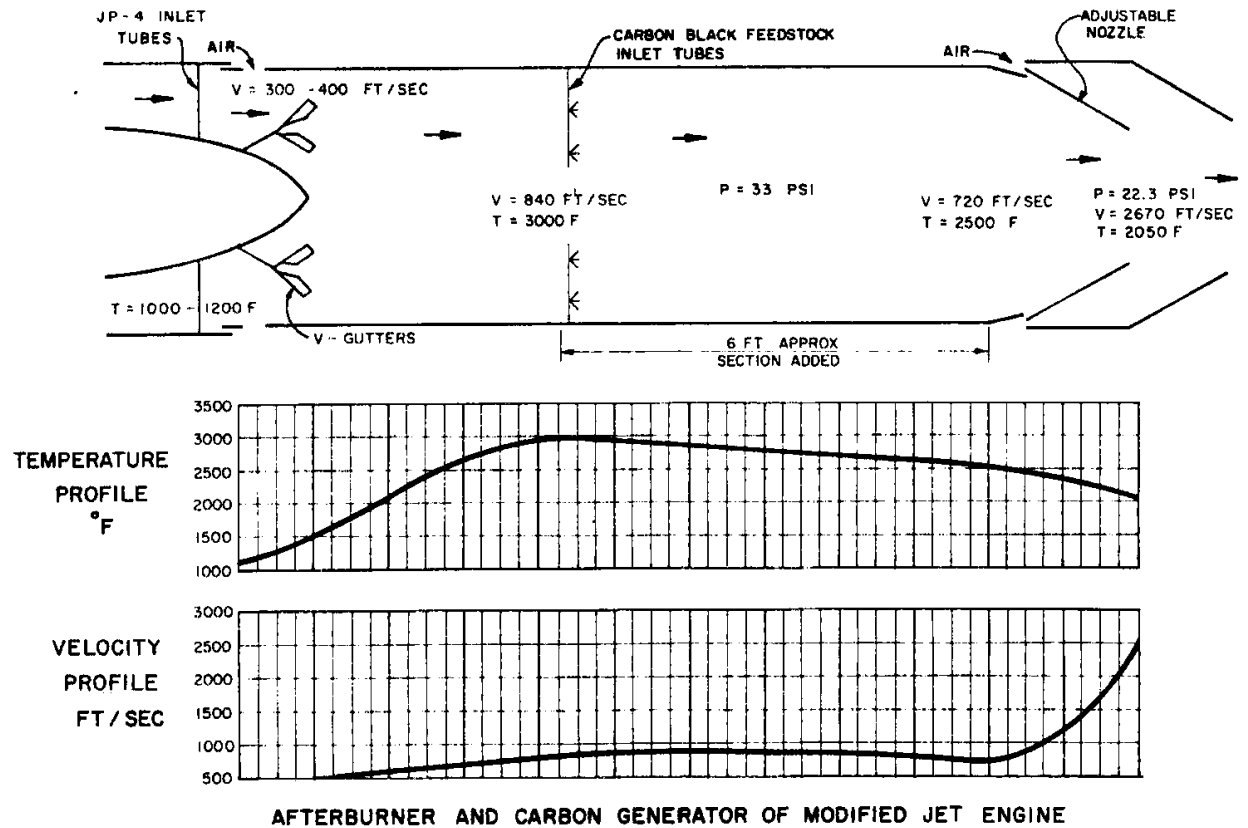

Fig. 2. Approximate conditions existing in the afterburner and tailpipe assembly of a jet engine modified for carbon production (based on estimates for the $\mathrm{J}-57$ and $\mathrm{J}-79$ jet engines). 
Fig. 3 shows how carbon dust would be generated and dispensed from a jet aircraft. Fig. 4 shows a carbon dust smoke plume being generated by an uncontrolled petroleum fire in Wyoming. This is typical of the type of carbon plume which would be used for weather modification. Note the shadow cast by the carbon plume.

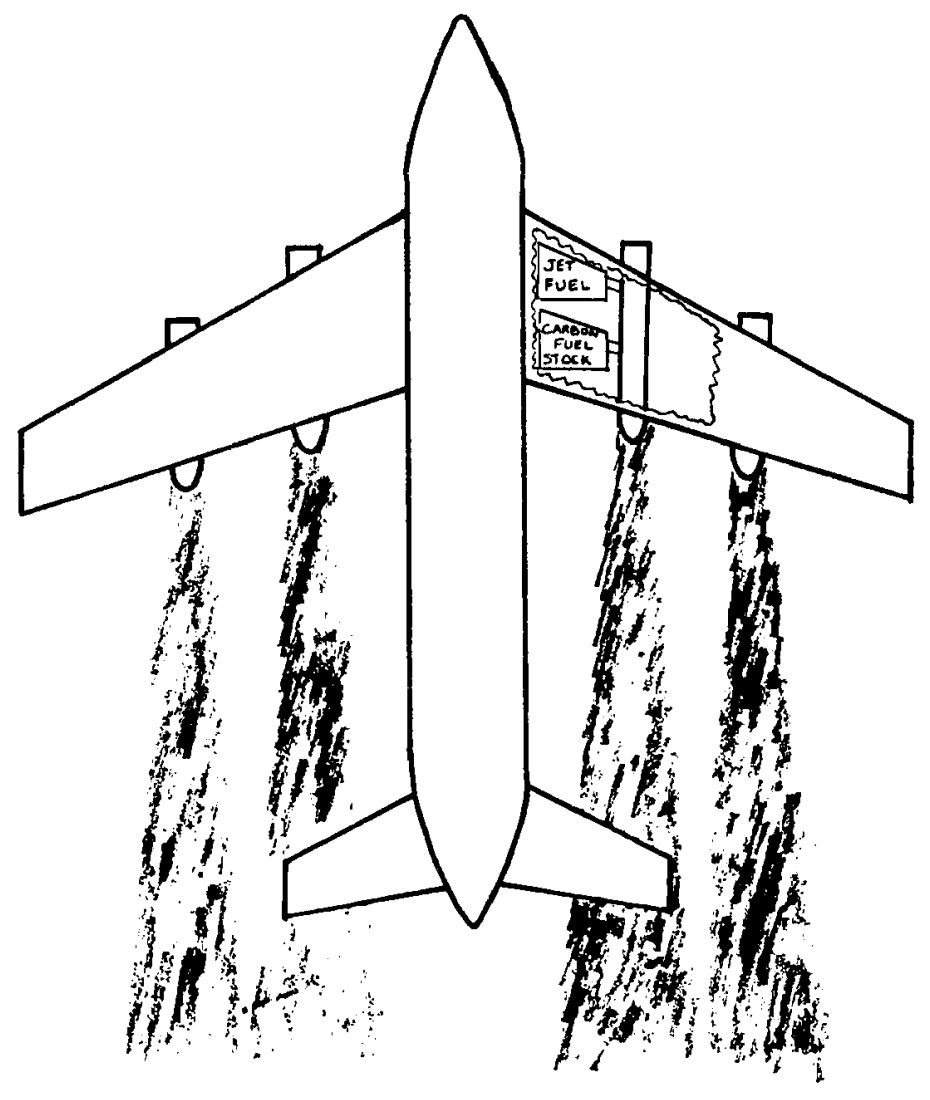

Fig. 3. Illustration of how carbon dust would be generated and dispensed from a jet aircraft. 


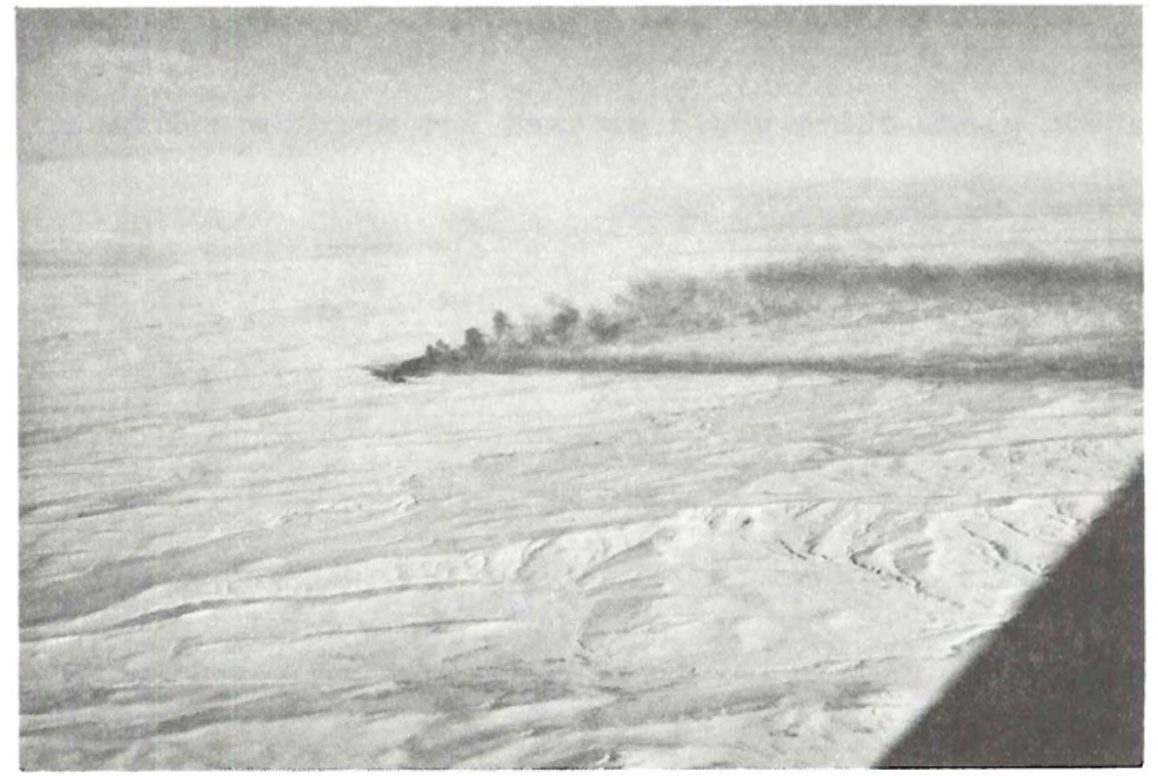

Fig. 4. Carbon dust smoke plume generated from an uncontrolled oil fire in Wyoming. 


\section{REFERENCES}

De Land, Charles L., 1967: U. S. Patent Number 3,301,639.

Downie, Major C. S., and R. B. Smith, 1958: Thermal techniques for dissipating fog from aircraft runways. Air Force Surveys in Geophysics No. 106, Air Force Cambridge Research Center, Bedford, Massachusetts, 38 pp.

Fenn, R. W., 1964: Theoretical aspects of carbon seeding. U. S. Army Electronics Research and Development Laboratories Report, 18 pp.

, and H. Oser, 1962: Theoretical considerations on the effectiveness of carbon seeding. U. S. Army Signal Research and Development Laboratory Report No. 2258, 25 pp.

Friauf, George F, and Brian Thorley, 1961a: U.S. Patent Number $3,010,794$

$3,010,795$

, 1961b: U.S. Patent Number

Krejci, J. C., 1958: U. S. Patent Number 2,865,717.

Latham, Burton F., Jr., and Robert G. James, 1967: U. S. Patent Number $3,353,915$.

Smith, R. B., R. Wexler, and A. H. Glasser, 1959: Modification of fog and cloud particles in the atmosphere. Allied Research Associates Inc., Final Report on Contract No. AF19 (604)-3492, 47 pp.

Stokes, C. A. and R. S. Reed, 1973: A feasibility study on the adaptation of an afterburner type jet engine to disperse sub-micron carbon particulates in the atmosphere for solar energy interception. A report prepared for Colorado State University, Atmospheric Science Department, $51 \mathrm{pp}$.

Van Straten, F. W., R. E. Ruskin, J. E. Dinger, and H. J. Mastenbrook, 1958: Preliminary experiments using carbon black for cloud modification and formation. U. S. Naval Research Laboratory Report No. $5235,17 \mathrm{pp}$.

Wexler, R., 1958: Seeding with carbon black. Allied Research Associates Inc. Documents No. ARA-553, 7 pp. 


\section{Weather Modification by Carbon Dust Absorption of Solar Energy \\ Paper IV: Environmental Impact}

William M. Frank and Myron L. Corrin

ABSTRACT

Large scale carbon dust weather modification operations will involve the introduction into the atmosphere of substantial quantities of carbon black particles and certain gaseous and particulate by-products of the carbon generation process. The effects of conducting a typical carbon seeding operation upon human health, long term atmospheric conditions, and the ocean and its ecosystem as well as esthetic considerations are discussed.

Carbon black particles are found to be essentially non-toxic to test mammals when ingested, placed in prolonged contact with skin, injected beneath the skin, or inhaled for any length of time and at any concentrations likely to be encountered during any carbon seeding operation. None of the by-products from the carbon generation process would be present in the atmosphere over populated areas at concentrations approaching Environmental Protection Agency (EPA) proposed standards. It was concluded that the generation and dispersal of carbon black particles and their by products into the atmosphere would not have any significant effect upon human health.

Atmospheric effects of carbon dust and its by products generated from carbon seeding operations would be insignificant with regard to alteration of global weather or climate, even if the operations were carried out as frequently as one per day.

Carbon dust which falls to the surface of the oceans would probably sink to the ocean bottom at a rate equal to or exceeding the Stoke's free fall velocity, and therefore, it should not alter the energy balance of the oceans. Being essentially non-toxic and inert, it should not affect the oceanic ecosystem.

Esthetic effects obviously involve highly subjective judgements. However, a typical carbon seeding operation should at most result in a temporary hazy appearance over populated areas which would be much less noticeable than the haziness of the air over most large urban areas. 


\section{INTRODUCTION}

It is probable that the carbon particles used in meso or synoptic scale operations will be manufactured as they are dispersed by the controlled incomplete combustion of some type of petroleum distillate. At this time, the exact nature of the products and the process to be used. are not known but the following estimates will be used:

For each pound of fuel burned, the products will be:

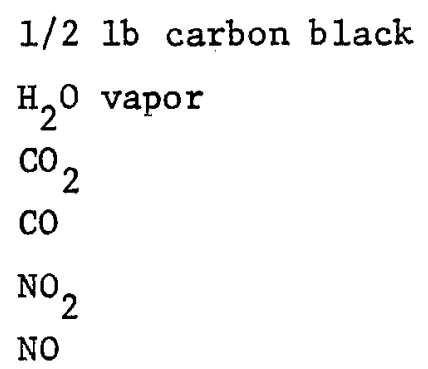

Various hydrocarbons in both gaseous and particulate form

The amounts of the various gases will be estimated later as will the nature of the hydrocarbons. This chapter deals with the physiological effects of the carbon particles and the possible ecological and climatic effects of all of the products. The physiological effects upon humans of $\mathrm{H}_{2} \mathrm{O}$ vapor, $\mathrm{CO}_{2}, \mathrm{NO}_{2}$, NO and $\mathrm{CO}$ are well documented. This section will show that the maximum potential concentrations of these gases will not be detrimental to human health. To evaluate the environmental impact of generating carbon particles and dispersing them into the atmosphere in relatively large amounts (1-2 million pounds per operation) it is convenient to divide the subject into five major areas. These are:

1) toxicity of the carbon black particles,

2) effects of the by-products of the carbon generation process upon human health,

3) 1ong-term effects of carbon black and its by-products upon the atmosphere,

4) impact of the carbon black dust upon the oceanic ecosystem, and

5) temporary esthetic effects of the carbon upon the local area.

Each of these areas will be treated separately below. 


\section{THE TOXICITY OF CARBON BLACK}

It is planned that the carbon particles used in weather modification work will probably be generated as they are dispersed by the incomplete combustion of fossil fuels. Until the actual apparatus has been designed and field tested, it will not be possible to determine the exact chemical composition of the carbon black produced. Therefore, this section is limited to discussion of toxicity studies performed with various existing commercial carbon blacks. The studies mentioned below employed carbon blacks of several different sizes produced by a variety of processes. It is felt that the carbon blacks generated in weather modification work would be essentially similar to some of these commercial varieties tested.

Present carbon weather modification proposals call for dispersal of carbon dust into the atmosphere over the sea about one day upwind of any major land area. Therefore, the initial carbon cloud (concentration of $40 \mu g / \mathrm{m}^{3}, 1 \mu g / \mathrm{m}^{3}=10^{-6} \mathrm{~g} / \mathrm{m}^{3}$ ) should diffuse to relatively low concentrations before encountering a populated area.

Carbon black particles are composed primarily of elemental carbon with variable amounts of oxygen, hydrogen, sulfur, and trace amounts of ash components. They are produced by the combustion of one or more hydrocarbons in an oxygen deficient environment and subsequent condensation of the carbon either in furnaces or in long rows of natural gas burners known as channels. Furnace blacks, which are of the most interest for the purposes of this study, are typically 95-99\% pure carbon. For most purposes, carbon black can be treated as a basically inert substance. The most complete study of the physiological effects of carbon black was performed by Nau, Neal, and Stembridge (1958, 1958, 1960, 1962) and 
was sponsored by the state of Texas. They studied the effects of:-
a) ingestion
b) skin contact
c) subcutaneous injection, and
d) intalation of carbon black by animals.

Fourteen different types of carbon particles ranging from approximately $.005 \mu$ to.$I \mu$ in diameter were used. These are the size ranges we propose for modification. Ten of the blacks were produced by variations of the furnace method (the process most likely to be used in weather modification operations), and four were manufactured by channel processes. The results of their tests are sumarized below.

\section{a. Ingestion of carbon black}

Carbon black was fed in large doses to a group of mice as part of their regular diet. Different groups were fed:

a) carbon as delivered from the manufacturer

b) carbon which had been extracted by hot benzene to remove certain hydrocarbons which had been absorbed by the carbon

c) a known carcinogen, and

d) carbon which had been allowed to absorb some of the known carcinogen.

Control groups were maintained on their normal diets. It was found that ingestion of large amounts of carbon black, as supplied by the industry or after benzene extraction, produced no changes from normal. Ingestion of the pure carcinogen produced abundant tumors in the mice, but eating carbon black which had absorbed some of the carcinogen caused no effects. Apparent1y, the carcinogen lost most of its toxicity when absorbed by the carbon. Carbon black appears to be harmless when ingested. This result is not surprising since carbon black has been used for years as a certified food coloring in certain foods (jelly beans, licorice, gum drops, etc.) with no reported ill effects. In addition, carbon black is capable of absorbing amounts of at least one carcinogenic hydrocarbon, greatly reducing the toxicity of that substance. 
b. Skin contact

The second phase of the Nau, Neal, and Stembridge (1958) tests dealt with possible effects of various types of carbon black upon prolonged skin contact. The results showed that there were no detectable changes from the normal in hamsters, mice, guinea pigs, rabbits, or monkeys regardless of the amount of carbon contacted by the skin or the exposure time.

c. Subcutaneous injection

Tests of the effects of carbon black when injected under the skin were performed on mice and rabbits to simulate the possible intrusion of carbon into the body through skin lacerations or abrasions. It was found that injecting carbon black under the skin caused no significant changes from normal. Certain hydrocarbons extracted from the carbon by benzene extraction caused tumors when injected, but these substances are apparently bound so tightly to the carbon that they cause no tumors when unextracted carbon is injected.

In separate lab tests carbon was suspended in solutions of blood plasma and of gastric juice for as long as 7 days. There was no significant elution of hydrocarbons from channel or furnace black suspended in either of these mediums.

\section{d. Inhalation of carbon black}

Hamsters, mice, guinea pigs, and monkeys were placed in dust inhalation chambers for 7 hours per day, five days a week. Monkeys were exposed to carbon black for up to 13,000 hours while the mice were exposed for virtually their entire lifetimes. Carbon black concentrations of $2400 \mu \mathrm{g} / \mathrm{m}^{3}$ for furnace blacks and $1600 \mathrm{\mu g} / \mathrm{m}^{3}$ for channel blacks were used. These concentrations are substantially higher than the carbon concentrations 
proposed for use in carbon black weather modification. Initial carbon concentrations during field operations would probably be on the order of $40 \mathrm{\mu g} / \mathrm{m}^{3}$ and would decrease steadily with time. This is $1 / 40$ to $1 / 60$ of the amounts that were used in the inhalation studies.

Results of the inhalation tests showed that there was measurable accumulation of carbon dust in the lungs of test animals only after breathing relatively large concentrations of carbon dust for exposure times greater than about 400 hours. No malignancies or other related disorders were encountered in test animals. These results indicate that inhalation of carbon black has no undesirable effects other than long term particle accumulation in the lungs. This accumulation represents a health hazard only when it occurs in the lower respiratory tract, particularly in the alveoli sacs of the lower lungs where oxygen and carbon dioxide are exchanged between air and the blood. As discussed in the National Air Pollution Control Administration Report No. AP-49 (1969) this intake and deposition of particles upon the alveoli is strongly size dependent. Fig. 1 from this report shows

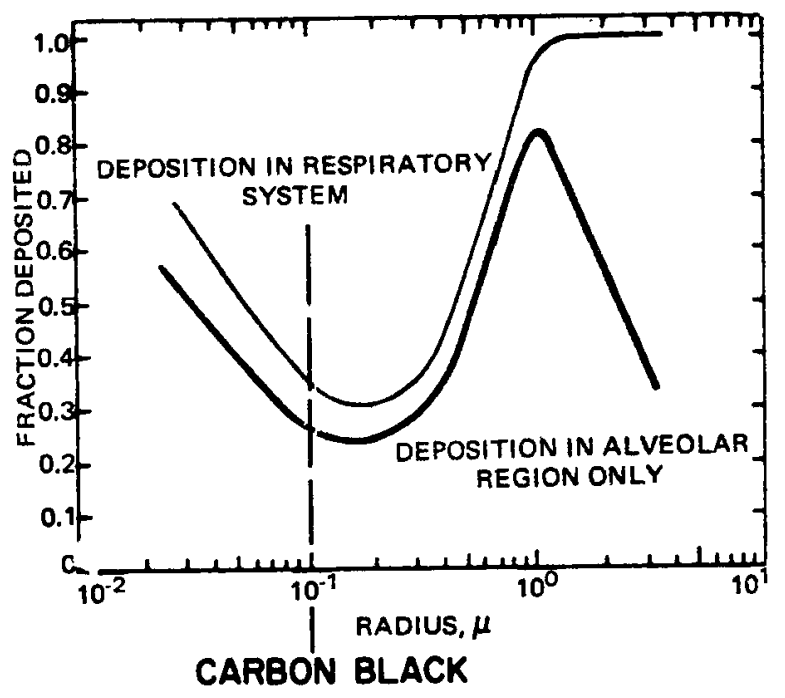

Fig. 1. Calculated fraction of particles deposited in the respiratory tract as a function of particle radius. (This figure represents the calculated efficiencies of deposition of particles of various sizes in the tracheobronchial and alveolar regions of the respiratory system, and shows the size for minimum efficiency.) (From NAPA Report AP-49, 1969). The broken line shows the $0.1 \mu$ carbon particles to be used. 
that there is a minimum efficiency in particle deposition within the alveoli for particles on the order of $r=.1 \mu$. These are the size carbon particles to be manufactured for weather modification operations. Therefore, the carbon particles used in this study are less likely to be retained in the alveoli than most natural or other man-made aerosols.

The Environmental Protection Agency (EPA) in the Federal Register of December 23, 1971, has set contaminants standards by mean geometric average of weight of particles per cubic meter. The minimum level representing the onset of undesirable particulate levels has been established as $70 \mu \mathrm{g} / \mathrm{m}^{3}$. By way of comparison, the particulate loadings of the proposed carbon experiment would initially be only about $40-50 \mu \mathrm{g} / \mathrm{m}^{3}$ (representing $10 \%$ equivalent horizontal area coverage by the carbon) and should decrease considerably due to diffusion and rainout before the carbon cloud would be advected inland over a populated area.

TABLE 1

Summary of NASN Suspended Particulate Samples for Urban Stations by Population Class, 1957-1963

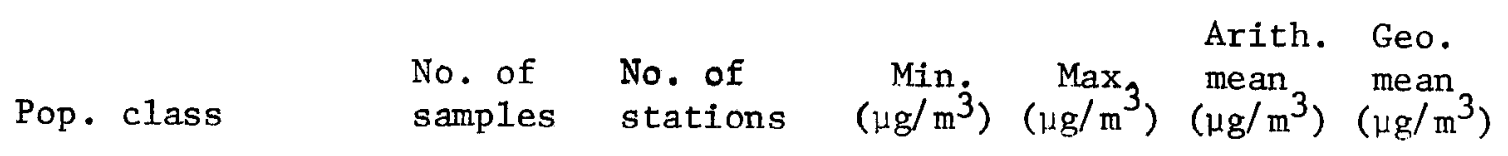

1. 3 million and over

2. 1-3 million

3. 0.7-1.0 million

4. 0.4-0.7 million

5. $0.1-0.4$ million

6. $50,000-100,000$

7. $25,000-50,000$

8. $10,000-25,000$

9. $<10,000$

316

519

1191

3053

9531

5806

1606

484

150

$\begin{array}{rrrrr}2 & 57 & 714 & 182 & 167 \\ 3 & 34 & 594 & 161 & 146 \\ 7 & 14 & 658 & 129 & 113 \\ 19 & 18 & 977 & 128 & 112 \\ 92 & 10 & 1706 & 113 & 100 \\ 81 & 6 & 982 & 111 & 93 \\ 23 & 5 & 679 & 85 & 71 \\ 6 & 11 & 539 & 80 & 63 \\ 5 & 22 & 396 & 100 & 84\end{array}$

Table from Stern, $1968, \mu \mathrm{g} / \mathrm{m}^{3}$ means micrograms per cubic meter $\left(10^{-6} \mathrm{~g} / \mathrm{m}^{3}\right)$. 
carried by the air) from the floor of the Atlantic Ocean off of West Africa by Chester (1972) indicate that the entire troposphere there is cleansed of the eolian dust in less than 10 days. More than $70 \%$ of the eolian dust particles measured are smaller than $4 \mu$ in diameter and were assumed to have been removed by precipitation scavenging, probably rain-. out. Figure 2 shows that natural aerosol particles range from about $.01 \mu$ to $100 \mu$ in size with the greatest number of particles being concentrated in the size range from .01 $\mu$ to .1 $\mu$ (Quanze1, 1970; Junge, 1955; Ikebe and Kawano, 1970; Junge and Jaenicke, 1971). Carbon particles of .1 4 radius should not differ greatly from mean atmospheric particles with respect to size. Although carbon particles differ in composition from most natural atmospheric aerosols, they should have aerodynamic properties similar to those of other basically inert particles. Therefore, an assumption that carbon particles dispersed in the lower troposphere $(1000 \mathrm{mb}-700 \mathrm{mb})$ would have mean residence times of but 3 to 8 days seems reasonable. Carbon particles dispersed in the oceanic tropical boundary layer would 1ikely dissipate more quickly than average due to the high levels of convective activity found there.

Carbon particles dispersed in the atmosphere may affect the global scale climate in two ways. They may slightly decrease the earth-atmosphere system albedo, and they could redistribute solar energy in the vertical if some of the carbon was to reach the upper atmosphere. Being basically inert and highly hydrophobic, the carbon should not cause any changes in condensation nuclei or ice nuclei concentrations. The albedo increase is due to the low backscatter of clouds of carbon particles (less than $2 \%$ for even a relatively dense carbon cloud) and their high absorptivity (Frank, 1973). A carbon cloud will absorb an appreciable amount of both incoming 


\section{LONG TERM ATMOSPHERIC EFFECTS}

To evaluate the long term atmospheric effects of performing one or more carbon weather modification operations, it is necessary to establish the approximate residence time of the carbon particles in the atmosphere as well as the physical effects of the carbon upon the earth atmosphere system. The principal mechanisms for removal of aerosols from the atmosphere are rainout (particles becoming attached to raindrops during the condensation process) and washout (particles being captured by falling raindrops during precipitation). Particles on the order of $r=.1 \mu$ will not fall out of the atmosphere from gravitational forces in any reasonable amount of time. Washout is an effective removal mechanism only for relatively large particles (larger than a few microns). Adam and Semonin (1970) have shown that for particles in the $1 \mu$ size range, a $0.5 \mathrm{~cm} / \mathrm{hr}$ rain will remove less than $1 \%$ of the particles per hour via washout. Kerker, et al. (1970) found that collection efficiencies (ratio of mass of particles swept out by falling droplet to total mass of particles in volume swept out by droplet) of $0.3 \mu$ particles by raindrops is only on the order of $.01 \%$. These results indicate that washout is a very inefficient removal mechanism for sub micron sized particles. Rainout appears to be the principal removal mechanism for sub micron aerosol particles. Peterson and Crawford (1970), using a large cloud diffusion code model with a precipitation scavenging option, found that rainout is a more important removal mechanism than washout for sub micron particles, but it is difficult to obtain accurate estimates of rainout efficiencies for specific particle sizes.

Martel (1970) estimated that natural atmospheric particles in middle latitudes have residence times of about 6 days in the lower to middle troposphere. Studies of sediment patterns of eolian dust (land derived dust 
upon humans. It may be concluded safely that there will be no hazard resulting from co during carbon manufacture. Nitrogen oxides and hydrocarbons would also be produced at levels significantly lower than proposed EPA standards. It should be noted that the estimate of $10 \%$ yield by mass of either of these two substances during the carbon manufacture process constitutes a very large overestimate of their likely concentrations. The above figures were chosen to demonstrate that even with a large margin of error local concentrations should not create a health hazard. Since the concentrations of all of the gases in Table 2 should be reduced by an order of magnitude before the carbon cloud is advected over land, it seems safe to say that the by-products of the carbon generation process should not create any important pollution problems. 
of $\mathrm{CO}$ and 400,000 1bs of nitrogen oxides and hydrocarbons will be assumed. A carbon cloud of this magnitude will cover approximately $40,000 \mathrm{~km}^{2}$ at $10 \%$ horizontal area coverage. The proposed cloud would extend from the surface to about $0.5 \mathrm{~km}$ when initially dispersed. The volume of the model cloud is approximately $2 \times 10^{13} \mathrm{~m}^{3}$. The concentrations of the by-product gases as initially dispersed together with proposed EPA standards are shown in Table 2. Particulate hydrocarbons are not differentiated

\section{TABLE 2}

Concentrations of Carbon By-Product Gases and Proposed EPA Standards

Gas Maximum Initial Dispersed Concentration

CO

$\mathrm{NO}, \mathrm{NO}_{2}$

Gaseous Hydrocarbons

$$
0.018 \mathrm{ppm}
$$$$
9 \mu \mathrm{g} / \mathrm{m}^{3}
$$$$
9 \mu g / m^{3}
$$

Proposed EPA Standards

9 ppm ( $\max 8$ hour concentration, not to be exceeded more than once per year). $100 \mu \mathrm{g} / \mathrm{m}^{3}$ (annual arithmetic mean) $125 \mu \mathrm{g} / \mathrm{m}^{3}(\max 3$ hour concentration, not to be exceeded more than once per year).

from other particulates in EPA standards. Their effect on the total particulate loading of the atmosphere is insignificant compared to the effects of the carbon particles themselves on that loading, and the particulate hydrocarbons will not be considered separately here. The effects of the carbon dust particles on atmospheric pollution levels are discussed elsewhere in this paper.

It is obvious that the carbon monoxide (CO) produced will be insignificant compared to proposed pollution standards. The concentration of $\mathrm{Co}$ produced would be far too small to have any physiological effect 


\section{HEALTH EFFECTS OF THE BY-PRODUCTS OF CARBON GENERATION}

The by-products of carbon black generation are water vapor $\left(\mathrm{H}_{2} \mathrm{O}\right)$, carbon dioxide $\left(\mathrm{CO}_{2}\right)$, carbon monoxide ( $\left.\mathrm{CO}\right)$, nitric oxide (NO), nitrogen dioxide $\left(\mathrm{NO}_{2}\right)$, and small amounts of various gaseous and particulate hydrocarbons. Since the exact fuel and generator design are not yet known, it is not possible to state exactly what proportions and amounts of each of these substances will be present. However, it is fairly well established that there will be at least $0.5 \mathrm{lb}$ of carbon produced from each pound of fuel consumed. Two of the gases, $\mathrm{CO}_{2}$ and $\mathrm{H}_{2} \mathrm{O}$, are not considered pollutants. Another, NO, is essentially non-toxic but is of interest because of its rapid conversion to $\mathrm{NO}_{2}$ in the atmosphere and because of its role in the formation of photochemical smog. For the purpose of estimating maximum effects, it will be assumed that $\mathrm{CO}$ will be produced in a quantity equal to $25 \%$ of the initial fuel weight and that the combined nitrogen oxides (NO and $\mathrm{NO}_{2}$ ) and the gaseous hydrocarbons will be produced equal to $10 \%$ of fuel weight. This should provide very generous overestimates of their concentrations. The resulting concentrations of these gases in the initially dispersed carbon cloud will be compared to the health standards proposed by the environmental protection agency. However, it should be noted that since the proposed weather modification operations would be carried out over the oceans at least one day upwind from coasts, the concentrations of the gases when they reach populated areas should be much lower, probably an order of magnitude more dilute. It is assumed that a large scale weather modification operation might utilize as much as 2 million 1 bs of carbon black requiring the consumption of about 4 million lbs of fuel. Using the above criteria, amounts of 1 million 1 bs 
Table 1 shows typical particulate loadings over different sizes of United States cities. It is clear that the carbon cloud, even at its initial concentration (10\% area coverage), represents a much smaller aerosol loading than would be found over any of these cities on an average day. This factor together with the low retention efficiency in the alveoli of $0.1 \mu$ size particles, the relatively short exposure time to be expected from advection of a carbon cloud over a populated area, and the nontoxicity of the carbon particles point to the conclusion that inhalation of carbon particles dispersed auring the proposed operation will not constitute a hazard to human health. 


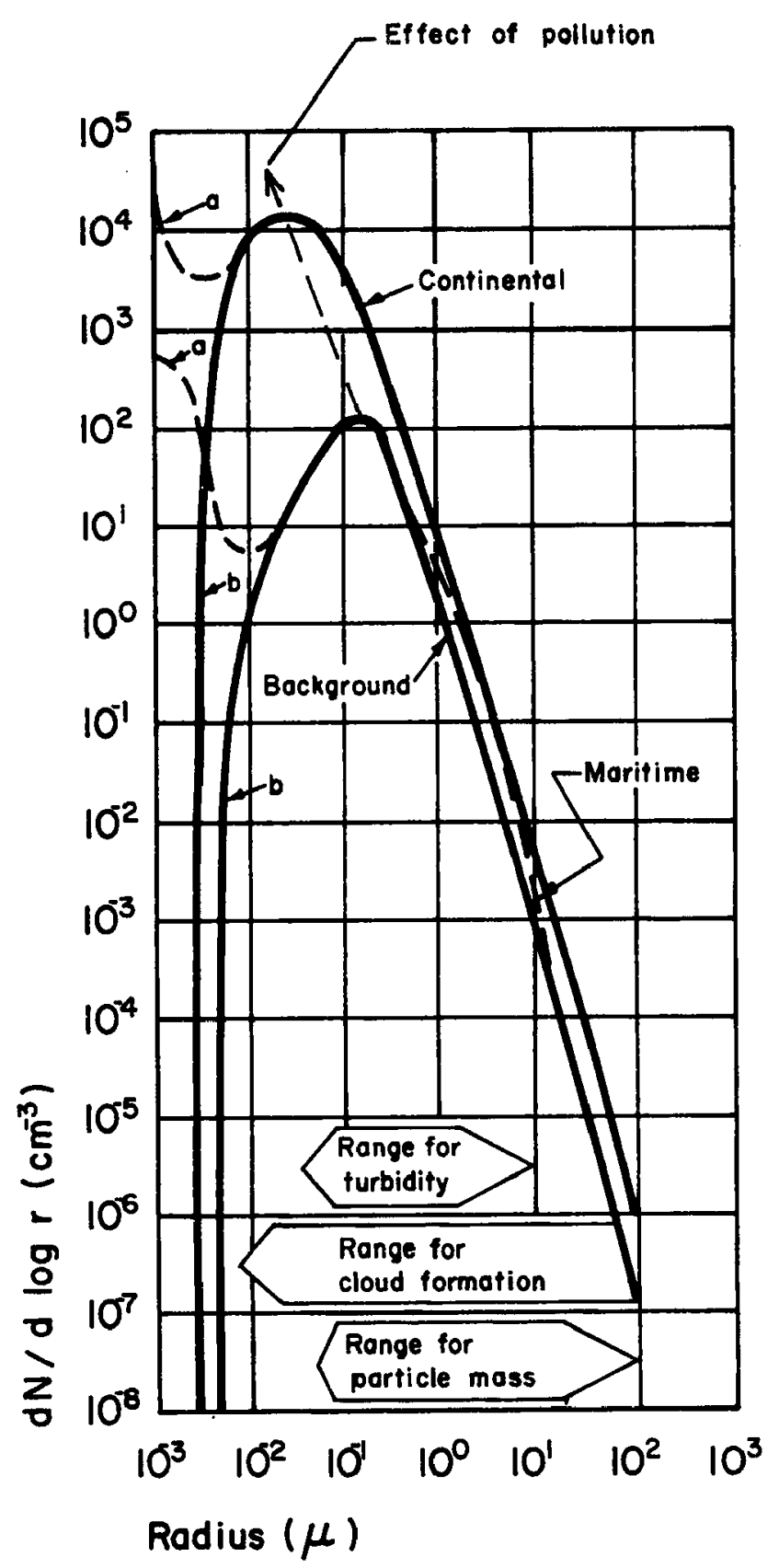

Fig. 2. Typical comprehensive size distributions for the principle tropospheric regimes and the size ranges important for turbidity, cloud formation, and mass concentration of particles. Curves $a$ and $b$ refer to possible variation of the size distribution with and without continuous production of very small particles. The arrow indicates the effect of pollution on the location of the maximum of the size distribution.

Source: Data from Quenzel, 1970; Junge, 1955; Ikebe and Kawano, 1970; Junge and Jaenicke, 1971. 
solar radiation and outgoing short wave radiation reflected from the earth's surface. Since the albedo of the carbon cloud itself is less than $2 \%$, the carbon particles should reduce the albedo of the earth-atmosphere system when located above virtually any normal surface type. (Carbon particles do not contribute significantly to the long wave radiative flux divergence of the atmosphere - Frank, 1973). The initial amount of solar radiation absorbed by the 2 million pounds of carbon dispersed in one operation is about $4 \times 10^{16} \mathrm{cal} /$ day assuming no loss of carbon during the first day. This figure is taken from the $40,000 \mathrm{~km}^{2}$ boundary layer cloud for about $10 \%$ area coverage by the carbon. Normally, about $10 \%$ of this absorbed radiation would be the net energy gain by the earth-atmosphere system due to the presence of the carbon cloud (assuming a surface albedo of about $20 \%$ and a carbon cloud albedo of $2 \%$ ). Hence, the net absorption gain of the atmosphere/earth system would be on the order of $4 \times 10^{15} \mathrm{cal} / \mathrm{day}$ for the first day and would decrease daily as the carbon was removed from the atmosphere. (Note that over the oceans, where the operations are most likely to be initiated, mean surface albedo is less than $20 \%$ resulting in still lower net energy gains). This figure is insignificant compared to the roughly $2 \times 10^{21} \mathrm{cal} /$ day of solar energy absorbed by the earth/ atmosphere system (Sellers, 1965). Even if enough operations were carried out to maintain this approximate leve1 of carbon in the atmosphere every day, the annual absorption by the earth/atmosphere system would only be increased by about $0.0002 \%$. It seems highly unlikely that any noticeable climatic change could result from such a small change in earth/atmosphere albedo. It is not too surprising that the addition of carbon to the atmosphere should have such a small effect on the earth's heat budget in view of the small fraction of the atmosphere's normal particulate loading which 
the carbon would constitute. Table 3 shows approximate masses of differer types of particles emitted into the atmosphere each year from natural and man-inade sources (Peterson and Junge, 1971).

\section{TABIE 3}

Mass per Year of Particulates Emitted into Atmosphere

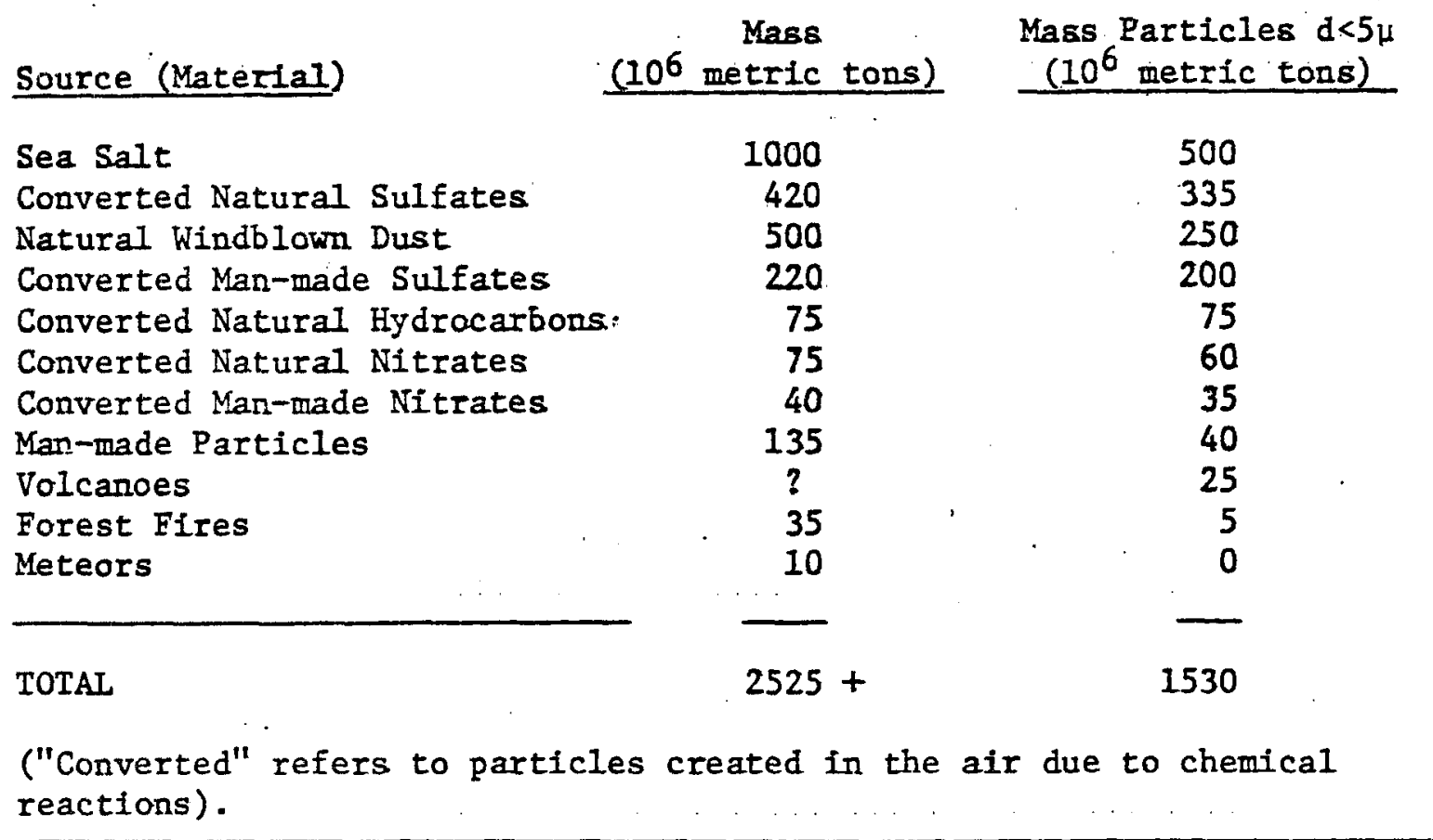

Each year about $1530 \times 10^{6}$ metric tons $\left(3.4 \times 10^{12} \mathrm{lbs}\right)$ of particles with diameters less than 5 i are emitted into the air. This is over a million times more than the amount of carbon to be introduced from one operation ( $\left.2 \times 10^{6} \mathrm{lbs}\right)$. It is inconcelvable that enough carbon seeding operations could be carried out in one year to have any noticeable effect on global particulate levels. At the present time automobile tires alone emit approximately $0.6 \times 10^{6}$ tons of carbon particles into the lower troposphere per year (Gray, 1973) due to the wearing down of the tread. (Automobile tire tread is approximately $50 \%$ carbon black by mass). There are also undetermined amounts of carbon black emitted into the air from 
combustion processes. Therefore, a single carbon seeding operation would not significantly alter even the annual amount of carbon particles emitted into the atmosphere.

One important area of interest concerning possible climatic effects of the carbon seeding involves the possible introduction of some of the particles into the stratosphere due to natural mixing processes. This area is of special interest due to the potentially long residence times (1-2 years) of small aerosol particles in the stratosphere. Since the carbon particles are to be dispersed in the lower troposphere, only a very small fraction of them would ever reach the upper atmosphere. The only activity of man at the earth's surface which appears to affect the particulate levels of the stratosphere significantly is the production of $\mathrm{SO}_{2}$ which can react to form sulfates as tropospheric air is mixed upwards (Kellogg, et al., 1971). The vast majority of particulates dispersed from the surface into the air are removed by precipitation scavenging. The exact amount of carbon which might possibly avoid scavenging long enough to reach the stratosphere is difficult to estimate, but it seems safe to say that it would be many orders of magnitude smaller than the amounts of particulates injected into the upper atmosphere periodically by volcanoes. One of the best documented of these eruptions was the. Mount Agung (Bali) eruption of 1963 which increased the dust content of the stratosphere up to 30 times and decreased solar radiation at the surface by about 1\% (Budyko and Pivovarova, 1971). Even this enormous injection of particulates into the stratosphere caused no noticeable changes in the temperature at the earth's surface during the 1-3 year residence time of the particles. It seems extremely unlikely that carbon seeding operations in the oceanic boundary layer could cause any measurable effect in stratospheric aerosal concentrations or energy balance. 


\section{CARBON IN THE OCEANS}

There has been some concern as to whether large amounts of carbon deposited on the ocean surface by precipitation scavenging would cause any detrimental effects to either the oceanic ecosystem or the physical characteristics of the sea surface. It seems likely that most of the carbon particles dispersed in the proposed seeding operation would fall directly onto the sea surface due to the amount of convective activity in the tropical oceanic boundary layer. Most of the particles so scavenged would agglomerate within the various precipitation drops to sizes on the order of $1 \mu$. Studies by Chester (1972) of eolian dust in the Atlantic off of West Africa indicate that the dust carried west from Africa by the north-east trade winds and deposited on the sea surface by precipitation scavenging apparently sinks to the ocean floor without significant lateral transport by ocean currents. This dust is primarily composed of particles less than $4 \mu$ in diameter. Stokes' Iaw would predict a fall rate of only about $1 \mathrm{~m} /$ day for a $4 \mu$ particle. By the time such a particle sank 100 ml it would have been transported some $4000 \mathrm{~km}$ by the North Equatorial current. Therefore, there must be some other mechanism for accomplishing the observed downward vertical transport of micron-sized dust particles. Deleny et al. (1967) has suggested that filter feeding organisms in the upper layers of sea water ingest the particles and then excrete them as fecal pellets wich are large enough to sink relatively rapidly. Smayda (1971) has concluded that this is a possible mechanism for accelerating the sinking rate of tiny particles. Osterberg et al. (1963) studied certain radionuclides with short half lives found in bottom feeding fish at depths of 2800 mi or mare and concluded that both organic and inorganic materials sink much faster than 
would be predicted by Stokes' Law. They too considered the filter organism theory to be a possible mechanism. The rained out carbon particles are generally inert and would be of the approximate size range of eolian dust deposited on the sea surface. Eolian dust is essentially hydrophilic while carbon dust is strongly hydrophobic. Hence, carbon particles would tend to remain on the sea surface somewhat longer than eolian dust particles. Once the particles become fully wetted, they should settle at a rate similar to that of the dust particles. Therefore, the overall time required for carbon particles to settle to the ocean floor should not be much longer than the 10-100 days (depending on particle size and ocean depth) required for eolian dust particles to sink. There should not be any significant buildups of carbon on the sea surface. If particles did accumulate on the ocean surface, they would tend to form larger aggregates and then settle to the bottom. Hence, there should be no significant alteration of the air/sea interface energy exchanges. The carbon will not remain long enough on the surface to have any effect on the distribution of absorption of solar radiation in the upper layers of the water. It is concluded that carbon seeding operations will not alter the physical characteristics or energy processes of the oceans.

There have been no direct studies done of the effects of carbon particles on the oceanic ecosystem. However, results of studies mentioned previously in this report indicate that carbon dust is non-toxic to a variety. of mammals. The carbon itself is nearly chemically inert. There is no reason to assume that ingestion of carbon particles should prove toxic to any of the forms of sea life. By the time the carbon from a seeding operation is rained out of the atmosphere and mixed with sea water, the concentrations of carbon would be too low to have any appreciable effect upon the normal concentrations of particulates in the micron size range found in the 
oceans. It does not seem possible that sea organisms could experience any ill effects due to excessive particulate concentrations in the water due to carbon seeding operations. The small amount of carbon dust would be processed by organisms in the same manner as the much larger amounts of naturally occurring dust materials are processed. It appears that carbon seeding operations of the scale envisaged would have no noticeable effect on the oceanic ecosystem. 


\section{ESTHETIC EFFECTS}

Perhaps the most frequent questions asked about the environmental effects of a carbon seeding operation concern the esthetic results of dispersing 2 million pounds of carbon into the air. It is natural for people to conjure up images of smokestacks in industrial cities belching out clouds of soot which fall over the city turning everything black. Fortunately, these images bear little resemblance to the effects of a carbon seeding operation.

The carbon particles dispersed during the proposed operation will be on the order of $0.1 \mu$ in radius. Particles of this size are not visible to the unaided eye and do not have an appreciable fall velocity when suspended in air. As a result, even if the carbon cloud was advected over a land area at the initially dispersed high concentrations, there would be no "fallout" of carbon particles dirtying the countryside. The uniformity of particle sizes of carbon manufactured by the furnace processes is quite good, so very few fallout sized particles would be produced. Those that were would probably fall out over the ocean in the day or more between the time the cloud is dispersed and the time the cloud is advected over land. Therefore, the esthetic impact of the carbon primarily concerns the appearance of the air containing the carbon.

In its initially dispersed concentration the carbon cloud would consist of a region approximately $200 \mathrm{~km}$ across and $0.5 \mathrm{~km}$ high (assuming a horizontal area coverage of approximately 10\%). The optical thickness of a vertical colum of the cloud would be about $\tau=0.1$. If an observer was located on the sea surface at the center of the cloud at noon, the sun would appear about $9 / 10$ as bright as it would from a 
point outside the cloud. Looking horizontally $90 \%$ of the light would be obscured from objects about $12 \mathrm{~km}$ away (assuming unlimited visibility outside of the cloud). The probable appearance would be that of a rather hazy day. Most main United States cities frequently experience days with visibilities lower than this. Typical dry haze visibility in Los Angeles is only about $8 \mathrm{~km}$ (Petterson, 1956). Carbon concentrations of the above magnitude would occur only at the initial site of the seeding. By the time the carbon cloud would be advected over a populated land area (one or more days) the concentration would be much lower. It is difficult to estimate exact dillution levels but based on diffusion estimates alone the concentration would likely decrease to $1 / 10$ or less of the initial cloud value after one day. Therefore, the concentration of carbon particles over populated areas should be on the order of $5 \mathrm{\mu g} / \mathrm{m}^{3}$ or less. This is considerably lower than the approximately $30 \mu \mathrm{g} / \mathrm{m}^{3}$ of particulates which is average for non-urban areas in the United States and the nearly $100 \mu \mathrm{g} / \mathrm{m}^{3}$ average for United States cities (Peterson and Junge, 1971). The esthetic effect of the carbon at most would be a slight reduction in visibility on the order of a few percent. Such a change would be scarcely noticeable since the day to day fluctuation in visibility over land areas is several times greater than the maximum carbon effect. In addition, the carbon cloud would continue to diffuse while over land, and by the end of 'the second day after dispersal it is doubtful if it would be visible at a11. It appears that there will be at mast a slight, temporary esthetic effect consisting of a small reduction in visibility with the appearance of a slight haze. There should be no other obvious effects of a carbon seeding operation sensed by people downwind from the seeding area except for the modification of the weather resulting from the operation. 


\section{SUMMARY}

\section{Summary}

Therefore, it is concluded that for the amount, concentration and location of the proposed carbon dust seeding, no significant environmental hazards should be encountered.

Acknowledgements

This research was financially supported by NOAA and NSF research grants. The authors appreciate the many beneficial discussions they have had with Dr. William M. Gray on the topic of this paper. 


\section{REFERENCES}

Adam, J. R. and R. G. Semonin, 1970: Collection efficiencies of raindrops for submicron particulates. U.S. Atomic Energy Commission Division of Technical Information, National Technical Information Service, U.S. Dept. of Commerce, Springfield, Virginia, 499 pp.

Budyko, M. I. and Z. I. Pivovarova, 1967: Influence of volcanic eruptions on the incoming surface solar radiation. Meteorologia 1 Hydrologia, 11: 301pp.

Chester, R., 1972: Geological, geochemical and environmental implications of the marine dust veil, published in Nobel Symposium 20 The Changing Chemistry of the Oceans, edited by Dyrssen and Jagner, Wiley Interscience Division, John Wiley and Sons, Inc., New York, 365 pp.

Deleny, A. C., D. W. Parlsin, J. J. Griffen, E. D. Goldberg and B. E. F. Reimann, 1967: Geochim. Cosmoclim. Acta, 31, 885.

Frank, W. M., 1973: Characteristics of carbon black as a large scale tropospheric heat source. Colo. State Univ., Dept. of Atmos. Sci. Research Report No. 195, 52 pp.

Gray, W. M., 1973: Feasibility of beneficial hurricane modification by carbon dust seeding. Colo. State Univ., Dept. of Atmos. Sci, Research Report No. 196, 130 pp.

Ikebe, Y. and H. Kawano, 1970: Dependence of the effective attachment coefficient of small ions upon the size of condensation nuclei. Pure and App1. Geophys., 83, pp 120-130.

Junge, C., 1955: The size distribution and aging of natural aerosols as determined from electrical and optical data on the atmosphere. J. Meteor., 12, pp 13-25.

Junge, C. and R. Jaenicke, 1971: New results in background aerosol studies from the Atlantic Expedition of the R.V. "Meteor", Spring 1969, (Submitted to J. Aerosol Sci.).

Kellogg, W. W., R. D. Eadle, E. R. Allen, A. L. Lazrus and E. A. Martell, 1971: Man's contributions are compared to natural sources of sulfer compounds in the atmosphere and oceans. Published in Inadvertent Climate Modification Report of the Study of Man's Impact on the Climate, M.I.T. Press, Cambridge, Mass., 308 pp.

Kerker, M., E. Matijeric, V. Hampl and D. Cooke, 1970: Collection efficiency of water droplets in AgCl Aerosol. U.S. Atmoic Energy Commission Division of Technical Information, National Technical Information Service, U. S. Dept. of Commerce, Springfiled, Virginia, 499 pp. 
REFERENCES (cont'd)

Marte1, E. A., 1970: Transport patterns and residence times for atmospheric trace constituents vs, altitude. Advances in Chemistry Series, 93, American Chemical Co., Washington, pp 421-428.

National Air Pollution Control Administration, 1969: Air quality for particulate matter. National Air Pollution Control Administration Publication No. AP-49, U.S. Dept. of Health, Education and Welfare, Public Health Service, Consumer Protection and Environmental Health Service, Washington, D.C., 211 pp.

Nau, C. A., J. Neal and V. Stembridge, 1958: A study of the physiological effects of carbon black: Part I. Ingestion. AMA Archives Industrial Health, 17, pp 21-281.

Nau, C. A., J. Neal and V. Stembridge, 1958: A study of the physiological effects of carbon black: Part II. Skin contact. AMA Archives Industrial Health, 18, pp 511-520.

Nau, C. A., J. Neal and V. Stembridge, 1960: A study of the physiological effects of carbon black: Part III. Adsorption and elution potentials subcutaneous injections. Archives Environmental Health, 1, pp 512533.

Nau, C. A., J. Neal, V. Stembridge and R. N. Cooley, 1962: A study of the physiological effects of carbon black: Part IV. Inhalation. Archives of Environmental Health, 4, pp 45-61.

Osterberg, C., A. G. Casey, H. Cur1, 1963: Nature, Land. 200, I276.

Peterson, K. R. and T. V. Crawford, 1970: Precipitation scavenging in a large-cloud diffusion code, Precipitation Scavenging (1970). U.S. Atomic Energy Commission Division of Technical Information, National Technical Information Service, U.S. Dept. of Commerce, Springfield, Virginia, 499 pp.

Peterson, J. T. and C. E. Junge, 1971: Sources of particulate matter in the atmosphere. Man's Impact on the Climate. ed. by Mathews, Kellogg and Robinson, M.I.T. Press, Cambridge, Mass., 594 pp.

Petterson, S., 1956: Weather Analysis and Forecasting. Vo1. II., McGrawHill Book Company, New York, 266 pp.

Quanzel, H., 1970: Determination of size distribution of atmospheric aerosol particles from spectral solar radiation measurements. J. Geophys. Res., 75, pp 2915-2921.

Sellers, W. D., 1965: Physical Climatology. Univ. of Chicago Press, Chicago, 272 pp.

Smayda, T. J., 1971: Marine Geo1., 11, 105.

Stern, A. C., 1968: Air pollution, second edition, Vol. I, Academic Press, N. Y., 694 pp. 
Weather Modification by Carbon Dust Absorption of Solar Energy Paper V: Evidence for Hypothesis and Proposed Research Program

William M. Gray and William M. Frank

\section{ABSTRACT}

This paper discusses various types of observational, theoretical and numerical modeling evidence which support the carbon dust hypothesis on mesoscale weather modification. Cost-benefit analyses are made. A recommended program of future research on this subject is proposed. 


\section{INTRODUCTION}

Papers II, III and IV have discussed the magnitude of the potential carbon dust heat source, shown the feasibility of direct carbon dust generation and dispersal, and indicated that the ecological impact is not likely to be a serious problem. Thus, we feel that this type of weather modification should now be given serious consideration. This paper discusses various types of observational, theoretical and early numerical modeling evidence which support the hypothesized types of atmospheric response expected from the proposed carbon dust mesoscale heat sources. Section 2 discusses the observational and theoretical evidence, section 3 the numerical modeling evidence. Cost-benefit analyses have been performed and are discussed in section 4. It is shown that very favorable cost-benefit ratios may be possible from this type of weather modification. A discussion of the scientific unknowns and potential problems and a recommended program of future research are outlined in section 5 . A proposed research program is presented in section 6. A comparison of this modification hypothesis with the current research with 'silver iodide' modification is made in section 7 . Scientific and humanitarian justification for this type of research is advanced in section 8 . 


\section{OBSERVATIONAL AND THEORETICAL EVIDENCE}

There are several natural phenomena which illustrate the formation of clouds and precipitation resulting from a localized atmospheric heat source. Although these phenomena differ in several ways from the proposed carbon dust heat source, some important analogies between the observed effects of natural heat sources and the expected effects of a carbon dust heat source can be made.

a. Heat island influences

Islands and peninsulas typically form daytime heat and cloud islands by giving off energy to the air passing over them. This often produces a sea breeze and/or daytime cloudiness over or just downwind from the islands and peninsulas. The surrounding sea areas typically have much less cloudiness. Satellite pictures clearly show that persistently high cloud concentrations are observed to occur over and just downwind from large tropical and sub-tropical islands.

Table 1 depicts the percentage of summertime cumulus cloud cover over various large tropical islands and peninsulas as compared with their surrounding bodies of water. In this study the water area considered was that surrounding the land with an area three times and a radius twice that of the land. As can be seen in this table the cloud cover over land is approximately three times that over the adjoining water. This is true not only for the average case but for most of the individual day cases as wel1.

There have been several observational and theoretical studies of the heat island effects of individual islands. Malkus (1963) showed that in the absence of synoptic scale disturbances, the small flat Caribbean island 
TABLE 1

\% of Cloud Cover Over Large Islands Or

Peninsulas

Jun JuI Aug

Land Bodies

(Dec) (Jan) (Feb) MEAN

West Pacific

Ocean

a) Taiwan

b) Hainan

c) Philippines

East Indian

$$
\text { Ocean }
$$

a) Sumatra

b) Borneo

c) Celebes

d) Java

e) New Guinea

Caribbean Sea
a)Yucatan
b) Cuba
c) Hispaniola
d) Puerto Rico

Madagascar

North Australia

TOTAL

$$
51
$$

$$
47
$$

42

$\underline{47}$

$\begin{array}{llll}35 & 34 & 37 & 35\end{array}$

$\begin{array}{llll}32 & 29 & 35 \quad \underline{32}\end{array}$

$\begin{array}{llll}41 & 41 & 29 & 37\end{array}$

$\begin{array}{llll}14 & 25 & 24 & 22\end{array}$

$\begin{array}{llll}36 & 35 & 34 & 35\end{array}$

\% of Cloud Cover Over Surrounding Water

Jun Ju1 Aug

(Dec) (Jan) (Feb) MEAN

$\begin{array}{llll}20 & 15 & 16 & 17\end{array}$ $\begin{array}{llll}14 & 15 & 10 & 14\end{array}$

of Anegada produced showering clouds over the island while no precipitation occurred from clouds in the surrounding ocean area. Malkus and Stern (1953), Smith (1957), and Estoque and Bhumralkar (1969) have developed numerical models of the heat island effect which show increasing tendencies for cloud formation with increasing island ground temperatures. One of the most complete studies of this effect was made by Bhumralkar (1972). He compared the results of his numerical model with observational data obtained over Grand Bahama Island on days with temperature, moisture, and 
wind conditions similar to the input values of his model. Computed and observed cloud and precipitation patterns agreed very well. This allowed some conclusions to be formed as to the nature of the heat island effect produced by the $10 \mathrm{~km}$ wide island in the presence of a prevailing cross island wind. It was found that in the absence of synoptic disturbances, the heated island perturbed the atmosphere enough to cause rainfall on the leeward side of the island or just off the leeward shore. The strength of the created disturbance increased with higher island temperatures and lower wind velocities. It was unexpected that a 10 by $130 \mathrm{~km}$ island could actually produce precipitation from its heating cycle alone.

The heat island effect differs from the proposed carbon dust heating scheme in two major ways:

1) The heat island is stationary and can provide heat to a given air mass only during the time the air is over the heat source. With windy conditions the air may not be over the island for a very long period of time. By contrast, the carbon dust travels with the air mass and heats it throughout the day. Air motion does not matter.

2) Carbon dust conducts heat to the air mass directly while the transfer of heat from a heated island surface to the air by conduction, convection and infrared radiation is a slower, more inefficient process. Daytime heating often lags considerably behind the sun, particularly when surface moisture is present and solar energy goes into evaporation.

Since tropical island heat sources appear to be sufficiently strong to cause clouds and precipitation to form on days with no synoptic disturbances, it seems likely that the more efficient carbon dust heat source 
covering a larger area might also develop deep cumulus convection and precipitation in certain situations.

Other evidence of cloud formation due to local heating of the lower atmosphere was presented by Purdom (1973). His study of satellite photographs over the United States showed that areas which are free of early morning cloud cover and which are wholly or partially surrounded by regions with early morning clouds are preferential areas for the development of thunderstorms and meso-scale convective systems. It was concluded that the differential solar heating between the clear and cloudy areas was responsible for the organization of strong convection in those areas which were free of morning cloudiness. It seems reasonable that differential heating of the lower atmosphere by a carbon dust cloud might result in similar dynamic responses.

Henz (1974) has recently studied the areal distribution of spring and summer cumulonimbus genesis relative to the Colorado Plains and the Front Range of the Rocky Mountains. Fig. 1 and Table 2 from his paper show the much higher incidence of thunderstorm (TRW) genesis over the elevated terrain features on the western edge of the Plains. This higher TRW frequency is believed to result from the terrain induced elevated heat sources which produce steeper lapse rates and enhanced upslope convergence. These elevated sources or "Hot Spots" produce more than seven times as many TRW's per unit area as the Plains region to the east. The question then arises as to whether it is possible to artificially generate similar types of elevated heat sources using carbon dust dispersed from aircraft?

b. Urban heat island effect

Recent studies of the effects of large urban areas upon their local environments have shown that precipitation amounts and thunderstorm 


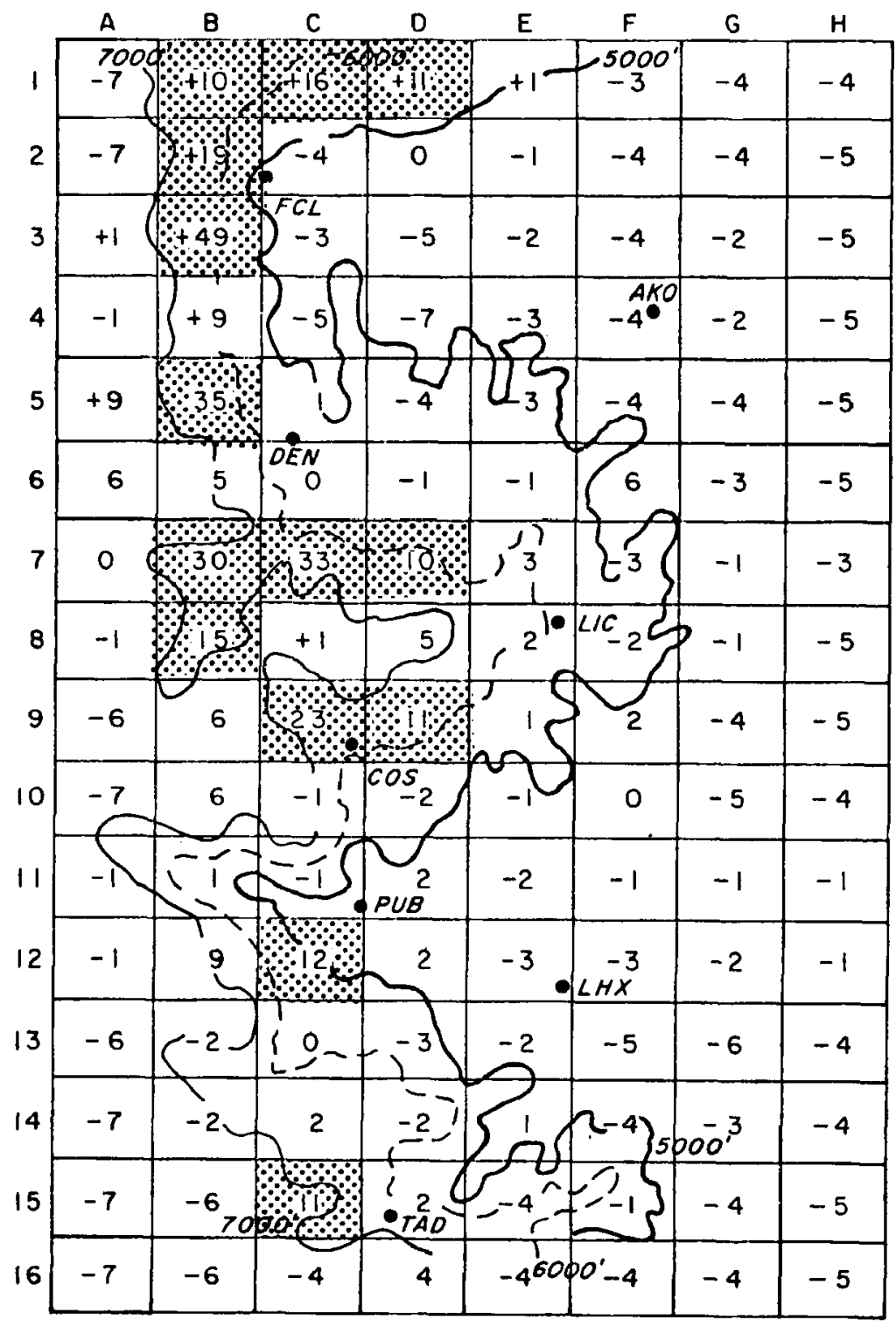

Fig. 1. Number of thunderstorm echoes generated in the eastern half of Colorado by each $30 \times 45 \mathrm{~km}$ rectangular box above the mean of all grid boxes for 1970-71. Values higher than 10 have been shaded. These have been denoted as 'Hot Spots' (from Henz, 1974). 
TABLE 2

Relationship of Thunderstorm Initiation to Elevation (from Henz, 1974)

\begin{tabular}{|c|c|c|c|c|c|}
\hline Location & $\begin{array}{l}\text { No. of } \\
\text { Blocks }\end{array}$ & $\begin{array}{l}\text { Percent } \\
\text { Area } \\
\end{array}$ & $\begin{array}{l}\text { No. of } \\
\text { TRW } \\
\end{array}$ & $\begin{array}{c}\text { Percent } \\
\text { TRW } \\
\end{array}$ & Ratio $\frac{\operatorname{TRW}(\%)}{\operatorname{Area}(\%)}$ \\
\hline Plains < $5000^{\prime}$ & 66 & 52 & 263 & 28 & 0.54 \\
\hline $5000-9000^{\prime}$ & 62 & 48 & 684 & 72 & 1.49 \\
\hline $5000-7000^{\prime}$ & 35 & 27 & 525 & 55 & 2.05 \\
\hline $7000-9000^{\prime}$ & 27 & 21 & 159 & 17 & 0.80 \\
\hline "Hot Spot" & 14 & 11 & 383 & 41 & 3.68 \\
\hline TOTAL & 128 & 100 & 947 & 100 & \\
\hline
\end{tabular}

frequencies and intensities tend to be greater immediately downwind from certain cities than in the upwind sectors (Changnon and Huff, 1973; Changnon, 1968; Beebe, 1972; Atkinson, 1968). The urban industrial areas affect the environment through the release of sensible heat, aerosols, moisture, by altering low level turbulence patterns, and by altering the natural land/air energy transfer characteristics. It is extremely difficult to obatin quantitative measurements of the magnitudes of all of these effects, but the primary dynamic effect of an urban area is generally considered to be the creation of an artificial heat island. In the presence of a moderate prevalling wind, this heat island takes the form of a hot plume as the city heats the air advecting over it.

It is interesting to compare the relative magnitude of the sensible heat emitted into the air in large urban industrial areas due to energy consumption with the heat added to the air by carbon particles during an operation of the magnitude envisaged $(\sim 1,000,000 \mathrm{Kg}$ of carbon over $\sim 4 \times 10^{4} \mathrm{~km}^{2}$ ). Although energy consumption is not the only heat source of an urban area, it will be assumed to be the dominant source for the very large areas $\left(\sim 4 \times 10^{4} \mathrm{~km}^{2}\right)$ discussed here. This is due to a large pro- 
portion of such urban areas consisting of suburban type areas not too unlike the surrounding countryside with respect to surface characteristics. Table 3 shows approximate energy consumption density levels for several large urban industrial areas estimated by Flohn (1971). The carbon modification operation would encompass an area of about $40,000 \mathrm{~km}^{2}$ or more, but it is doubtful if there are any industrial areas of this size with enough heat concentration to act as a single heat source (the Washington-Boston megalopolis apparently acts as a series of heat islands). Consider a hypothetical urban complex of maximum impact with an upper size limit of $10^{4} \mathrm{~km}^{2}$ and a maximum expected energy consumption rate of about 10 watts $/ \mathrm{m}^{2}$.

TABLE 3

Urban/Industrial Area

Nordrhein-Westfalen

Industrial Area

Los Angeles County

Los Angeles, City

21 Metropolitan Areas

(Washington-Boston)
Area

$\left(\mathrm{km}^{2}\right)$

10,300

10,000

3,500

87,000

200

$\sim 40,000$
Energy Consumption (watts $/ \mathrm{m}^{2}$ )

10.2

7.5

21.0

4.4

Cincinnati 26.0

Proposed Carbon dust heat island

Even if light prevailing winds of only $10 \mathrm{~km} / \mathrm{hr}$ are assumed, the average contact time of air parcels with the heat source would be only about 5 hours during a 10 hour period. By comparison, a carbon cloud with $10 \%$ horizontal area coverage would add heat to the air at an average rate of about 110 watts $/ \mathrm{m}^{2}$ for a 10 hour period. In addition, the carbon heat source is advected along with the air so that the air is heated continuously for the entire 10 hours. Therefore, the air is heated over 20 times as much by a carbon cloud as it is by the energy consumption of a 
large urban heat source during a 10 hour daylight period. The carbon cloud also covers about 4 times as large an area as the largest urban industrial complexes resulting in a total heat addition to the air 50-100 times greater than that of the large hypothetical urban area. Many of the urban areas which apparently affect their downwind climate (e.g. St. Louis, Cincinnati) are an order of magnitude smaller than the hypothetical urban area discussed.

It is encouraging that a heat source as relatively small as an urban heat plume apparently can cause increases in convective activity and precipitation in certain locations, although the relative importance of the heat island effect and cloud physics effects are not well understood at this time. It seems likely that a heat source of the magnitude proposed for carbon dust operations would, if placed selectively in the atmosphere, cause a much greater atmospheric response.

c. Tropical cloud cluster characteristics and modification potential

As discussed by Gray (1972), Williams and Gray (1973) and Ruprecht and Gray (1974), typical tropical cloud clusters with meso-scale rainfalls of 2-4 cm/day usually occur in association with very weak pressure-wind systems. Cloud cluster surface pressure anomalies are but 1-2 mb. Wind speeds are hardly different than in the surrounding clear areas. These cloud clusters have mean tropospheric temperature anomalies of but a small fraction of $1 \mathrm{C}$. The net available potential energy (both thermal and moist) of such clusters is hardly different from the available potential energy which is theoretically possible from a carbon dust heat source of 1-2 million $\mathrm{Kg}$. Therefore, it does not seem unreasonable that if atmospheric thermal stability is in a conditionally unstable state, a carbon dust energy triggering mechanism might indeed act to generate or enhance a tropical cloud cluster system. 
If carbon dust is spread at an areal coverage of 10 percent, then extra artificial heating amounts as large as $110 \mathrm{cal} / \mathrm{cm}^{2}$ per 10 hours are possible. This amount of energy is portrayed on the tephigram in Fig. 2 . A decided buoyancy advantage would be gained for cumulus convection. The solar absorption by carbon dust is but one influence. This extra heating should, as discussed in Paper I, also stimulate an increase of evaporation. The increased surface warming will stimulate an extra downward mixing of dryer upper level air to the ocean. This dryer air will increase the water vapor pressure difference between the ocean and the air and lead to increased evaporation rates. The potential buoyancy of the low levels will thus be enhanced not only by the additional low-level warming, but also by the extra water vapor content from the extra evaporation. If introduced on the meso-scale, this artificial energy source should lead to significant development or enhancement of tropical or sub-tropical cloud clusters.

d. Hurricane modification

The dynamics of a vortex or hurricane circulation requires that a low level inflow be continually present to balance surface frictional retardation. Other things being equal, the strength of the vortex is directly related to the lower tropospheric vertical stability. If conditions are very stable, then the inflowing low level air cannot easily rise in cumulus convection and a higher percentage of inflowing air penetrates to small radii. Angular momentum conservation dictates that the inflowing air reach a high velocity. If more unstable conditions are present, then a smaller amount of inflow mass will penetrate to near the storm center. Much of the inflowing low level mass will, instead, rise in cumulus convection at further out radii. The inner core circulation will 


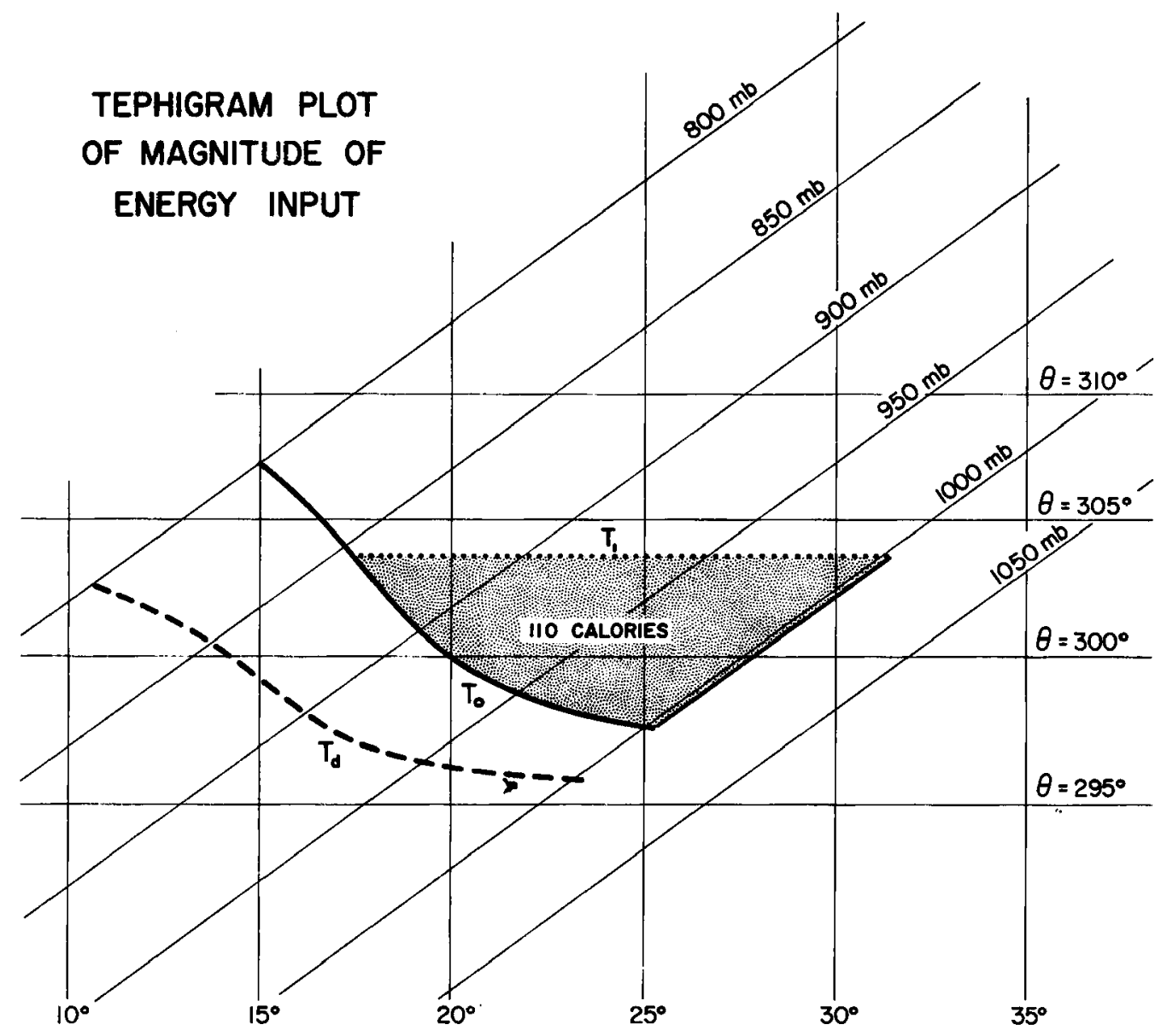

Fig. 2. Tephigram plot of temperature $\left(T_{0}\right)$ and dew point $\left(T_{d}\right)$ for a typical sumertime tropical or sub-tropical sounding. The extra energy input (shaded area) to the low levels in ten hours ( 110 calories $/ \mathrm{cm}^{2}$ ) that results from solar absorption due to 10 percent area coverage of carbon dust is shown.

consequently be less intense. Direct and inferred observational evidence for both the hurricane-typhoon and the tornado agrees with this general physical assessment.

The absolute angular momentum $\left(M_{a}\right)$ of a parcel when expressed in a cylindrical coordinate system with the origin at the hurricane center is given by:

$$
M_{a}=u r+f r^{2} / 2
$$


where $r=$ the radial distance from the center of the vortex,

$u=$ the tangential wind velocity, and

$\mathrm{f}=$ Coriolis parameter.

Absolute angular momentum decreases towards the hurricane center. This decrease is due to exchange of momentum between the air and the ocean. This shows that a hurricane represents a strong sink region of angular momentum.

Riehl (1963) and Gray and Shea (1973) have noted that beyond the radius of maximum wind the hurricane radial profiles of tangential wind can typically be approximated by an equation of the form,

$$
\mathrm{ur}^{\mathrm{x}}=\text { constant }
$$

where $\mathrm{x}$ is equal to $\sim 0.5$.

Fig. 3 portrays the inward radial increase of wind velocity from boundary layer inflow starting with a velocity of $15 \mathrm{~m} / \mathrm{sec}$ at $400 \mathrm{~km}$ radius. A parcel conserving its angular momentum follows the top curve. The lower curve represents the increase of wind in the real storm. The difference in the two curves is due to the transfer of angular momentum to the ocean. Note how the wind velocities are dependent on the degree of inward radial penetration of boundary layer air. Parcels penetrating to a radius of $40 \mathrm{~km}$ will have velocities of $45 \mathrm{~m} / \mathrm{sec}$. Those penetrating to radii of 20 and 10 kilometers will have velocities of 63 and $80 \mathrm{~m} / \mathrm{sec}$ respectively, etc.

Steady state tangential equation of motion for hurricane. An examination will now be made of the terms in the symmetrical, steady-state, cylindrical, tangential equation of motion with origin at the hurricane center. This equation may be written as: 


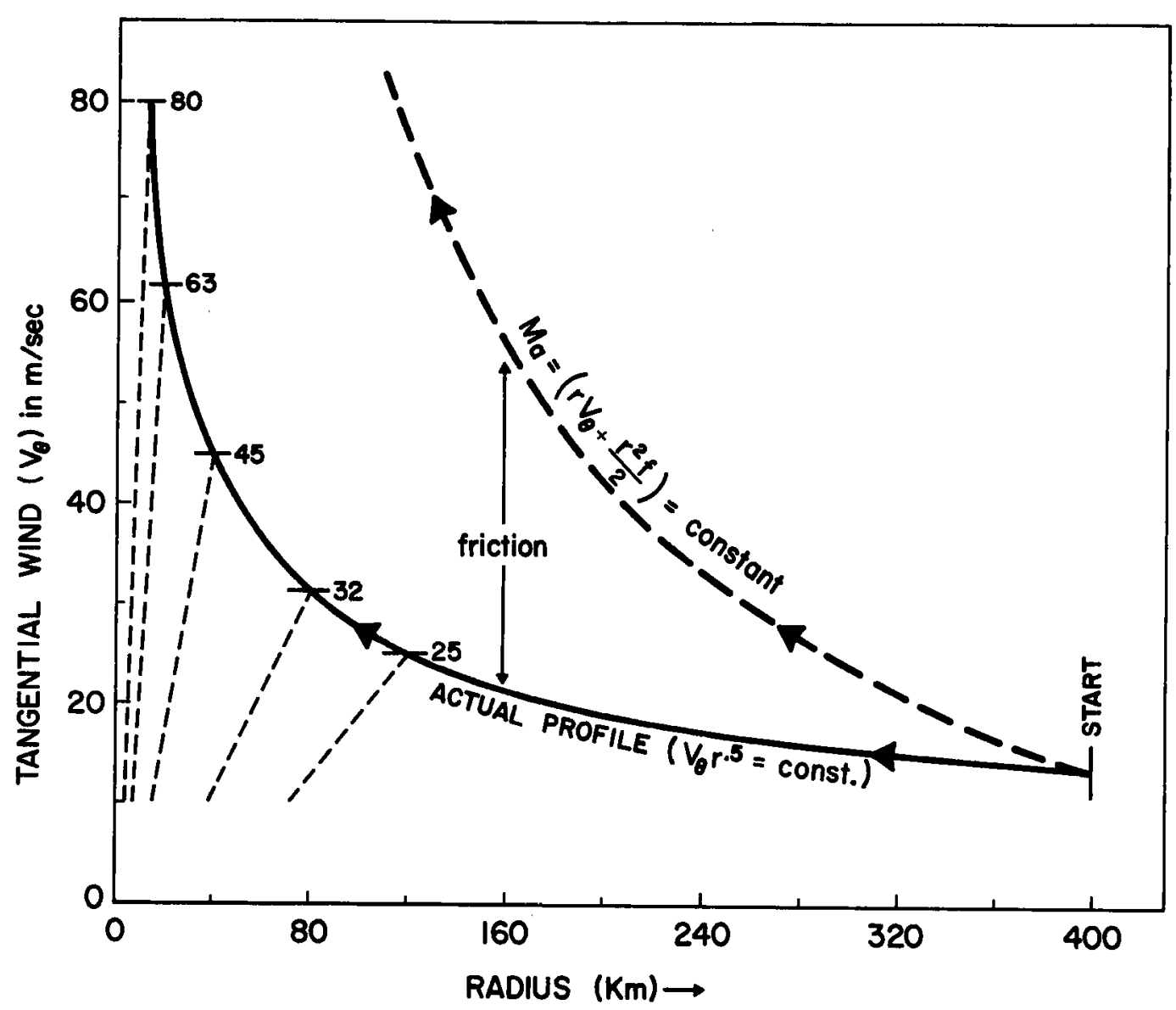

Fig. 3. Hurricane tangential wind profiles. Portrayal of increase of tangential wind with inward penetration of boundary layer air parcels assuming constant absolute angular momentum, $M_{a}$, (top curve), and usual storm case where surface friction plays a large role (lower curve). The difference between these curves is due to momentum transfer to the ocean. Note how the maximum wind speeds are strongly related to the distance of inward penetration of the boundary layer air towards the storm center.

$$
0=-v \zeta_{a}-w \partial u / \partial p+F_{\theta}
$$

where $v$ is the radial wind, $\zeta_{a}$ the absolute vorticity, $p$ is pressure and $F_{\theta}$ represents tangential friction; the other symbols are as before. The very small vertical gradient of tangential wind in the lower levels makes the $w \partial \mathrm{u} / \partial \mathrm{p}$ term negligible. The boundary layer steady-state, symmetrical tangential equation can thus be simplified to 


$$
0=-v \zeta_{a}+F_{\theta}
$$

Here the balance of tangential acceleration is only between the terms $\mathrm{F}_{\theta}$ and $-v \zeta_{a}$. The retarding influence of tangential friction is just balanced by low level inflow. Thus, for steady conditions the magnitude of the boundary layer inflow $(-v)$ is determined by the value of $F_{\theta} / \zeta_{a} \cdot F_{\theta}$ may be represented by $\partial \tau_{\theta z_{0}} / \rho \partial z \sim \Delta \tau_{\theta z_{0}} / \rho \Delta z$, where $\tau_{\theta z_{0}}$ is the surface stress, $\rho$ is density, and $\Delta z$ is the thickness of the layer over which the gradient of stress is applied. Normally the "turbulent gust" induced stress decreases to a small percentage of its surface value at the $\sim 1 \mathrm{~km}$ leve1. Surface stress is typically represented as $\tau_{\theta z_{0}}=C_{D} \rho u_{0}{ }^{2}$ where $C_{D}$ is the surface drag coefficient and $u_{0}$ the wind at $10 \mathrm{~m}$ height. The drag coefficient has been estimated by Palmen and Rieh1 (1957) and Miller (1964) to be approximately $1.5-2.5 \times 10^{-3}$ in the hurricane circulation beyond the radius of maximum wind. Accepting empirical estimates of $C_{D}$ and $\Delta z$ and disregarding vertical variations of $\rho$ and $u$, the boundary layex frictional acceleration can be represented in terms of the low level tangential wind alone, thus $F_{\theta}=-\mathrm{ku}^{2}$ where $\mathrm{k}=\mathrm{C}_{\mathrm{D}} / \Delta \mathrm{z}$.

The $u^{0.5}$ relationship implies that the rotational component of the vorticity $(u / r)$ is twice the magnitude of the negative shearing component $(\partial u / \partial r)$. In this case the absolute vorticity $\left(\zeta_{a}\right)$ can be represented as $(u / r+\partial u / \partial r+f)=(1 / 2 u / r+f)$.

With these substitutions for $\mathrm{F}_{\theta}$ and $\zeta_{\mathrm{a}}$, the boundary layer radial wind in Eq. (4) can be expressed

$$
\mathrm{v} \approx-\mathrm{k} \mathrm{u}^{2} /(\mathrm{u} / 2 \mathrm{r}+\mathrm{f})
$$


For given values of $\mathrm{r}$ and $\mathrm{f}$ the steady-state mean boundary layer radial wind $(\bar{v})$ and tangential wind $(\bar{u})$ are directly related to each other. At radii greater than the radius of maximum wind this relationship turns out to be approximately

$$
\bar{v} \approx-\bar{u} / 10
$$

Thus, for every $\mathrm{m} / \mathrm{sec}$ decrease of sub-cloud layer inflow, the new adjusted steady tangential velocity to satisfy Eq. (6) must take on a value $10 \mathrm{~m} / \mathrm{sec}$ less than its previous value.

Influence of alteration of bound ary layer radial wind. Fig. 4 portrays model specified and observed mean sub-cloud layer (surface to $600 \mathrm{~m}$ ) values of radial wind and divergence plus resulting mean vertical motion at the top of this layer. Values are given in $200 \mathrm{~km}$ segments. The top drawing shows these parameters as they result from a hurricane sub-cloud layer model assuming $\overline{u r}^{0.5}=$ constant and $v=-\bar{u} / 10-$ with the constant determined from the lower curve of Fig. 4. The bottom drawing is determined from data composites surrounding typhoons. Although the observed divergences and vertical motions of the bottom drawing are not very accurate their magnitude is correct.

Note the small divergence of $1-2 \times 10^{-6} \mathrm{sec}^{-1}$ and the small mean upward vertical motion at cloud base $(\sim 600 \mathrm{~m}$ ) of only 6 and $10 \mathrm{mb} /$ day ( $\sim .05$ to $0.1 \mathrm{~cm} / \mathrm{sec}$ ) between $400-600 \mathrm{~km}$ radius. It would not take a great deal of extra cumulus convection to substantially increase this mean vertical motion at cloud base. If this were to occur a substantial reduction in the mean sub-cloud layer inflow at radii inside of this extra cumulus convection region would occur. 
SUB-CLOUD LAYER (sfc-600m) CONDITIONS
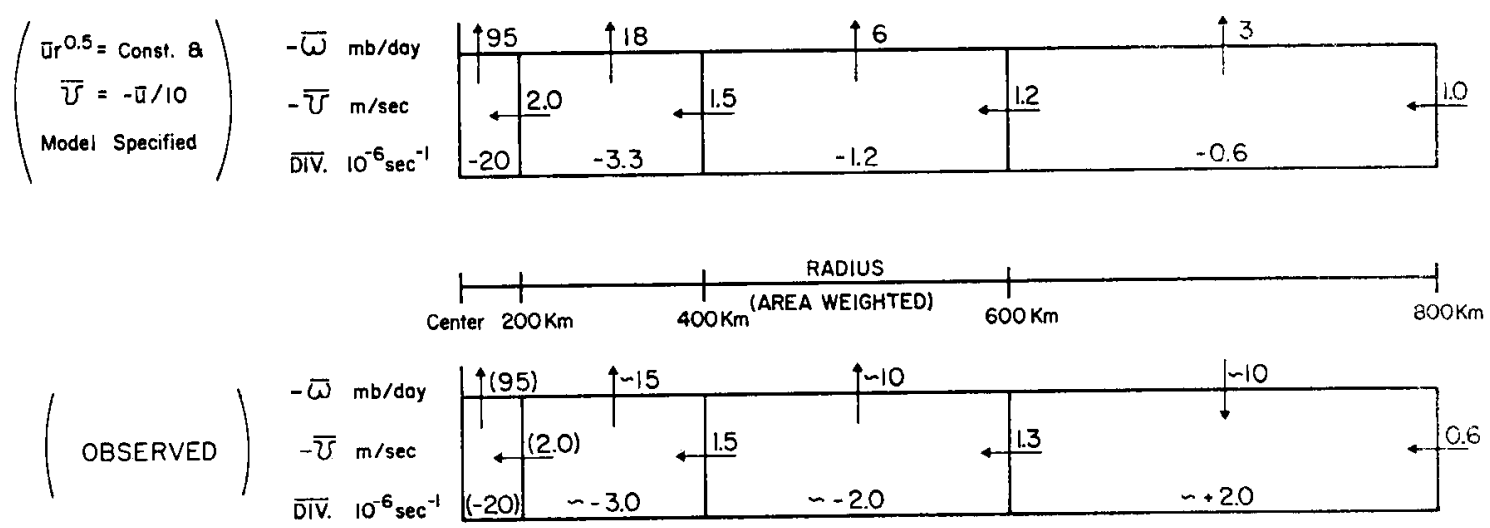

Fig. 4. Radial distribution in $200 \mathrm{~km}$ segments of mean sub-cloud layer radial wind ( $\vec{v})$ and mean divergence (Div.). The resulting mean vertical motion $(\bar{\omega})$ at the top of the sub-cloud layer is also shown. The data accuracy of the bottom drawing is such that the divergence and vertical motion values shown are only accurate to about \pm 50 percent. The small magnitude of these values at outer radii is to be noted.

Fig. 5 portrays the equilibrium sub-cloud layer u profiles which would result if the mean vertical motion at radii between 400 and $600 \mathrm{~km}$ were arbitrarily increased by 50 percent ( $3 \mathrm{mb} /$ day) - curve $B$, and 100 percent ( $7 \mathrm{mb} /$ day) - curve C. Vertical motion changes of this amount result in an increase of boundary layer convergence of $\sim 0.7$ and $1.5 \times 10^{-6}$ $\sec ^{-1}$, respectively. These are not large convergence changes, yet their influence would be to reduce the $400 \mathrm{~km}$ radial inflow by 25 and 50 percent. For balanced acceleration in Eq. (6) a consequent reduction of the tangential winds by the same percentages must also occur. For the relationship ur ${ }^{0.5}$ = constant to apply at inner radii, a reduction of the tangential wind at $400 \mathrm{~km}$ by 25 and 50 percent requires that the radial profile of $u$ follow curves $B$ and $C$-- a substantial reduction of the inner core winds from curve A. The fundamental influence to inner storm wind reduction of increasing the top of the sub-cloud layer vertical motion at outer storm radii is clearly evident. It is hypothesized that carbon 


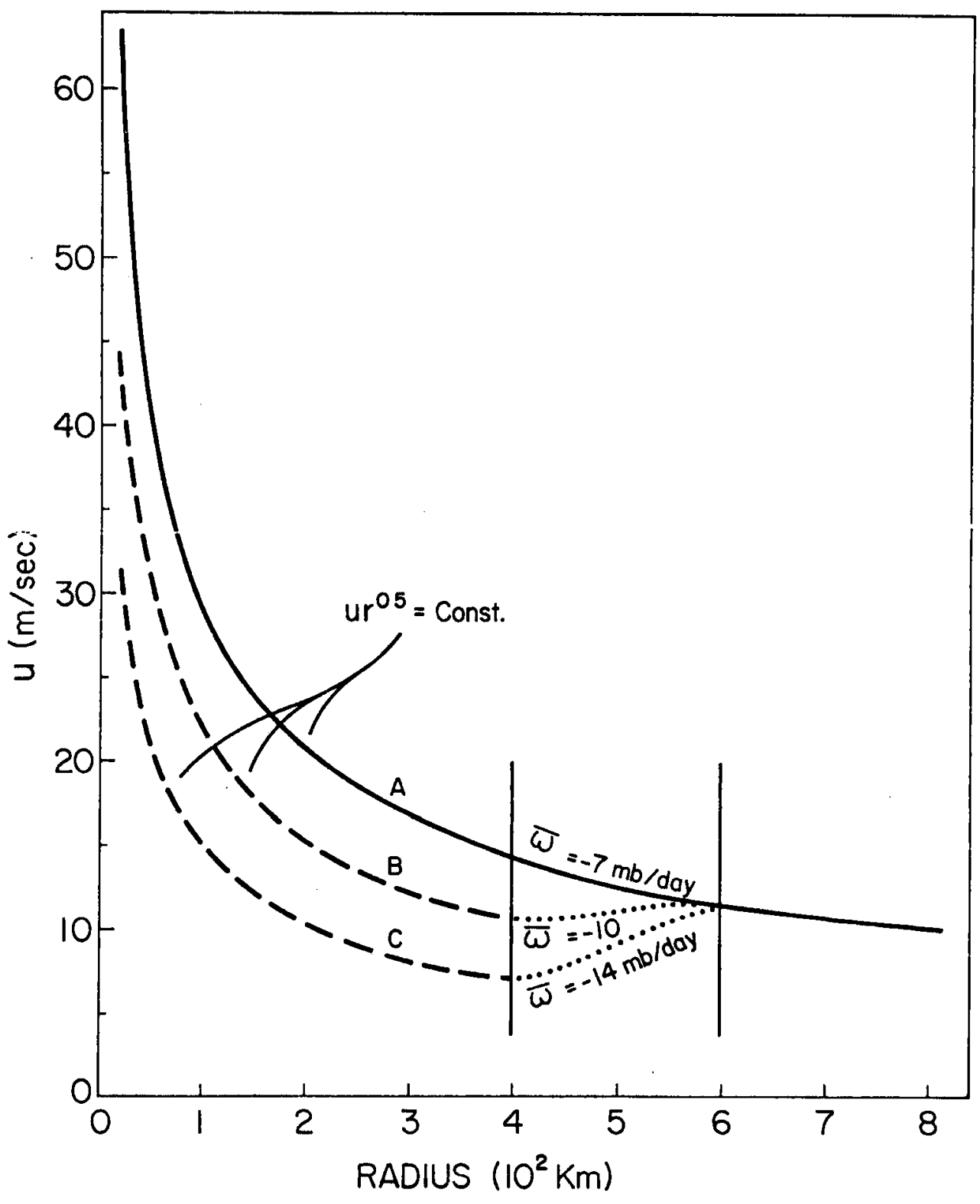

Fig. 5. Radial profile of equilibrium tangential wind (u) at the top of the sub-cloud layer which is present in the normal hurricane (curve A). Mean vertical motion between $400-600 \mathrm{~km}$ radius is $-7 \mathrm{mb} /$ day. Curves $B$ and $C$ show the same equilfbrium $u$ profiles which would result if the mean vertical motions between 400-600 $\mathrm{km}$ were increased to values of -10 and $-14 \mathrm{mb} /$ day, respectively. This would lead to 25 (curve B) and 50 (curve C) percent reductions of the sub-cloud layer radial wind at $400 \mathrm{~km}$ and consequent reductions of the inner equilibrium wind profiles as shown. 
dust could be spread in the boundary layer at outer hurricane radii where enhanced cumulus convection would take place and a similar type of inner core wind reduction obtained.

Conclusion. Hurricane intensity is crucially dependent on the radius to which the boundary layer inflow penetrates and upon the magnitude of the radial inflow. Rapid and sizable reductions in the hurricane inner core wind structure should occur if the boundary layer inflow could be artificially reduced by but 5 to 10 percent at outer radii from stimulation of cumulus convection from carbon dust warming. For a more complete discussion on the subject of hurricane intensity reduction by carbon dust seeding please see the recent project report by Gray (1973). e. Fog dissipation

There have been a number of theoretical and experimental studies of the ability of carbon particles to absorb solar radiation within fog and to evaporate the fog by direct warming of the air (Smith, Wexler, and Glaser, 1959; Downie, 1960; and Fenn and Oser, 1962). These studies typically employed only 1-5 lbs of carbon per seeding operation, and the carbon was dispersed into the air either from a bulk package or in aqueous solution. The consensus results were that clouds seeded with carbon particles of $0.1 \mu$ radius (manufactured size) tended to be grayer in appearance and to dissipate more quickly than non-seeded clouds.

Calculations based on estimates of the radiative absorptivity of carbon and of the amount of solar radiation available inside clouds or fog indicated that if the carbon particles maintained their approximately $0.1 \mu$ radius, they could absorb enough solar radiation to greatly dissi- 
pate the cloud by evaporation in a few minutes. ${ }^{*}$ Carbon particles in bulk storage (as supplied by the manufacturer) tend to agglomerate to much larger sizes - perhaps $100 \mu$ radius - and as a result are very difficult to work with. The above researchers were aware of the clumping problem but often tended to greatly underestimate the sizes of the dispersed particles, assuming values of $r=0.1 \mu$ to $r=1.0 \mu$. Since the amount of solar radiation per unit mass of carbon is maximized for particles of $x=0.1 \mu$ (Frank, Paper II, Fenn and Oser, 1962), it is clear that the early field experiments achieved much lower absorption efficiencies than are potentially possible. As discussed by Stokes (Paper III), it now appears feasible to generate and disperse carbon particles directly into the air without appreciable agglomeration. Thus, one may obtain much more efficient use of carbon particles than was accomplished by earlier researchers.

Computation of solar energy absorption rates by carbon particles dispersed inside fog is an extremely complex problem requiring assumptions of type of fog, radiative flux levels inside the fog, and the physical interaction between the carbon particles and the fog droplets. It is beyond the scope of this paper to do a detailed analysis of this problem, but the following rather simple calculation of the energy required to evaporate fog will attempt to demonstrate that ground fog burn-off can, indeed, be speeded up.

\footnotetext{
* There have also been hypotheses of cloud dissipation mechanisms other than evaporation, but they concern convective type clouds and are not of interest for fog dissipation.
} 
It will be assumed that the highly hydrophobic carbon particles dispersed in an existing fog cloud will tend to remain essentially independent of the cloud droplets over the time scale of interest. Assuming, for example, a fog with a water content $\left(\bar{q}_{L}\right)$ of $0.1 \mathrm{gm} / \mathrm{m}^{3}$, the amount of solar energy which must be absorbed (A) by the carbon particles in a given volume of air to evaporate all of the droplets in that cloud volume is given approximately by Eq. (7) .

$$
\mathrm{dA}\left(\operatorname{cal} / \mathrm{m}^{3}\right)=\mathrm{L} \overline{\mathrm{q}}_{\mathrm{L}}+\mathrm{C}_{\mathrm{p}_{\mathrm{a}}} \rho_{\mathrm{a}} \mathrm{dT}+\mathrm{C}_{\mathrm{W}} \cdot \overline{\mathrm{q}}_{\mathrm{L}} \mathrm{dT}
$$

where

$$
\begin{aligned}
\overrightarrow{\mathrm{q}}_{\mathrm{L}}= & \text { liquid water of fog, } 0.1 \mathrm{gm} / \mathrm{m}^{3} \\
\mathrm{~L} & =\text { latent heat of condensation, } 590 \mathrm{cal} / \mathrm{gm} \\
\mathrm{C}_{\mathrm{p}_{\mathrm{a}}}= & \begin{array}{l}
\text { specific heat at constant pressure of air, } \\
.24 \mathrm{cal} / \mathrm{gm}^{\circ} \mathrm{C}
\end{array} \\
\rho_{\mathrm{a}}= & \text { density of air, } 10^{3} \mathrm{gm} / \mathrm{m}^{3} \\
\mathrm{C}_{\mathrm{W}}= & \text { specific heat of water, } 1 \mathrm{cal} / \mathrm{gm}^{\circ} \mathrm{C}
\end{aligned}
$$

The heating of the carbon particles has been neglected since even at a concentration of 10,000 particles $/ \mathrm{cm}^{3}$ the mass of the carbon particles would only be $10^{-7}$ of the mass of the air. Substituting the assumed values into equation (7):

$$
\mathrm{dA}=(59+240 \Delta \mathrm{T}+.1 \Delta \mathrm{T}) \mathrm{cal} / \mathrm{m}^{3}
$$

If, for example, the initial fog water vapor content is assumed to be $\bar{q}_{\mathrm{v}}=12 \mathrm{~g} / \mathrm{kg}$, the temperature increase required to increase the satur- 
ation vapor content of the air to $12.1 \mathrm{~g} / \mathrm{kg}$ (sufficient to accomodate the entire liquid water content after evaporation) is only about $1 / 3 \mathrm{C}$. Therefore, the energy required to evaporate fog with a liquid water content of $\bar{q}_{L}=.1 \mathrm{gm} / \mathrm{m}^{3}$ is about:

$$
\begin{aligned}
& \mathrm{dA}=(59+72+.03) \mathrm{cal} / \mathrm{m}^{3} \\
& \mathrm{dA}=131 \mathrm{cal} / \mathrm{m}^{3}
\end{aligned}
$$

For a fog layer $200 \mathrm{~m}$ thick, the amount of absorbed solar radiation required to completely evaporate the fog would be approximately $2.6 \mathrm{cal} / \mathrm{cm}^{2}$ of horizontal fog area. It is difficult to estimate the exact amount of carbon needed to produce this warming. The albedo of fog varies from as high as $80 \%$ to very low values for very thin fog layers. This reduces direct solar radiation flux levels within the fog, although this radiation is still quite strong in the uppermost levels of the fog. However, the strong scattering of the solar radiation within the fog greatly increases the optical path length traveled by the radiation and the effective area of the carbon particles is increased by the diffuse nature of the radiation. This effect tends to increase the efficiency of the carbon absorption process. If it is assumed that a cloud of carbon particles dispersed in a 200 m thick fog absorbs $1 / 3$ as much solar radiation during strong daylight hours (say 0900 to 1500) as it would in clear air, a carbon dust cloud of $20 \%$ horizontal area coverage (about 400 Ibs per square mile of fog area) would absorb solar radiation at about 0.3 $\mathrm{cal} / \mathrm{cm}^{2} \mathrm{~min}$. This absorption rate would completely evaporate the fog in less than 9 minutes. Higher concentrations would provide faster evaporation rates.

In some cases it might be useful to use very high carbon concentrations in limited areas to "burn" holes in the fog bank and allow natural 
solar heating of the land in the exposed areas to hasten fog dissipation. Since carbon dust particles can be produced for approximately $10 c$ per $\mathrm{Kg}$, a net carbon cost of only about $\$ 20.00$ per square mile of fog evaporated would be required. The carbon cloud could be generated from ground sources (possibly mobile) at relatively low operating costs. It must be emphasized that only by carefully generating the carbon and dispersing it in the air directly as it is produced is it possible to approach the desired particle size of $\sim 0.1 \mu$ radius.

The problem of dissipating fog through artificially increased solar absorption is a much more complex problem than the simple computation performed above. Nevertheless, there appears to be sufficient additional energy available using carbon dust clouds to allow man to operate on an energy scale comparable to the natural fog energy processes.

\section{f. Accelerating snowmelt in agricultural areas}

As the albedo of snow is typically very high, only a small percentage of the solar radiation received at the snow surface is used for melt or evaporation. Might it be possible for man to artificlelly trap and utilize some of this solar energy for snowmelt? Using absorption values calculated by Frank (Paper II) adjusted for mid-1atitude spring incidence of solar radiation, a carbon dust cloud of $10 \%$ horizontal area coverage could absorb on the order of 50 calories per day depending upon latitude, date, weather, and snow cover conditions. This is enough heat to warm a $1 \mathrm{~km}$ layer of air about 4C per day. It is not clear just how much of this absorbed energy would result in additional snowmelt, but given multiple day usage of the carbon, the effect might be substantial. The carbon particles should have a relatively long boundary layer residence time due to the large temperature inversion usually present. This could lead to 
multiple day use of the carbon. Diamond (1953) has shown that when air temperatures are above $O C$ and relative humidities are low ( 20\%) an increase in air temperature of $5 \mathrm{C}$ can increase the snowmelt rate enormously through increased heat transfer from the air to the ground. On days when the air temperature would normally remain at or just below freezing, the heating of the boundary layer air by 3-4C could result in significant snowmelt when natural snowmelt levels might be very low.

It appears that carbon dust seeding in the boundary layer for certain springtime conditions could accelerate snowmelt and significantly increase the agricultural growing season. Dispersal could be accomplished from ground sources. The enormous economic benefit of such an increase in certain parts of the world makes further research on this topic very desirable.

g. Initial measurements of carbon dust particle characteristics

A beginning abservational attempt at directly measuring the solar attenuation of carbon dust has recently been made. Measurements of solar radiation extinction by the plume of the Cabot Corporation carbon black plant near Skellytown, Texas were taken on May 3, 1974 about 1/4 mile downwind from the source. The plume consisted almost completely of carbon black particles and had the general appearance of a black smoke plume of moderate opacity as shown in Fig. 6. It appeared to remain below the level of the morning inversion, and it was relatively homogeneously dispersed throughout that layer. Particle samples taken in the plume and analyzed by a scanning electron microscope showed that the carbon particles were on the order of $0.1 \mu$ radius and tended to form chains consisting of an average of 4 or 5 particles. A typical sample of these carbon particles is shown in Fig. 7. These particles are in the size range desired 


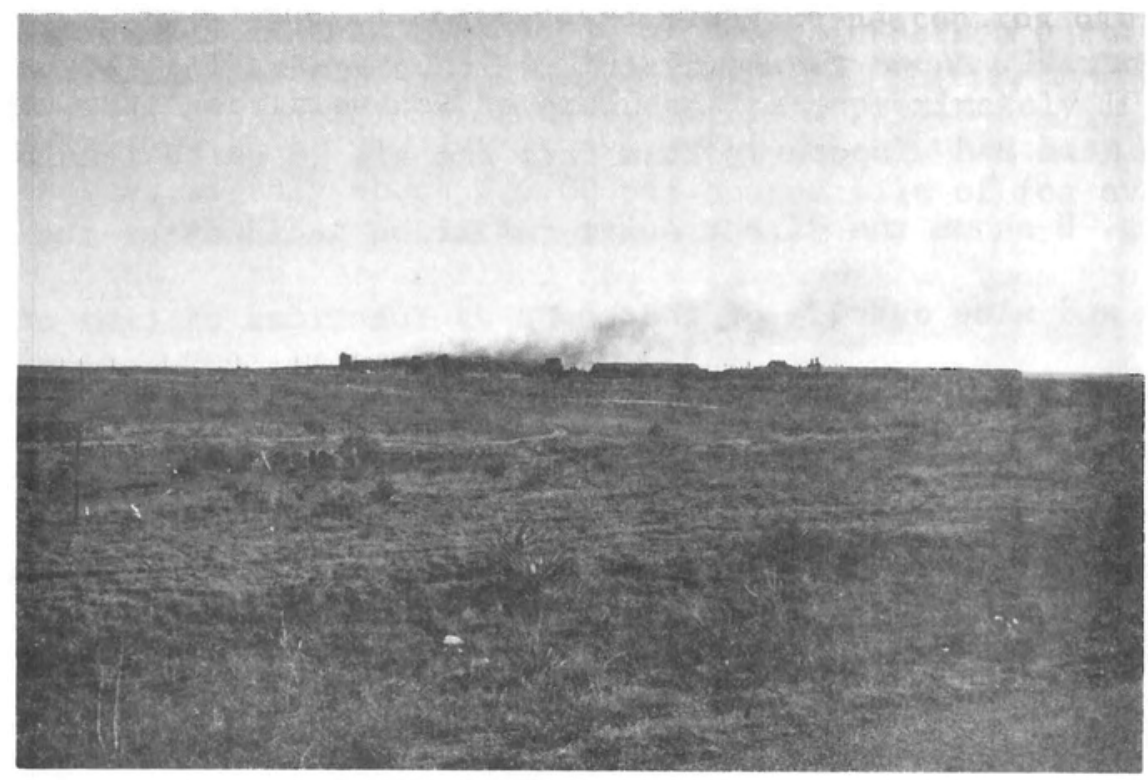

Fig. 6. Plume of Cabot Corp. carbon black plant near Pampa, Texas; May 3, 1974.

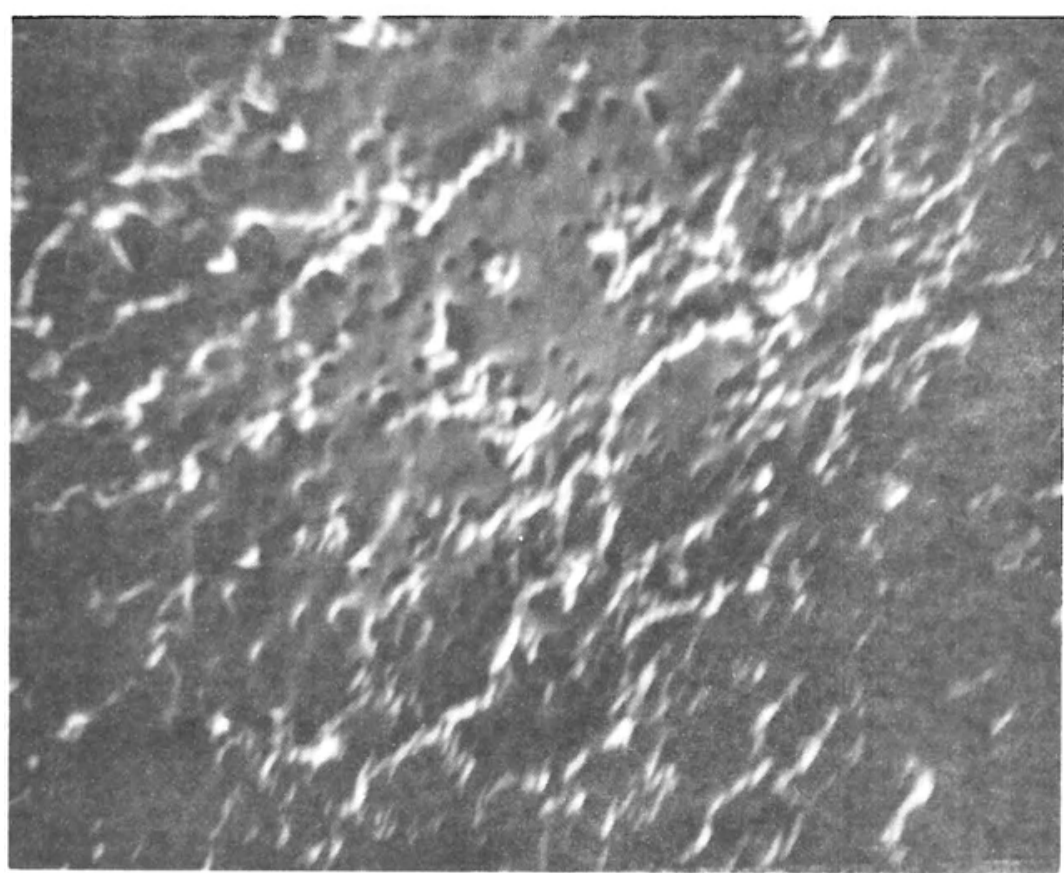

Fig. 7. Scanning electron microscope determination of the size of the carbon particles from Cabot Corp. carbon black plume, Pampa, Texas, on May 3, 1974. White dots are carbon particles $\mathrm{x}$ $10,000$ ( $1 \mathrm{~cm}=1.0$ micron $)$. 
for maximum absorption of solar radiation per unit mass (Frank, Paper II). This generally supports the hypothesis that generating carbon particles of this size and dispersing them into the air is quite feasible.

Fig. 8 shows the direct solar radiation incident at the surface beneath and also outside of the cloud as functions of time of day (and hence of zenith angle). Using this data a mean plume extinction of about $13 \%$ was determined. Measurements of extinction of total solar radiation (direct + diffuse) gave similar results. Since it was not possible to determine the mass concentrations of the plume, a direct check of the theoretical absorption values was not possible. However, several theoretical studies and laboratory experiments have quantitatively verified the radiative absorption properties of carbon black quite well as discussed in Paper II. It is gratifying, nonetheless, to note that a moderate concentration of carbon dust particles did indeed cause the extinction of a significant percent of the direct and total incoming solar radiation, primarily due to absorption.

h. Summary

Observational and theoretical evidence indicates that if a mesoscale heat source of the magnitude which is possible through carbon dust interception of $10-20 \%$ solar radiation is applied in a selective way to a potentially favorable environment, it is likely to induce a significant enhancement of cumulus convection and precipitation. A number of other potentially beneficial effects may also be possible. 


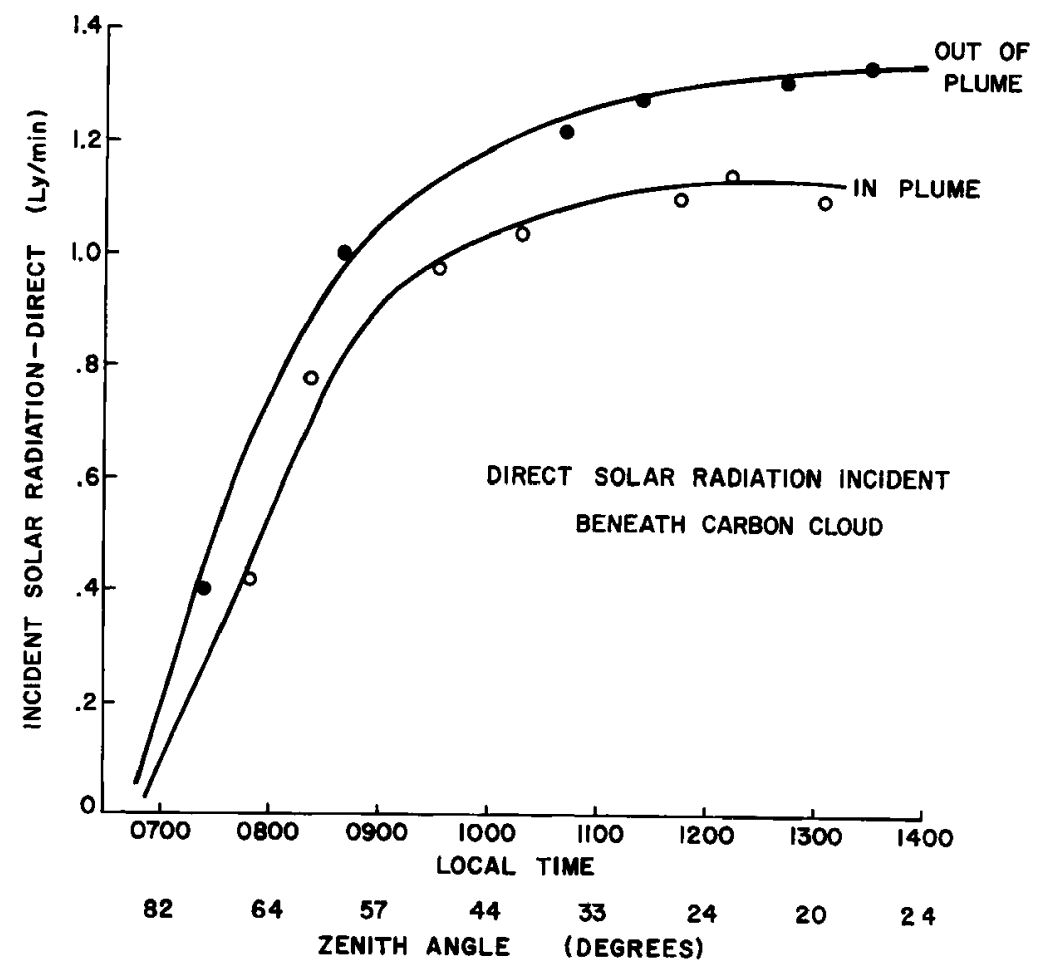

Fig. 8. Pyroheliometer measurements of direct solar radiation incident at the surface beneath and outside of the carbon plume shown in Fig. 6. 
III. NUMERICAL MODELING EVIDENCE

A number of early numerical modeling results lend various degrees of support to the carbon dust physical hypothesis using heat sources of the magnitude of $\sim 5-10 \mathrm{C} / 50 \mathrm{mb}$ per 10 hours. The results from some of these models will now be briefly discussed.

a. Boundary layer modeling

J. Deardorff (1973) has run an initial test on the influence of artificial boundary layer heating in a one-dimensional tropical subcloud layer model. He assumed an artificial boundary layer heat source of $1 / 4 \mathrm{C} /$ hour for ten hours. This is only a quarter of the amount of heating which is being proposed; nevertheless, substantial influences occurred. The results of the model are shown in Fig. 9. The model ran for four days in a normal state, and then the heating was applied. After 10 hours the heating was abruptly shut off. The effect upon cloud base (h), percent area of cumulus cloudiness $(\sigma)$, evaporation $\overline{\left(\bar{w}^{\top} q^{\top}\right)}{ }_{s}$, and ocean-air virtual potential temperature difference $\left(\Delta \theta_{v}\right)$ are shown in this figure from Deardorff's paper.

To quote from Deardorff's report on the influence of the extra heating:

"The first result, of course, is a warming of the mixed layer. This warming causes $\Delta \theta_{v}$ to decrease drastically from $0.55 \mathrm{C}$ to about $0.1 \mathrm{C}$ in 4 hours, and causes the relative humidity to drop. The first effect causes $h$ (the cloud base) to rise from $580 \mathrm{~m}$ to $980 \mathrm{~m}$ at the end of the 10-hour period. Both effects together cause convective cloud-base level to rise. .... This causes $\sigma$ (percent area with cumulus) to more than double after the end of only the third hour following initiation of the enhanced heating rate. A dip in $\sigma$ just as the heating is first applied reflects the decreased relative humidity before $h$ has had a chance to rise. As expected $\left(\omega^{\prime} \theta^{\prime}\right)_{s}$ decreases and even becomes negative, while $\overline{\omega^{\top} \theta^{\top}}$ only barely stays positive by the end of the 10th hour. The enhanced cloud induced mixing causes the boundary layer 


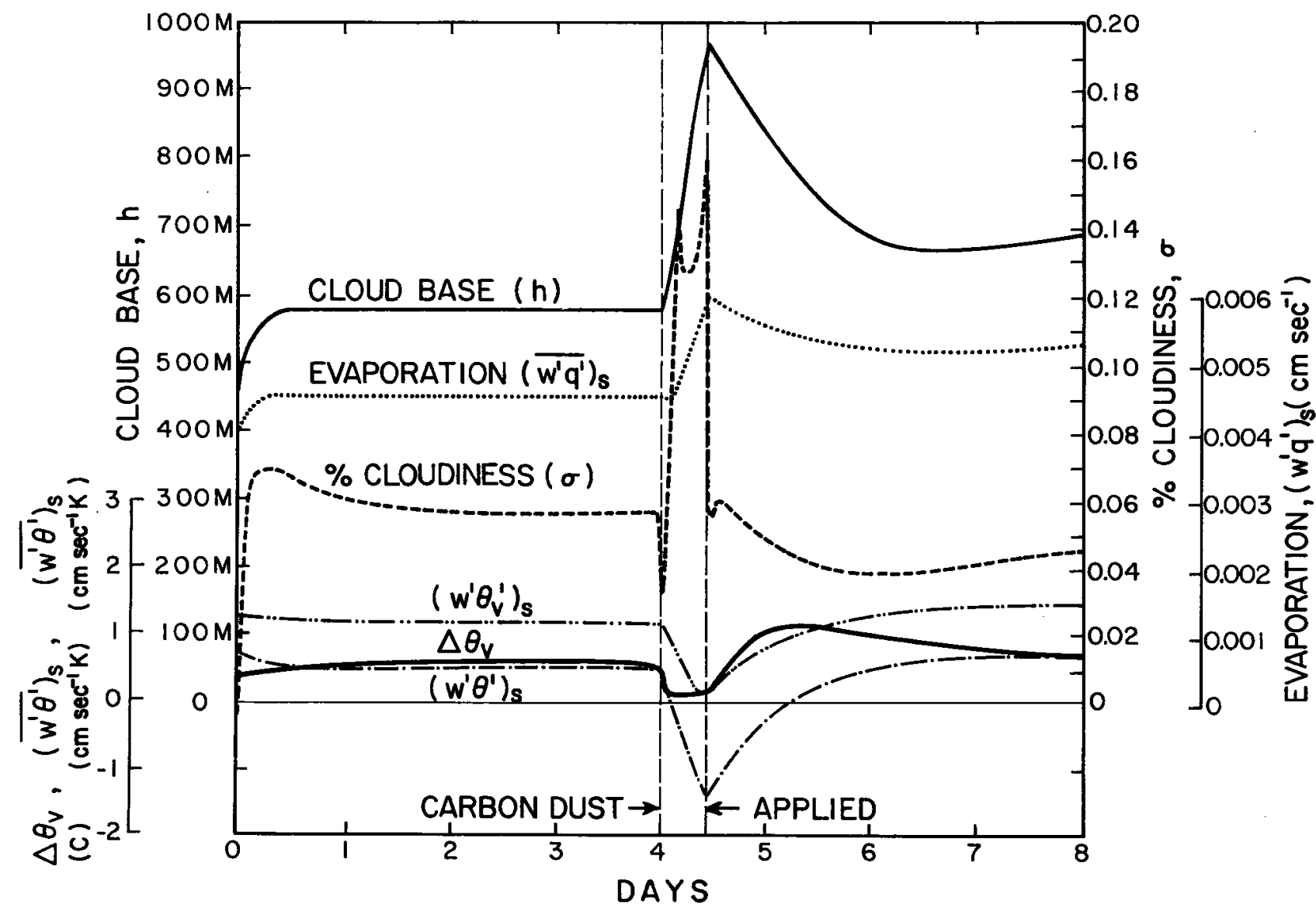

Fig. 9. Deardorff (1973) test to determine the influence of carbon dust energy input. An energy input rate equivalent to $0.25 \mathrm{C} / \mathrm{hr}$ has been applied during the first 10 hours of Day 5 . 
specific humidity to decrease to a minimum of $13.1 \times 10^{-3}$, and thereby causes increased surface moisture flux (evaporation) to persist long after application of the carbon black has ceased."

"Although the model takes no account of dissipative effects such as horizontal diffusion, it does strongly support one portion of Gray's hypothesis. Increased convective activity is predicted to occur despite a reduced surface virtual temperature flux during the modification period. The much increased depth of the mixed layer, moreover, suggests that the convective clouds will have greater diameters and reach greater heights. The model could not treat cases with greater applied heating rates, unfortunately, because $\left(\omega^{\prime} \theta^{\prime}\right)_{s}$ then becomes negative and the model invalid".

This artificial stimulus to cumulus convection was obtained with a boundary layer heating of only $1 / 4 \mathrm{C} /$ hour. The authors are proposing boundary layer heating rates 2 to 5 times the amount which Deardorff has tested here. A favorable enhancement of convection is indeed indicated.

b. Meso-scale tropical model

The new 3D meso-scale, tropical model results of Elsberry et al. (1974) and W. Fingerhut (of Colorado State University) also lend support to the envisaged influences of carbon dust induced heat sources.

This three and five layer model is being developed to simulate processes which occur on scales below the normally predicted synoptic scales. A key feature is the nesting, or telescoping of the grids of 25, 50 and $100 \mathrm{~km}$. Each interior grid is allowed to move, following the meso-scale cumulus convective fields. Energy exchanges through the grid interfaces appear to be unconstrained through the use of mutually determined boundary conditions. Thus, energy input within the fine mesh region is free to pass to the larger scales of motion, represented on the coarse mesh grid (see the reports of Harrison and Elsberry, 1972; and Harrison, 1974; for more discussion of the model). 
Elsberry et al. (1974) with a three layer model and W. Fingerhut (Colorado State University) with an updated five layer version of this model have tested for the influence of this artifically induced mesoscale heating on an atmosphere initially at rest. Results indicate a significant influence from energy inputs of $\sim 5 \mathrm{C} / 10$ hours per $100 \mathrm{mb}$ in the lowest layer. The response of the model to upper level heating effects was much less favorable.

When the assumed artificial carbon dust heating $\sim 5 \mathrm{c} / 10$ hours per $100 \mathrm{mb}$ is placed in the lowest layer, a very large atmospheric response is felt. A large artificial enhancement of cumulus convection and/or precipitation is likely to result. Fig. 10 shows the magnitudes of the model's lowest $100 \mathrm{mb}$ inward radial flow components and vertical motions after 10 hours of heating at a rate of $\sim 13 \mathrm{cal} / \mathrm{cm}^{2}$ per $\mathrm{hr}(\sim 0.5 \mathrm{C} / \mathrm{hr})$. The extra radiation-induced vertical motion at the top of the boundary layer is no less than $180 \mathrm{mb} /$ day. The radial inflow at $75 \mathrm{~km}$ radius is $1.3 \mathrm{~m} / \mathrm{sec}$. After ten hours lower tropospheric convergence is $\sim 30 \times 10^{-6}$ $\sec ^{-1}$. This is approximately five times larger than the average $4^{\circ}$ convergence occurring in the typical tropical cloud cluster (Williams and Gray, 1973). Thus, it appears that the implementation of this extra heat source on a meso-scale over the tropical or sub-tropical oceans would, indeed, have a signiftcant influence on generation and/or enhancement of tropical weather systems. More modeling must be accomplished, however, before this influence can be explicitly established.

c. ' Hurricane intensity reduction

The author (Gray, 1973) has extensively discussed the potential of hurricane inner-core intensity reduction from carbon dust induced outer 


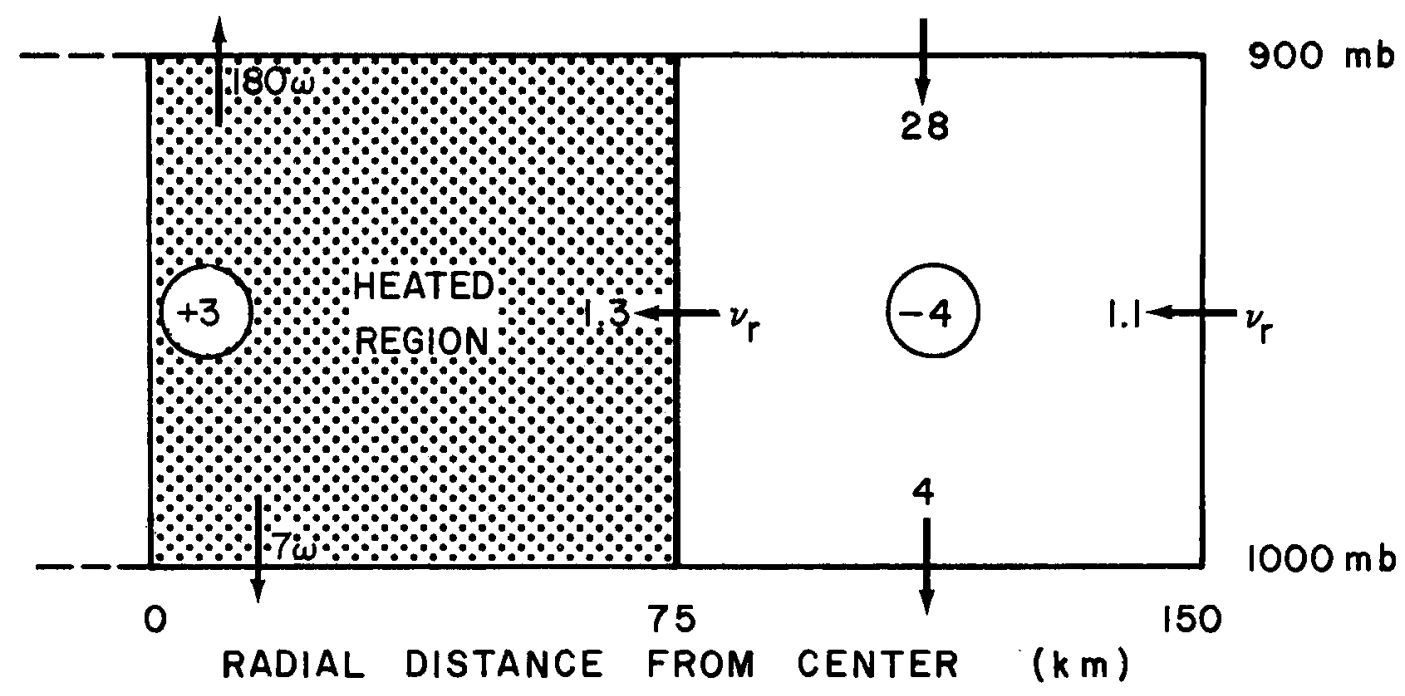

Fig. 10. Boundary layer response of an atmosphere initially at rest to 10 hours of assumed carbon dust heating at the rate of $0.5 \mathrm{C} / \mathrm{hr}$ in the lowest $100 \mathrm{mb}$ layer and in the inner $75 \mathrm{~km}$. Radial velocity $\left(v_{r}-m / s e c\right)$, vertical velocity $(\omega-m b /$ day $)$, and moisture convergence (circled - gm/Kg per day).

radii boundary layer heating of $1 / 2$ to $1 \mathrm{c} /$ hour. This is 1 ikely to stimulate extra cumulus convection at outer hurricane radil and lead to a reduction of the hurricane's boundary layer inflow and thus the mass circulation into and out of the storm's inner region. Angular momentum and surface frictional considerations dictate that the hurricane inner core region weaken.

This outer heating modification hypothesis has recently been tested in the Rosenthal (1970, 1971a, 1971b) circular symetric tropical cyclone model and has been found to verify the physical hypothesis to a high degree (see report by Gray, op. cit.).

The model is a seven level primitive equation model containing the water vapor cycle and parameterized cumulus convection. The radial interval is $10 \mathrm{~km}$ and the time step is 2 minutes. In an overall sense it appears to handle the basic dynamics of the hurricane quite well. 
The model is initialized with a symmetric vortex with maximum winds of $7 \mathrm{~m} / \mathrm{sec}$ at $250 \mathrm{~km}$ radius. The model is then integrated in time. It slowly builds up a moist layer during the first seventy hours of integration and then intensifies rapidly to a hurricane vortex with maximum winds of $\sim 50 \mathrm{~m} / \mathrm{sec}$ at a radius of $25 \mathrm{~km}$ in another $80-100$ hours. The vortex then stops intensifying and remains in an approximate steady state for several days. It is the latter steady-state that is used for energy response experimentation. The Rosenthal papers fully describe this mode1.

Artificial heating values have been input to the steady-state stage at the four black dots shown at radii of 415 and $425 \mathrm{~km}$ and at the surface and $900 \mathrm{mb}$ in Figs. 11 and 12. Heating rates are applied at these grid points for a ten-hour period to simulate the solar heating of the carbon dust. They are then discontinued for 14 hours. Two heating rates have been used at the 4 grid points shown. They are:

1) $1 / 2 \mathrm{C}$ per $\mathrm{hr}$ for 10 hours, no heating after this but integration of the model to 24 hours, and

2) $1 / 4 \mathrm{C}$ per hr for 10 hours, no heating for 14 hours, then a second rate of $1 / 4 \mathrm{C}$ per $\mathrm{hr}$ from $24-34$ hours. The model is integrated to 34 hours in this latter case.

The maximum artificial heating influences are felt about 24 hours after integration is started. It takes 12-24 hours for the effects of the outer heating to manifest itself into changes in the inner core of the hurricane.

Figs. 11 and 12 are vertical cross-sections showing the influences on the tangential and vertical winds after 10 and 24 hours of applying an artificial heat source of $1 / 2 \mathrm{C} / \mathrm{hr}$ at the four black dotted grid points 

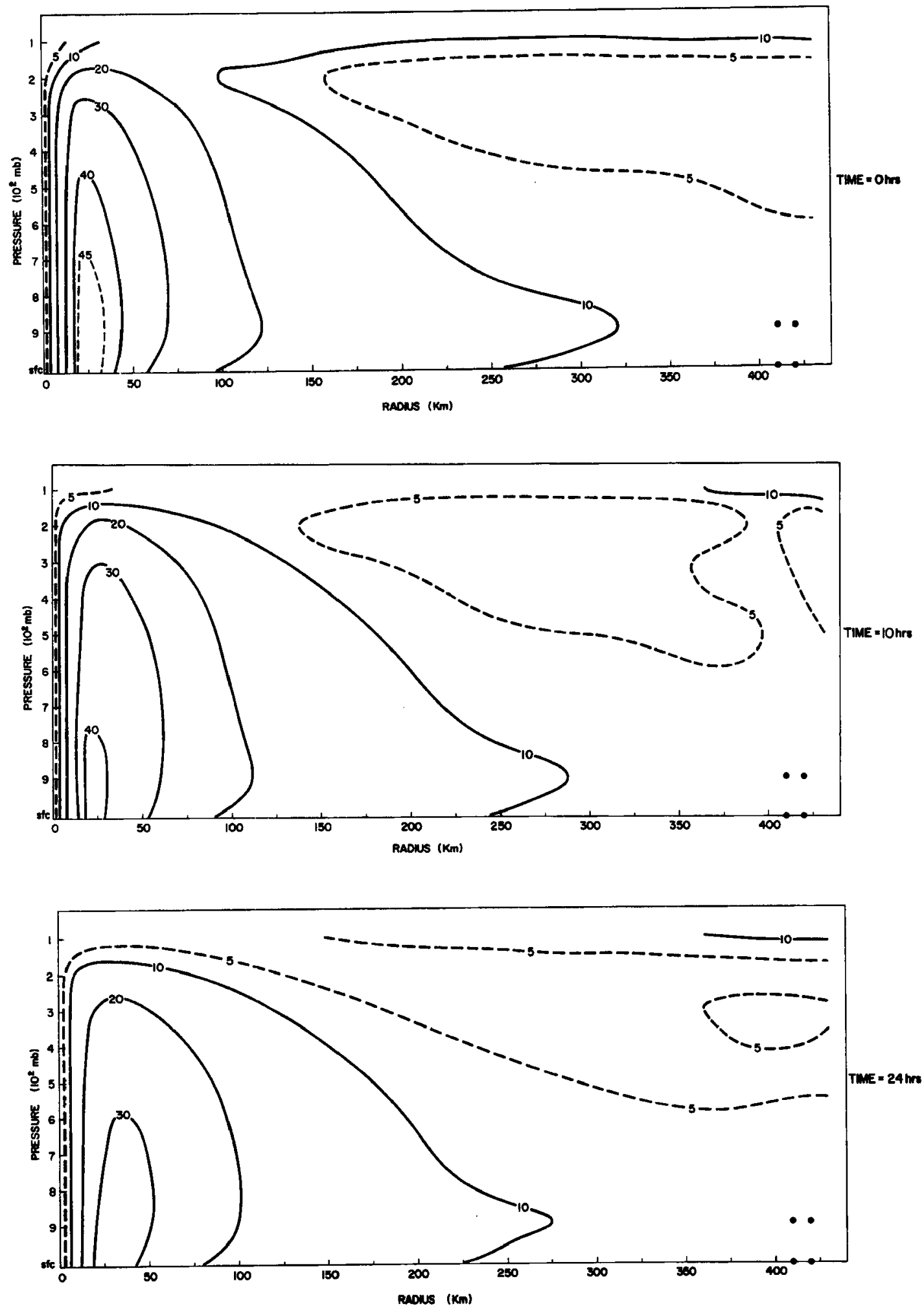

Fig. 11. Rosentha1 (1971a, 1971b) symmetric model total wind speed (in $\mathrm{m} / \mathrm{sec}$ ) at various time periods as a result of artificial heating rate of $1 / 2 \mathrm{C} /$ hour for the first 10 hours applied at the four grid points shown at the lower right. 

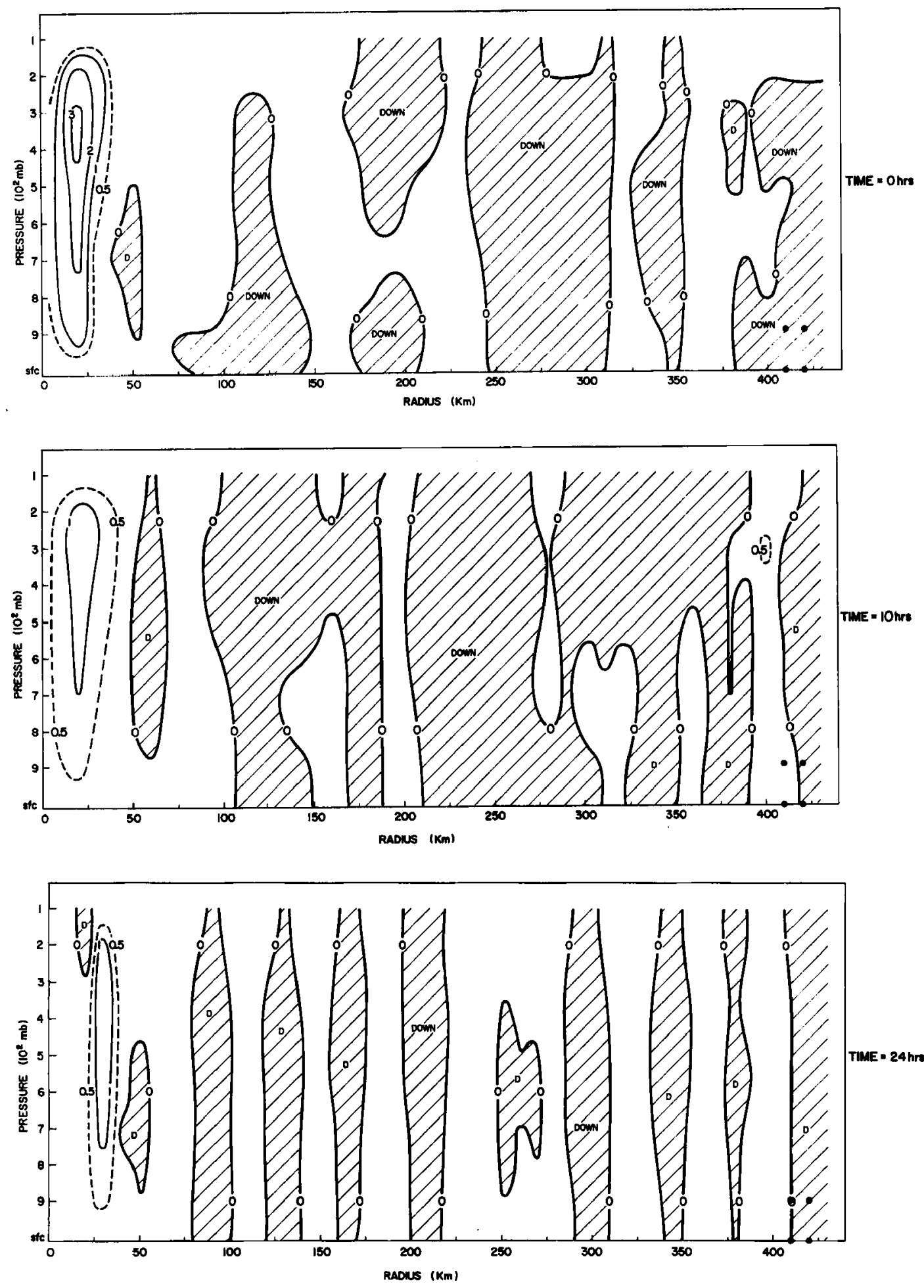

Fig. 12. Rosenthal (1971a, 1971b) symmetric model vertical wind (in $\mathrm{m} / \mathrm{sec}$ ) at various time periods as a result of artificial heating rate of $1 / 2 \mathrm{C} / \mathrm{hr}$ for the first 10 hours applied at the four black dot grid points shown at the lower right. 
for the first 10 hours. Note that the maximum reductions in the horizontal and vertical winds occur where these values are the highest. Such changes would be beneficial in terms of storm damage reduction. After 24 hours the wind at the surface at the radius of maximum winds is reduced by $15 \mathrm{~m} / \mathrm{sec}$ ( $30 \%$ reduction from the original value). The surface kinetic energy at the radius of maximum winds has been reduced by $60 \%$ of its original value. The radial winds and vertical motion at the inner core radii have likewise been greatly altered.

If these hurricane modification results are realistic, then a large potential for alleviating hurricane destruction may be possible. These modeling results appear to warrent more study and discussion.

\section{d. Individual cumulus model}

R. Lopez's (1973a, 1973b) whole life cumulus cloud model offers further supporting evidence to the carbon dust heating hypothesis. This model has been used to test the influence of increased boundary layer temperature and relative humidity on individual cumulus growth.

Fig. 13 shows a cloud top vs. time diagram of different cumulus clouds that have had their boundary layer temperature increased by various amounts. Cloud (a) is the null case. The other clouds which grow higher and more rapidly have had their boundary layer temperature values $\left(\mathrm{T}_{\mathrm{BL}}\right)$ increased by the amount specified. Note that temperature increases of but 1 or 2 degrees in the boundary layer can lead to significantly more intense cumulus convection (with all other factors held constant).

Fig. 14 shows a similar influence for a two gram per kilogram increase in the boundary layer specific humidity with all other influences held constant. Here again the cumulus convection is much more intense. Thus, it appears that an energy or moisture input into the boundary 


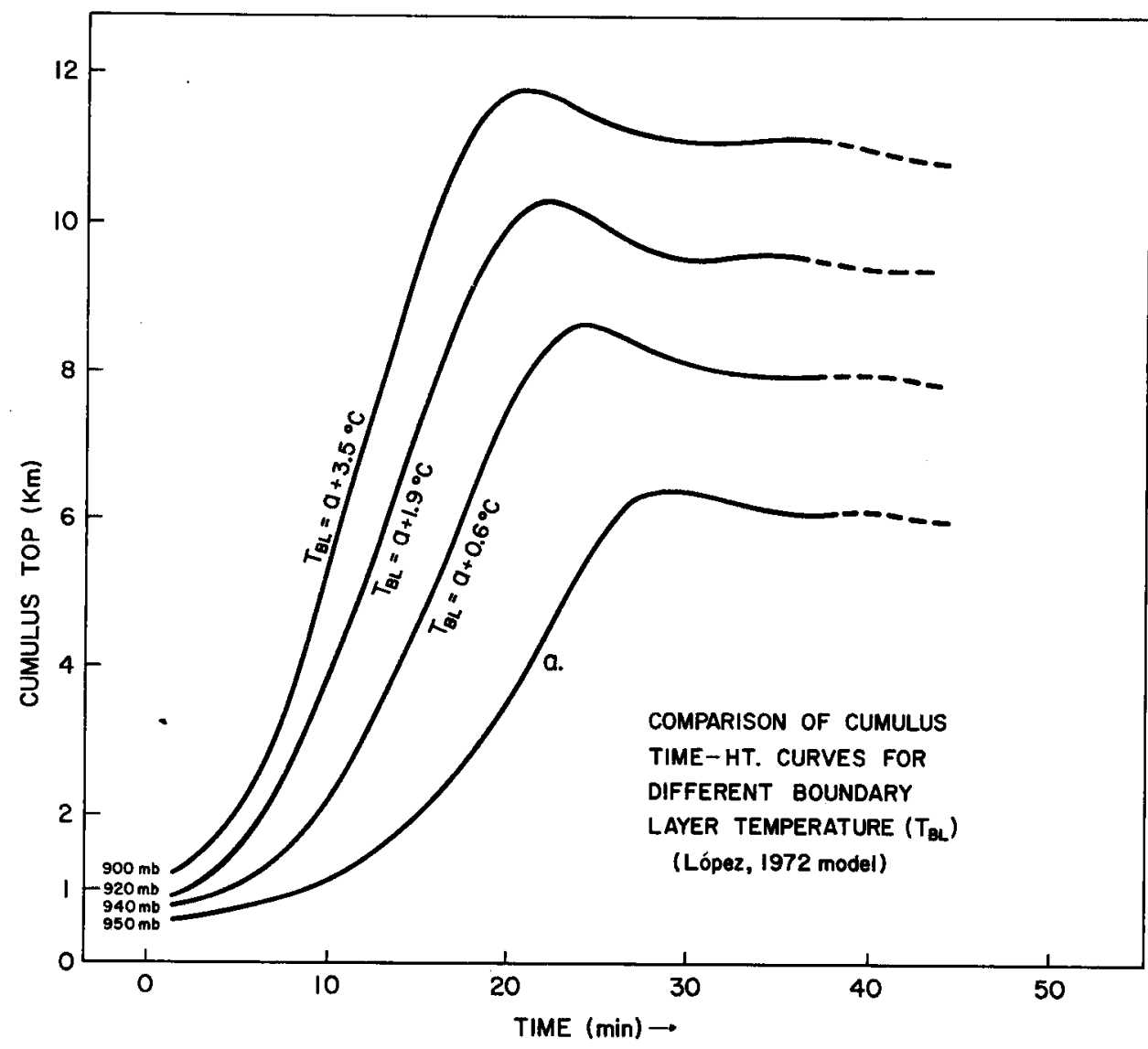

Fig. 13. Time vs. height diagram of cumulus growth for a towering cumulus (a) of Lopez's (1972) whole life cloud model. The other curves portray the increased growth rates and heights of this same cloud if the boundary layer temperatures $\left(\mathrm{T}_{\mathrm{BL}}\right)$ are increased by the amounts shown and all other parameters remain the same.

layer would have a very significant influence on the enhancement of extra cumulus convection.

e. Cloud and cloud environment modeling

H. Orville (1965a, 1965b, 1968) and his group (Orville and Sloan, $1970 \mathrm{a}, 1970 \mathrm{~b}$; Chang and Orville, 1973) have investigated the influence of elevated heat sources on the generation and enhancement of cumulus convection, and their findings appear to offer additional supporting evidence. He and his group have shown that elevated heat sources of the 


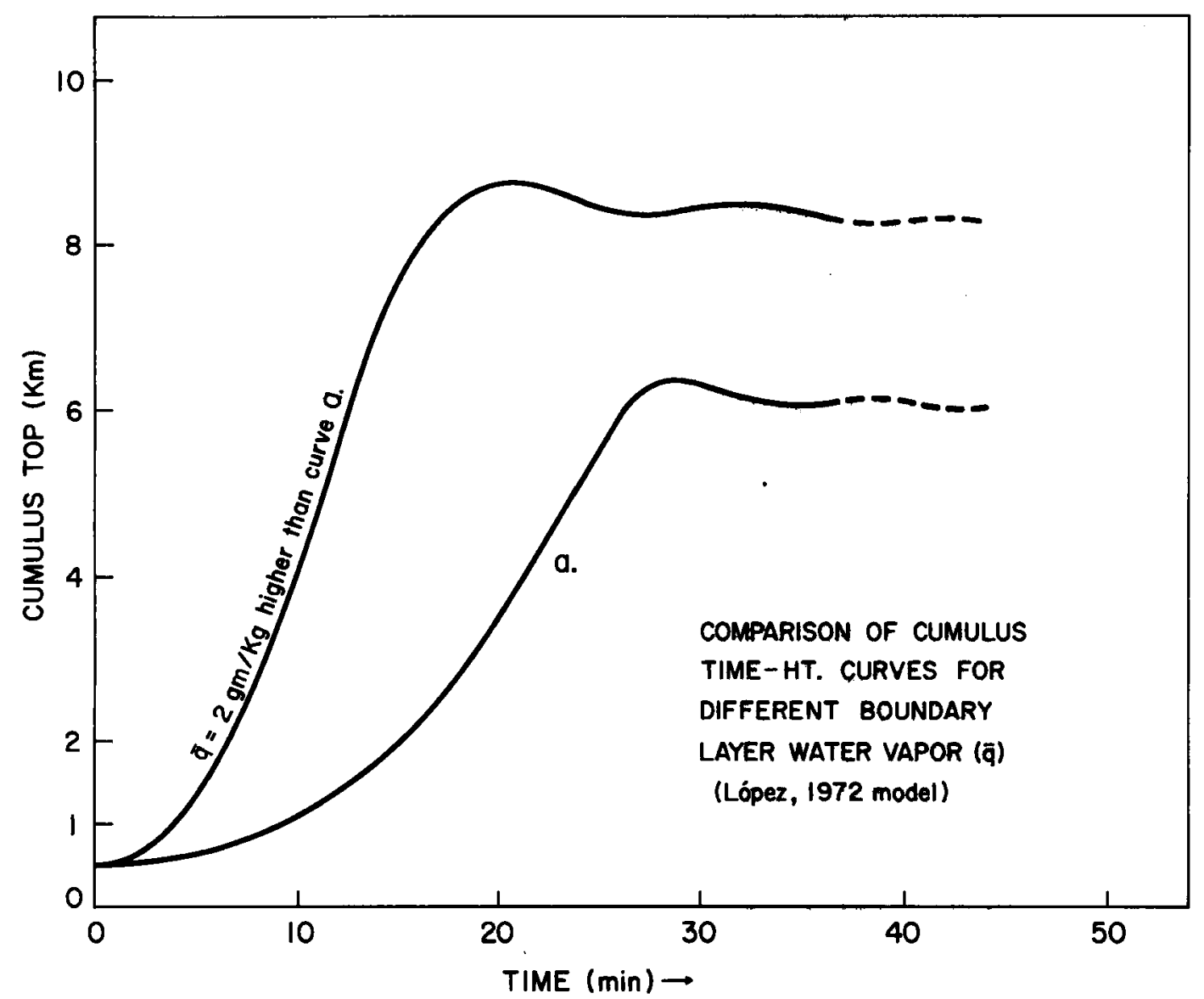

Fig. 14. Time vs. height diagram of cumulus growth for a towering cumulus (a) of Lopez's (1972) whole life cloud model, and the increased growth rate and height of the same cloud if it had an extra boundary layer water vapor content of $2 \mathrm{gm} / \mathrm{Kg}$ with all other parameters remaining the same.

magnitude $1 / 4$ to $1 / 2 \mathrm{C} /$ hour per $100 \mathrm{mb}$ (as developed by mountains) produce substantial early day generation and enhancement of cumulus convection as compared to the surrounding lower terrain areas. This can be qualitatively verified by anyone living near the mountains in the summer.

If dispensed from aircraft or elevated terrain, the proposed carbon dust heat source is likely to act as an elevated heat source and allow for concentration of lower level convergence and cumilus convection in selective areas over land and the ocean. The magnitude of the elevated heat source which is possible from carbon dust can be as large as that produced by mountains. If man is able to control the place, time, size 
and intensity of this elevated heat source, a slgnificant local stimulation of cumulus convection and precipitation may be possible.

f. Meso-scale mountain model

Dirks (1969) has developed a 2D meso-scale circulation model with a sloping (1/10) heat source similar to that developed by a mountain during its diurnal solar heating cycle. Starting from rest, Dirks develops a substantial meso-scale mountain-plains cellular circulation system after only two hours of integration. An analogous type heat source might also be possible with the carbon dust heating mechanism. There is much to be learned, however, about how the mountain terrain and the mountain heat source interact with one another. Would a similar type of circulation be developed for an identical heat source without the mountain?

g. Summary

Preliminary numerical modeling evidence indicates that an artificial heat source of the size and magnitude here discussed would likely have a beneficial influence on a number of weather modification schemes. 


\section{COST-BENEFIT CONSIDERATIONS}

It is estimated that carbon dust can be generated for about $\$ 0.10$ per $\mathrm{Kg}$. A 10 percent cross-sectional area coverage by $0.1 \mu$ radius particles would require $\sim 25 \mathrm{Kg}$ of carbon per $\mathrm{km}^{2}$ (or $\sim 2001 \mathrm{bs}$ per $\mathrm{n} . \mathrm{mi} .^{2}$ ). To cover a $(200 \mathrm{~km})^{2}$ or $(100 \mathrm{n} . \mathrm{mi} .)^{2}$ square area would require $\sim 1$ million $\mathrm{Kg}$ of $0.1 \mu$ carbon particles. This would result in about 15 percent solar radiation absorption and would require about $\$ 100,000$ worth of petroleum products. If the cost of dispersal of the carbon from surface sources (ship and 1and sites) is 1-2 times the cost of the petroleum products and the cost of dispersal from aircraft is 3-4 times the cost of the petroleum, an estimate for a 1 million $\mathrm{Kg}$ carbon particle seeding operation would be:

1) from surface sites $\sim \$ 0.3$ million, and

2) for aircraft sources $\sim \$ 0.5$ million.

Please see the papers by Gray (1973) and Frank (1973) for more discussion of the economics of carbon dust dispersion, etc. It is envisaged at this time that the surface releases would be used primarily for tropical and sub-tropical meso-scale precipitation augmentation, cyclone modification, enhancement of snowmelt and most types of fog dissipation. Aircraft operations would be more suitable for hurricane destruction alleviation and certain types of fog dissipation.

\section{a. Precipitation augmentation}

It is assumed that the surface release of 1 million $\mathrm{Kg}$ of carbon particles into the oceanic boundary layer 1 day or more upwind from a coastal target area would generate or intensify a meso-scale weather system similar to a typical trade wind cloud cluster. Such clusters give an average of $2 \mathrm{~cm} /$ day of rain over a $(500 \mathrm{~km})^{2}$ area (Gray, 1972). However, 
this cost estimate wili assume that an average oi $2 \mathrm{~cm}$ of rain will occur only over an area approximately equal to the carbon seeded area of (100 miles $)^{2}$. If half of the rainfall $(1 \mathrm{~cm}$ ) could be utilized productively, the total amount of useful water generated by the system would be approximately $4 \times 10^{14} \mathrm{~cm}^{3}$ or $3 \times 10^{5}$ acre-feet. The average minimum price for irrigation water in typical agricultural countries is about $\$ 10$ per acrefoot. At that price one system would produce about $\$ 3$ million of usable water resulting in a favorable cost-benefit ratio of about 10 to 1 . When certain areas become desperately in need of rain, the value of usable water can easily exceed $\$ 100$ per acre-foot resulting in much more favorable cost benefit ratios. It is also possible that the generated system would rain over an area much larger than $(100 \text { miles })^{2}$ and on subsequent days. It is most unlikely that individual cumulus cloud modifications from silver iodide or warm cloud seeding are capable of having as profitable a cost-benefit ratio.

\section{b. Hurricane damage reduction}

A study of hurricane damage in the United States (Howard et al. 1972) showed that, in general, the damage cost of the typical storm is roughly proportional to the 4 th power of the maximum sustained wind speed. Accepting their estimates, Fig. 15 was constructed. This figure shows the potential economic gains from hurricane damage reduction as a function of the percent of reduction of maximum sustained surface wind speeds. A more extensive discussion of the economics of hurricane damage reduction vs, cost of carbon aus: dispersion is given in the report of Gray, 1973. Table 4 gives our estimate from the Howard et al. report of the lamage reduction to modificatio- cost for different storm intensities and percentage maximum wind de: eases. It can be seen that for 


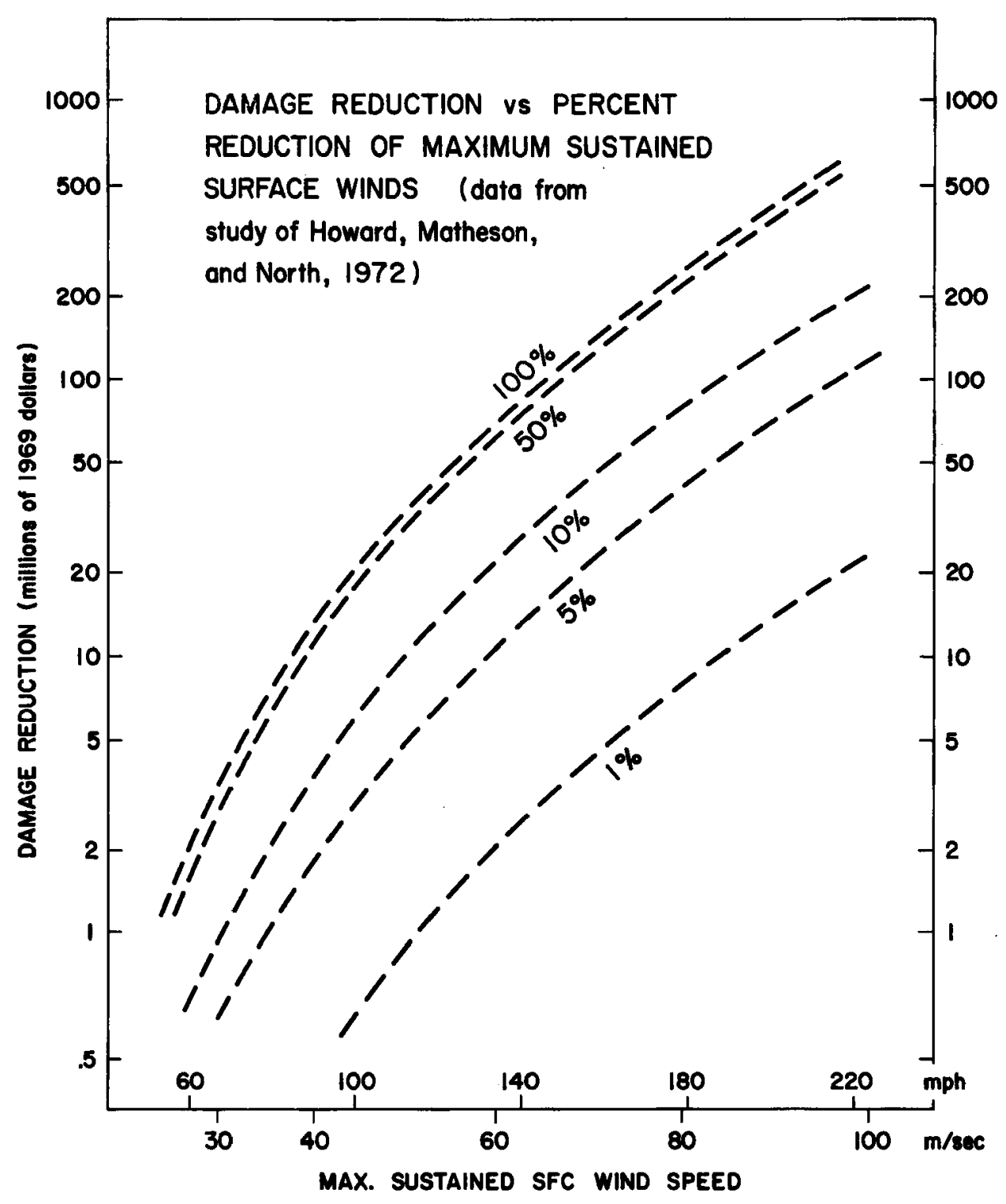

Fig. 15. Storm damage reduction in millions of dollars vs. percentage modification reduction of maximum sustained surface winds (sloping curves). (Data from study of Howard, Matheson, and North, 1972). 


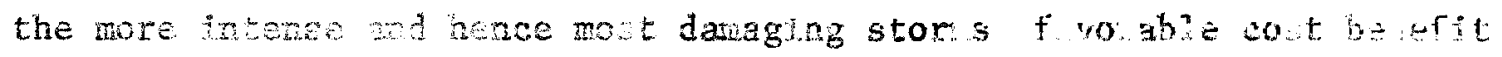
ratios of 10-1 to 100-1 may be possible. Since souse hurrtcanes can cause up to $\$ 1$ billion in destruction plus great loss of Luman life, the potential savings might be enormous.

c. Mid-1atitule cyclone modification

Since this type of modification has not been analyzed in detail, is very difficult to speculate meaningfully about cost-benefit ratios. However, if it is assumed that a 1 million $\mathrm{Kg}$ mid-latitude cyclone seeding operation might enhance the precipitation occurring in approxiwateiy a

TABLE 4

Ratio of Damage Reduction to Modification Cost for Different Intensity Tropical Cyclones and Percentage Maximum Wind Decreases

Maximum Sustained

Percentage Reduction of Maximum Sustained Cyclone Cyclone Surface

Wind $(\mathrm{m} / \mathrm{sec})$

1 Surface Winds

\begin{tabular}{|c|c|c|c|c|c|c|}
\hline $\begin{array}{c}>80 \text { (assuming } 2 \text { million } \\
\mathrm{Kg} \text { of carbon dust) }\end{array}$ & $7 / 1$ & $35 / 1$ & $70 / 1$ & $120 / 1$ & $160 / 1$ & $200 / 1$ \\
\hline $\begin{array}{c}\text { 60-80 (assuming } 1.5 \\
\text { million } \mathrm{Kg} \text { of } \\
\text { carbon dust) }\end{array}$ & $3 / 1$ & $15 / 1$ & $35 / 1$ & $60 / 1$ & $75 / 1$ & $95 / 1$ \\
\hline $\begin{array}{l}\text { 40-60 (assuming } 1.0 \\
\text { million } \mathrm{Kg} \text { of } \\
\text { carbon dust) }\end{array}$ & $1 / 1$ & $5 / 1$ & $10 / 1$ & $18 / 1$ & $25 / 1$ & $30 / 1$ \\
\hline $\begin{array}{l}\text { 25-40 (assuming } 0.5 \\
\text { million } \mathrm{Kg} \text { of } \\
\text { carbon dust) }\end{array}$ & 0 & $2 / 1$ & $4 / 1$ & $6 / 1$ & $10 / 1$ & $14 / 1$ \\
\hline
\end{tabular}

$(1000 \mathrm{mile})^{2}$ area by $1 \%$, then about $2 \times 10^{5}$ acre-feet of extra precipitation would be produced. If half of this water was utilized, about $\$ 1$ 
million worth of excra water would be produced (assuming \$10 per acrefoot, a conservative price estimate). The cost of generating this much carbon from ground sources would be about $\$ 100,000$ to $\$ 200,000$ resulting in 5-1 to 10-1 favorable cost-benefit ratios. These figures are highly speculative in that no quantitative data on this modification hypothesis has been obtained.

d. Fog dissipation

It should be possible to evaporate certain types of radiation fog at least 1 hour earlier than the natural dissipation time using carbon dust seeding. A typical major airport may have 30 flights per hour scheduled to arrive, so dissipating fog at such an airport one hour earlier could save the cost of 30 flight reroutings. Fabre (1966) has estimated that the cost of rerouting a typical commercial flight is about $\$ 2500$. Therefore, approximately $\$ 75,000$ could be saved for each hour of successful artificial fog dissipation. This result should require no more than 10,000 to $25,000 \mathrm{lbs}$ of carbon dust produced from ground generators at $10 \mathrm{c}$ per pound or less. The total cost would be only about $\$ 1000-\$ 2000$ resulting in favorable cost-benefit ratios of approximately $\sim 30-1$ to $75-1$.

\section{e. Enhancement of early snowmelt}

It is very difficult to estimate the possible benefits from this type of modification. However, under certain climatic conditions seeding the boundary layer over agricultural areas for several days with about $10 \%$ area coverage of carbon dust and accelerating snowmelt might lengthen the growing season a week or more. In some years this could easily increase agricultural output by at least $1 \%$. Based on a rough estimate of $\$ 100 /$ acre agricultural output, the savings would be on the order of $\$ 1$ per acre or more. In some situations savings many times this amount might 
be obtained. Carbon dust at $10 \%$ area coverage requires about $1 / 6 \mathrm{~kg}$ of carbon per acre. Since the carbon could be generated from relatively cheap ground sources for about $\sim 5-10 c$ per $\mathrm{Kg}$, the cost of carbon seeding should be no more than $3 c$ per acre per day. Since multiple day use of the carbon is likely for this large-scale application, a week of seeding should cost $10 \mathrm{c}$ per acre or less. This would result in a favorable cost-benefit ratio of at least $10-1$.

f. Summary

Although the above estimates are quite crude, they do indicate that favorable cost-benefit ratios may indeed be realized for a number of carbon dust schemes. Even though petroleum prices are likely to continue to rise in the future, so too will agricultural prices. These ratios should not be significantly altered by the rising price of petroleum. 


\section{SCIENTIFIC UNKCNOWNS AND POTENTIAL PROBLEMS}

Although the potential for meso-scale weather modification with carbon dust appears to be very possible at this time, there is a great deal more research that must be accomplished. Much more must be learned ab out:

1) The best and most efficient ways of manufacturing carbon dust from $j$ et engines and in other ways from ship and land sites, and all the attendant technical problems. Some of these have been discussed by Stokes in Paper III. What are the best petroleum fuels to use? Can a good quality control on the size of the particles be maintained? Will the small $1 / 100$ to $1 / 10$ micron particles diffuse out from the jet exhaust without appreciable agglomeration? Can we guarantee that the cracking of the hydrocarbon feedstock will not produce significant amounts of carcinogenic material?

2) How does the carbon horizontally diffuse in the natural environment of the boundary layer and in the area above the boundary layer? Will it tend to cluster in selective areas as might be expected if the boundary layer is structured with horizontal roll vortices or with Benard type thermal convection?

3) How will the carbon warming affect the vertical diffusion and advection of the carbon dust during the heating day? How will the shielding of the carbon by the clouds affect the energy gain? These are both potentially serious problems. It may prove to be difficult to hold a high percentage of the carbon dust within the boundary layer during the solar heating day. The initial morning heating will likely cause early day convection and lead 
to significant boundary layer carbon loss. If spread evenly over large areas, however, the carbon loss in 10 hours through upward advection should not lead to massive dust depletion out of the lowest $200-300 \mathrm{mb}$.

When the carbon stimulates extra convection, an additional local up and down recycling of mass occurs. In these situations, the mean motion is not representative of the actual vertical motion. As previously discussed by Gray (1973) for tropical cloud clusters, the mean vertical motion at cloud base is but a fraction of the actual up-and-down local circulation. If the carbon dust stimulates very active cumulus convection, then it is likely that an extra up-and-down circulation perhaps 5 to 10 times the mean vertical circulation will occur. In a 10 hour period this extra upward circulation may advect as much as half to two-thirds of the sub-cloud layer mass to higher levels and largely replace it by descending motion surrounding the cumulus. The carbon induced solar heating inputs to the boundary layer are thus likely to be significantly reduced, especially during the latter part of the heating day.

A large portion of this sub-cloud layer heating loss by upward carbon advection will be made up for by a compensating heat gain at levels just above the boundary layer. Much of the carbon dust to leave the sub-cloud layer will be carried upward by the small cumulus or stratocumulus and will remain within the lower troposphere. These smaller cumulus have lifetimes of but 10-20 minutes. As they die out, the carbon they captured from lower levels should again be liberated for solar absorption, although 
in-drop agglomeration will reduce the high energy absorption to mass ratios. Some of the upward advected carbon particles will later be carried back into the sub-cloud layer in downdraft motions and again be available for low-level solar energy input. Only the carbon carried upward in tall cumulus or that scavenged by raindrops during the 10 hour solar heating period will be lost from the lower troposphere.

Additional loss of heating will result from clouds sheltering the carbon dust. This is only a significant problem with the development of layered clouds, since the meso-scale area percentage coverage with cumulus is typically less than 5-10 percent. Most of the solar radiation penetrates through the majority of cirrus cloud decks which are not surrounding active $\mathrm{Cb}$ convection.

It may prove more desirable to seed the more thermally stable layer just above the sub-cloud region. As shown in Figs. 16 and 17, this layer will hold the heating without convection for a much longer period and permit a higher level of solar energy gain than would be possible in the boundary layer. Vertical motion induced just above the boundary layer should be nearly as effective in inducing meso-scale convergence as that in the boundary 1ayer.

Despite these losses in optimum sub-cloud layer heating, it is expected that the largest part of the theoretical energy gains of about 110 calories $/ \mathrm{cm}^{2}$ for $10 \%$ carbon coverage wi11 be received by the atmosphere below $600-700 \mathrm{mb}$ - the level of minimum total energy. Meso-scale energy gain at levels below 600-700 mb will enhance the meso-scale low level vertical motion and lead 


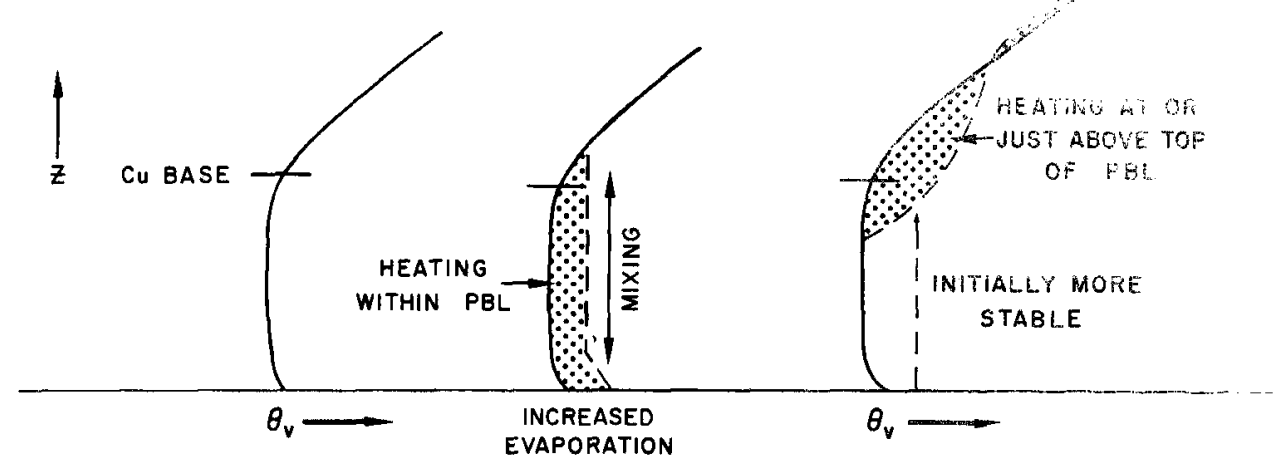

Fig. 16. Typical vertical profile of virtual potential temperature $\left(\theta_{\mathrm{v}}\right)$ over the oceans (left), possible $\theta_{\mathrm{V}}$ profile after carbon dust heating of the boundary layer to decrease stability (center), and $\theta_{\mathrm{v}}$ profile after placing a carbon dust cloud at the cumulus cloud base to inhibit early day cumulus convection (right).

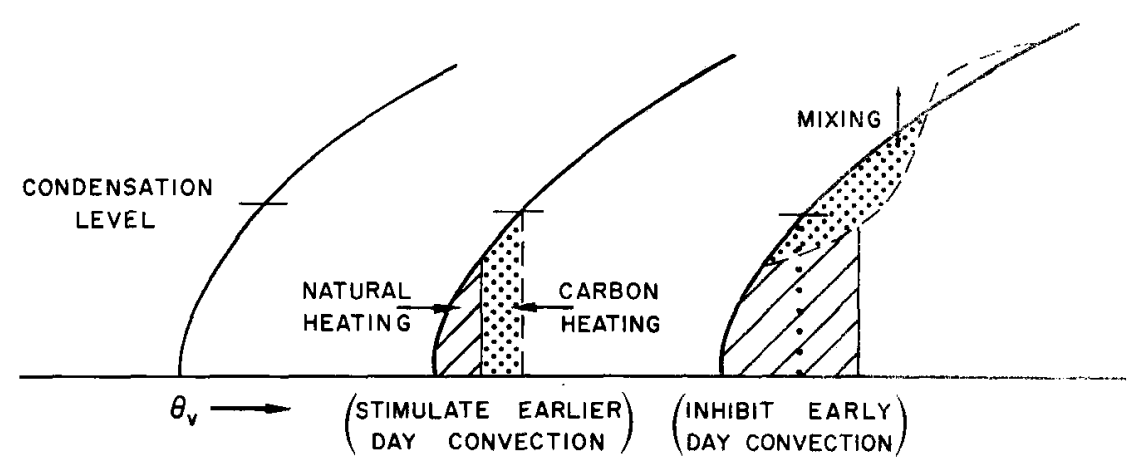

Fig. 17. Typical morning profile of virtual potential temperature $\left(\theta_{\mathrm{V}}\right)$ over land (left), possible $\theta_{v}$ profile after both natural and carbon dust heating of the boundary layer to decrease stability (center), and possible $\theta_{\mathrm{y}}$ profile after placing a carbon cloud at the condensation level to inhibit early day convection (right). 
to lower tropospheric convergence. Increased relative humidity and extra precipitation should follow. It must also be remembered that the extra evaporation rates are dependent on a downward mixing of upper level air. Much of the loss of thermal energy will be compensated for by a gain of moist energy.

We do not expect to be able to tap all of the potential artificial solar energy which is available. The carbon dust hypothesis does not depend on complete realization of all potentially available solar radiation. The assumed absorption values represent only about $15 \%$ of the total incident solar radiation. It is expected that beneficial weather changes can be brought about by only a 25 to 50 percent utilization of the theoretical values shown. A 25 percent utilization of the potential carbon dust solar energy gains still represents a 5 billion cal/lb solar energy source. Extra energy will result from evaporation. We expect the cloud and cloud environment numerical models to give considerable insight into this problem. It is hoped that models will be developed which will treat the carbon dust as a variable and explicitly follow it in the model. 4) The amount of extra evaporation which will occur due to the downward mixing of drying air to the sea surface must be better specified and its later influence on cumulus enhancement better understood. What are these quantitative values?

5) To what extent will the artificially enhanced cumulus convection act as a 'feed back' mechanism to further Intensify the mesoscale flow system in which it is embedded? To what extent will the tropospheric vertical wind shear of the artificially enhanced 
meso-system inhibit a cumulus convection feed back? These are basic meteorology problems which are presently being attacked by a variety of meteoralogical groups under the overall objectives of the GARP program.

6) If carbon dust induced extra precipitation can be achieved, what are the best estimates of the economic gains to be realized? If hurricane inner core structure can be weakened, what are the potential economic gains? In what other ways might carbon dust be beneficially utilized by man?

7) Although, as discussed in Paper IV, no rational environmental problems are foreseen, all aspects of the pollution and health questions must be considered. A larger number of environmental experts must be consulted and a broad ranging dialogue on this subject started.

\section{a. Summary}

There are many problems to be investigated before the potential of carbon dust can be fully realized. Nevertheless, our careful consideration of this subject leads us to believe that these as yet unresolved questions and problems will, with more study and experiment, be shown not to be insurmountable hurdles. 


\section{PROPOSED RESEARCH PROGRAM}

The authors believe that a broad ranging research program on the feasibility of weather modification from carbon dust seeding should be started. Research should be directed in four topic areas. They are:

a) numerical modeling studies,

b) observational studies of naturally occurring meso-scale heat sources,

c) engineering and field test studies,

d) economic studies of potential modification influence.

\section{a. Numerical modeling studies}

It is crucially important that numerical simulations of the influence of carbon dust heat sources on several different scales of motion be conducted on many different types of models. These models in combination are likely to determine the atmospheric response to the proposed heating mechanism. The areas which should be modeled include:

1) Individual cumulus modeling. Individual cumulus modeling is required to more thoroughly study the influence of local convergence and heat and moisture sources and sinks on individual cumulus convection. These models will also aid in the study of carbon dust diffusion and dispersion.

2) Cloud-cloud enviroment modeling. This type of modeling should simulate the influence of carbon dust heating on clcud and pre-cipitation stimulation. It will also allow the determination of carbon dust trajectories and changes of carbon concentration with time both in and around the cloud.

3) Meso-scale tropical modeling. Meso-scale modeling of the tropical atmosphere will simulate the carbon dust enhanced cumulis con- 
vection on a size and time scale larger than that accomplished by cloud-cloud environment modeling. It will deal with precipitation enhancement associated with the carbon dust induced tropical cloud cluster genesis and its intensification, etc.

4) Sma11-scale boundary layer simulations. Modeling of moist boundary layer response to forced heating is desirable to determine the character of the cumulus response to varying lapserate, moisture, wind patterns, etc. How rapid is the boundary layer response? How do the cumulus sizes and area coverages vary? This model should also permit analysis of the amount of extra carbon dust inducted evaporation.

5) Tropical storm modeling. It is desirable to evaluate the carbon dust hurricane wind reduction hypothesis using a variety of tropical storm models. What is the best way to alter the tropical storm?

The above types of numerical models can treat the artificial carbon dust heat source on a variety of scales of motion. It is expected that considerable insight into the potential for this type of weather modification will result from such model studies.

\section{b. Proposed observational program}

Extensive observational studies should be conducted to better define and better understand naturally occurring heat and energy sources. Many of the questions we have concerning the potential influence of carbon dust heat sources may likely be found in the available meteorological observations if we make the effort to look at all the available data sources. These observational studies should include:

1) Extensive satellite investigation of cloud development in asso- 
clation with islands and peninsulas. The synchronous satellite pictures should be the primary tool for this. The regular weather satellites should also be used.

2) More sea-breeze studies should be accomplished. They are a part of the meso-scale source influence. Extra insights are likely to be obtained. More radar studies of cumulus convection near coasts, islands and peninsulas will be made. The good weather radars at Key West, Miami, Applalachacola, and along the Gulf and United States Coasts can 1ikely be very well exploited for better understanding of the influence of daytime heat sources.

3) Observational investigations of the influence of surrounding seasurface temperatures on hurricane and typhoon intensity should be made. As hurricanes move northward to extra-tropical latitudes, they sometimes intensify for 12-18 hours before weakening. This is believed to result from an increase of the surrounding vertical stability as cold air begins to surround the storm while the center stays warm. This is likely to be an analogous but opposite influence to the proposed carbon dust heating of the surrounding hurricane circulation. In the former situation the storms strengthen from the stabilizing of the boundary layer. In the latter case they are hypothesized to weaken from an opposite influence. Studies like this are likely to give important verifying information about the association of outer hurricane thermal stability and hurricane inner-core intensity.

4) More observational studies of the influence of mountains and terrain features on the diurnal cycle of cumulus convection should also be accomplished along the lines of Henz's (op.cit.) 
study. There are many sources of information which can be studied from this point of view. Mountain and terrain heat sources are believed to be reasonably analogous to the type of heat source which is possible from carbon dust.

5) The effects of naturally occurring large local concentrations of aerosols on the atmosphere should be further studied to determine if any significant similarities exist between the effects of carbon dust and those of other natural or man-induced aerosols.

6) More detailed satellite observations of clouds over land areas should be made to determine the correlation between morning clear areas and afternoon thunderstorm locations as is being researched by Purdom (op,cit.). How are the daily heating and the vertical stability curves altered?

\section{c. Engineering and field test program}

Engineering tests. Paper III discussed the technical feasibility of carbon dust generation from jet aircraft engines. No insurmountable problems are envisaged. However, much study and testing must go on before all of the engineering technicalities of the best method of carbon dust generation can be specified.

In the initial development stages of this project, field programs will probably be accomplished from ground sources only. The deployment and alteration of jet aircraft is believed to be too expensive for early tests. This can be accomplished at a later date.

The exact modifications to an existing jet engine required to produce the necessary sizes and amounts of carbon dust must be better determined. First, an after-burner type jet engine must be obtained and 
testing begun to determine the quantity, particle size, cost, etc., of the carbon generated. A sub-contractor must be found to set the engine up and test it. There are few jet engine test facilities in the United States. At certain of these facilities, such as the Naval Air Station in Trenton, New Jersey, testing would probably not be feasible because of the large smoke plume. The Air Force has test facilities at remote sites in Tennessee and at Edwards Air Force Base in California. Smoke testing is possible at these locations. Another facility is located in a jungle type region near West Palm Beach, Florida.

Once the necessary engine modifications have been tested, the generator should be evaluated with respect to its airborne operational capability. These test operations would be necessarily more complex. The modified engine would have to be operated on an engine test stand to evaluate performance characteristics and to permit more detailed analysis of its operation. We envisage this stage of development as best being accomplished after a number of ground-based field tests have been completed to substantiate the atmospheric response to the carbon heat source.

Field tests. Once a ground-based carbon generator has been designed, fabricated, and tested, two stages of field operations should likely be undertaken. The first stage would consist of small scale plume generation and evaluation tests while the second would entail a large scale field program designed to evaluate atmospheric response to the carbon heat source.

The small scale test would probably entail only one or two carbon generators. Carbon dust plumes would be generated over an uninhabited area such as the ocean just northeast of Key West or in one of the western deserts. Using aircraft and mobile ground observers, measurements 
would be taken to determine carbon particle concentrations and size distributions, radiation attenuation, and sensible temperature changes. Position of the carbon dust cloud would be recorded, and environmental parameters would be monitored. The results of this first test should provide quantitative data regarding the production of carbon dust and the amounts of solar energy absorbed by the carbon clouds as well as estimates of the motion and diffusion of the carbon dust under various weather conditions. Any atmospheric responses to the plume would be noted, but these effects should be small due to the small amounts of carbon which would be utilized in these initial tests. The location of the test site is not critical for this type of operation.

If the small scale tests prove successful, a larger scale field program should be undertaken. The purposes of this second field program would be to demonstrate the feasibility of dispersing a large amount of carbon dust (probably $100,000 \mathrm{Kg}$ or more) into a carbon cloud of the dimensions and characteristics desired and to produce a detectable atmospheric response. This operation would be carried out on a large enough scale so that the results of a few runs should give a strong indication of the feasibility of the proposed full scale carbon modification programs.

This large field test program should be carried out in an environment similar to that proposed for the full scale modification operations and also one free from initial pollution considerations. The two ground sites which seem to offer the best combination of logistical and support capabilities, climatological conditions, and minimum possible pollution potential are the western end of the Florida Keys and the Mariana Islands in the Pacific, specifically Guam, Rota or Saipan. Both of these sites are located in the trade winds so that carbon plumes could be generated 
simultaneously from a number of points on their western coasts merging into a single carbon cloud downwind over the ocean. The preferable location for this large scale program is the Florida Keys. If the politically sensitive question of pollution were to touch off irrational and emotional problems, then it might be necessary to move the field test site to Guam or one of the islands just north of Guam. As discussed in Paper IV, there appear to be no valid rational pollution problems for a seeding operation which creates a carbon cloud over the ocean. Both sites offer good logistical support facilities and radar coverage for monitoring the tests. The primary disadvantage of operating in the Mariana Islands is the large distance from the continental United States. If long lead time planning were accomplished, the Mariana Island location should prove to be satisfactory. Military transportation is available on a low priority basis. The primary disadvantage of the Florida Keys site is the large recreational tourist industry in this area. Precautions would have to be taken to avoid conflicts with private fishing boats in the dispersal area on test days. However, a large portion of the sea area likely to be affected is a U.S. Navy and Air Force operational training area subject to their control. This should facilitate coordination of the testing with local interests.

Either of the above sites should prove suitable for a large scale field operation of the proposed dimensions. The exact scale and nature of the program would be determined by the results of the previous testing. The ultimate purpose of the field programs would be to obtain enough information concerning the feasibility question to reach a yes or no decision such that if yes, a large governmental agency could step in and undertake an expansion of the program in a number of directions. 
d. Economic studies

Economic studies must be undertaken simultaneously with the theoretical and engineering studies. As more quantitative data is obtained from the modeling and observational studies more detailed studies must be accomplished concerning the individual regional potential cost-benefit ratios of the various proposed schemes. Each type of operation can be analyzed in terms of economic potentials. Before operational modifications can be undertaken, the exact target sites must be carefully studied so that the potential effects of the operation upon all facets of the regional economy are well understood. 
VII. COMPARISON OF CARBON DUST AND SILVER IODIDE MODIFICATION TECHNIQUES

Weather modification over the last quarter-century has been almost exclusively concerned with the use of silver iodide to freeze supercooled cloud material. Space and time scales of modification have been restricted to those of the cloud. This type of modification requires the presence of preexisting super-cooled clouds which, due to the typically large variations of convective activity, are often not available. The effectiveness of the silver iodide scheme is thus limited by both the amount of super-cooled water available and by the cloud enhancement potential of the release of heat of fusion. By contrast, the potential for energy gain from carbon dust seeding is not restricted by the amount of convective activity or, disregarding cost, by space scale.

As extensively discussed by Simpson (1970), Woodley (1970) and Simpson and Woodley (1971), direct enhancement of individual cumilus cells appears to be feasible. However, it has not yet been demonstrated that seeding of individual cumulus clouds to increase precipitation can be cost-effective except in special cases as may be possible over southern Florida. In addition, the times and locations of applications of individual cloud seeding are quite limited by the special conditions required for economic gain by this type of seeding. It would appear that greater potential economic benefit may be possible from modification of the atmosphere on a larger scale.

The primary problem with silver lodide as a meso-scale modification agent is that much of the heat gained from the extra cumulus convection does not result in a sufficient energy accumulation. Much of the libera- 
ted heat of fusion goes to increased cloud vertical motion and potential energy gain which is exported to the surroundings without local energy gain. In addition, energy is lost when the extra condensed and frozen cloud material later melts and reevaporates. In contrast, carbon dust directly warms the atmosphere. Much larger energy accumulations are possible.

The evaluation of carbon dust modification experiments should be considerably easier than the evaluation of silver iodide experiments. This is because:

1) With silver iodide one is always operating within the natural atmospheric 'noise' level. Hypothesis verifications require long and complicated radomized sampling. By contrast, carbon dust modification on the meso-scale is likely to produce influences large enough such that verification will be 'sélf evident' to a considerable extent. Complicated verification is likely not to be necessary.

2) The carbon dust radiation induced influences on the atmosphere can be much more readily understood and numerical models developed to simulate these influences. By contrast, the fundamental physical processes associated with cloud drop formation, freezing, accretion, etc. are not as well understood at this time. Numerical modeling of cloud micro-physical processes is very complicated and the results accepted with less confidence. It may be beneficial to employ the silver iodide type of cumulus enhancement techniques in conjunction with the carbon dust seeding. Meso-scale atmospheric response might be enhanced if the carbon dust was used to create or stimulate a meso-scale cumulus convective system and silver iodide seeding was then employed to further enlarge the already existing cumulus elements. 


\section{RESEARCH JUSTIFICATION}

Continued research concerning large-scale carbon dust weather modification appears to be well justified on scientific, economic and humanitarian grounds.

1) Predicted future global water and food shortages dictate that man fully explore his potential for beneficial weather modification. Even if man does not now contemplate using many of the schemes studied, it is important to have multiple modification techniques "on the shelf" as insurance in case of unforeseen weather catastrophies. We are all aware of the severe detrimental consequences which weather catastrophies can have; witness the Bangladesh tropical storm of December 1970 and the recent draught in North Africa. A variety of future benefits may result if man is able to develop programs to meet these and similar situations.

2) It is important for weather modification to have a new stimulus and a new avenue of direction. Modification efforts in the last quarter century have been almost exclusively directed towards bringing about changes in individual clouds or small groups of clouds. It is time for man to consider weather modification from other physical hypotheses and on other scales of motion.

3) A considerable investment of scientific manpower and funds have gone into the development of numerical models. Many fine meteroological models treating a variety of atmospheric phenomena are now available. The influence of carbon dust heat sources can be readily tested in most of these numerical models with only small model alterations. This will offer a greater utilization of these 
models, and will allow for a great deal of hypotheses testing at minimum cost. The physical processes on the meso and synoptic scales of motion are much better understood than the sub-cloud and microphysical processes which are necessary for individual cloud alteration. Therefore, it is likely that the 'carbon dust' hypothesis can be simulated in numerical models better than the sub-cumulus processes can be modeled.

4) A number of other beneficial uses of the carbon dust heat source are very likely to be uncovered by this research. Much of the knowledge gained may well be relevant and useful to studies in solar energy, urban pollution abatement, and weather forecasting. It is important that man explore all aspects of solar energy.

\section{a. Summary}

Research on the potential use of carbon dust seems well justified by the likely future needs of mankind for more reliable amounts of rainfall and other weather related benefits.

\section{Acknowledgements}

The authors acknowledge beneficial discussions on this subject matter with Professor Myron Corrin of Colorado State University, Dr. Russell Elsberry of the U.S. Navy Postgraduate School, Dr. Raul Lopez of the University of Puerto Rico, Dr. Stanley L. Rosenthal of the NOAA Miami office, Professor Harold Orville of the South Dakota School of Mines and Mr. William M. Fingerhut of Colorado State University. The authors are also appreclative of the excellent assistance rendered them in manuscript preparation by Mrs. Barbara Brumit and Mr. Edwin Buzzel1. 


\section{REFERENCES}

Atkinson, B. W., 1968: A preliminary examination of the possible effect of London's urban area on the distribution of thunder rainfall, 19511960. Trans. Inst. British Geogra., 44, 97-118.

Beebe, R. C. and G. M. Morgan, 1972: Synoptic analyses of sumer rainfall periods exhibiting urban effects. Preprints Conference on Urban Environments, AMS, Boston, 173-175.

Bhumralkar, C. M., 1972: An observational and theoretical study of atmospheric flow over a heated island. U. of Miami Division of Atmospheric Science Research Report, NSF Grant No. GA-14156, 150 pp.

Chang, S. W. and H. D. Orville, 1973: Large scale convergence in a numerical cloud mode1. J. Atmos. Sci., 30, 947-950.

Changnon, S. A., 1968: The Laporte weather anomaly-fact or fiction? Bull. American Meteor. Soc., 49, 4-11.

Changnon, S. A. and F. A. Huff, 1973: Enhancement of severe weather by the St. Louis Urban-Industrial Complex. Preprints of Eighth Conference on Severe Local Storms, AMS, Boston, 122-129.

Deardorff, J. W., 1973: Test of a parameterization of the tropical subcloud layer. NCAR Research Report, 35 pp.

Diamond, M., 1953: Evaporation or melt of snow cover. U.S. Snow, Ice, and Permafrost Research Establishment Research Paper No. 6, 6 pp.

Dirks, R. A., 1969: A theoretical investigation of connective patterns in the lee of the Colorado Rockies. Dept. of Atmos. Sci., Colo. State Univ. Research Report No. 145, 122 pp.

Downie, C., 1960: Cloud modification with carbon black. Wentworth H.H. Conference on Cumulus Dynamics 191-208.

Elsberry, R. L., E. Harrison and W. M. Gray, 1974: Simulation of development of meso-scale convection regions by artificial heat sources. Preceeding of WMO-AMS Conference on Tropical Meteorology, Nairobi, Jan., (companion paper to this report).

Estoque, M. A. and C. M. Bhumralkar, 1969: Flow over a localized heat source. Mon. Wea. Rev., 97, 850-859.

Fabre, M. R., 1966: Improvement of visibility over airport runways during foggy weather. Translated by G. S. Rinehart, Nov., 1967. U.S. Army Electronics CommandReport on DA TASK No. 1T014501 B53 A-06, $51 \mathrm{pp}$.

Fenn, R. W. and H. Oser, 1962: Theoretical considerations on the effectiveness of carbon seeding. U.S. Army Signal Research and Development Lab. Report No. 2258,25 pp. 


\section{REFERENCES (cont'd)}

Flohn, H., 1971: Data published in inadvertent climate modification. M.I.T. Press, Cambridge, Mass., 308 pp.

Frank, W. M., 1973: Characteristics of carbon black dust as a large-scale tropospheric heat source. Dept. of Atmos. Sci., Colo. State Univ. Research Report No. 195, 52 pp.

Gray, W. M., 1972: Cumulus convection and large-scale circulation, Part III. Broadscale and meso-scale considerations. Dept. of Atmos. Sci., Colo. State Univ. Research Report No. 190, 80 pp.

Gray W. M., 1973: Feasibility of beneficial hurricane modification by carbon black seeding. Dept. of Atmos. Sci., Colo. State Univ. Research Report No. 196, 130 pp.

Gray W. M., and D. J. Shea, 1973: The hurricane's inner core region, II, J. Atmos. Sci., 30, 1565-1577.

Harrison, E. J., Jr., 1974: Experiments with a nested, three-dimensional grid system. To be published in J. Atmos. Sci.

Harrison, E. J., Jr. and R. L. Elsberry, 1972: A method for incorporating nested finite grids. J. Atmos. Sci., 29, 1235-1245.

Henz, J. E., 1974: Colorado high Plains thunderstorm systems. M.S. thesis Dept. of Atmos. Sci., Colo. State Univ., 82 pp.

Howard, R. A., J. E. Matheson, and D. W. North, 1972: The decision to seed hurricanes. Science, 176, No. 4040, 1191, 1202.

Lopez, R. E., 1973a: A parametric model of cumulus convection, J. Atmos. Sci., 30, 1354-1373.

Lopez, R. E., 1973b: Cumulus and meso-scale interactions. Mon. Wea. Rev., $101,856-870$.

Malkus, J. S., 1963: Tropical rain induced by a small natural heat source. J. Appl. Meteor., 2, 547-556.

Malkus, J. S. and M. E. Stern, 1953: The flow of a stable atmosphere over a heated island-Part I; Observational studies of convection. I. Meteor., $10,30-41$.

Miller, B. I., 1964: On the filling of tropical cyclones over land. Mon. Wea. Rev., 92 pp.

Orville, H. D., 1965a: A numerical study of the initiation of cumulus clouds over mountainous terrain. J. Atmos. Sci., 22, 684-699.

Orville, H. D., 1965b: A photogrammetric study of the initiation of cumulus clouds over mountainous terrain. J. Atmos. Sci., 22, 700-709. 
REFERENCES (cont'd)

Orville, H. D., 1968: Ambient wind effects on the initiation and development of cumulus clouds over mountains, J. Atmos. Sci, 25, 385-403.

Orville, H. D. and L. J. Sloan, 1970a: Effects of higher order advection techniques on a numerical cloud model. Mon. Wea. Rev., 98, 7-13.

Orville, H. D. and L. J. Sloan, 1970b: A numerical simulation of the life history of a rainstorm. J. Atmos. Sci., 27, 1148-1159.

Palmén, E., and H. Rieh1, 1957: Budget of angular momentum and energy in tropical cyclones. J. Meteor. 14, 150-159.

Purdom, J. F. W., 1973: Satellite imagery and the mesoscale convective forecast problem. Preprints of Eighth Conference on Severe Local Storms, AMS, Boston, Mass., 244-251.

Rieh1, H., 1963: Some relations between wind and thermal structure of steady-state hurricanes. J. Atmos. Sci., 20, 276-287.

Rosenthal, S. L., 1970: A circularly symmetric primitive equation model of tropical cyclone development containing an explicit water vapor cycle. Mon. Wea. Rev., 98, No. 9, 643-663.

Rosenthal, S. L., 1971a: A circularly symmetric primitive equation mode1 of tropical cyclones and its response to artificial enhancement of the convective heating functions. Mon. Wea. Rev., 99, 414-426.

Rosentha1, S. L., 1971b: The response of a tropical cyclone mode1 to variations in boundary layer parameters, initial conditions, lateral boundary conditions, and domain size. Mon. Wea. Rev., 99, 767-777.

Ruprecht, E. and W. M. Gray, 1974: Analysis of satellite-observed tropical cloud clusters. Dept. of Atmos. Sci., Colo. State Univ. Research Report No. 219, 91 pp. (Submitted for publication in Tellus).

Simpson, J., 1970: Cumulus cloud modification: Progress and Prospects. A Century of Weather Progress, AMS, 143-155.

Simpson, J., and W. M. Woodley, 1971: Seeding cumulus in Florida: New 1970 results. Science, 172, 117-126.

Smith, R. C., 1957: Air motion over a heated land mass - Part II. Quart. J. Roy. Meteor. Soc., 83, 248-256.

Smith, R. B., R. Wexler and A. H. Glaser, 1959: Modification of fog and cloud particles in the atmosphere. Allied Research Associates, Inc., Final Report, Part II, Air Force Contract No. AF 19(604)-3492, $56 \mathrm{pp}$. 


\section{REFERENCES (cont'd)}

Williams, K. and W. M. Gray, 1973: Statistical analysis of trade wind cloud clusters of the western North Pacific. Tellus, 25, 313-336.

Woodley, W. L., 1970: Rainfall enhancement by dynamic cloud modification. Science, $170,127-132$. 
William M. Gray, is professor of Atmospheric Science at Colorado State University. He has been on the Colorado State University Faculty since 1961. He received a B.A. from George Washington University in 1952 and M.A. and $\mathrm{Ph} . \mathrm{D}$. degrees from the University of Chicago In 1959 and 1964 . He has been engaged in observational meteorological research for 17 years. He was a weather forecaster in the U.S. Air Force from 1953 to 1957. His research interests have been directed to studies of cumulus convection, cumulus broader-scale flow interaction, tropical storms, tornadoes, cloud clusters and tropical meteorology in general.

William M. Frank, is a $\mathrm{Ph} . \mathrm{D}$. graduate research assistant at Colorado State University. He received a B.S. degree in aeronautical engineering from M.I.T. in 1968 and a M.S. in atmospheric science from Colorado State University in 1973. He received an award as outstanding graduate student in the College of Engineering in 1974. From 1968 to 1972 he was a U.S. Air Force officer assigned as an Aeronautical Systems Test Engineer for the C-5A Project at Edwards AFB, Ca. He has been involved in all phases of the carbon dust research. His meteorological background is in tropical storms, tropical meteorology and radiation.

Myron L. Corrin, has been a professor of Atmospheric Science at Colorado State University since 1967. He received his B.S. and M.S. degrees in chemistry from Marquette University in 1939 and 1940 . He received a $\mathrm{Ph} . \mathrm{D}$. degree in physical chemistry from the University of Chicago in 1946. He has previously been on the faculties of the University of Chicago, University of California and the University of Arizona. He has approximately 40 publications on the subjects of atmospheric chemistry, air pollution, heterogeneous nucleation, surface chemistry, and on the chemistry and physics of aerosols. He is a consultant to the Phillips Petroleum Co. and the National Science Foundation. Other activities include: alternate member to Colorado Air Pollution Variance Board; Transportation Committee, Colorado Energy Task Force; Chairman, Environmental Engineering Committee, Colorado State University; Chairman, Environmental Resources Center, Colorado State University.

Charles A. Stokes, is a consulting chemical engineer, 157 Hun Road, Princeton, N.J. Dr. Stokes is a registered professional engineer. He received a B.S. from the University of Florida in 1938 and a Sc.D. degree from M.I.T. in 1951. Dr. Stokes previous positions include: Vice President of Technology and Planning and Director of Columbian Carbon (subsidiary of Cities Service), 1960-69; Director Petroleum Chemicals, Inc. and Columbian Carbon International, 1964-67; Vice President and Technical Director of Texas Butadiene and Chemical Corp., 1955-59; Director Research and Development of Cabot Corporation, Boston, Mass., 1945-55; Vice President and Director, Petrocarb Inc., 1943-45. The scope of his activities have included: Technical and management consultant in the chemical and allied products fields. Special experience in the following fields: Carbon black, activated carbon, and industrial carbons; basic petrochemicals; synthetic rubber and plastics; air pollution control, jet engine power and exhaust problems, etc. 


\section{APPENDIX A.}

Equations for absorption, reflection, and transmission of incident solar radiation, derived by Korb and Moller (1962) from Chandrasehkar's equation of radiative transfer.
A) for albedo $=0$.
Transmission $=\mathrm{T}_{0}$
Reflection $=R_{0}$
Absorption $=A_{0}$
Zenith angle $=z$

$$
\begin{aligned}
T_{0}= & \frac{1}{2 \cos z}\left[\frac{(N-M)\left[e^{-(\sec z-\sqrt{E F}) t}-e^{-(\sec z+\sqrt{E F})}\right]+(M+N)\left(\frac{P}{Q}-\frac{Q}{P}\right)}{\left(\frac{Q}{P}\right) e^{\sqrt{E F} t}-\left(\frac{P}{Q}\right) e^{-\sqrt{E F} t}}\right] \\
& +e^{-(\sec z) t}\left(1+\frac{M+N}{2 \cos z}\right)
\end{aligned}
$$

$$
\begin{aligned}
& A_{0}=1-T_{0}-R_{0} \\
& K_{a}=\text { absorption Quantity }
\end{aligned}
$$

Where: $\quad E=\left(\alpha_{0}-\beta_{0}\right)\left(1-K_{A}\right)-1$.

$$
\begin{aligned}
& F=\left(\alpha_{0}+\beta_{0}\right)\left(1-K_{A}\right)-1+\frac{2 \alpha_{90}\left(1-K_{A}\right)^{2} \gamma_{z}}{1-\gamma_{90}\left(1-K_{A}\right)} \\
& G=\left(\alpha_{z}-\beta_{z}\right)\left(1-K_{A}\right) \\
& H=\left(\alpha_{z}+\beta_{z}\right)\left(1-K_{A}\right)+\frac{2 \alpha_{90}\left(1-K_{A}\right)^{2} \gamma_{z}}{1-\gamma\left(1-K_{A}\right)}
\end{aligned}
$$




$$
\begin{aligned}
& K=E I-G \sec z \\
& L=F G-H \sec z \\
& M=\frac{K}{\sec ^{2} z-E F} \\
& N=\frac{L}{\sec ^{2} z-E F} \\
& P=\sqrt{E F}+F \\
& Q=\sqrt{E F}-F
\end{aligned}
$$

$t=$ optical depth $=\int_{0}^{h}\left(\sigma_{E} N \pi r^{2}+\rho_{W} K_{W}\right) d h$

$$
\begin{aligned}
& \mathrm{N}=\text { number particles } / \mathrm{cm}^{3} \\
& \mathbf{r}=\text { radius particle }=. I \mu \\
& \rho_{\mathrm{W}}=\text { density water } \\
& \mathrm{K}_{\mathrm{W}}=\text { absorption quantity of water vapor }
\end{aligned}
$$

$\alpha, \beta, \gamma$ are scattering coefficients and depend upon the zenith angle of the sun. Values used are:

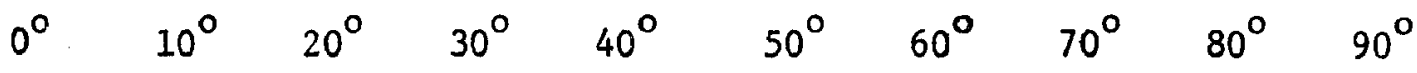

$$
\begin{aligned}
& \begin{array}{lllllllllll}
\alpha & .325 & .320 & .313 & .305 & .295 & .282 & .265 & .244 & .218 & .184
\end{array} \\
& \begin{array}{lllllllllll}
\beta & .108 & .111 & .115 & .119 & .124 & .129 & .140 & .152 & .165 & .184
\end{array} \\
& \begin{array}{llllllllllll}
\gamma & .567 & .569 & .572 & .576 & .581 & .589 & .595 & .604 & .617 & .632
\end{array} \\
& \text { B) For albedo } \neq 0 \\
& T_{T}=\text { Transmitted } \\
& R_{T}=\text { Reflected } \\
& A_{T}=\text { Absorbed } \\
& T_{T}=\frac{T_{0}}{1-q_{1}} \text { where }
\end{aligned}
$$




$$
\begin{aligned}
& q_{1}=\frac{A_{S}}{2}\left[\frac{\left(N^{\prime}-M^{\prime}\right)(Q / P-P / Q) e^{-t}+\left(M^{\prime}-N^{\prime}\right)\left(e^{-t \sqrt{E F}}-e^{t t \sqrt{E F}}\right)}{(Q / P) e^{t \sqrt{E F}}-(P / Q) e^{-t \sqrt{E F}}}\right. \\
& \left.-\left(N^{\prime}-M^{\prime}\right)\right] \\
& \text { and } R_{T}=R_{\mathrm{o}}+q_{2} T_{T} \\
& \text { where } \\
& q_{2}=\frac{A_{S}}{2}\left[\frac{\left(N^{\prime}-M^{\prime}\right)\left[e^{-(t-\sqrt{E F} t)}-e^{-(t+t \sqrt{E F})}\right]+\left(M^{\prime}+N^{\prime}\right)(P / Q-Q / P)}{\left(\frac{Q}{P}\right) e^{t \sqrt{E F}}-\left(\frac{P}{\bar{Q}}\right) e^{-t \sqrt{E F}}}\right. \text { (A 18) } \\
& \left.+e^{-t}\left(2+M^{\prime}+N^{\prime}\right)\right] \\
& G^{\prime}=(\bar{\alpha}-\bar{\beta})\left(1-K_{A}\right) \\
& 2 \alpha_{90}\left(1-\mathrm{k}_{\mathrm{A}}\right)^{2} \bar{\gamma} \\
& H^{\prime}=(\bar{\alpha}+\bar{\beta})\left(1-K_{A}\right)+\frac{}{1-\gamma_{90}\left(1-K_{A}\right)} \\
& \mathrm{K}^{\prime}=\mathrm{EH}^{\prime}-\mathrm{G}^{\prime} \\
& L^{\prime}=F G^{\prime}-H^{\prime} \\
& \mathrm{M}^{\prime}=\frac{\mathrm{K}^{\prime}}{1-\mathrm{EF}} \\
& N^{\prime}=\frac{L^{\prime}}{1-E F} \\
& A_{S}=\text { albedo expressed as a percentage } \\
& \bar{\alpha}=.275 \\
& \bar{\beta}=.135 \text { mean scattering coefficients } \\
& \bar{\gamma}=.590
\end{aligned}
$$


APPENDIX B

PROPOSED DESIGN, DEVELOPMENT, AND TESTING OF CARBON BLACK GENERATORS

by

Charles A. Stokes and Richard S. Reed

157 Hun Road, Princeton, New Jersey 08540

(Consultant to Department of Atmospheric Science, Colorado State University Fort Collins, C0)

This appendix discusses many of the proposed design and test procedures for the modification of jet engines to generate carbon black dust from surface or airborne sources.

\section{PROPOSED DESIGN}

\section{a. Sources of information}

Discussions were held with Pratt \& Whitney Aircraft Division of United Aircraft Corporation and with General Electric Company's Advanced Engineering and Technology Programs Department. The basis for design of facilities for carbon black production is our general background in the industry and patent literature.

\section{b. Approaches}

Two methods of producing carbon black in a jet engine were considered. In one carbon black feedstock (CBF) is injected into the engine in or near the plane of the V-gutters (see Figure 1 of paper II). The advantage of this method is that it requires only slight modification of the engine and is relatively free of the problems associated with injection of oil into very high temperature areas. The problem with this method is that there is a lot of oxygen present at the injection point and carbon black feedstock is as likely to be consumed as JP-4 fuel. It was suggested that the vaporized CBF would tend to go through the engine in streaks with limited mixing, and therefore would produce a reasonably good yield of 
carbon. However, it is probable that a large share of the carbon black feedstock would be burnt rather than cracked and that the yield of carbon would be quite low. A further complication of the addition of fuel well in excess of stoichiometric quantities is that flame stability might be poor. Finally, the increased luminousity of the flame and attendant increased radiation to the wall could easily cause overheating of the liner of the afterburner.

The second way of using a jet engine for carbon black production is the one which has been studied most. It consists of using a jet engine substantially as it is intended to operate except that instead of direct flow from the afterburner to the propulsion nozzle a section is added between these two components for carbon black production (see Fig. 2 of Paper III).

It is only at the outlet of the afterburner that the flame envelopes from various fuel inlet points have merged and that a reasonably consistent temperature profile across the chamber is obtained. This temperature is about $3,500^{\circ} \mathrm{F}$ at the center of the chamber. It falls gradually to around $3,000^{\circ} \mathrm{F}$, a fraction of an inch from the wall, and by means of perforations in the 1iner of the afterburner a lower temperature film is maintained next to the metal surface. The temperature of the metal liner of the afterburner is $1,400^{\circ}$ to $1,500^{\circ} \mathrm{F}$. Our plan would separate the nozzle, currently attached to the afterburner, and insert a section 6 feet long, and of the same internal diameter as the afterburner, between the afterburner and the exhaust nozzle. This should provide the conditions necessary to produce carbon black at high yields. 
c. Suitable engines

Both manufacturers of engines (Pratt \& Whitney and General Electric) agreed that for the purposes of this project, the best engines to use are some of the earlier models. These less advanced engines would be easier to modify and more readily available.

Pratt \& Whitney suggested the J57 as a suitable engine. This engine has an "air rate"* of $100 \mathrm{Ib} / \mathrm{sec}$ and an overall fuel consumption of .065 1bs. of fue1 per 1b. of air. The portion of this which is of concern is the .045 lbs. of fuel per 1b. of air which is consumed in the afterburner. For this project's purposes, the afterburner performs the same functions as the blast combustors in a conventional carbon black furnace. The JP-4 rate could be reduced to $3.0 \mathrm{lbs} / \mathrm{sec}$ to provide some air for the carbon section and feed about $10 \mathrm{lbs} / \mathrm{sec}$ of CBF. At a yield of $4.5 \mathrm{lbs} /$ gallon this would make about 5.0 Ibs. of carbon black per second. This would amount to a production of 18,000 lbs. of carbon black per engine per hour.

General Electric has suggested a larger engine, the J79, which has an air rate of $170 \mathrm{lb} / \mathrm{sec}$. Fuel combustion ratios in turbine and afterburner are approximately the same, so a carbon production of $30,0001 \mathrm{~b} / \mathrm{hr}$ per engine could be obtained. For test purposes, General Electric suggested the use of a J85 which is about one third the size of a J79. They do not foresee any problems in translating information obtained on the $J 85$ to the $J 79$.

* This is the total quantity of air entering the engine and is a common measure of engine size. 
d. Characteristics of jet engines

Arrangements of the $\mathrm{J} 57$ and the $\mathrm{J} 79$, and all other engines that would be considered, are sufficiently similar to be represented by Fig. 1(Paper III). This figure shows the air coming from the turbine section to the afterburner. The ratio of fuel to air in an engine is such that approximately one quarter of the oxygen content of the entering air has been consumed in the turbine section. The temperature of the air entering the afterburner ranges from $1,000^{\circ}$ to $1,200^{\circ} \mathrm{F}$. Engines do differ in the air velocity entering the afterburner. In the J57, this velocity may be close to $500 \mathrm{ft} / \mathrm{sec}$ but with the J79, a diffuser is used to increase the afterburner pressure, and this results in a reduction in the velocity to something in the reighborhood of $300 \mathrm{ft} / \mathrm{sec}$. These design differences have an effect on the length of carbon producing sections required to obtain a given contact time and, therefore, may be important to the selection of the most appropriate engine.

JP-4 fuel is admitted to the afterburner section through a number of axially oriented tubes with holes drilled at $90^{\circ}$ to the gas flow. The oil is quickly vaporized at the temperature of the surrounding air and the vapor is mizec with the air by the V-gutters, which may be arranged in many different patterns. In every case, the function of the V-gutters is to mix and to stabilize the flame. Flame envelopes initiate immediately down stream from the $\nabla$-gutters and then merge prior to the exit nozzle. Temperature profiles across the stream are very uneven until the entrance to the nozzle is approached. At that point, a reasonable estimate of the bulk stream temperature would be $3,000 \mathrm{~F}$. To protect the liner of the afterburner from excessive leat, air is bypassed around the turbine and admitted at the beginning of the afterburner, along the length of the afterburner 
through the holes drilled in the liner, and again just prior to the discharge nozzle. These air flows are carefully balanced, and any change in flame characteristics would require adjustment of the air distribution to maintain the metal temperatures below $1,600 \mathrm{~F}$. The outlet nozzle is automatically regulated to maintain the desired pressure in the afterburner. Velocity in the throat of the discharge nozzle is always the sonic velocity at the conditions present.

At the bottom of Fig. 1 of Paper III, the temperature profile through the afterburner is shown along with the velocity profile for an engine in normal full load operation. The change in velocity is due to temperature and pressure changes since the increase in moles of gases due to combustion is slight. The exhaust of a jet engine normally contains $5 \%$ excess air.

\section{e. Engine modifications}

To make carbon black efficiently, the conditions needed at the point where the oil is injected are: as high a temperature as possible, excess air in the range of 140 to $180 \%$, a high degree of turbulence, and sufficient residence time at temperature to permit the cracking reaction to take place. A standard engine could be run to provide a temperature near the outlet of the afterburner of $2,500 \mathrm{~F}$ to $3,000 \mathrm{~F}$. This should be sufficient. The quantity of air entering the afterburner is fixed by the turbine speed. By reducing the quantity of JP-4 burnt in the afterburner the amount of excess air required by the carbon section can be provided. The requirement of a high degree of turbulence is met. The requirement for residence time for the cracking reaction is not met and is the basis for the need for a separate carbon producing section following the afterburner. 
The primary modification required to make a jet engine an efficient carbon black producer is addition of a chamber in which the carbon black feedstock can be mixed with the hot gases from the afterburner, and given sufficient time, to condense or polymerize into primary carbon particles. No other basic changes in the operation of the jet engine occur as a result of adding a tailpipe extension and means for $C B F$ oil addition. The additional volume produced by vaporizing carbon black feedstock oil is not a major volume increase to the system, and any change in pressure which might tend to occur as a result of it would be compensated for by the automatic control on the nozzle.

Fig. 2 (Paper III) shows the arrangement of an engine as it would appear after addition of the carbon black producing section. A typical air velocity in this section would be about $800 \mathrm{ft} / \mathrm{sec}$; therefore, a residence time of 7.5 milliseconds would be obtained by addition of this section. Decomposition of the carbon black feedstock is an endothermic reaction. The heat for this reaction is provided by burning a portion of the feedstock. The amount which burns is controlled by regulating the amount of excess air available at the point where the carbon black feedstock is admitted. Since the amount of air brought through the engine is fixed, the primary control is therefore the amount of JP-4 admitted to the afterburner. In the temperature profile of Fig. 2 (Paper III), it has been assumed that an amount of excess air for the carbon section exists which is optimum from the standpoint of carbon production efficiency rather than propulsion. The engine will continue to provide almost as much thrust when making carbon black as when not. Thus, the velocity profile of this figure indicates that velocity is almost entirely a function of the temperature and is little influenced by the combustion reactions and the gas resulting 
from the cracking of the carbon black feedstock. In a rigorous analysis the influence of these components will need to be calculated, but their mass is so small in comparison with the system that it is negligible for our purposes.

\section{f. Thermodynamics}

The effect of adding a carbon production section to a standard jet engine can best be appreciated through a review of the thermodynamics of the complete system to which this unit has been added. Fig. A and calculations accompanying it provide such a review based on conditions typical of the engines recommended. The equipment and the cycle, in temperatureentropy coordinates, are shown in Fig. A. In this cycle, the work done by the turbine is just sufficient to drive the compressor. The gases are expanded in the turbine to a pressure such that the turbine work is equal to the compressor work. The exhaust pressure of the turbine is above that of the surroundings, and the gas can be expanded in the nozzle to the pressure of the surroundings. This is the situation of a jet engine without afterburner, and its cycle is that of points $1,2,3$, and 4 on the TS diagram. Since the temperatures in and out of the compressor are known, we can calculate the work and from it the temperature out of the turbine. This calculates to $1,300 \mathrm{~F}$ which is $100^{\circ}$ higher than the temperature which both GE and Pratt \& Whitney said would occur. Since the calculations in this paper are based on an ideal cycle, it is expected that they would come out higher than an actual cycle, due to the Irreversibilities in the compressor and turbine and because of the pressure drop in the flow passages and combustion chamber. Adjusting to the temperature measured in practice of 1,200 F, the calculated pressure in the afterburner is 33psi. In normal use the amount of fuel burnt in the afterburner is varied to produce the thrust desired, but the maximum 
THERMODYNAMICS OF JET ENGINE WITH AFTERBURNER AND CARBON PRODUCING SECTION
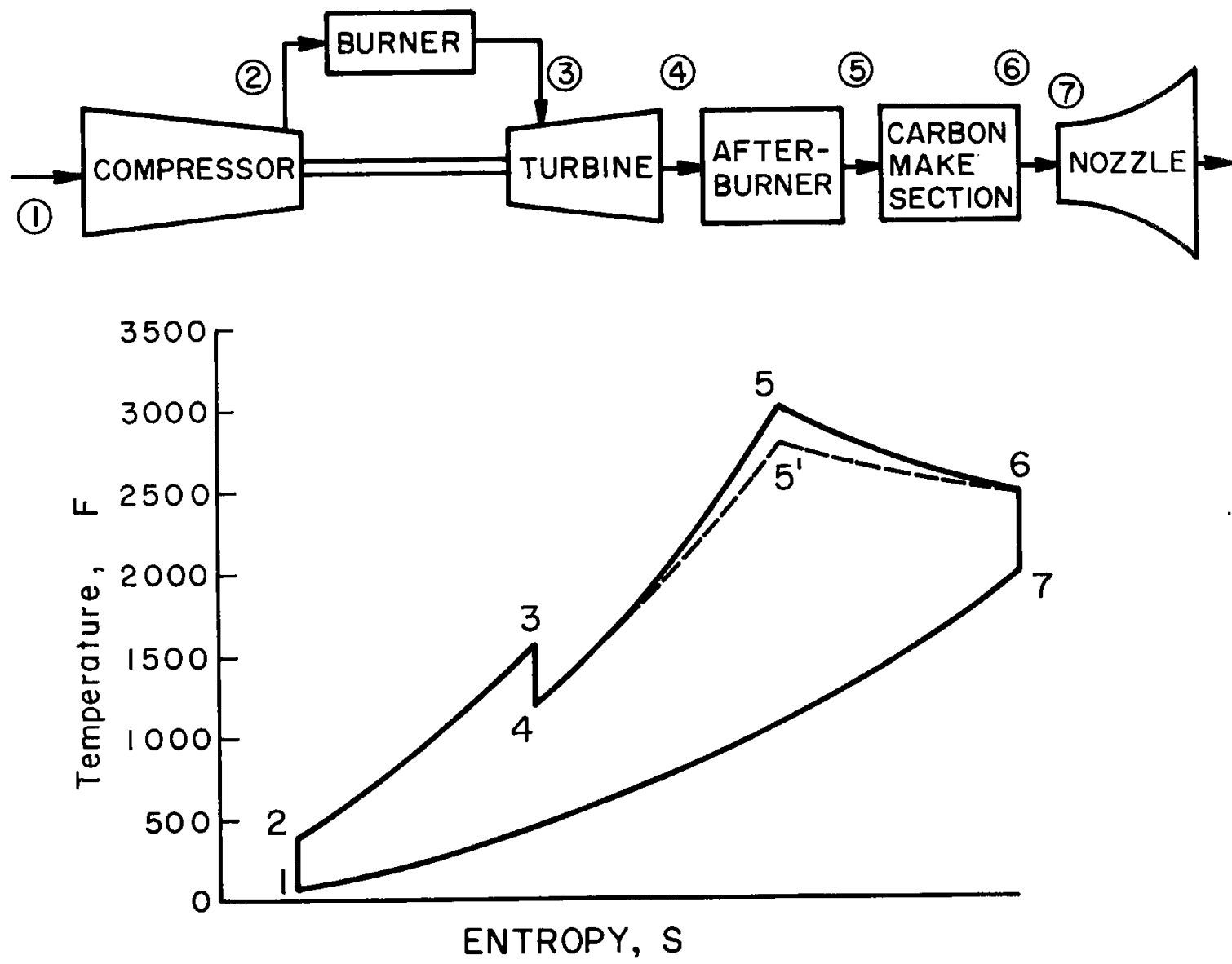

Fig. A. Thermodynamics of proposed engine modifications.

KNOWN

$$
\begin{aligned}
T_{1} & =60 \mathrm{~F}=520 \mathrm{R} \\
P_{1}=P_{7} & =14.7 \mathrm{PSI} \\
P_{2}=P_{3} & =70 \mathrm{PSI} \\
T_{3} & =1,600 \mathrm{~F}=2,060 \mathrm{R} \\
T_{4} & =1,000 \mathrm{~F}=1,460 \mathrm{R}
\end{aligned}
$$

WORK IN COMPR = WORK IN TURBINE

$$
W_{c}=W_{t}=C_{p}\left(T_{3}-T_{4}\right)
$$

BRAYTON CYCLE RELATIONSHIPS

$$
\begin{aligned}
& \frac{P_{3}}{P_{4}}=\frac{P_{2}}{P_{1}} \\
& \frac{P_{2}}{P_{1}}=\left(\frac{T_{2}}{T_{1}}\right)^{k /(k-1)}=\frac{P_{3}}{P_{4}}=\left(\frac{T_{3}}{T_{4}}\right)^{k /(k-1)}
\end{aligned}
$$

$\frac{T_{3}}{T_{4}}=\frac{T_{2}}{T_{1}}$

COMPRESSOR $W_{c}=h_{2}-h_{1}, S_{2}=S_{1}$

TURBINE $W_{\dagger}=h_{3}-h_{4}, s_{3}=S_{4}$ 
COMPRESSOR

$$
\begin{aligned}
& \left(\frac{P_{2}}{P_{1}}\right)^{k /(k-1)}=\left(\frac{70}{14.7}\right)^{0.286}=\frac{T_{2}}{T_{1}}=1.563, T_{2}=1.563(520)=814 R=354 \mathrm{~F} \\
& W_{c}=h_{2}-h_{1}=C_{p}\left(T_{2}-T_{1}\right)=0.24(814-520)=70.6 \mathrm{BTU} / L B
\end{aligned}
$$

TURBINE

$T_{3}-T_{4}=\frac{70.6}{0.24}=294 \mathrm{R}$

$T_{4}=2060-294=1766 \mathrm{R}=1306 \mathrm{~F}$

A DIFFUSER IS OFTEN USED BETWEEN THE TURBINE AND AFTERBURNER. ACTUAL TEMPERATURE ENTERING AFTERBURNER IS APPROXIMATELY I2OO F

USE $T_{4}=1660 \mathrm{R}$

$$
\begin{aligned}
& \frac{T_{3}}{T_{4}}=\left(\frac{P_{3}}{P_{4}}\right)^{(k-1) / k}=\frac{2060}{1660}=1.24 \\
& \frac{P_{3}}{P_{4}}=1.24^{3.5}=2.12 \\
& P_{4}=\frac{70}{2.12}=33.0 \mathrm{PSI}
\end{aligned}
$$

AFTERBURNER

$$
\begin{aligned}
& P_{4}=P_{5}=33.0 \mathrm{PSI} \\
& T_{5}=3,000 \mathrm{~F}=3,460 \mathrm{R}
\end{aligned}
$$

THERE IS A VOLUME INCREASE OF ABOUT $2 \%$ IN AFTERBURNER DUE TO HYDROGEN IN FUEL 
CARBON MAKE SECTION

TEMPERATURE AT OUTLET WILL DEPEND ON AMOUNT OF OXYGEN PRESENT FOR COMBUSTION TO BALANCE ENDOTHERMIC CRACKING REACTION

$T_{6}=2,500 \mathrm{~F}$ ESTIMATED

$P_{6}=33.0$ PSI

VELOCITIES FOR ENGINE USING 100 LB/SEC AIR (J57) AND WITH 30 INCH ID AFTERBURNER AND CARBON MAKE SECTION.

$\frac{100}{0.29}=3.448 \mathrm{MOLS} / \mathrm{SEC}$

$A=\pi(1.25)^{2}=4.91 \mathrm{FT}^{2}$

$V_{4}=\frac{3.448(359)}{4.91} \times \frac{1460}{460} \times \frac{14.7}{33}=356 \mathrm{FT} / \mathrm{SEC}$

$V_{5}=356 \times \frac{3460}{1460}=844 \mathrm{FT} / \mathrm{SEC}$

$V_{6}=356 \times \frac{2960}{1460}=721 \mathrm{FT} / \mathrm{SEC}$

JET ENGINE NOZZLES ADJUST AUTOMATICALLY TO MAINTAIN SONIC VELOCITY IN THE NOZZLE THROAT. THIS SYSTEM IS A CONVERGENT NOZZLE. ENGINES ACTUALLY HAVE A SLIGHT DIVERGENCE FOLLOWING THE THROAT, BUT ITS EFFECT IS NEGLIGIBLE.

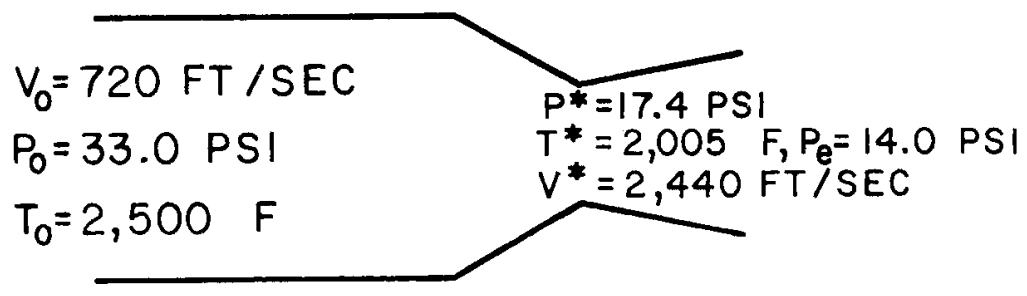


FROM GAS TABLE FOR MACH $=1 \quad \frac{P^{*}}{P_{0}}=0.528$

$P^{*}=0.528(33)=17.4$ PSI CHOKED CONDITION

DECREASING BACK PRESSURE WILL NOT INCREASE FLOW

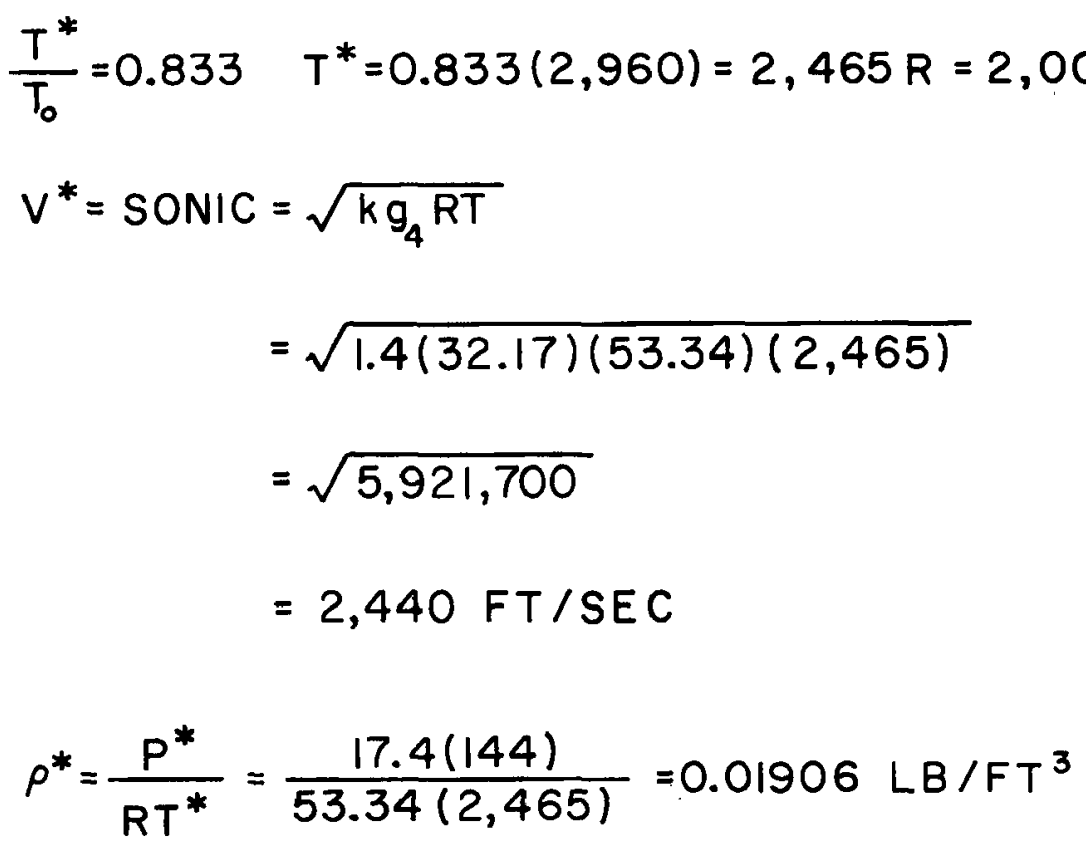

MASS RATE OF FLOW $=m=\rho$ AV

$$
\begin{aligned}
& =0.01906(3.27)(2,440) \\
& =152 \mathrm{LB} / \mathrm{SEC}
\end{aligned}
$$


consumption of fuel is limited by the available air. At maximum burning rate in the afterburner, the temperature at the exit of the afterburner is reported to average $3,000 \mathrm{~F}$. The first modification of the cycle occurs at this point. The amount of fuel burnt in the afterburners is reduced and, consequently, reduces somewhat the final temperature of the gases leaving the afterburner in order to supply the following section in which carbon black is made with an appropriate amount of air. Point 5 and dotted lines indicate the change this makes in the TS diagram. The amount of carbon black feedstock admitted to the engine can be varied and, therefore, can balance the heat liberation with the endothermic requirement of cracking to produce a fairly uniform temperature through the carbon black section. Point 6 is therefore shown tentatively as $2,500 \mathrm{~F}$. Since jet engines operate at sonic velocity in the nozzle throat, this velocity is calculated to be $2,440 \mathrm{ft} / \mathrm{sec}$ under the control conditions we have chosen for our engine to produce. Inder these conditions, the temperature at the nozzle throat is $2,000 \mathrm{~F}$.

Gas velocity at the entrance to the carbon production section is about $840 \mathrm{ft} / \mathrm{sec}$, and at the exit of the section it is about $720 \mathrm{ft} / \mathrm{sec}$. At average velocity approximately 1.25 milliseconds of contact time is obtained for each foot added to the carbon black production section. The $7 \frac{1}{2}$ milliseconds contact time provided by a 6 foot extension is believed to be adequate to obtain high carbon yields.

\section{g. Design considerations}

There are two types of design considerations. One is a modification required for any testing, ground or airborne; the other is the support and structural features which will be required for the modified engine 
to enable it to be mounted on an aircraft. It is proposed that all questions relating to how the engine would be mounted on an aircraft be deferred until ground level testing problems have been solved. Therefore, the two main design problems are how to inject feedstock oil into the high temperature gas stream, and how to protect the walls of the carbon black generator from excess temperature.

In order to get rapid mixing of the feedstock before it is carried through the extended tailpipe provided for its decomposition, it is important to distribute the oil very well by means of multiple nozzles. The temperature at the point where the nozzles are introduced will be approximately 3,000 F. Therefore, a cooling system will be necessary to protect them. At the same time, it is preferred that the feedstock enter as a vapor since this will improve mixing. A review should be made of the nozzles developed by the carbon black industry where this problem is not unique. It may be necessary to design a more elaborate cooling system for nozzles than has been necessary heretofore.

The system devised by jet engine manufacturers of using air which has bypassed the forward part of the engine as a cooling film, introduced through the liner of the afterburner, is an excellent one when there is always excess air in the combustion chamber. In the carbon black production section the last two-thirds will contain free hydrogen. Therefore, we cannot admit air for cooling of the walls. The alternatives that are open are cooling of the liner by means of air flowing on the outside of it, not through holes into the reaction chamber, or refractory lining of the walls of the carbon production section.

In ground tests a blower would be required to provide air for the cooling of the liner by heat transfer. In airborne units this could be 
accomplished by air scoops. The problem with this method of cooling is that it might not be effective enough to prevent failure of the liner. General Electric ran some tests of refractory lined afterburners not long ago and found that their life was rather short due to cracking during the heating and cooling cycle. Since long life between repairs is not likely to be a requirement of the system which is eventually selected for use in full scale operation, it might be practical to use a refractory liner or better to use a combination of refractory liner with air cooling on the outside of it. Selection of the best material for this purpose must receive close attention. A material with reasonably good insulating properties at the temperature to which it will be exposed, plus sufficient durability and flexibility to provide a reasonable service life must be found.

\section{h. Recommendations}

The next step should be an engineering study utilizing engine design specialists with the object of producing a preliminary design to guide in the procurement of an engine for ground testing. If possible, the same organization which did the preliminary design should, upon procurement of the engine prepare detailed engineering drawings for the modifications. Next, it will be necessary to obtain bids and to place a contract with an engine manufacturer or an engine maintenance facility capable of producing and assembling the hardware.

While there are several challenging problems associated with this engine modification, none would appear to present a risk to which a solution could not be found. The type of modifications required need special alloys and fabricating methods and will not be obtainable quickly. It is recommended that investigation of available engines proceed concurrently 
with preliminary engineering so that each activity may have the benefit of what the other has learned. In this way it might be possible to arrive quickly at the selection of an engine and obtain a head start in the specification of the modifications required. 


\section{PROGRAM FOR PROTOTYPE DEVELOPMENT \& TESTING}

Selection of a facility where the type of testing required at ground level can be accomplished is one of the first and largest problems to be solved. Each of the jet engine manufacturers has a remote testing site; Pratt \& Whitney's is 18 miles west of West Palm Beach in the Everglades, while General Electric's is at Peeples, Ohio. Another possibility is the test facility at Edwards Air Force Base in California. The basic problem is that a well-equipped test station with available personnel is required, and a location where it is possible to release several thousands of pounds an hour of finely divided carbon dust is needed. Due to the quantity involved, it would be very costly to remove carbon in filters. At a facility with a high smoke stack, it would be possible to distribute this dust and reduce the problem. There is no toxicity to animals or plants from this dust and the problem is entirely one of appearance. The foregoing is by way of perspective on the problem, a solution has not yet been attempted.

If the problem of finding a suitable test station proves to be very severe, it may affect the size of engine procured. It might be possible with a smaller engine, such as the J85 suggested by General Electric, to use a bag filtration system. This would be difficult and costly however, and should be held in reserve until it is determined whether a facility is available which would permit an open discharge of the gas from the engine.

As soon as an engine is selected, procurement activities and design of modifications can start. Fabrication of the new section and assembly of the complete engine are the next step. Following this, a series of runs would be made at a test center and then, in all likelihood, there would be some modifications required before it could be considered optimum 
for its function. Final ground tests and plans for airborne installations would follow.

The above steps are presented in Table 1 with preliminary estimates of the time which will be required for each one.

There are some indications that time could be well spent in investigating sources of supply of engines. J57 engines which cost initially $\$ 150,000$ are believed to be available for $\$ 10,000$ to $\$ 20,000$ from the Special Projects Office of Wright Field in Dayton. NASA recently bought a number of these engines at very attractive terms. The Air Force is also reported to have an interest in carbon black production in jet engines as a method of foiling rockets with heat seeking guidance systems. If this program provides them with useful information, the Air Force might be willing to buy the engine and perhaps provide some support services as well. If it is decided to do the test work on a smaller engine, the General Electric $\mathrm{J} 85$ is also available at a cost in the $\$ 10,000$ to $\$ 20,000$ range. 
PROJECT SCHEDULE

JGEMENTS FOR TESTING AINARY ENGINEERING

T \& PROCURE ENGINE

ED ENG. OF MODIFICATIONS

ATE \& ASSEMBLE ENGINE

L, INSTRUMENT \& CHECKOUT SERIES OF TESTS

IENT MODIFICATIONS

SERIES OF RUNS

DROCESSING \& REPORTING

ING AIRBORNE ENGINES

MONTHS FROM START

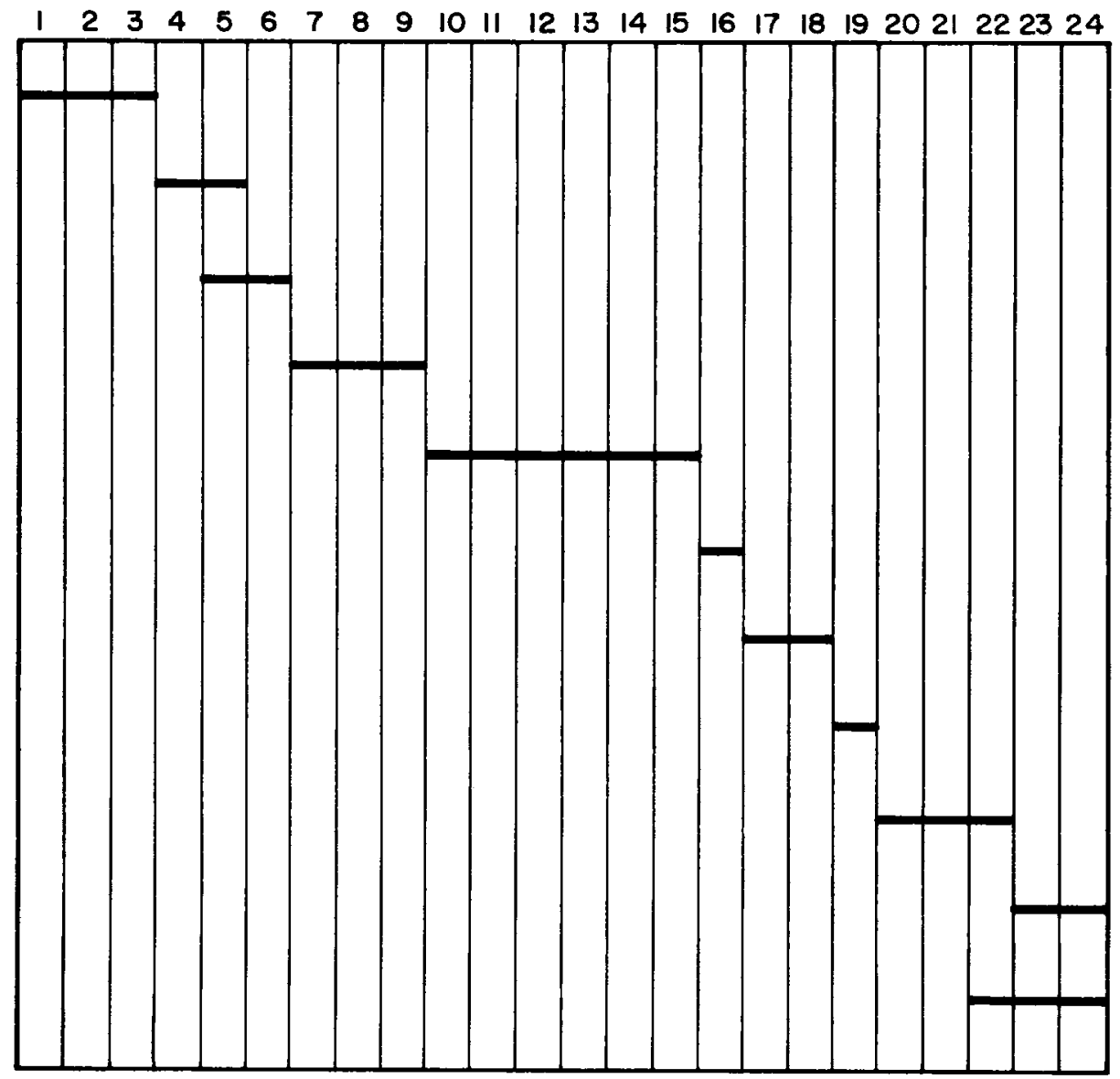

Table 1. Proposed Development and Testing Schedule 


\section{CARBON RAW MATERIAL}

\section{A. Technica1 Requirement}

The raw material should be as dense and as aromatic as possible compatible with a cloud point of under about $120^{\circ} \mathrm{F}$ and a low viscosity at a temperature of about $200^{\circ} \mathrm{F}$ so as to permit easy pumping and good atomization. The lower the cloud point and viscosity the better, other things being reasonably equal.

\section{B. Cost Factors}

The required raw material will have to be supplied in tank cars or tank trucks since the consumption will be large. (This does not apply to early stage testing wherein drums might suffice.) The cost delivered to a remote location will vary from about $\$ 7$ to $\$ 10$ per barrel ( 42 gallons) or about $1.8 \mathrm{c}$ to $2.6 \mathrm{c}$ per pound, say $2 c$ to $3 c$. Yield will be about $50 \%$ or a raw material cost of $4 c$ to $6 c$ per pound of carbon particles, a very reasonable cost.

C. Specific Raw Materials

1. Methyl naphthalenes from pertroleum and coal tar.

This material is available, but the supply is limited. It remains liquid at room temperature and has a very low viscosity at atomizing temperature. This would be a good material to start with. It would cost $2-3 c / 1 b$. A $50 \%$ yield is possible.

2. Heavy creosote

This material would be harder to use but would give a higher carbon yield -- perhaps $60-65 \%$-- and is more available. It would cost $2-3 c / 1 b$. 
V. CARBON RAW MATERIAL (continued)

C. Specific Raw Materials (continued)

2. Heavy creosote (continued)

Typical properties are:

API $\quad-10$

Viscosity SSU $\quad 130^{\circ} \mathrm{F} \quad 85 \mathrm{sec}$.

$2100 \mathrm{~F} \quad 35 \mathrm{sec}$.

S

0.7

BMCI

168

$\mathrm{H} / \mathrm{C}$

0.78

asphaltenes

2.0

sediment

0.1

NA

2 ppm

$\mathrm{K}$

0.2 ppm

$99 \%$ aromatics

IBP

$500^{\circ} \mathrm{F}$

$50 \%$

$670^{\circ} \mathrm{F}$

may show crystallizable solids at room temperature.

3. Lighter creosotes

These are available if needed for handling reasons. 


\begin{tabular}{|c|c|c|}
\hline $\begin{array}{l}\text { BIBLIOGRAPHIC DATA } \\
\text { SHEET }\end{array}$ & $\begin{array}{l}\text { 1. Report No. } \\
\text { CSU-ATSPि-225 }\end{array}$ & 3. Recipient's Accession No. \\
\hline \multirow{2}{*}{\multicolumn{2}{|c|}{$\begin{array}{l}\text { 4. Tirle and subtifle } \\
\text { WEATHER MODIFICATION BY CARBON DUST ABSORPTION OF SOLAR } \\
\text { ENERGY }\end{array}$}} & 5. Report Date \\
\hline & & (July, 1974 \\
\hline 7. Author(s) W.M. Gra & , W.M. Frank, M.L. Corrin and C.A. Stokes & $\begin{array}{l}\text { 8. Performing Organizarion Repr. } \\
\text { No. CSU-ATSP-225 }\end{array}$ \\
\hline \multirow{2}{*}{\multicolumn{2}{|c|}{$\begin{array}{l}\text { 7. Performing Organizarion Name and Address } \\
\text { Atmospheric Science Department } \\
\text { Colorado State University } \\
\text { Fort Collins, Colorado } 80523\end{array}$}} & 10. Project/Task/Work Un it No. \\
\hline & & 11. Contract/Grant No. \\
\hline \multirow{2}{*}{\multicolumn{2}{|c|}{ 12. Sponsoring Organization Name and Address }} & $\begin{array}{l}\text { 13. Type of Report \& Period } \\
\text { Covered } \\
\text { Project Report }\end{array}$ \\
\hline & & 14. \\
\hline
\end{tabular}

75. Supplementary Notes

16. Abstacts one dispanses carbon black dust of $\sim 0.1$ micron sizes over areas of $\sim 10^{4}$ to $10^{5} \mathrm{~km}$ then, a large potential for beneficial meso-scale weather modification may result. It may be possible to beneficially modify hurricanes, induce rainfall along tropical and sub-tropical coastlines, enhance $\mathrm{Cb}$ convection over land, and perhaps speed up fog dissipation and snowmelt. This report discusses the chemical and radiative properties of carbon dust, ways in which it can be manufactured and dispersed from aircraft and surface sites, and proposes methods of how meso-scale weather modification of this type might be accomplished. Discussion is presented of the probable meteorological questions and problems which are likely to be encountered. A summary of preliminary modeling results of the atmospheric response to artificial heat sources is given.

17. Key Words and Document Analysis. 17a. Descriptors

Meso-Scale Weather Modification 551.509 .61

Tropical Meteorology

551.515 .2

Solar Absorption by Aerosols

551.521 .31

17b. Identifiers/Open-Ended Terms

17c. COSATI Field/Group

\begin{tabular}{|c|c|c|}
\hline \multirow[t]{2}{*}{ 18. Availability Statement } & $\begin{array}{l}\text { 19. Security Class (This } \\
\text { Report) } \\
\text { UNCLASSIEIFD }\end{array}$ & $\begin{array}{c}\text { 21. No. of Pages } \\
191 \\
\end{array}$ \\
\hline & $\begin{array}{l}\text { 20. Security Class (This } \\
\text { Page } \\
\text { UNCLASSIFIFD }\end{array}$ & 22. Price \\
\hline
\end{tabular}


Authors: W.M. Gray, W.M. Frank,

M.L. Corrin, C.A. Stoke

WEATHER MODIFICATION BY CARBON DUST ABSORPTION OF SOLAR ENERGY

551.509 .61

551.515 .2

551.521 .31

Subject Headings:

Meso-Scale Weather Modification Troplcal Meteorology

Solar Absorption by Aerosols

Department of Atmospheric Science

If one dispenses carbon black dust of $\sim 0.1$ micron stzes over areas of $\sim 10^{4}$ to $10^{5} \mathrm{~km}$ then, a large potential for benefictal meso-scale weather modification may result. It may be possible to beneficially modify hurricanes, induce rainfall along tropical and sub-tropical coastlines, enhance $\mathrm{Cb}$ convection over 1 and, and perhaps speed up fog coastifines, enhance $C b$ convection over land, and perhaps speed up fog
dissipation and snowmelt. Th1s report discusses the chemical and radissipation and snowmelt. This report discusses the chemical and raand dispersed from aircraft and surface sites, and proposes methods of how meso-scale weather modifications of this type might be accomplished. Discussion is presented of the probable meteorological questions and problems which are likely to be encountered. A sumary of preliminary is given.

Authors: W.M. Gray, W.M. Frank, M.L. Corrin, C.A. Stoke

WEATHER YODIFICATION BY CARBON DUST ABSORPTION OF SOLAR ENERGY

Colorado State University Department of Atmospheric Science
551.509 .61

551.515 .2

551.521 .31

Subject Headings:

Meso-Scale Weather Modification ropical Meteorology Solar Absorption by Aerospls

If one dispenses carbon black dust of $\sim 0.1$ micron sizes over areas of $\sim 10^{4}$ to $10^{5} \mathrm{~km}$ then, a large potential for benefictal meso-scale weather modification may result. It may be possible to beneficially modify hurricanes, Induce rainfall along tropical and sub-tropical coastlines, enhance $\mathrm{Cb}$ convection over land, and perhaps speed up fog dissipation and snowmelt. This report discusses the chemfcal and radiative propertes of carbon dust, ways in which it can be manufactured and dispersed from alrcraft and surface sites, and proposes methods of how meso-scale weather modflcations of this type might be accomplished. Discussion ls present problems which are 11kely to be encountered. A sumary of preliminary modeling results of the atmospheric response to artificial heat sources 18 given.

Authors: W.M. Gray, W.M. Frank, M.L. Corrin, C.A. Stokes

WEATHER MODIFICATION BY CARBON DUST ABSORPTION OF SOLAR ENERGY

Colorado State University

Department of Atmospheric Science

If one dispenses carbon black dust of $\sim 0.1$ micron sizes over areas of $\sim 10^{4}$ to $10^{5} \mathrm{~km}$ then, a large potential for benefictal meso-scale modify hurricanes, induce rainfall along tropical and sub-tropical coastlines, enhance $\mathrm{Cb}$ convection over 1 and, and perhaps speed up disstpation and snowmelt. This report discusses the chemical and radissipation and snowmelt. This report dacusses the chemcal and radiative properties and dispersed from al coposes methods of how meso-scale weather modthe accomplish Discussion lo presented of the probable meteorological questions and problems which are likely to be encountered. A sumary of preliminary 1s given.
Authors: W.M. Gray, W.M. Frank, M.L. Corrin, C.A. Stokes

WEATHER MODIFICATION BY CARBON DUST ABSORPTION OF SOLAR ENERGY

Colorado State Un1versity Department of Atmospheric Sclence
551.509 .61

551.515 .2

551.521 .31

Subject Headings:

Meso-Scale Weather Modification Tropical Meteorolog Solar Absorption by Aerosols
If one dispenses carbon black dust of $\sim 0.1$ micron sizes over areas of $\sim 10^{4}$ to $10^{5} \mathrm{~km}$ then, a large potential for benefictal meso-scale weather modification may result. It may be possible to beneficially modify hurricanes, Induce rainfall along tropical and sub-tropical coastlines, enhance $\mathrm{Cb}$ convection over 1 and, and perhaps speed up fog dissipation and snowmelt. This report discusses the chemical and radiative properties of carbon dust, ways in which it can be manufactured diative and dispersed from alrcraft and surface sites, and proposes methods of how mesolon is Discusslon is presented of the probable meteorological questlons and problems which are likely to be encountered. A sucary of prellminary modeling results of the atmospheric response to artiflclal heat sources Is given. 